GÖTTINGER STUDIEN ZUR ENTWICKLUNGSÖKONOMIK / GÖTTINGEN STUDIES IN DEVELOPMENT ECONOMICS

Julian Weisbrod

\title{
Growth, Poverty and Inequality Dynamics
}

Four Empirical Essays at the Macro and Micro Level 


\section{Julian Weisbrod}

\section{Growth, Poverty and Inequality Dynamics}

Since the Second World War the world has seen an economic growth spurt unprecedented in history. Economic growth is a necessary but not sufficient condition for improving human development, or in other words, economic growth is an important pre-requisite for the ultimate goal of human well-being. The four empirical essays of this book add to the general debate concerning dynamics of growth, poverty and inequality over the past 40 years from four different dimensions. The first chapter analyses the dynamics of the cross-country per capita income distribution and the existence of convergence clubs. The second chapter focuses on the dynamic development of the global income distribution and resulting implications for global income convergence, poverty reduction, propoor growth and the evolution of global inequality within and between countries. The third chapter investigates the deterministic relationship between ethnic fractionalisation and growth in a macro cross-country regression framework. Finally, the fourth chapter adds to the understanding of micro determinants of growth and poverty in the context of Indonesia.

Julian Weisbrod was born in Bochum in 1979. He attained his IB from Pearson College, United World College, in Canada 1998. Subsequently, he studied Economics and Economic History at the University of Edinburgh and at the University of California, San Diego. Between 2003 and 2007 he was a Ph.D. Candidate, as well as teaching assistant and research associate at the Department of Economics at the University of Göttingen. During this time he also worked as a consultant with the World Bank in Jakarta and the OECD in Paris. 
Growth, Poverty and Inequality Dynamics 


\section{Göttinger Studien zur Entwicklungsökonomik Göttingen Studies in Development Economics}

Herausgegeben von/Edited by Hermann Sautter und/and Stephan Klasen

Bd./Vol. 25

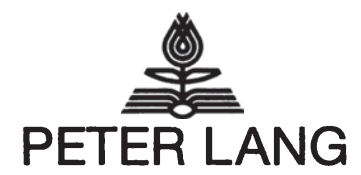

Frankfurt am Main · Berlin · Bern · Bruxelles - New York · Oxford · Wien 
Julian Weisbrod

\section{Growth, Poverty and Inequality Dynamics}

Four Empirical Essays at the Macro and Micro Level

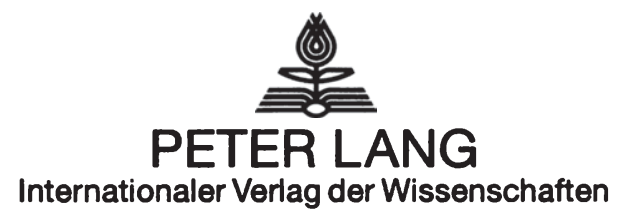




\title{
Bibliographic Information published by the Deutsche Nationalbibliothek
}

The Deutsche Nationalbibliothek lists this publication in the Deutsche Nationalbibliografie; detailed bibliographic data is available in the internet at <http://www.d-nb.de>.

Open Access: The online version of this publication is published on www.peterlang.com and www.econstor.eu under the international Creative Commons License CC-BY 4.0. Learn more on how you can use and share this work: http://creativecommons. org/licenses/by/4.0.

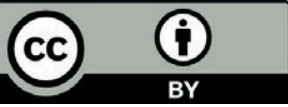

This book is available Open Access thanks to the kind support of ZBW - Leibniz-Informationszentrum Wirtschaft.

Zugl.: Göttingen, Univ., Diss., 2007

Gratefully acknowledging the support of the Ibero-Amerika-Institut für Wirtschaftsforschung, Göttingen.

\author{
D 7 \\ ISSN 1439-3395 \\ ISBN 978-3-631-57255-9 \\ ISBN 978-3-631-75361-3 (eBook) \\ (c) Peter Lang GmbH \\ Internationaler Verlag der Wissenschaften \\ Frankfurt am Main 2008 \\ All rights reserved.
}

All parts of this publication are protected by copyright. Any utilisation outside the strict limits of the copyright law, without the permission of the publisher, is forbidden and liable to prosecution. This applies in particular to reproductions, translations, microfilming, and storage and processing in electronic retrieval systems.

\section{Printed in Germany 123457 \\ www.peterlang.de}




\section{Editor's Preface}

Economic growth remains the most important driver of human development. However, it has become increasingly clear that economic growth in and of itself is not a sufficient condition per se to change human wellbeing. Thus, recent research has not only focused on the determinants of economic growth, but increasingly also on its distributional nature, which is of utmost importance to effectively reduce poverty and inequality. The four essays of this thesis contribute to the ongoing academic debate concerning income, poverty and inequality dynamics, or the drivers and pro-poorness of economic growth, by empirically investigating four panel data sets on selected issues at the macro and micro level.

In the first essay, Julian Weisbrod analyses the cross-country per capita income convergence and the emergence of difference convergence clubs generated by the past growth record. In particular, he shows that any such analysis should focus on the number of distinct components in order to identify convergence clubs rather than modes, as the number of modes in non-parametric estimated cross-country per capita income models strongly depend on the scale chosen. Hence the essay demonstrates, by applying a likelihood ratio test and other model selection criterion, the increased divergence of the cross-country per capita income distribution towards three components after 1976. Furthermore, the method used allows for the calculation of posterior probabilities using the fitted model and thus for a detailed picture of the intra-distributional dynamics of the cross-country per capita income distribution. Hence, the essay is the first to suggest that the cross-national per capita income distribution is not strictly polarising towards "twin peaks", but that there are rather three distinct different components or income "clubs" evolving from 1976 onwards.

In the second essay, Weisbrod focuses on a related, but fundamentally different question, namely the evolution and distributional change of the global income distribution. Unlike other studies, it models the global income distribution as a parametric mix of lognormal distributions combining national account income data and national measures of inequality. This methodology allows for an unprecedented detail by generating growth incidence curves to semi-decade and regional specific income data which allows identifying the pro-poorness of past growth. Moreover, it finds that overall the past years have seen a convergence of the global income distribution, as the bottom-middle part of the distribution grew the fastest. These findings go hand in hand with declining poverty rates and absolute numbers of poor in most regions of the world, with 
the most dramatic decline taking place during the late 1970s and early 1980s. Most notably are the significant positive changes in the regional distributions of South East Asia and South Asia which include the two population heavy weights China and India. Overall global inequality declined slightly, due to a decrease in between country inequality, which is however, counteracted by a slight increase of within country income inequality.

The third essay applies a cross-country growth regression framework to a cross-national panel dataset and contributes to the wider growth regression literature by enhancing the understanding concerning the interaction between ethnic fractionalisation and growth. In particular, Weisbrod shows that ethnic fractionalisation remains a growth hampering factor in post 1990 Sub-Saharan Africa, even after controlling for a wide policy framework or good governance. Furthermore, the essay empirically investigates, if there is a possibly counteracting positive effect of high ethnic fractionalisations in countries which are ethnically diverse due to past immigration, and are thus capable to benefit from co-ethnic trading networks. The fourth essay is a detailed household panel data study concerning the development and sectoral drivers of income and poverty in Indonesia over the 1990s. In particular, Weisbrod analyzes which pathways out of poverty have been most successful and promising in the Indonesian context. Most of the literature suggests that productivity gains in agriculture and non-farm activities as well as intersectoral shifts can play a large role, and thus an answer to this question ultimately necessitates an empirical approach. The essay demonstrates that while the non-farm sector plays an important and dynamic role in facilitating growth, urbanisation and alleviating poverty, it is equally important to foster agriculture productivity increases as most of the poor are living from agriculture and managed to leave poverty while remaining in agriculture. Moreover, the essay confirms the importance of education or human capital in poverty reduction as it allows the poor to participate in high productivity activities in general and increases the chance of a successful change of sector or location.

The four empirical essays of this dissertation thus add significantly to the debates about the dynamics of growth, poverty and inequality over the past 40 years in different dimensions.

Prof. Stephan Klasen, $\mathrm{PhD}$.

Göttingen, April 2008 


\section{Acknowledgment}

I am indebted and grateful to my advisor, Stephan Klasen, for his support and helpful comments. Without him this work would not have been possible. I would also like to thank the members of my committee, Michael Grimm and Walter Zucchini for their advice and time. Furthermore, I owe a debt of gratitude to Neil McCulloch who incorporated me into ongoing work during my three months stay at the World Bank Office in Jakarta. My special thanks also go to numerous colleagues at the University of Göttingen for their advice, practical help and friendship. Lastly, I would like to thank my family and close friends for their invaluable support during my work on this thesis.

Julian Weisbrod

Göttingen, November 2007 
Julian Weisbrod - 978-3-631-75361-3

Downloaded from PubFactory at 01/11/2019 05:55:15AM

via free access 


\section{Contents}

List of Figures $\quad$ XI

List of Tables $\quad$ XIV

Introduction and Overview 1

1 Twin Peaks or Three Components? 9

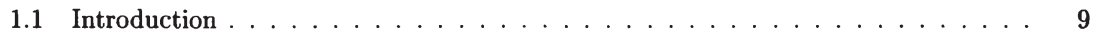

1.2 Statistical Methodology and Data . . . . . . . . . . . . . . . . 11

1.2 .1 Data . . . . . . . . . . . . . . . . . . 11

1.2.2 Testing for the Number of Components in a Finite Mixture - the Modified Likelihood Ratio Test . . . . . . . . . . . . . . . . . . 11

1.2.3 Discriminant Analysis via Posterior Probabilities . . . . . . . . . . . 15

1.2.4 Nonparametric Kernel Density Estimation and Mode Testing . . . . . . 16

1.3 Results . . . . . . . . . . . . . . . . . . . . . . . . . 19

1.3.1 Selecting the Number of Components . . . . . . . . . . . . . . . . . 19

1.3.2 Evolution of the Cross-Country Distribution of Income . . . . . . . . . 19

1.3.3 Intra-Distributional Dynamics Based on Posterior Probabilities . . . . . . 23

1.4 Conclusion . . . . . . . . . . . . . . . . . . . . . . . 25

1.5 Extension: Mixtures with Distinct Variances . . . . . . . . . . . . . . 26

2 Global Income Distribution Dynamics and Pro-Poor Growth 29

2.1 Introduction . . . . . . . . . . . . . . . . . . . . . . 29

2.2 Methodology and Data . . . . . . . . . . . . . . . . 31

$2.2 .1 \quad$ Data . . . . . . . . . . . . . . . . . . . . . 31

2.2 .2 Mixtures of Log-normal Distributions . . . . . . . . . . . . . . 31

2.3 The Global Income Distribution . . . . . . . . . . . . . . . . . . . . 33

2.3.1 Inequality and Poverty . . . . . . . . . . . . . . . . . 33

2.3.2 Growth Incidence Curves and Pro-Poor Growth . . . . . . . . . . . . . 35

2.4 Regional Distributions, Inequality, Poverty and Growth Incidence Curves . . . . 40

2.4.1 Regional Income and Log-Income Distributions . . . . . . . . . . . . . 40 
2.4.2 Regional Poverty and Inequality Measures

2.4.3 Regional Semi-Decade Specific Growth Rates, Rates of Pro-poor Growth and Growth Incidence Curves . . . . . . . . . . . . . . . . . 44

2.5 Conclusion . . . . . . . . . . . . . . . . . . . . 49

3 Ethnic Fractionalisation, Migration and Growth 51

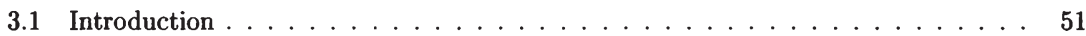

3.2 Theoretical Framework . . . . . . . . . . . . . . . . . . . . . . 52

3.3 Existing Empirical Investigations . . . . . . . . . . . . . . . 55

3.4 Data and Methodology . . . . . . . . . . . . . . . . 56

3.5 Results . . . . . . . . . . . . . . . . . . . . . . . . . 58

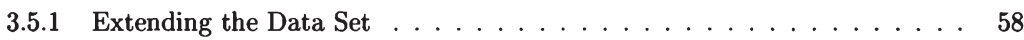

3.5.2 Migration and Ethnic Fractionalisation . . . . . . . . . . . . 66

3.6 Conclusion and Future Research Questions . . . . . . . . . . . . . . . . 68

4 Pathways out of Poverty in Indonesia $\quad 71$

4.1 Introduction . . . . . . . . . . . . . . . . . . 71

4.2 Conceptualisation and Methodological Issues . . . . . . . . . . . . 73

4.2.1 Conceptualisation and the "Naive" Model . . . . . . . . . . . . . . 73

4.2 .2 Data . . . . . . . . . . . . . . . . . . . . . 75

4.2 .3 Poverty Line . . . . . . . . . . . . . . . 76

4.3 Descriptive Analysis, Income \& Poverty Transition Matrices . . . . . . . . . . 77

4.3.1 Descriptive Statistics . . . . . . . . . . . . . . . . . . 77

4.3.2 Income Growth . . . . . . . . . . . . . . . . . 79

4.3.3 Poverty Transitions . . . . . . . . . . . . . . . . . . 81

4.4 Micro Determinants of Income and Poverty Transitions . . . . . . . . . . . . . 87

4.4.1 The Determinants of Income and Poverty Levels . . . . . . . . . . . 87

4.4.2 The Determinants of Income Change . . . . . . . . . . . . . . . 88

4.4 .3 Poverty Dynamics . . . . . . . . . . . . . . . . 90

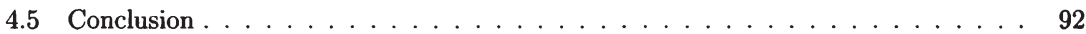

$\begin{array}{ll}\text { A Appendix A } & 95\end{array}$

$\begin{array}{ll}\text { B Appendix B } & 101\end{array}$

$\begin{array}{ll}\text { C Appendix C } & 111\end{array}$

$\begin{array}{ll}\text { D Appendix D } & 121\end{array}$

$\begin{array}{ll}\text { Bibliography } & 131\end{array}$ 


\section{List of Figures}

1.1 Three-Component Mixture Density and Kernel Density . . . . . . . . . . . . . 14

1.2 Kernel Density Estimates and Transformed Kernel Density Estimates, 2003 . . . 17

1.3 Kernel Density Estimates Normal and Log-Scale . . . . . . . . . . . . . . 18

1.4 Weights of Components . . . . . . . . . . . . . . . . . 22

1.5 Means of the Distinct Groups . . . . . . . . . . . . . . . . 23

1.6 Density Estimates for $1970 \ldots \ldots \ldots \ldots \ldots \ldots$

1.7 Density Estimates for $2003 \ldots \ldots \ldots \ldots \ldots \ldots$

2.1 Global and Regional Distribution of Income . . . . . . . . . . . . . . . 37

2.2 Global and Regional Distribution of Log-Income . . . . . . . . . . . . . . 39

2.3 Global and Regional Cumulative Distribution of Log-Income . . . . . . . . . . 41

2.4 Global Semi-Decade specific Growth Incidence Curves . . . . . . . . . . . . . 43

2.5 Global and Regional Growth Incidence Curves 1970-2003 . . . . . . . . . . . 45

2.6 Growth Incidence Curves of Various Years . . . . . . . . . . . . . . . 46

4.1 Pathways out of Poverty . . . . . . . . . . . . . . . . . 74

4.2 Poverty Transition Matrix, 1993 to 2000, IFLS Panel Data, Unweighted. . . . . . 85

B.1 Semi-Decade specific Growth Incidence Curves, OECD Countries . . . . . . . . . 104

B.2 Semi-Decade specific Growth Incidence Curves, East Asia and the Pacific . . . 105

B.3 Semi-Decade specific Growth Incidence Curves, Latin America and the Caribbean 106

B.4 Semi-Decade specific Growth Incidence Curves, Middle East and North Africa . . 107

B.5 Semi-Decade specific Growth Incidence Curves, Eastern Europe and Central Asia 108

B.6 Semi-Decade specific Growth Incidence Curves, South Asia . . . . . . . . . . 109

B.7 Semi-Decade specific Growth Incidence Curves, Sub-Saharan Africa . . . . . . . 110

D.1 Changes in Employment Share, 1993 to $2002 \ldots \ldots \ldots$. . . . . . . . 124 
Julian Weisbrod - 978-3-631-75361-3

Downloaded from PubFactory at 01/11/2019 05:55:15AM

via free access 


\section{List of Tables}

1.1 Model Selection Criteria for Mixture Models Fitted to Log Cross-Country Income Distribution $1976 \ldots \ldots \ldots \ldots \ldots \ldots$

1.2 Results of Silverman's Test for 2003, 124 Countries . . . . . . . . . . . . 18

1.3 Component Test and Goodness of Fit, 1970-2003 . . . . . . . . . . . . . 20

1.4 Fit of the Three Component Model . . . . . . . . . . . . . . . . . . . . . 21

1.5 Model Selection Criteria for Mixture Models Fitted to Log Cross-Country Income Distribution $1970 \ldots \ldots \ldots \ldots$. . . . . . . . . . . . . . 27

1.6 Model Selection Criteria for Mixture Models Fitted to Log Cross-Country Income Distribution $2003 \ldots \ldots \ldots \ldots \ldots \ldots$

2.1 Global and Regional Gini, Theils' Inequality Measure and Theil's Decomposition 34

2.2 Global and Regional $\$ 1$ and $\$ 2$ per day Poverty Headcount and Poverty Gap Measure 36

2.3 Global and Regional Population and Absolute Number of $\$ 1$ and $\$ 2$ per day Poor 38

2.4 Global and Regional Semi-Decade specific Growth Rates 1970-2003. . . . . . . . 42

3.1 Sample Means of Fractionalisation Indices by Region . . . . . . . . . . . . . 57

3.2 Baseline Regression. . . . . . . . . . . . . . . . . . . . 59

3.31990 s Effect. . . . . . . . . . . . . . . . . . . . . . 60

3.4 Decade Specific Growth Regression. . . . . . . . . . . . . . . . . . . 62

3.5 Sub-Saharan African and Latin American Results. . . . . . . . . . . . . . . . 63

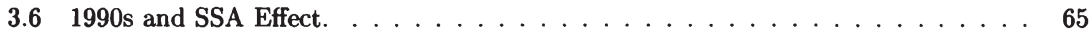

3.7 SSA Effect including Investment and the Kaufmann, Kraay and Zoido-LobatonIndex. . . . . . . . . . . . . . . . . 66

3.8 Past Settlement, Ethnic Fractionalisation and Growth. . . . . . . . . . . . . 68

4.1 Descriptive Statistics for IFLS 1993 and $2000 \ldots \ldots \ldots \ldots \ldots$

4.2 Income Growth Transitions by Rural, Urban and Sector 1993-2000 . . . . . . . 82

4.3 Poverty Transition Matrix, 1993 to $2000 \ldots \ldots$. . . . . . . . . . . . 84

4.4 Simple Logit Regression of Poverty Exit and Entry (1993-2000) . . . . . . . . . . 92

A.1 Results Posterior Estimation . . . . . . . . . . . . . . . . . . . . 97

B.1 Regions and Associated Countries . . . . . . . . . . . . . . 103 
C.1 Unrestricted SUR Model. . . . . . . . . . . . . . . . . . . . . . 113

C.2 Unrestricted SUR Model including Kaufmann, Kraay and Zoido-Lobaton Index. . 115

C.3 Immigration Country Definition . . . . . . . . . . . . . . . 117

C.4 Comparison Alesina et al. with our Results . . . . . . . . . . . . . . . 118

C.5 Indirect Effect of Fractionalisation on Good Governance. . . . . . . . . . . . . 119

D.1 True Rural-Urban Migration, 1990-1995 . . . . . . . . . . . . . . 123

D.2 Employment in Agriculture and Non Agriculture. . . . . . . . . . . . . . . 123

D.3 The Determinants of Log Real Income in 1993 and 2000 . . . . . . . . . . . 125

D.4 Cross Sectional Poverty Logit Regression in 1993 and 2000 . . . . . . . . . . . 126

D.5 Income Difference Regression 1993-2000 . . . . . . . . . . . . . . . 127

D.6 Geographic and Absolute Convergence . . . . . . . . . . . . . . . . . . 129

D.7 Full Logit Regression of Poverty Exit and Entry (1993-2000) . . . . . . . . . . 130 


\section{Introduction and Overview}

Since the Second World War the world has seen an economic growth spurt unprecedented in history. This accelerated growth was combined with a process of ever-increasing globalisation. Despite various problems associated with this process, it appears beyond contestation that considerable progress in material well-being and life expectancy has been achieved. Most people would agree that most of these gains were only achievable in a framework of strong economic performance. However, to consider economic growth as a goal in itself is misleading as it fails to capture the multidimensional nature of human development. Thus, economic growth is a necessary but not sufficient condition for improving human development, or in other words, economic growth is an important prerequisite for the ultimate goal of human well-being.

Therefore, it is not only important to analyse and understand economic growth per se, but rather the welfare impact or pro-poorness of economic growth. In particular, the past record shows that economic growth has been highly uneven between regions, countries and citizens. While some of the more fortunate managed to escape material poverty and low life expectancy, others remain in a devastating welfare situation even today. This is not only a tragedy for the individuals concerned, but also increasingly constitutes a global problem in an ever-more globalised world. In other words, in times of global communication and mass media, poverty is not only a socially unbearable situation, but fosters favourable conditions for environmental neglect, increased violence, including terrorism, and/or poverty-driven mass migration. Hence, a deeper understanding concerning the determinants, impact and distributive pattern of growth and its subsequent welfare implications, with respect to citizens, regions and/or countries, is of utmost importance in order to overcome some of globalisation's challenges and poverty in general. This dissertation contributes four empirical essays, analyzing growth, poverty and inequality dynamics at the macro and micro level.

On a purely quantitative note, if anything, economic growth is a rough guide for the dynamic development of an economy and its well-being. Hence, it is unsurprising that, starting from the early 1990s, with increasing data availability and processing power, economists turned towards analysing countries' growth records and cross-country growth regressions. From basic visual inspection alone it is apparent that, firstly, South East Asia has been growing remarkably fast, closing the income gap to the rich countries and, secondly, that Sub-Saharan Africa has mostly been economically stagnating over the past decades. Hence, the first impression is that 
most Sub-Saharan African nations' economic growth record is characterised by the persistence of low income and low growth equilibria, which implies a relative economic retardation in relation to the OECD countries. In contrast, most South East Asian nations' economic growth record was sufficiently good to facilitate an income catch-up towards the rich countries' high income and medium growth equilibria. However, whether this is the case, the global cross-national distribution of income should display at least two, or even more, distinct components. This in turn would imply the need for policy intervention to move nations from a low income and low growth equilibrium towards a self-sustaining fast growth trajectory, allowing an income catch-up to the richer countries. Hence, the question, whether past economic growth has led to an income per capita convergence among all countries has received much attention in the recent literature. Several recent papers (Jones, 1997; Quah, 1996a, b; Sala-i-Martin, 1996; Beaudry et al., 2005) have this debate at heart and discuss which type of convergence governs the development of the cross-national per capita income distribution and what is to be expected in the future. Bianchi (1997) is the first to formally test for multimodality of the cross-national income distribution based on Kernel density estimates and finds increasing evidence of bimodality implying a polarisation of the global cross-national income distribution.

The first essay of this dissertation, based on joint work with Hajo Holzmann and Sebastian Vollmer, adds to this debate. One major limitation of the previous academic papers is that the income data is analysed non-parametrically and based on a logarithmic scale which entails the problem that the number of modes of a density strongly depends on the scale chosen. Hence, our paper models the cross-national income distribution as a mixture in which the number of components is independent of the scale chosen, as it is not the number of modes in the cross-national income density which contains the most relevant information, but rather the number of components or "convergence clubs". Thus, speaking in statistical terms, the number of components in a mixture model provides key information on convergence. In order to identify the number of components, we applied the recently developed modified likelihood ratio test methodology (cf. Chen et al. 2001, 2004, and Chen and Kalbfleisch, 2005) on the cross-national per capita income distribution and find the emergence and divergence of a third clearly distinct component by the mid 1970s. This allows us to contribute to the convergence debate by extensively investigating the evolution and, in particular, the intra-distributional dynamics of the cross-country income distribution by using posterior probability estimates from our fitted model. We find intradistributional dynamics in particular for the Asian (upward mobility) and the Latin-American (downward mobility) countries, while most Sub-Saharan African countries remain stuck in the lowest component. The overall picture that we obtain is that of three diverging groups in the cross-national income distribution. Hence, we must strongly reject the notion that the crossnational per capita income distribution is converging. Moreover, we are the first to suggest that the cross-national per capita income distribution is not strictly polarising (the alleged "twin peaks" Quah, 1996; Bianchi, 1997), but that there are three distinct different "clubs" from 1976 onwards. 
However, our cross-country income per capita analysis also shows very clearly that particular populous countries managed to grow fast enough to facilitate an income catch-up to the richest countries over the past 40 years. This leads to an equally interesting question, from a global welfare point of view. Namely: Is the global income distribution converging and what was the global participatory and distributional impact of past growth on global poverty rates and inequality measures? ${ }^{1}$ Current research is focusing ever more closely on the participatory and distributive nature of growth. Furthermore, a better understanding of the participatory nature of growth, as well as its determinants, is also clearly important if the world is to meet its Millennium Development Goals (MDGs) of halving global poverty and hunger by 2015. A number of recent papers (Dowrick \& Akmal, 2005; Milanovic, 2002; Chen \& Ravallion, 2004; Chotikapanich, Valenzuela \& Rao, 1997; Bourguignon \& Morrisson, 2002; Quah 2002; Bhalla, 2002; Sala-i-Martin, 2002a, 2006) used two basic methodological approaches to model a global income distribution in order to draw conclusions concerning the development of global poverty and inequality. Both combine population weighted national average income and distribution estimates in order to derive a global income distribution.

The second essay, based also on joint work with Hajo Holzmann and Sebastian Vollmer, contributes to the existing and ongoing research. We implement the method of a parametric mixed lognormal distribution on national account income data and household-based income distribution measures. In particular, the paper highlights the fact that this parametric mixed lognormal approach has many statistically desirable properties and displays practical advantages to analyse the question at hand. Furthermore, we introduce recently developed methodologies and concepts such as growth incidence curves and rates of pro-poor growth (Ravallion and Chen, 2003; Ravallion, 2004) on a global scale to analyse the participatory and distributional impact of past global growth on the global poverty headcount and inequality via semi-decade and region specific growth incidence curves. Moreover, we calculate a decomposed Theil's measure of inequality, which allows for a decomposition of global income inequality into a between and within country component. Our results indicate that even though the cross-national income per capita distribution is not converging as concluded in the first essay, it is clearly the case that the global income distribution is indeed converging. This global income convergence is characterised by a rapid and dramatic decline in poverty headcount rates, not only reducing the relative but also the absolute number of people globally living below the poverty line. Moreover, our Theil's inequality decomposition shows that, while global income inequality is declining, this reduction is due to the decrease of between country inequality, which is counteracted by a slight increase of within country income inequality. Furthermore, the analysis of growth incidence curves shows the bottom-middle part of the income distribution experienced above average percentile growth rates, which explains the occurring global income convergence. In particular, the late 1970s and

1 Note: The global income distribution is the distribution of every persons' income on this planet and thus the suitable measure to answer questions concerning global welfare. Moreover, it is not equal to the distribution of cross-country income per capita which models the distribution of average per capita income in which the observation of Luxemburg is treated equally to China's. 
early 1980s are characterised by high global rates of pro-poor growth, initiating the rapid decline of global poverty rates.

Unsurprisingly, it is mostly the success of the East Asian region with the population heavy weight China, and to a lesser extent the success of South Asia, which includes India, that drives these remarkable results and high rates of pro-poor growth. In comparison, the initially rather wealthy regions of Latin America and the Caribbean and the Middle East and North Africa remained rather stagnant on a high level contributing only very modestly to the global poverty dynamics. Lastly, Sub-Saharan Africa has remained virtually stagnant and has become the poorest region in relative and absolute terms, implying a steady divergence and disconnection from the global growth process. Thus, despite the fact that our results indicate a tremendous success in economic growth and connected social welfare gains on a global scale over the past decades, the remaining very lowest percentiles also experienced the lowest percentile income growth rates, such that the remaining extreme poor might be particularly hard to reach. This is likely due to the fact that those remaining poor are mostly citizens of countries whose economies are stuck in a low level income equilibrium and thus fail to connect to the global growth process. However, poverty also remains a pressing issue in many countries which managed to launch their economies on a successful growth trajectory, but which have remaining pockets of poverty, in particular in rural areas, within their national boundaries. Thus, any attempt to reduce global poverty even further must focus on those countries stuck in general national poverty traps and on remaining, in particular rural, national pockets of poverty. The regional decomposition of growth suggest that countries and regions which managed to participate the most in the process of globalisation, managed to reduce poverty the fastest, despite the considerable problems inherent in such a process.

Given the stylised fact of a diverging cross-national per capita income distribution, as analysed in detail in the first essay, the question remains: what determines different income per capita growth rates that enable some countries to thrive, while others remain economically stagnant? Following pioneering work by Mankiw, Romer and Weil (1992) and Barro (1991), many different growth regressions with multiple specifications and covariates in a cross-country deterministic neo-classical growth framework were formulated in order to explain this diverging growth experience. The main initial findings are, firstly, that much of the world-wide growth variation can be explained remarkably well by the variables specified in the theoretical Solow growth model. Secondly, however, it became equally clear that there is a sizeable unexplained residual accounting for a wide heterogeneous experience between different countries and regions. In particular, Sub-Saharan Africa's growth tragedy could be hardly explained by the plain cumulative parameters of the Solow growth model alone. Hence, main "groups" of determinants are identified in the literature which account for, or are associated with, factor accumulation and/or differences in productivity levels. One set of growth determinants stress the unfavourable geographic conditions (e.g. Sachs and Warner 1994) such as tropical climate, and the implied endemic disease environment, or the lack of access to the sea, and the implied higher cost of 
trade participation. Closely connected are determinants which measure the impact of openness and/or trade on growth (Frankle and Romer, 1999). This in turn is also closely associated with the institutionalists' point of view that highlights more the importance of historical development trajectories, man made institutions, human capital accumulation and good governance as prerequisite for efficient resource allocation and public good provision (e.g. Acemoglu et al., 2001, Englebert, 2000). More recently the debate has shifted beyond the mere accumulation of factors of production towards determinants of different productivity levels (e.g. Feyrer, 2007).

The paper by Easterly and Levine (1997) argues that Sub-Saharan Africa's worse than average growth performance is mainly due to a high degree of ethno-linguistic fractionalisation and a resulting adverse policy climate. The paper concludes that "the results lend support to theories that interest group polarisation leads to rent-seeking behavior and reduces the consensus for public goods, creating long-run growth tragedies". ${ }^{2}$ The paper by Alesina et al. (2003) improves the argument by creating and testing three new indices of ethnic fractionalisation, namely linguistic, religious and ethnic fragmentation. It shows that the linguistic and ethnic indices have a similarly negative impact on the policy environment and subsequently on growth in a cross-country growth regression. Furthermore, Easterly (2001a) showed that the negative effect of ethnic fractionalisation is mitigated by institutional quality. Moreover, in a second paper Easterly (2001b) argues that the "middle class consensus", or the lack of strong ethnic or class differences, results in the highest growth rates. However, the channels through which ethnic fractionalisation has a negative impact on growth have been analysed only partially by these studies. Furthermore, the impact of ethnic fractionalisation on economic progress might be far more complex than the existing empirical studies would suggest. For this reason the third essay intends to extend the existing analyses.

The third essay, based on joint work with Dana Schüler, adds to this large growth deterministic research by firstly updating the regression framework data set used by Alesina et al.(2003) into the 1990s in order to analyse the robustness of their results in a wider time range. The results indicate that their initial model specification yields different results once the 1990s are included, as the negative effect of ethnic fractionalisation remains substantial and statistically significant even after the inclusion of policy variables. Hence, we apply region specific regressions, as well as a region and decade specific ethnic fractionalisation interaction term, in order to identify whether this result is driven by a decade or region-specific effect. Our results indicate that the model specifications, accounting for the impact of ethnic fractionalisation on growth via policy variables alone, as in the Alesina et al. (2003) model, are incomplete, as they fail to fully account for the recent Sub-Saharan growth experience. One plausible reason would be the increased frequency and severity of ethnic conflicts, in particular in Sub-Saharan Africa, after the collapse of the balance of superpowers. Another reason might be the increased importance of good governance which is not captured sufficiently in the policy variables used so far. A further different reason

$2 \quad$ Easterly, W. and Levine, R. Africa's Growth Tragedy: Policies and Ethnic Divisions. The Quarterly Journal of Economics, Vol. 112, No. 4, 1997, p. 1241. 
would be that the implied channels of ethnic fractionalisation on growth cannot be completely confirmed, suggesting that other channels which have not yet been accounted for are equally or more important. We find that the growth-hampering impact of ethnic fractionalisation remains only in the 1990s and in Sub-Saharan Africa once the policy framework is controlled for. In the end our results show that this Sub-Saharan 1990s effect can be explained by different levels of governance in the 1990s, if we implement the Kaufman-Kraay-Zoido-Lobaton-Indicator as measurement for governance. However, we cannot confirm the hypothesis that the remaining negative impact of ethnic fractionalisation is due to violent conflict.

In addition, it might be the case that the alleged negative effect of ethnic fractionalisation on growth described above is mitigated by possible positive effect prevailing in multi-ethnic societies. In particular, there is a large body of literature which suggests that the existence of co-ethnic networks has a large positive impact on trade and thus growth. The theoretical argument is, that immigrants have an informational and trust advantage in arranging trade with their home countries over their local counterparts (Epstein and Gang (2004), Casella and Rauch (1997), Rauch (2001)). Hence, we empirically investigate, if ethnic fractionalisation might be positive in a nation which is ethnically diverse, partially due to past immigration. We find some indication that countries which are ethnically diverse due to past immigration can mitigate the negative impact of ethnic fractionalisation on growth. We distinguish between these two different kinds of ethnic fractionalisation in order to determine if the result empirically indicates this multidimensionality of ethnic diversity.

In summary, this third essay shows that ethnic divide remains an explanatory factor for diverging growth records in Sub-Saharan Africa and Latin America even after the inclusion of the 1990s data and policy control variables. Furthermore, it demonstrates that ethnic diversity is not necessarily growth hampering, but contrarily can be growth enhancing if ethnic diversity today is the result of free past immigration and subsequent resulting trade networks. However, this kind of ethnic diversity is not currently present in most developing countries. Hence, in particular nations in Sub-Saharan Africa seem to be trapped in a situation of low income, low growth and high ethnic divide. However, it is highly likely that the ethnic divide often goes along with high inequality and interest group polarisation; the implication would be to improve equal access to resources, political participation and, in particular, human capital. This situation might indeed characterise one of multiple possible low income and low growth, high poverty equilibria mentioned above. High income and human capital inequality can have two consequences. Firstly, it could have a direct negative effect on growth. Secondly, it could prevent the poor from participating in the growth process. Thus, a strand of research, including the second essay of this dissertation, has concentrated more strongly on the participatory and distributive nature of growth on various levels ranging from micro household community to global data analysis. The second essay argues that the largest part of the remaining poor of the global income distribution are to be found either in poor countries or in the poorest percentiles or national pockets of poverty in the intermediate, particular populous and regionally diverse income countries. In fact, 
as mentioned above, it might be the case that certain, mainly rural, provinces in intermediate countries suffer from very similar growth hampering factors as economically poor performing developing countries.

More specifically, it is very clear that the vast majority of the world's poor remain in the countryside engaged in low productivity, mainly agricultural activities. Hence, recent and current research is aiming to identify and understand the determinants of rural income growth and poverty reduction from a regional to micro level. One theme of recent and past literature argues that from an empirical point of view growth originating in the agricultural sector has tended to be more "pro-poor" than growth originating from the industrial or service sectors (Mellor, 1976; Ravallion and Datt, 1996; Ravallion and Chen, 2004; Timmer, 2002). Indeed, agricultural growth has often been an important ingredient in the formula that connects economic growth to the poor (Ravallion and Huppi, 1991; Ravallion and Datt, 1996; Ravallion and Chen, 2004; Sumarto and Suryahadi, 2003; Fan, Zhang and Zhang, 2004; Fan, Thorat and Rao, 2004; Timmer, 1997, 2004) and separate reviews by Thirtle, et al. (2003) and by Majid (2004) confirm the strong empirical link between higher agricultural productivity and poverty reduction. Moreover, the current interest in this topic is well documented by the forthcoming World Development Report "Agriculture for Development" (2008).

However, an equally important and connected debate is concerned with the role of rural nonfarm activities in rural income growth and rapid poverty alleviation. This is particularly true, as in most developing countries rural non-farm output accounts for roughly half of rural income. Non-farm activities can be most conducive towards poverty reduction, especially in the absence of physical infrastructure and human capital constraints (Datt and Ravallion, 1996, 1998a\&b, 2002a). Moreover, rural non-farm enterprises are likely to be pro-poor, as they tend to use factors of production at their real opportunity costs to the economy, so they are often labour-intensive in nature, reducing underemployment, help smooth income seasonally and bid up local wages (Lanjouw and Lanjouw, 2001).

These literatures on rural poverty reduction are bridged in a broader literature which attempts to understand the nature of pro-poor growth, which inevitably must encompass the rural poor and their potential pathways out of poverty (Ravallion 2004, World Bank, 2004a, 2006b). In other words, is agriculture productivity the main driver behind rural poverty alleviation? Moreover, do non-farm enterprises encompass predominantly low productivity, supplementary and insurance activities or are they a potential source of dynamic growth and poverty alleviation in rural areas? Most of the literature suggests that productivity gains in both, agriculture and non-farm activities, matter and that non-farm activities fulfil both important functions. However, to answer these questions ultimately necessitates an empirical approach.

The last paper of this dissertation adds to this debate by utilising, among other things, micro-growth regressions on Indonesian household survey panel data (IFLS 1993, 2002) in order to identify the determinants of growth and poverty reduction, or pathways out of poverty, in Indonesia. This detailed micro-study is based on work with Neil McCulloch and Peter Timmer, and 
was conceived as an academic background paper to the World Bank's rural investment climate assessment in Indonesia in 2005. The main findings are that urbanisation has been rapid, but only a small part is due to actual physical migration of workers and households while most is due to local economic agglomeration and subsequent re-classification of former rural areas. Furthermore, while the non-farm sector plays an important and dynamic role in facilitating growth and alleviating poverty, it is equally important to foster agriculture productivity increases as most of the poor are living from agriculture and managed to leave poverty while remaining in agriculture. Moreover, we confirm the importance of education or human capital in poverty reduction as it allows the poor to participate in high productivity activities in general and increases the chance of a successful sectoral or locational change. The absence of human capital endowment might indeed constitute an individual poverty trap or low income, low growth equilibrium. Hence, the persistence of low income and low growth equilibria or poverty traps might again be due to limiting geographic, institutional and/or educational factors.

This, in turn connects to the three essays before, as it shows how the global analysis and conclusions of growth, poverty and inequality patterns might be also applicable and even determined on a micro-level. As it might well be the case that rural poor regions, just like countries stuck in poverty traps, suffer from very similar structural weaknesses, which hamper their growth potential and disconnect them from the global growth process. In simplified words, an individual who lacks crucial factor endowments might find it particularly hard to shift occupation or to profit from specialisation and thus to improve his productivity and income. The same argument can be made for national economies. Thus, fair integration into the global economy and equitable human capital accumulation should be the best guarantee to strengthen pro-poor growth of structurally weak economies, national pockets of poverty and individuals. This will reduce global poverty and inequality even further, assuring that the global community reaches the targeted MDGs.

The four empirical essays of this dissertation add to the general debate about this dynamics of growth, poverty and inequality over the past 40 years in four different dimensions. The first paper analyses the dynamics of the cross-country per capita income distribution and the existence of convergence clubs. Moreover, the second paper analyses the dynamic development of the global income distribution and the implications for global income convergence, poverty reduction and the evolution of global inequality within and between countries. Furthermore, the third essay contributes to the understanding of growth determinants in a macro cross-country regression framework. Finally, the fourth paper adds to the understanding of micro determinants of growth and poverty in a national setting, among others, in a micro growth regression framework. 


\section{Chapter 1}

\section{Twin Peaks or Three Components?}

\subsection{Introduction}

The behaviour of the cross-national income distribution is for many reasons of great interest. In particular, the development of twin or even more peaks would indicate a world of growing cross-country average income polarisation and suggest the existence of multiple equilibria. $\mathrm{Nu}$ merous papers (Barro, 1991; Jones, 1997; Quah, 1996a, b; Sala-i-Martin, 1996; Beaudry et al., 2005; Durlauf and Quah, 1999) have this debate at heart and discuss which type of convergence governs the development of the cross-national income distribution and what is to be expected in the future. In particular, they show that a focus on $\beta$-convergence ${ }^{1}$ is informative regarding the nature of intra-distributional dynamics but cannot provide information concerning the development of the entire distribution, which appears to be polarising. In order to overcome this traditional shortcoming of the $\beta$-convergence debate, probabilistic income mobility models are used to estimate likelihoods of convergence groups. Hence, there is a discussion on whether the twin peak phenomenon is either persistent as probabilities of switching are too low (Quah, $1996 \mathrm{a}, \mathrm{b})$ or is only a temporary occurrence due to increasing frequencies of growth miracles (Jones, 1997). Thus, the existing literature either gives a descriptive picture of the cross-national income distribution by observing the development of two or "twin" income per capita peaks in the cross-national income distribution, or, alternatively, is concerned with $\beta$-convergence in crossnational income growth regressions. Bianchi (1997) employed a non-parametric test for multimodality based on kernel density estimation to the cross-country income distribution. Further non-parametric approaches include those by Anderson (2004), who used stochastic dominance techniques, and by Maasoumi et al. (2007), who analysed the cross-sectional distribution of growth rates. Regarding parametric modelling of the cross-country income distribution, Paap

based on joint work with Hajo Holzmann and Sebastian Vollmer

1 By definition $\beta$-convergence occurs, if the coefficient on initial income is negative when regressed on the change of $\log$ real income, or, in other words, if initially poorer economies grow on average faster than the initially rich. Moreover, $\sigma$-convergence is defined as the decrease of the dispersion of the entire income distribution. If there are no other control variables in the growth regression, we speak of absolute $\beta$-convergence, which would be a necessary but not sufficient condition for $\sigma$-convergence. 
and Dijk (1998) used a two-component mixture, consisting of a truncated normal distribution and a Weibull distribution.

Using nonparametric density estimates, several authors find a twin-peaked cross-country income distribution (Quah, 1996b; Bianchi, 1997). In particular, Bianchi (1997) observes increasing evidence of bimodality in the GDP per capita distribution across countries over the period from 1970 to 1989 indicating global divergence rather than convergence. However, income data is often analysed on a logarithmic scale, and the number of modes of the log-income distribution may differ substantially from the number of modes of the income distribution itself. In contrast, when modelling a density as a finite mixture, the number of components of this mixture is independent of the chosen scale. Furthermore, if one wishes to address convergence one can argue that it is not the number of modes in the cross-national income density which contains the most relevant information, but rather the number of convergence clubs, which correspond to the components in the finite mixture.

When modelling the cross-national income distribution by a finite mixture, determining its number of components is an essential step in the analysis. In their model, Paap and Dijk (1998) use a mixture with two distinct components, which resembles the fit of a histogram of the crossnational income distribution. Thus, the "stylised fact" of a distinction between poor and rich countries is already integrated into their model. We argue that via a statistical inference procedure, the data itself should determine the number of components and to this end a finite mixture with normal components of the log-income distribution (or log-normal components of the income distribution itself) is the appropriate tool. We shall apply the recently developed modified likelihood ratio test methodology (cf. Chen et al. 2001, 2004, and Chen and Kalbfleisch, 2005) for the number of components in a finite mixture to the cross-national income distribution.

In contrast to the twin-peaks literature and also to Paap and Dijk (1998), we find evidence of two components only at the beginnings of the 1970s, whereas in the mid-70s, a third intermediate component emerges, which tends to separate itself ever more clearly from the poorest component. Thus, we find statistical evidence for three components rather than for "twin peaks" in the cross-country income distribution.

Moreover, besides determining the number of components (three components from 1976 onward), we contribute to the convergence debate by extensively investigating the evolution and the inter-distributional dynamics of the cross-country income distribution by using the posterior probability estimates from our fitted model. In particular, we find intra-distributional dynamics for Asian (upward mobility) and Latin American (downward mobility) countries. The overall picture which we obtain is that of three diverging groups in the cross-national income distribution.

The paper is structured as follows: Section 1.2 introduces the statistical methodology and highlights the differences (and advantages) of our approach compared with those taken in previous studies. Section 1.3 discusses our results, before we conclude. 


\subsection{Statistical Methodology and Data}

\subsubsection{Data}

Following most other papers, our analysis is based on income data from the Penn World Tables Version 6.2 (Summer, Heston \& Aten, 2006), from which we extract the real PPP GDP/per capita series of all years and countries available (chain series, base year 2000 in international $\$$ ). In order to compare our observations over time, we restrict ourselves to those countries having more than half a million inhabitants, of which complete income data for the whole time period is available. This restriction leaves 124 countries for the period from 1970 to 2003 in our analysis. These countries represent about 95 percent of the world population.

\subsubsection{Testing for the Number of Components in a Finite Mixture - the Mod- ified Likelihood Ratio Test}

Let $f_{X}$ denote the density of the cross-country income distribution of a fixed year, and let $f_{Y}$ be the corresponding density of the log-incomes, so that $f_{Y}(y)=f_{X}\left(e^{y}\right) e^{y}$. Multimodality of $f_{X}$ can arise by $f_{X}$ being a finite mixture of other (unimodal) densities, so that

$$
f_{X}(x)=p_{1} g\left(x ; \mu_{1}, \sigma_{1}\right)+\ldots+p_{m} g\left(x ; \mu_{m}, \sigma_{m}\right), \quad x>0
$$

where the weights $p_{i} \geq 0, \sum_{i} p_{i}=1$ and $g(x ; \mu, \sigma)$ is a parametric family of densities, e.g. the log-normal distribution.

If $f_{X}$ is a finite mixture of densities $g(\cdot ; \mu, \sigma)$, there is no general simple connection between the number of modes of $f_{X}$ and the number of components $m$. Typically, for unimodal $g$, the number of modes of $f$ will be at most $m$, but often will be less than $m$. Furthermore, one is more interested in the number of components $m$ of the finite mixture than in the number of modes. For example, in the cross-country income distribution the components correspond to groups with different income level. Therefore, if we model the cross-country distribution of income by a finite mixture, determining its number of components statistically is a task of major importance, since this number will have essential economic consequences.

Note that the number of components is preserved if the data are transformed via a strictly monotonic transformation. In fact, if the $x_{i}$ have density of form (1.1), the $\log$-data $y_{i}=\log \left(x_{i}\right)$ have the transformed density

$$
f_{Y}(y)=p_{1} g\left(e^{y} ; \mu_{1}, \sigma_{1}\right) e^{y}+\ldots+p_{m} g\left(e^{y} ; \mu_{m}, \sigma_{m}\right) e^{y} .
$$

Thus, the number of components is preserved, while the number of modes evidently may not. Therefore, in this paper we model $f_{X}$ (and hence $f_{Y}$ ) as a finite mixture and then determine its number of components, mainly via hypothesis testing, but also by the use of model selection 
criteria. We model $f_{Y}$ as a finite mixture of normal distributions, so that $f_{X}$ is a finite mixture of log-normal distributions.

Estimation in finite mixture models (with a fixed number of components) typically proceeds by maximum likelihood. However, as already discussed in Pittau (2005), the likelihood function in a finite normal mixture with different variances is unbounded, thus, a global maximiser of the likelihood function does not exist. There are some solutions to this problem. One is to look for the largest local maximum. Another is to the variances by restrictions of the form $\sigma_{i}^{2} \leq c \sigma_{j}^{2}$ for all $i, j=1, \ldots m$ and some $c>1$ (cf. Hathaway 1985), which again leads to the existence of a global maximum and, if the true parameters satisfy the restriction, consistency. However, these solutions have practical problems, and therefore, here and regarding the analysis in section 1.3 we shall use finite mixtures with equal variances. For further discussion see section 1.5.

Testing in parametric models is often accomplished by using the Likelihood Ratio Test (LRT). However, in order to test for the number of components in finite mixture models, it has long been known that the standard theory of the LRT does not apply. This is due to a lack of identifiability under the null hypothesis: The null can be realised either by a weight zero for one of the components, or by equal parameters of two component distributions. Recently, it has been discovered that the asymptotic distribution of the LRT concerning the testing for the number of components in finite mixtures is superior to a truncated Gaussian process (Chen and Chen, 2001; Dacunha-Castelle and Gassiat, 1999). The covariance of this process depends on the unknown true parameter, thus, the asymptotic distribution is too complicated and the LRT loses its practical appeal.

In methodologically related studies, Pittau and Zelli $(2005,2006)$ fitted finite normal mixtures to the per-capita log GDP distribution across European regions in the years 1977-1996. They used a bootstrap version of the likelihood ratio test suggested by McLachlan (1987) to determine the number of components. However, this approach is computationally expensive and typically has low power properties, since under an alternative, the parameters from which resamples are obtained, are not correctly estimated (cf. Chen, Chen and Kalbfleisch, 2004, for related simulation results).

Recently, Chen et al. (2001, 2004) and Chen and Kalbfleisch (2005) suggested modified LRTs to solve these problems, which retain a comparatively simple limit theory as well as the good power properties of the LRT. We shall apply these tests to our problem concerning the number of groups in the income distribution. At this point, we want to mention that the LRT and also the modified LRT are invariant under strictly monotonic transformation of the data (if candidate densities are correspondingly transformed). Thus, no matter whether we test on the level of the $x_{i}$ or on the level of the $y_{i}$, the results are (in contrast to Silverman's test) completely consistent.

We first of all consider testing one against two components in a mixture. Suppose that $\phi(y ; \mu, \sigma)$ is the normal distribution with mean $\mu$ and standard deviation $\sigma$, and consider the two-component mixture 


$$
f_{Y}\left(y ; p, \mu_{1}, \mu_{2}, \sigma\right)=p \phi\left(y ; \mu_{1}, \sigma\right)+(1-p) \phi\left(y ; \mu_{2}, \sigma\right)
$$

with equal standard deviation $\sigma$. The testing problem is

$$
H_{1}: f_{Y} \text { is normally distributed against } \quad K_{1}: f_{Y} \text { is of the form (1.2). }
$$

The modified likelihood function is given by

$$
l_{n}\left(p, \mu_{1}, \mu_{2}, \sigma\right)=\sum_{i=1}^{n} \log \left(p \phi\left(y_{i} ; \mu_{1}, \sigma\right)+(1-p) \phi\left(y_{i} ; \mu_{2}, \sigma\right)\right)+C \log (4 p(1-p)),
$$

where $C$ is a fixed constant (we set $C=2$ ). Let $\left(\hat{p}, \hat{\mu}_{1}, \hat{\mu}_{2}, \hat{\sigma}\right)$ maximise $l_{n}\left(p, \mu_{1}, \mu_{2}, \sigma\right)$ over the full parameter space, and let $(\hat{\mu}, \hat{\sigma})$ maximise $l_{n}(1 / 2, \hat{\mu}, \hat{\mu}, \hat{\sigma})$. The hypothesis $H_{1}$ is rejected for large values of the modified LRT statistic

$$
M_{n}=2\left(l_{n}\left(\hat{p}, \hat{\mu}_{1}, \hat{\mu}_{2}, \hat{\sigma}\right)-l_{n}(1 / 2, \hat{\mu}, \hat{\mu}, \hat{\sigma})\right)
$$

More precisely, Chen, Chen and Kalbfleisch (2001) show that for known $\sigma, M_{n}$ asymptotically follows the distribution $1 / 2 \chi_{0}^{2}+1 / 2 \chi_{1}^{2}$, where $\chi_{0}^{2}$ is the point mass at zero. For unknown $\sigma$, as formulated above, the precise asymptotic distribution of $M_{n}$ is unknown, however, Chen and Kalbfleisch (2007) show that the $\chi_{2}^{2}$ distribution is an upper bound to the asymptotic distribution of $M_{n}$.

Chen, Chen and Kalbfleisch (2004) also consider the problem of testing for two against more components of a mixture distribution. More precisely, the problem is to test

$H_{2}: f_{Y}$ is of the form (1.2) against $K_{2}: f_{Y}$ has more than two components.

Here, we again assume equal variances for all components, also under the alternative. Furthermore, one fixes a maximal number of components under the alternative (which can also be estimated, e.g. $m=4$ ). For a mixture with $m$ components, slightly changing the notation, the modified maximum likelihood estimators (MLEs) are defined as the maximiser of

$$
l_{n}\left(\mu_{1}, \ldots, \mu_{m}, \sigma\right)=\sum_{i=1}^{n} \log \left(p_{1} \phi\left(y_{1} ; \mu_{1}, \sigma\right)+\ldots+p_{m} \phi\left(y_{m} ; \mu_{m}, \sigma\right)\right)+C \log \left(\prod_{i=1}^{m} p_{i}\right) .
$$

These estimates are then inserted into the LRT statistic. Chen, Chen and Kalbfleisch (2004) showed that given a known $\sigma$, this modified LRT is asymptotically distributed as $q \chi_{0}^{2}+\frac{1}{2} \chi_{1}^{2}+(1-$ $q) \chi_{2}^{2}$, where the proportion $q$ depends on the mixing distributions. For unknown $\sigma$, Chen and Kalbfleisch indicate that the $\chi_{3}^{2}$ distribution is an upper bound of the asymptotic distribution.

As an illustration, we give the results of the analysis of the year 1976. The complete results are discussed in section 1.3.1. First we fit a single normal distribution to the log-income distribution 
Figure 1.1: Three-Component Mixture Density and Kernel Density
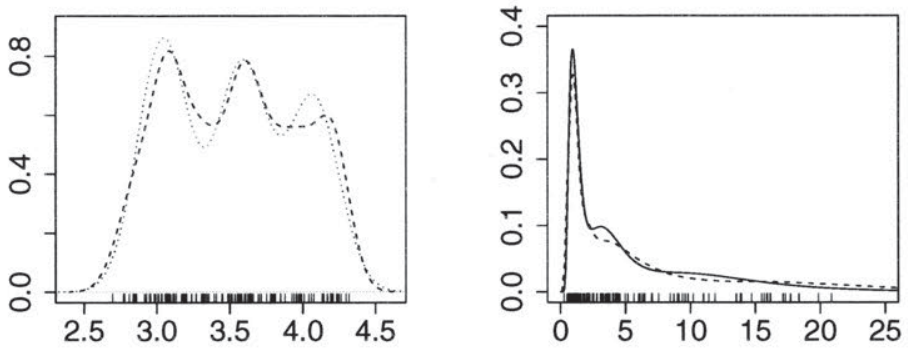

Left: Three-component mixture density with modified MLEs (solid line) and Kernel density estimate based on $h_{c}(3)$ (dashed line) for the log-data (logarithm to the base 10) for 1976. Right: Corresponding three-component log-normal fit (solid line) and transformation Kernel density estimate based on $h_{c}(3)$. Scale: $x$-axis $10^{3}, y$-axis $10^{-3}$.

( $\log$ to the base 10 ). Doing so, we obtain the following parameters: $\hat{\mu}=3.52$ and $\hat{\sigma}=0.46$. The modified MLEs of the two-component mixture with equal variances and penalisation parameter $C=2$ are calculated as $\hat{p}=0.51, \hat{\mu}_{1}=3.15, \hat{\mu}_{2}=3.89$ and $\hat{\sigma}=0.26$. The resulting value of the modified likelihood ratio function is equal to $T_{n}=14.00$, which based on the upper bound of the $\chi_{2}^{2}$-distribution yields a p-value of 0.0009 . Thus, the hypothesis of a single component is clearly rejected.

Next we consider testing two against three (or more) components. Concerning the fit using three components and equal variances, the parameter estimates based on penalised maximum likelihood are given by

$$
\hat{p}_{1}=0.38, \hat{p}_{2}=0.34, \hat{\mu}_{1}=3.04, \hat{\mu}_{2}=3.58, \hat{\mu}_{3}=4.07, \hat{\sigma}=0.18 \text {. }
$$

The resulting value of the modified LR statistic is $T_{n}=7.91$. Based on the upper bound by a $\chi_{3}^{2}$ distribution, this gives a p-value of 0.048 , in favour of three components. The three-component fit based on the modified MLEs, both for the $y_{i}$ 's as well as for the $x_{i}$ 's, are displayed in Figure 1.1 .

Apart from testing the number of components, we also compare the mixture models via two popular model selection criteria, namely the Akaike information criterion (AIC, c.f. Akaike, 1978 ) and the Bayesian information criterion (BIC, Schwarz, 1978), given by $-2 l+2 k$ and $-2 l+k \log n$, respectively, where $l$ is the $\log$-likelihood, $k$ the number of parameters and $n$ the number of observations. The results are displayed in Table 1.1. Here, the model selected by AIC is the model with three components, while BIC is slightly in favour of a model with only two components. Although it is theoretically known that the BIC is consistent in finite mixtures 
Table 1.1: Model Selection Criteria for Mixture Models Fitted to Log Cross-Country Income Distribution 1976

\begin{tabular}{|ccccc|}
\hline no. components & - loglike. & no. param. & AIC & BIC \\
\hline 1 & 77.86 & 2 & 159.72 & 165.41 \\
2 & 70.86 & 4 & 149.72 & 161.10 \\
3 & 66.90 & 6 & 145.80 & 162.87 \\
\hline
\end{tabular}

(Kerebin, 2000), in finite samples it often selects too few components. Finally, in Fig. 1.1 we compare the fitted three-component density with a nonparametric density estimate with bandwidth $h_{c}(3)$ (cf. Section 1.2.4). Such a comparison could also be used for a formal goodness of fit test for our mixture model, cf. e.g. Fan (1994). The nonparametric and our parametric estimate are quite close, thus, our model of the data is appropriate. The whole picture that we get from our analysis of the log cross-country income distribution in 1976, taking into account the modified likelihood ratio tests and the model selection criteria AIC and BIC as well as the shape of non-parametric density estimates, is clearly in favour of three components rather then two components or "twin peaks".

\subsubsection{Discriminant Analysis via Posterior Probabilities}

Mixture models are usually used for discriminant analysis, see e.g. Fraley and Raftery (2002). In our analysis of the cross-country income distribution via mixtures, once we have a mixture fitted to the cross-country income distribution, each observation can be assigned posterior probabilities which give the probability of the observation to belong to each of the components in the mixture model.

Consider the log-income distribution in 1976. In section 1.2.2, we fitted a three-component normal mixture

$$
f_{Y}\left(y ; \hat{p}_{1}, \hat{p}_{2}, \hat{\mu}_{1}, \hat{\mu}_{2}, \hat{\mu}_{3}, \hat{\sigma}\right)=\hat{p}_{1} \phi\left(y ; \hat{\mu}_{1}, \hat{\sigma}\right)+\hat{p}_{2} \phi\left(y ; \hat{\mu}_{2}, \hat{\sigma}\right)+\left(1-\hat{p}_{1}-\hat{p}_{2}\right) \phi\left(y ; \hat{\mu}_{3}, \hat{\sigma}\right)
$$

where the parameter estimates are given in (1.4). This yields three levels of income which we label poor, middle and rich, with indices $1,2,3$. The posterior probability of an observation $y$ to belong to group $j, j=1,2$, is equal to

$$
p(j ; y)=\frac{\hat{p}_{j} \phi\left(y ; \hat{\mu}_{j}, \hat{\sigma}\right)}{f_{Y}\left(y ; \hat{p}_{1}, \hat{p}_{2}, \hat{\mu}_{1}, \hat{\mu}_{2}, \hat{\mu}_{3}, \hat{\sigma}\right)},
$$

and $p(3 ; y)=1-p(1 ; y)-p(2 ; y)$. Therefore, we do not merely assign an income level to each country, but rather a probability distribution, which makes transitions from one group to the other much more transparent. 
If one wishes to assign a single number to each country $y$, one has several possibilities. One is the Maximum a-Posterior Estimate (MPE), which assigns to observation $y$ the $j, j \in\{1,2,3\}$, such that $p(j ; y)$ is maximal. One can also determine the thresholds $t_{j, j+1}, j=1,2$, for the values of $y$ at which the MPE changes between the state $j$ and $j+1$, by solving the equations $p\left(j, t_{j, j+1}\right)=p\left(j+1, t_{j, j+1}\right), j=1,2$, yielding the (in model (1.5)) unique solutions

$$
t_{j, j+1}=\frac{\hat{\mu}_{j}+\hat{\mu}_{j+1}}{2}+\hat{\sigma}^{2} \frac{\log \left(\hat{p}_{j} / \hat{p}_{j+1}\right)}{\hat{\mu}_{j+1}-\hat{\mu}_{j}}, \quad j=1,2 .
$$

If the weights $\hat{p}_{1}$ and $\hat{p}_{2}$ are sufficiently close, the values $t_{j, j+1}$ will indeed be between $\hat{\mu}_{j}$ and $\hat{\mu}_{j+1}$, in which case they may be properly interpreted. For example, for the year 1976 we get $t_{1,2}=3.32$ and $t_{2,3}=3.83$, which on the original scale correspond to the values 2089.30 and 6760.83 respectively. In 1976 , by maximum a-posterior estimation there are 46 countries in the poor group, 42 countries in the middle group and 36 countries in the rich group.

Another, more informative, possibility is the posterior mean of $y$, which is defined as $p(1 ; y)+$ $2 p(2 ; y)+3 p(3 ; y)$, a number between one and three. In our situation, since the choice of the values $1,2,3$ is arbitrary, this should not be interpreted as a mean but rather as a refined onenumber summary of the posterior distribution. For example, if the posterior mean of $y$ is 1.3 , then the country will belong to group 1 , but will have a tendency towards group 2. A tedious but straightforward computation shows that the posterior mean in model (1.5) with equal $\hat{\sigma}^{2}$ is a monotonically increasing function of $y$. Thus, one can uniquely determine thresholds $s_{j, j+1}$, $j=1,2$, for which the posterior mean is equal to $i+1 / 2$. Solving these equations numerically for the parameters in 1976 yields the values 3.32 and 3.84 .

\subsubsection{Nonparametric Kernel Density Estimation and Mode Testing}

In this section we draw attention to possible shortcomings of previous approaches based on nonparametric kernel density estimation. Specifically, we show that the "twin peak" phenomenon in the cross-country income distribution is not a structural feature, but rather an artifact from improper use of non-parametric kernel density estimates.

Indeed, the cross-country income distribution is concentrated in lower regions, and then has a rather long, small tail at the upper end. For example, in 2003 most values are $<10^{4}$, but there is a tail up to $4 \cdot 10^{4}$ (cf. Fig. 1.2). Such a shape can lead to a very poor performance of kernel estimates with a global bandwidth (cf. Wand and Jones 1995, p. 36). Therefore, to illustrate this, we also fitted a transformation kernel density estimate (Wand and Jones, 1995, p. 43) based on the log-transform to the data (cf. Fig. 1.2). Evidently, the estimates differ strongly, as the usual kernel density estimator puts too much mass to the tails. This leads to the emergence of the second peak in the "twin peaks" phenomenon of the cross-country income distribution, which is just an artefact of direct kernel density estimation with global bandwidth 
Figure 1.2: Kernel Density Estimates and Transformed Kernel Density Estimates, 2003

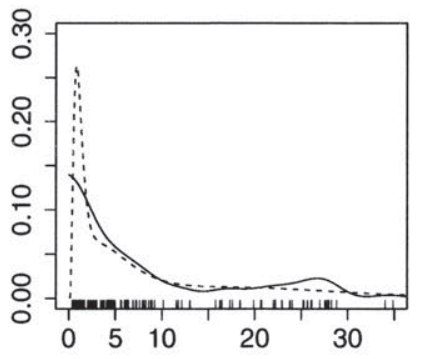

Note: Kernel density estimate (solid line) and transformation kernel density estimate (dashed line) with log-transform, both with bandwidth estimated by direct plug-in, for 2003 . Scale: $x$-axis $10^{3}, y$-axis $10^{-3}$.

of heavy-tailed data. Also note that the usual kernel estimator has a boundary problem at 0 (cf. Wand and Jones 1995, p. 46).

In summary, for the cross-country income distribution itself, simple nonparametric kernel density estimation and related inference techniques such as Silverman's (1981) test should not be used. It is also important to realise that Paap and Dijk (1998) choose their two-component mixture with distinct components to resemble the histogram of the cross-country income distribution, which is just a simple kernel estimator. Thus, their model (and in particular the number of components) is motivated by an inappropriate preliminary estimate.

The situation is different in the case of log-incomes (which are no longer heavy-tailed), for which kernel density estimates and Silverman's (1981) test are valid tools. In order to illustrate this issue, let us first briefly recall Silverman's test. Formally, a mode of $f_{X}$ (and similarly of the kernel estimator $\hat{f}$ ) is a local maximum of $f_{X}$ (or $\left.\hat{f}\right)$. Silverman (1981) showed that the number of modes of $\hat{f}$ is a right-continuous, monotonically decreasing function of the bandwidth $h$ if the normal kernel is employed for $K: K(x)=(2 \pi)^{-1} \exp \left(-x^{2} / 2\right)$. This allowed him to define the $k$-critical bandwidth $h_{c}(k)$ as the minimal $h$ for which $f(\cdot ; h)$ still just has $k$ modes and not yet $k+1$ modes. Based on the notion of the $k$-critical bandwidth, Silverman (1981) proposed a bootstrap test for the hypothesis

$$
\tilde{H}_{k}: f \text { has at most } k \text { modes against } \quad \tilde{K}_{k}: f \text { has more than } k \text { modes, }
$$

where in our context, $f=f_{X}$ (or $f=f_{Y}$, the density of logarithms $y_{i}=\log \left(x_{i}\right)$ ).

The results of Silverman's test for the year 2003 are displayed in Table 1.2. Here one typically proceeds iteratively by testing $\tilde{H}_{k}$ for increasing $k$, starting with $k=1$, until one finds $k$ such 
Table 1.2: Results of Silverman's Test for 2003, 124 Countries

\begin{tabular}{|r|rrrrrr|}
\hline & $h_{c}(1)$ & $p_{1}$ & $h_{c}(2)$ & $p_{2}$ & $h_{c}(3)$ & $p_{3}$ \\
\hline$y_{i}$ 's & 0.27 & 0.11 & 0.23 & 0.00 & 0.07 & 0.91 \\
$x_{i}$ 's & 5.72 & 0.01 & 2.14 & 0.44 & 1.83 & 0.24 \\
\hline
\end{tabular}

that $\tilde{H}_{k}$ cannot be rejected with a given level $\alpha$ (e.g. $\alpha=0.05$ ). Concerning the log-incomes and their density $f_{Y}$, the hypothesis $\tilde{H}_{1}$ cannot be rejected at a $5 \%$ (or even $10 \%$ ) level. However, the corresponding p-value is still comparatively small. Note that this result does not mean that $\tilde{H}_{1}$ is true, only that there is not enough evidence to reject it on a level of $5 \%$ (or $10 \%$ ). However, if one continues the analysis, one can clearly reject $\tilde{H}_{2}$ (p-value $<0.001$ ), but $\tilde{H}_{3}$ has a high p-value of 0.45 . Thus, there is some evidence of three modes in $f_{Y}$, but none of only two modes. The associated density estimates with the critical bandwidths are displayed in Fig. 1.3 (right).

As an illustration we also applied Silverman's (1981) test to the original income data $x_{i}$. The hypothesis $\tilde{H}_{1}$ is clearly rejected with a p-value of $<0.001$, and the hypothesis $\tilde{H}_{2}$ is not rejected with a high p-value. Thus, the procedure stops at $k=2$, strongly indicating two modes. However, observe Figure 1.3 (left). It shows (boundary corrected) plots of the densities with bandwidths $h_{c}(1)$ and $h_{c}(2)$. For $h_{c}(2)$, the third mode (which is not statistically significant according to Silverman's test) is about to occur in the two highest observations of the distribution (at about $35 \cdot 10^{3}$ ). Thus, the kernel density estimator is about to put a spurious mode into the tail, and all that Silverman's test tells us is that this mode is indeed spurious. Thus, kernel estimation and Silverman's (1981) test are inappropriate on the level of the $x_{i}$.

Figure 1.3: Kernel Density Estimates Normal and Log-Scale
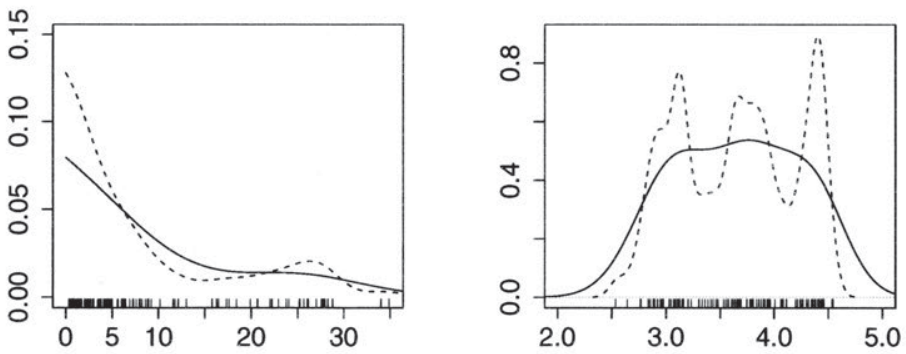

Left: Kernel density estimates with boundary correction at zero with bandwidths $h_{c}(1)$ (solid line) and $h_{c}(2)$ (dashed line) for the cross-country income distribution in 2003. Scale: $x$-axis $10^{3}, y$-axis: $10^{-3}$. Right: Kernel density estimates with bandwidths $h_{c}(1)$ (solid line) and $h_{c}(3)$ (dashed line) for the log-income distribution in 2003. For conveniently interpreting the figure, we here use the logarithm to the base 10 . 


\subsection{Results}

\subsubsection{Selecting the Number of Components}

Applying the methodology above to the time range from 1970 to 2003, and to the 124 countries for which we have consistent GDP data, yields some surprising and telling insights into the evolution of the cross-country distribution of income. Table 1.3 displays the results of the modified likelihood ratio test for one versus two components and two versus three components as well as the AIC and BIC model selection criteria for the respective fitted models ranging from 1 to 4 component mixtures (all having equal variances). First of all, we note that two components are always preferable to one. In 1970 we cannot reject the hypothesis of two versus three components, however, over the first years of the 1970s the p-values are decreasing and by 1976 the modified likelihood ratio test rejects a two component model at a level of $5 \%$. This is also supported by the values of the model selection criteria AIC and BIC, which initially are in favour of a two component model, but over time switch towards the three component mixture model. ${ }^{2}$ In summary, our analysis shows that starting with a two-component (twin-peak) mixture distribution in 1970, in between the "rich" and "poor" components, in the middle of the 1970s a third component evolves in the cross-national distribution of income, thus resulting in a three-component mixture model. All subsequent distributional analysis is based on the three component mixture model from 1976 to 2003.

\subsubsection{Evolution of the Cross-Country Distribution of Income}

Table 1.4 summarises the main distributional characteristics of the three-component mixture model after 1976. The first three columns display the weights $p_{1}, p_{2}$ and $p_{3}$ of the three components in the mixture model, which can be directly interpreted as the percentage of data, i.e. the relative number of countries, ascribed to a certain component. As can be seen in Figure 1.4, the percentage of data ascribed to the first "poor" component, despite small variation, dropped slightly over time from initially 37.9 percent in 1976 to 35.7 percent in 2003 . In comparison, the second component weight gained slightly over time from 33.8 percent to 35.3 percent, leaving the third component weight largely unaltered (28.4 percent in 1970 and 29 percent in 2003). Hence, the relative number of countries ascribed to each component is fairly stable over the given observational period.

Regarding the log-income data, it can be observed that the mean of the first component did not grow, but rather experienced stagnation and even a slight decline. In comparison, the mean of the second and third components clearly increased over the given time period from 3.59 to 3.73 and 4.08 to 4.33 respectively. The standard deviation parameter $\sigma$ of the three components remains also rather stable over the given time period. However, these model parameters are harder to interpret on the logarithmic scale. Therefore, we also computed the mean and the

$2 \quad$ There are two small exceptions. The AIC is only slightly in favour of four components in 1976 and 1980. However, the BIC is always robustly in favour of the three component model. 
Table 1.3: Component Test and Goodness of Fit, 1970-2003

\begin{tabular}{|l|cc|ccc|ccc|cc|}
\hline & \multicolumn{3}{|c|}{ One Component } & \multicolumn{3}{|c|}{ Two Components } & \multicolumn{3}{c|}{ Three Components } & \multicolumn{2}{c|}{ Four Components } \\
\hline Year & AIC & BIC & p of 1 vs 2 & AIC & BIC & p of 2 vs 3 & AIC & BIC & AIC & BIC \\
1970 & 152.47 & 158.12 & 0.001 & 142.64 & 153.92 & 0.868 & 145.88 & 162.81 & 145.27 & 167.84 \\
1974 & 159.30 & 164.94 & 0.001 & 149.64 & 160.92 & 0.243 & 149.45 & 166.37 & 149.46 & 172.02 \\
1975 & 157.47 & 163.11 & 0.001 & 147.49 & 158.77 & 0.171 & 146.47 & 163.39 & 146.40 & 168.97 \\
1976 & 159.72 & 165.36 & 0.001 & 149.72 & 161.00 & 0.048 & 145.80 & 162.73 & 145.43 & 167.99 \\
1980 & 167.20 & 172.84 & 0.000 & 155.68 & 166.96 & 0.037 & 151.21 & 168.14 & 155.21 & 177.78 \\
1985 & 173.07 & 178.71 & 0.001 & 162.51 & 173.79 & 0.023 & 156.95 & 173.87 & 157.43 & 179.99 \\
1990 & 183.20 & 188.84 & 0.001 & 172.40 & 183.68 & 0.006 & 163.84 & 180.77 & 164.47 & 187.03 \\
1995 & 200.08 & 205.72 & 0.001 & 189.17 & 200.46 & 0.004 & 179.83 & 196.75 & 183.83 & 206.39 \\
2000 & 204.57 & 210.21 & 0.000 & 192.40 & 203.68 & 0.000 & 173.05 & 189.97 & 173.23 & 195.80 \\
2003 & 206.50 & 212.14 & 0.000 & 191.62 & 202.90 & 0.000 & 173.58 & 190.50 & 174.50 & 197.06 \\
\hline
\end{tabular}


Table 1.4: Fit of the Three Component Model

\begin{tabular}{|l|lll|lll|l|lll|lll|}
\hline Year & $p_{1}$ & $p_{2}$ & $p_{3}$ & $\mu_{1}$ & $\mu_{2}$ & $\mu_{3}$ & $\sigma$ & Mean1 & Mean2 & Mean3 & SE 1 & SE 2 & SE 3 \\
\hline 1976 & 0.379 & 0.338 & 0.284 & 3.044 & 3.587 & 4.076 & 0.175 & 1147 & 3998 & 12335 & 310 & 1082 & 3337 \\
1980 & 0.366 & 0.351 & 0.282 & 3.041 & 3.622 & 4.115 & 0.177 & 1141 & 4342 & 13526 & 313 & 1191 & 3710 \\
1985 & 0.358 & 0.372 & 0.270 & 3.035 & 3.639 & 4.154 & 0.181 & 1126 & 4524 & 14806 & 316 & 1268 & 4149 \\
1990 & 0.357 & 0.367 & 0.276 & 3.041 & 3.649 & 4.211 & 0.182 & 1140 & 4628 & 16887 & 320 & 1299 & 4741 \\
1995 & 0.355 & 0.364 & 0.281 & 2.996 & 3.665 & 4.247 & 0.189 & 1032 & 4813 & 18396 & 303 & 1413 & 5400 \\
2000 & 0.345 & 0.371 & 0.284 & 3.017 & 3.698 & 4.313 & 0.177 & 1079 & 5174 & 21312 & 295 & 1415 & 5830 \\
2003 & 0.357 & 0.353 & 0.290 & 3.037 & 3.725 & 4.326 & 0.176 & 1128 & 5504 & 21938 & 307 & 1496 & 5962 \\
\hline
\end{tabular}


Figure 1.4: Weights of Components

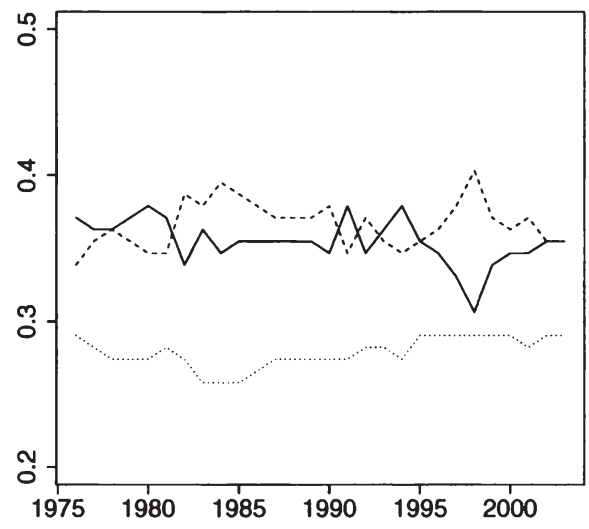

Note: Poor (solid line), intermediate (dashed line) and rich component (dotted line).

standard deviation of the log-normally distributed components for the original income data to get more interpretable results.

Observing Table 1.4 and Figure 1.5 we can see that the mean GDP per capita of the countries belonging to the first component decreased slightly over time from $\$ 1147$ to $\$ 1128$. The countries belonging to the second component saw a strongly increasing income from on average $\$ 3998$ to $\$ 5504$ which corresponds to an overall 37 percent increase between 1976 and 2003 . However, over the same period the countries in the third (the richest) component experienced an increase of mean income from $\$ 12335$ to $\$ 21938$ (increase of 77 percent). Hence, from 1976 onward the countries in the poorest component experienced stagnant or even slightly declining average income. Moreover, despite the clear emergence of a third "transitional" component in the middle of the 1970s, the mean income gain experienced in this component is not sufficient to facilitate any catch-up to the third "rich" component, which in turn improves both its absolute and relative position. Thus, the three components of our model of the cross-national distribution of income per capita actually diverge over time. This leaves slightly over $1 / 3$ of the poor economies in a poverty trap, whereas slightly over $1 / 3$ of the 124 countries, "the middle group", experience growth, but not fast enough to catch-up with the rich countries club, which consists of little less than $1 / 3$ and which improved its absolute and relative position. Thus, one may claim that the cross-national distribution of income is not converging. 
Figure 1.5: Means of the Distinct Groups

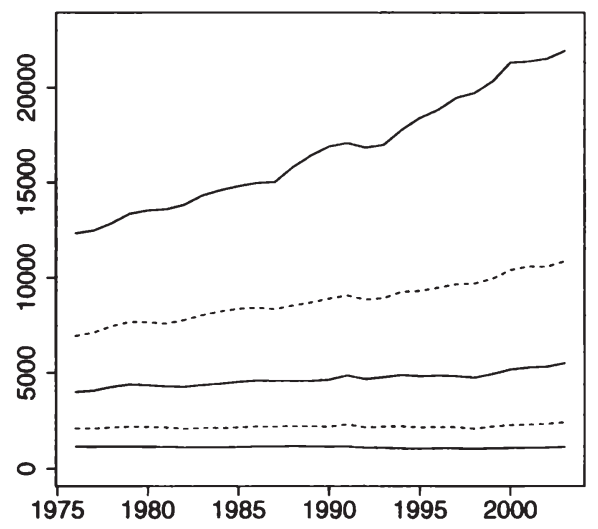

Note: Means of distinct groups (solid lines). Income levels where the maximum a-posterior estimates switch from one group to the other (dashed lines).

\subsubsection{Intra-Distributional Dynamics Based on Posterior Probabilities}

As mentioned in section 1.2.3, one major advantage of a mixture model with equal variances for the components is that it makes accessible consistent posterior analysis. In the following, we shall mainly use the posterior mean. In Table A.1 all countries are ranked by their change in posterior mean. The biggest winner is China, which increased its posterior probability mean from 1 to 2 and is one of 14 countries which managed to move up by one component. Out of these 14 countries, half moved from the 1st component to the 2nd component, leaving the other half to move from the 2 nd component to the 3rd component. Of the 12 countries which dropped by one component 5 countries dropped from the 2 nd to the 1st and 7 countries dropped from the 3rd to the 2 nd component. The average posterior probability mean increased slightly from 1.91 in 1976 to 1.93 in 2003, which implies a slight increase in the size of the second and/or third components. Comparing results in 1976 and 2003, we find that 26 out of 124 countries, about 21 percent, changed the component of the cross-national income distribution (although a few further temporary changes might have taken place in between). This implies a relatively low mobility of countries as, comparing 1976 and 2003, only one out of five countries changed its component position or group affiliation.

An even closer look at Table A.1 tells a more detailed story for selected countries belonging to different regions. Most notably Asia composes half of the 14 countries which improved by one component and none of the South East Asian, East Asian or South Asian Countries experienced 
a deterioration of their posterior mean. Thus, the Far East is generally the most upwardly mobile region, of which most countries belong to the second component and experienced on average higher growth rates than the other countries belonging to this component. In particular, China's extraordinary growth is mirrored in the jump from the very bottom to a median position of the cross-country mean income distribution. Obviously, it is these countries in particular which account for the rising mean of the second component over time. In fact, the average growth rate of these countries is more than sufficient for a catch-up in mean income to the richer group of countries.

However, a second region is also very prominent in the second group which lowers the average growth rate of this component, namely Latin America. While only one country, Chile, managed to improve by one component, Latin America accounts for one third of the countries which moved down by one component. In particular, richer countries, like Argentina and Venezuela lost relatively and were assigned to the second component in 2003. This sub-average performance of Latin America in general, of which most countries belong to the second component, helps to explain why the growth rate in the mean is not sufficient to facilitate any catch-up of the entire component to the third component.

The worst performing region by far is Sub-Saharan Africa, which accounts for 32 of the 46 countries, about 70 percent, belonging to the "poor" first component in 1976 and 32 of 44 countries, about 73 percent in 2003 respectively. It is mostly the non-existing growth record of these countries in Sub-Saharan Africa which accounts for the stagnant and even declining mean of the first poor component. Moreover, not only did the poorest countries remain extremely poor, but those countries which were relatively well-off in 1976, namely South Africa, and to a lesser extent Zimbabwe, belong to the group of countries, whose posterior mean decreased most. Despite the overall bleak record of Sub-Saharan Africa, there are a few examples which also show quite remarkable improvement, in particular Botswana and Lesotho. Moreover, Cameroon, Mauritius and Equatorial New Guinea even improve by one component and are the only three Sub-Saharan African Countries that display upward mobility. ${ }^{3}$ However, these few encouraging examples are not enough to change the Sub-Saharan stagnant and very poor growth record.

Unsurprisingly, most OECD countries belong firmly to the third component displaying hardly any change in their posterior probability mean. It is mainly their growth record which accounts for the increase in the third component mean. Eastern Europe lost in particular after the breakdown of the Iron Curtain, but had resurging growth, which lead to a rather stable position in between the second and the third components over time. Morocco and Egypt show the success of some Arabic countries, while Iraq is the extreme opposite and is the country which lost most over the time period 1976 to 2003.

Overall, the country specific data and posterior mean helps to explain the development of the cross-national distribution of income from 1976 to 2003 . The following general picture emerges:

$3 \quad$ However, Mauritius is an island and Equatorial New Guinea a small oil exporting economy and are arguably two special cases in Sub-Saharan Africa that belonged already to the second component in 1976. 
First, Sub-Saharan Africa accounts mostly for the lowest component which remains stagnant and "poor". Second, the emergence of the "transition" component is mostly due to the growth spurt of the Far East and the relative decline of Latin America. The contrary growth experience accounts mainly for the relatively slow growing mean of the second component. While most Far Eastern countries grow fast enough to catch up with the richer countries of the third component, this is not the case for most of Latin America, which experienced disappointing growth records in particular in the 1980s. Thus, the overall cross-national income distribution does not display absolute cross-national average income convergence, but rather divergence over time, despite the fact that some countries, in particular in the Far East, are rapidly catching-up. However, in the global picture this is counteracted by the relatively poor growth record of Latin America and the average income stagnation in most parts of Sub-Saharan Africa. In particular, almost all of Sub-Saharan Africa seems to be stuck in a poverty trap in which the unit under scrutiny, the national economy, is not capable to deliver any form of sustained per capita growth. However, our data also shows that some of the most populous countries, in particular India and China, are doing extraordinarily well. Thus, the global (and not cross-national) income distribution, which takes into account the distribution of the income within countries as well as the sizes of their populations, might indeed be converging. ${ }^{4}$

\subsection{Conclusion}

Previous investigations on the twin-peak phenomenon in the world's cross-country distribution of income were mostly based on non-parametric kernel density estimates, in particular concerning the number of modes of such estimates.

In this paper we use finite mixtures in order to investigate the cross-country income distribution since a.) the number of modes depends on the scale (original or logarithmic) whereas the number of components in the mixture does not; b.) finite mixtures allow for an accurate analysis of the intra-distributional dynamics by using posterior probability estimates; c.) components in the mixture arguably correspond better to income clubs in the distribution than its modes; and $d$.) the heavy tail of the cross-country income distribution on the original scale can cause poor performance of nonparametric density estimates. Furthermore, we argue that, in contrast to Paap and Dijk (1998), who simply use a fixed two-component model obtained by comparison with a histogram, the number of components in the mixture model should be determined by statistical inference.

In contrast to the twin peaks literature, we find evidence for an emerging intermediate component in the 70s, resulting in a three-component distribution from 1976 onwards. This alone is a strong indication of divergence within the distribution and might be an indicator of convergence within groups. Diverging estimates of the three group means and very different growth rates

$4 \quad$ As shown in the second essay. 
between the groups support this conclusion. While the mean of the third (richest) component almost doubled from 1976 to 2003, the mean of the second (intermediate) component only increased by 40 percent (corresponding to a very low annual growth rate), and the first (poor) component even stagnated. One should mention that up- and downward movements of countries affect these growth rates. The growth of the third component is slowed down by countries moving up from the second component. Regarding the second component there are positive and negative effects, in which the negative effects outweigh the positive effects, since only a few countries move from the third to the second component. In the first component there should be positive effects from countries coming from the second group, which however are counterbalanced by the poor overall growth record within this component.

The regional differences are remarkable. While many Asian countries managed to catch up to the third component, the opposite holds true for Latin American countries. Sub-Saharan Africa seems to be stuck in the first component and looses more and more contact with the other groups. The very populous countries China and India on the other hand performed extremely well. This fact would foster convergence in a global distribution of income which takes population size and within country inequality into account (i.e. Sala-I-Martin, 2006).

A possible application of our methodology, beyond the conclusions already drawn in this paper, would be a classification of countries according to their mean income, as an alternative concept to the most prevalent "poor, middle and rich" classification of the World Bank. Indeed, the maximum posterior estimates can be used to assign countries to certain groups. Due to its statistical nature, this approach would be less policy dependent than current approaches. The boundary points of income, separating the three groups, from our point of view currently somewhat arbitrarily obtained, could be replaced by the incomes where the maximum a-posterior estimate switches. For the year 2003 these are $\$ 2405$ and $\$ 10859$, respectively (PPP, base year 2000). However, our main aim was not to suggest a new system of classification of countries, but rather to obtain a better understanding of the cross-national distribution of income, its development, number of components and its intra-distributional dynamics over the past decades.

\subsection{Extension: Mixtures with Distinct Variances}

In Sections 1.2.2 and 1.3.1 we restricted the model class of finite normal mixtures to have equal variances. There were several reasons for this restriction. First, maximum likelihood inference in mixtures of normal distributions with distinct variances becomes technically difficult since the likelihood function is unbounded. Moreover, the number of parameters increases drastically (up to 8 in a three-component mixture), which increases the risk of overfitting the data (in a sample of merely 124 observations). Second, as regards the economic content, we wanted a model class which is adequate for the whole period 1976-2003 in order to draw conclusions about the evolution of the groups in the income distribution, in particular concerning their number. 
Table 1.5: Model Selection Criteria for Mixture Models Fitted to Log Cross-Country Income Distribution 1970

\begin{tabular}{|c|cccc|}
\hline no. components & no. variances & no. param. & AIC & BIC \\
\hline 1 & 1 & 2 & 152.47 & 158.16 \\
2 & 1 & 4 & 142.64 & 154.01 \\
& 2 & 5 & 142.81 & 157.03 \\
3 & 1 & 6 & 145.88 & 162.95 \\
& 2 & 7 & 139.73 & 159.64 \\
& 3 & 8 & 141.51 & 164.27 \\
\hline
\end{tabular}

Figure 1.6: Density Estimates for 1970

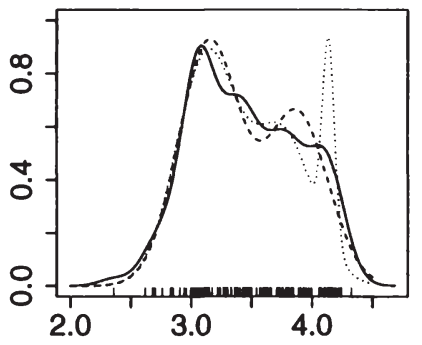

Kernel density estimate with $h_{c}(3)$ (solid line), two-component normal mixture with equal variances (dashed line) and three-component mixture with two distinct variances (dotted line).

Furthermore, equal variances guarantee that groups are equally wide, i.e. that no components are fitted to a very small, selective group. Third, if distinct variances are allowed, the posterior analysis is no longer consistent. In fact, higher observations can have smaller MPE or posterior mean than smaller observations, if the variance of components with smaller mean are much larger than those with higher mean. Thus, a posterior analysis does not make sense for such general models.

Nevertheless, in this section we briefly investigate the consequences if one allows the general model class (1.1) for the world's cross-country income distribution, in particular if one allows for some or even all variances to be distinct. We start the analysis with the year 1970. Table 1.5 gives the values of the model selection criteria AIC and BIC for distinct mixture models with up to three components.

The AIC selects a model with three components and equal variances for the first two components (with small means), while the BIC selects the model with two components and equal variances (which would also be selected by the AIC3 as used in Pittau, 2005). These two 
Table 1.6: Model Selection Criteria for Mixture Models Fitted to Log Cross-Country Income Distribution 2003

\begin{tabular}{|c|cccc|}
\hline no. components & no. variances & no. param. & AIC & BIC \\
\hline 1 & 1 & 2 & 206.50 & 212.19 \\
2 & 1 & 4 & 191.62 & 203.00 \\
& 2 & 5 & 189.90 & 204.12 \\
3 & 1 & 6 & 173.58 & 190.65 \\
& 2 & 7 & 162.13 & 182.03 \\
& 3 & 8 & 163.83 & 186.58 \\
\hline
\end{tabular}

Figure 1.7: Density Estimates for 2003

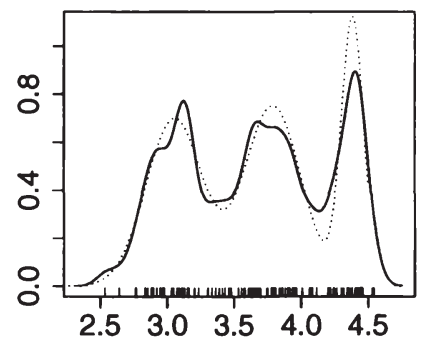

Kernel density estimate with $h_{c}(3)$ (solid line) and three-component mixture with two distinct variances (dotted line).

competing "best" models are rather incomparable. Observing in addition the plots in Figure 1.6, of the income distribution in 1970, one would decide for the two-component model with equal variances, since the third component in the three-component model, when compared to the nonparametric density estimate, looks much like fitting an artifact.

The picture changes over time, and in 2003 is rather in favour of the three-component model with two distinct variances, as can be observed from Table 1.6. The resulting fit is visualised in Figure 1.7. However, the standard deviation $\sigma$ of the third component is about twenty times smaller than the sigmas of the other two components. This makes the model inaccessible to posterior analysis. For example, posterior analysis would assign the USA to the second group. This is caused by the fact that mean income in the USA is much higher than the mean of the third component, and is thus not captured in this component. Hence, we find that the model with equal variances discussed in Section 1.3.1 is most adequate to describe and analyse the data at hand. 


\section{Chapter 2}

\section{Global Income Distribution Dynamics and Pro-Poor Growth}

\subsection{Introduction}

Over the past decade attention has increasingly been given to the evolution of global income inequality and the connected questions of global welfare and poverty development. In the light of an ever intensifying globalisation of the world economy, a rising concern is to identify global and regional winners and losers of this process. From a welfare point of view, the question might not be whether globalisation generated economic growth per se, but rather how pro-poor this growth was or, in other words, which section of the global income distribution benefited most from the relatively successful global growth record of the past decades.

Recent papers model the global income distribution, or a distribution limited to major economic players, by taking into account the underlying national income distributions (Dowrick \& Akmal, 2005; Milanovic, 2002; Chen \& Ravallion, 2004; Chotikapanich, Valenzuela \& Rao, 1997; Bourguignon \& Morrisson, 2002; Quah 2002; Bhalla, 2002; Sala-i-Martin, 2002a, 2006). In fact, an objective way to construct the global income distribution from the distinct national income distributions is as a population-weighted finite mixture of the national income distributions. Intuitively, if one picks at random an individual with a certain income from this global income distribution, one first randomly draws the country they come from (with probability equal to that countries proportion in the world population), and then obtains their income from the corresponding country income distribution. The main task in this approach is to determine the national income distributions.

A debate continues concerning the data sources on which estimates of the income distributions should be obtained. Two main concepts have been used so far. The first approach, labelled concept 2 by Milanovic (2006), combines national accounts income data with household survey inequality data to derive a global income distribution. The second approach (labelled concept 3

based on joint work with Hajo Holzmann and Sebastian Vollmer 
by Milanovic 2006) is purely based on income and inequality data from household surveys. Both approaches have their associated merits and serious caveats, which have been discussed extensively in the literature (Milanovic, 2006; Sala-i-Martin, 2006; Ravallion, 2003; Deaton, 2005).

As far as the poverty headcount is concerned, the headcount for the $\$ 2$ per day poverty line of studies based on concept 2 (Sala-I-Martin, 2002a, 2006) roughly corresponds to the headcount of the $\$ 1$ poverty line estimated under concept 3 (Chen \& Ravallion, 2004). A simple reason is that the ratio of household level income to national account is about $1 / 2$ (cf. Deaton, 2005). However, it is beyond the scope of this paper to discuss the advantages or disadvantages of certain poverty lines. We decided to stick to the $\$ 1$ and $\$ 2$ US (PPP) poverty lines applied to income as it makes our results comparable to those by Chen and Ravallion (2004) and Sala-i-Martin (2006). ${ }^{1}$

Sala-i-Martin (2006) argues that from the methodological point of view, one should use nonparametric kernel estimates instead of parametric models for the country income distributions, since these do not assume any specific shape for the income distributions. While we agree with it on a methodological basis, in our opinion non-parametric modelling would require actual income data for all countries under consideration, and on a comparable basis. We therefore prefer to model the national income distributions parametrically as log-normally distributed. The parameters of each country's log-normal income distribution can be determined from its real PPP GDP/per capita and its Gini coefficient (cf. section 2.2.2). Hence, the data required for this approach is much more readily available than for nonparametric estimation. Our approach also has some methodological merits, which allow us to obtain new insights into the income distribution dynamics. In particular, the resulting global income distribution (a finite mixture of log-normal distributions) is much easier to handle than a non-parametric analogue. A number of measures, such as poverty rates, percentile specific growth rates and rates of pro-poor growth, can be determined directly from the distribution without sampling and without loss in accuracy, moreover, it is a simple matter to sample from the distribution as well. It is this advantage which allows us to construct growth incidence curves of the world income distribution for several semi-decades and for different regions as well as a decomposition of inequality into between and within country income inequality. Thus, we obtain a broad and detailed picture of global and regional inequality, poverty and pro-poor growth, which extends and refines previous studies.

The paper is structured as follows. Section 2.2 describes the data and our methodology. Section 2.3 presents our results of the global income distribution. We give estimates of the evolution of global poverty and inequality over time and compare them with previous research (Milanovic 2002; Chen \& Ravallion 2001, Sala-i-Martin, 2006). In particular, our findings concerning between and within country income inequality based on Theil's measure appear to be novel. Moreover, we discuss semi-decade specific global growth incidence curves, and therefore can give a precise description of pro-poor growth. In Section 2.4, we decompose the world into

$1 \quad$ Furthermore, we show in Figure 2.3 that any reasonably selected monetary poverty line would show a decline in the poverty headcount ratio as the cumulative distribution function of global income of subsequent time periods dominates over the cumulative distribution function of the prior time period. 
seven main regions and investigate the regional variation in poverty and inequality development. We also analyse the underlying regional growth incidence curves, which yield a regionally comprehensive picture of pro-poor growth and of the intra-distributional dynamics, before we conclude.

\subsection{Methodology and Data}

\subsubsection{Data}

The subsequent analysis is based on two main data sources. Income data are drawn from the Penn World Tables 6.2 (Heston, Summers and Aten, 2006), which report the real GDP per capita in constant international dollars (chain series, base year 2000), available for most countries. However, for three particularly populous countries, namely Bangladesh, Russia and Ukraine we estimated the initially missing values. ${ }^{2}$ Our second data source is the inequality dataset by Grün and Klasen (2007) based on the WIDER database. ${ }^{3}$ Their adjusted Gini dataset derived by estimation techniques has substantive advantages in terms of comparability, as the raw Ginis in the WIDER database are not fully comparable over time and countries. ${ }^{4}$ Furthermore, as inequality does not change too dramatically over time, we assume the first real observation of the Gini in any given country to be equal to its initial level of inequality. Starting from this initial level we used a moving average to catch changes in trends of inequality. ${ }^{5}$

\subsubsection{Mixtures of Log-normal Distributions}

As stated in section 2.2, the national income distributions will be modeled by a log-normal distribution. Formally, the log-normal distribution $L N(\mu, \sigma)$ is defined as the distribution of the random variable $Y=\exp (X)$, where $X \sim N(\mu, \sigma)$ has a normal distribution with mean $\mu$ and standard deviation $\sigma$. It can be shown that the density of $L N(\mu, \sigma)$ is

$$
f(x ; \mu, \sigma)=\frac{1}{x \sigma \sqrt{2 \pi}} \cdot e^{-\left(\log (x)-\mu_{i}\right)^{2} / 2 \sigma^{2}}, \quad x>0,
$$

and its mean and variance are given respectively by

$$
E(Y)=e^{\mu+\sigma^{2} / 2}, \quad \operatorname{Var}(Y)=\left(e^{\sigma^{2}}-1\right) e^{2 \mu+\sigma^{2}} .
$$

$2 \quad$ For Bangladesh we calculated the values for the two initial years 1970-1971 using the average income per capita growth rate of the rest of the decade. For Russia and Ukraine we used the derived (Penn World Tables 5.6) USSR growth rates to estimate the average income for the years before 1990.

3 We would like to thank Grün and Klasen for providing their dataset.

4 This is mainly due to different methodological approaches and measurement units. The adjustement by Klasen and Grün takes these methodological differences into account.

5 Unfortunately, there is no reliable inequality data for the populous Democratic Republic of Congo, hence we used the neighbouring Central African Republic's Gini as a substitute. 
We should briefly discuss the interpretation of the parameters $\mu$ and $\sigma$, which is different from that of the normal distribution. In fact, from (2.1) one sees that $\log \mu$ is proportional to the expectation and $(\log \mu)^{2}$ is proportional to the variance, and in fact, $\log \mu$ is the scale parameter of the log-normal distribution, whereas $\sigma$ is a shape parameter. Since the Gini coefficient is invariant under changes of scale (it does not matter whether income is measured in Euro or in Dollar), it should be independent of $\mu$ and only depend on $\sigma$. This is indeed the case: The Gini coefficient $G$ of $L N(\mu, \sigma)$ is given by

$$
G=2 \Phi(\sigma / \sqrt{2})-1
$$

where $\Phi$ is the distribution function of the standard normal distribution. Therefore, the parameters $\mu$ and $\sigma$ of $L N(\mu, \sigma)$ can be determined from the mean $E Y$ and the Gini coefficient $G$ as follows.

$$
\sigma=\sqrt{2} \Phi^{-1}\left(\frac{G+1}{2}\right), \quad \mu=\log (E(Y))-\sigma^{2} / 2
$$

In summary, the parameters $\mu$ and $\sigma$ of each country's log-normal income distribution are easily determined from the real PPP GDP / per capita $(E Y)$ and its Gini $G$.

To conclude this section, we formalise how the density of the world income distribution $f_{W}$ is obtained as a mixture of national (log-normal) distributions. Assuming that there are $n$ countries under investigation and that the (log-normal) density of the distribution of country $i$ is given by $f\left(x ; \mu_{i}, \sigma_{i}\right)$, then

$$
f_{W}\left(x ; \mu_{1}, \ldots, \mu_{n}, \sigma_{1}, \ldots, \sigma_{n}, p_{1}, \ldots, p_{n}\right)=\sum_{i=1}^{n} p_{i} f\left(x ; \mu_{i}, \sigma_{i}\right),
$$

where $p_{i}$ is equal to the proportion of country $i$ 's population in the whole population of these $n$ countries.

It has to be stressed that although the density $f_{W}$ is a simple finite mixture of the component country densities $f\left(x ; \mu_{i}, \sigma_{i}\right)$, this does not transfer to relevant quantities such as the Gini or other inequality or poverty measures: the world Gini $G_{W}$ is not simply the corresponding finite mixture of the country Ginis $G_{i}$. Nevertheless, once the parameters of the density $f_{W}$ are estimated, it is not difficult to compute the poverty rates as well as percentile specific growth rates numerically from the distribution for any given level of accuracy without sampling. Furthermore, we obtained a number of other inequality and poverty measures by Monte Carlo simulation from $f_{W}$. To this end we used a random sample of size $10^{6}$ to obtain the desired accuracy. Since there are no substantial differences between the results of different poverty or inequality measures, we will only discuss the poverty measures by Foster, Greer and Thorbecke as well as the Gini and Theil's measure of inequality. Theil's measure is especially informative since it can be decomposed into separate measures for inequality between and within countries. Our poverty line is set at $\$ 469.9$ 
US (PPP) and $\$ 935.45$ US (PPP) a year, which corresponds to the World Bank 1993 poverty line of $\$ 1.08$ US and $\$ 2.15$ US per day adjusted to our income baseline year 2000 respectively. ${ }^{6}$ Finally, let us remark that, if the world income $Y$ is distributed as $f_{W}$, then the log world income $\log Y$ has density

$$
l f_{W}\left(x ; \mu_{1}, \ldots, \mu_{n}, \sigma_{1}, \ldots, \sigma_{n}, p_{1}, \ldots, p_{n}\right)=\sum_{i=1}^{n} p_{i} \phi\left(x ; \mu_{i}, \sigma_{i}\right),
$$

where $\phi(x ; \mu, \sigma)$ is the density of $N(\mu, \sigma)$. Thus $l f_{W}$ is simply a finite mixture of normal densities.

\subsection{The Global Income Distribution}

\subsubsection{Inequality and Poverty}

Figures 2.1 and 2.2 show estimates of the global income distribution as well as of the log-income distribution, determined as discussed in Section 2.2.1, for selected years. Two striking features are apparent: First, the average global income increased drastically over the given time period, and second, the world income distribution has become less dispersed. Interestingly, the 1970s and 1980s still seem to display two distinct modes in the global log-income distribution. However, these "twin peaks" disappear over the years and in particular between 1990 and 2003. Thus, the results clearly show global income expansion and convergence of real global individual income in SUS (PPP). ${ }^{7}$ The Gini and Theils' inequality measures reported in Table 2.1 confirm this first impression as both measures decline over the given time period, from 0.68 to 0.64 and from 0.88 to 0.80 respectively. ${ }^{8}$ The decomposition of Theil's measure shows that this decline in inequality was mainly due to a strong decline in inequality between countries, while inequality within countries even increased. This observation is consistent with a first impression of the biggest countries China and India where inequality increased over time.

Table 2.2 shows the results of the Foster-Greer-Thorbecke (FGT) poverty measures for the poverty headcount and the poverty gap ratio. Furthermore, the absolute number of people below the two poverty lines is reported in Table 2.3. It is apparent that from 1970 to 2003 all measures of poverty, absolute and relative, declined strongly. The percentage of the world population living below $\$ 1$ a day declined drastically from 21 percent in 1970 to 6 percent in 2003 . The reduction of this measure of extreme poverty was particularly rapid in the 1970s and early 1980s as the headcount ratio dropped from 21 percent in 1970 to 8 percent in 1985 which corresponds to a decline of the absolute number of people living with less than $\$ 469.9$ (PPP, 2000) per year from slightly over 785 million in 1970 to roughly 400 million in 1985 . From 1985 to 2003 the headcount fell further to 6 percent which corresponds to about 365 million people living below $\$ 469.9$ (PPP,

\footnotetext{
Adjusted to our 2000 base year $\$ 1.08(1993)$ per day $=\$ 1.287(2000)$ per day $=\$ 469.9$ per year. In the case of the $\$ 2$ line $\$ 2.15(1993)$ per day $=\$ 2.562(2000)$ per day $=\$ 935.45$ per year.

7 Contrarily to the cross-national income distribution which is diverging as shown in paper 1.

8 We calculated a number of other inequality measures. However, they all show more or less the same overall picture, so we only report Gini and Theil.
} 
Table 2.1: Global and Regional Gini, Theils' Inequality Measure and Theil's Decomposition

\begin{tabular}{|c|c|c|c|c|c|c|c|c|}
\hline Year & Gini & Theil & $\begin{array}{l}\text { Theil } \\
\text { Be- } \\
\text { tween }\end{array}$ & $\begin{array}{l}\text { Theil } \\
\text { Within }\end{array}$ & Gini & Theil & $\begin{array}{l}\text { Theil } \\
\text { Be- } \\
\text { tween }\end{array}$ & $\begin{array}{l}\text { Theil } \\
\text { Within }\end{array}$ \\
\hline & \multicolumn{4}{|c|}{ World } & \multicolumn{4}{|c|}{ OECD Countries } \\
\hline 1970 & 0.682 & 0.881 & 0.615 & 0.266 & 0.385 & 0.251 & 0.020 & 0.231 \\
\hline 1975 & 0.684 & 0.887 & 0.612 & 0.275 & 0.377 & 0.240 & 0.015 & 0.225 \\
\hline 1980 & 0.679 & 0.875 & 0.608 & 0.267 & 0.378 & 0.244 & 0.015 & 0.229 \\
\hline 1985 & 0.669 & 0.859 & 0.592 & 0.267 & 0.387 & 0.259 & 0.019 & 0.240 \\
\hline 1990 & 0.662 & 0.848 & 0.571 & 0.277 & 0.387 & 0.259 & 0.014 & 0.244 \\
\hline 1995 & 0.655 & 0.845 & 0.531 & 0.314 & 0.404 & 0.284 & 0.016 & 0.269 \\
\hline 2000 & 0.646 & 0.816 & 0.502 & 0.314 & .404 & 0.285 & 0.019 & 0.267 \\
\hline \multirow[t]{2}{*}{2003} & 0.640 & 0.796 & 0.468 & 0.328 & 0.407 & 0.290 & 0.018 & 0.272 \\
\hline & \multicolumn{4}{|c|}{ East Asia Pacific } & \multicolumn{4}{|c|}{ Latin America Caribbean } \\
\hline 1970 & 0.497 & 0.522 & 0.269 & 0.253 & 0.573 & 0.620 & 0.072 & 0.547 \\
\hline 1975 & 0.509 & 0.551 & 0.307 & 0.244 & .591 & 0.686 & 0.048 & 0.639 \\
\hline 1980 & 0.524 & 0.583 & 0.334 & 0.249 & 0.540 & 0.541 & 0.040 & 0.501 \\
\hline 1985 & 0.475 & 0.484 & 0.257 & 0.227 & 0.544 & 0.558 & 0.031 & 0.527 \\
\hline 1990 & 0.495 & 0.501 & 0.248 & 0.253 & 0.567 & 0.619 & 0.034 & 0.585 \\
\hline 1995 & 0.491 & 0.482 & 0.196 & 0.285 & 0.582 & 0.654 & 0.042 & 0.612 \\
\hline 2000 & 0.477 & 0.436 & 0.150 & 0.286 & 0.590 & 0.677 & 0.050 & 0.627 \\
\hline \multirow[t]{2}{*}{2003} & 504 & 0.473 & 0.124 & 0.350 & 0.583 & 0.657 & 0.048 & 0.609 \\
\hline & \multicolumn{4}{|c|}{ Middle East North Africa } & \multicolumn{4}{|c|}{ Eastern Europe and Central Asia } \\
\hline 1970 & 0.551 & 0.570 & 0.144 & 0.426 & 0.362 & 0.221 & 0.048 & 0.172 \\
\hline 1975 & 0.555 & 0.572 & 0.190 & 0.382 & 357 & 0.214 & 0.045 & 0.169 \\
\hline 1980 & 0.513 & 0.484 & 0.089 & 0.395 & 0.360 & 0.220 & 0.052 & 0.168 \\
\hline 1985 & 0.505 & 0.468 & 0.087 & 0.382 & 0.367 & 0.226 & 0.062 & 0.164 \\
\hline 1990 & 0.489 & 0.439 & 0.077 & 0.363 & 0.368 & 0.226 & 0.063 & 0.163 \\
\hline 1995 & 0.491 & 0.450 & 0.116 & 0.333 & 0.448 & 0.356 & 0.027 & 0.328 \\
\hline 2000 & 0.506 & 0.474 & 0.100 & 0.374 & 0.436 & 0.334 & 0.034 & 0.300 \\
\hline \multirow[t]{2}{*}{2003} & 512 & 0.480 & 0.114 & 0.366 & 0.441 & 0.345 & 0.049 & 0.296 \\
\hline & \multicolumn{4}{|c|}{ South Asia } & \multicolumn{4}{|c|}{ Sub-Saharan Africa } \\
\hline 1970 & 0.351 & 0.207 & 0.001 & 0.206 & 0.637 & 0.879 & 0.347 & 0.532 \\
\hline 1975 & 0.413 & 0.295 & 0.002 & 0.292 & 0.638 & 0.859 & 0.349 & 0.509 \\
\hline 1980 & 0.375 & 0.239 & 0.004 & 0.235 & 0.660 & 0.948 & 0.411 & 0.537 \\
\hline 1985 & 0.373 & 0.238 & 0.005 & 0.232 & 0.666 & 0.968 & 0.452 & 0.516 \\
\hline 1990 & 0.366 & 0.229 & 0.006 & 0.223 & 0.677 & 1.027 & 0.432 & 0.595 \\
\hline 1995 & 0.396 & 0.269 & 0.008 & 0.261 & 0.666 & 1.040 & 0.442 & 0.599 \\
\hline 2000 & 0.412 & 0.295 & 0.009 & 0.286 & 0.663 & 1.049 & 0.448 & 0.601 \\
\hline 2003 & 0.412 & 0.295 & 0.009 & 0.286 & 0.659 & 1.033 & 0.442 & 0.590 \\
\hline
\end{tabular}

2000) per year. Moreover, the poverty gap ratio also displays a constant decline over the given time period, hence, not only did the absolute number of people living in extreme poverty fall, but those which remained poor saw their income improved toward the poverty line. The halving of the number of people living in poverty is especially impressive since the world's population almost doubled in the given time period. The results of the $\$ 2$ poverty line follow a very similar pattern. The headcount declined strongly from 43 percent, almost half the world's population, 
in 1970 to 14 percent in 2003 . The most dramatic decline of the $\$ 2$ headcount was in the late 1970s and the 1980s from 42 percent in 1975 to 21 percent in 1990. Overall, the absolute number of people who lived below $\$ 935.45$ (PPP, 2000) per year declined from 1,571 million in 1970 to 893 million, in 2003. Furthermore, the poverty gap or "distance" of those people below the poverty line to the poverty line also declined considerably. Thus, all conceivable measures show a dramatic decline of global poverty in relative and even in absolute terms, although clearly some decades experienced more pro-poor progress than others. In order to get a more refined picture of pro-poor growth we now investigate the global growth incident curves and corresponding rates of pro-poor growth.

\subsubsection{Growth Incidence Curves and Pro-Poor Growth}

In Figure 2.4 global growth incidence curves for different time periods are displayed, which show the percentile specific growth rates over the global income distribution. ${ }^{9}$ The main results are also summarised in Table 2.4 below. If one considers the entire observational period, it is apparent that the middle percentiles of the global income distribution experienced the highest growth rates. In fact, the growth rate from the 8.5th to the 63.5th percentile of the global population experienced income growth rates above the mean of growth rates of all percentiles, which is equal to 2.3 percent per annum. Thus, the bottom-middle of the global income distribution experienced the fastest income growth, which also explains the declining income inequality and global income convergence. This effect is slightly counteracted by the less than average growth performance of the bottom percentiles (up to the 8.5 percentile), with the poorest percentiles experiencing the lowest income growth overall. Furthermore, the global average income grew by 1.8 percent per annum, whereas the median global individual experienced a per annum income increase of 3.0 percent. The rate of pro-poor growth ${ }^{10}$ for the $\$ 1$ per day poverty line exceeds with 2.2 percent per annum the growth rate of the mean by about 0.4 percentage points per annum. Hence, the 34 years from 1970 to 2003 can be termed pro-poor in the relative sense, as the poor experienced higher income growth rates than the average income. ${ }^{11}$ For the $\$ 2$ per day poverty line the period was even more pro-poor as the rate of pro-poor growth with 2.7 percent per annum exceededs the growth rate of the mean with almost 0.9 percentage points per annum and is even greater than the mean percentile growth rate. Hence, the global growth incidence curves over the period from 1970 to 2003 confirm and strengthen our inequality and poverty results above, as they show that over the 34 years the incomes of the poor have grown much faster than the average income. In fact, the bottom-middle income percentiles experienced the highest income growth rates explaining global income convergence, declining inequality and falling poverty headcounts. In order to understand in which era growth was particularly pro-

$9 \quad$ For a methodological discussion of growth incidence curves see Ravallion \& Chen (2003).

10 The rate of pro-poor growth is defined as the average growth rate of the percentiles below the poverty line.

11 Note: a time span is considered to have been relatively pro-poor if the mean growth rates of the percentiles below the poverty line is larger than the growth rate in mean. 
Table 2.2: Global and Regional $\$ 1$ and $\$ 2$ per day Poverty Headcount and Poverty Gap Measure

\begin{tabular}{|c|c|c|c|c|c|c|c|c|}
\hline Year & $\begin{array}{l}\text { Poverty } \\
\text { Head- } \\
\text { count } \\
(\$ 1) \\
\end{array}$ & $\begin{array}{l}\text { Poverty } \\
\text { Head- } \\
\text { count } \\
(\$ 2) \\
\end{array}$ & $\begin{array}{l}\text { Poverty } \\
\text { Gap } \\
(\$ 1)\end{array}$ & $\begin{array}{l}\text { Poverty } \\
\text { Gap } \\
(\$ 2)\end{array}$ & $\begin{array}{l}\text { Poverty } \\
\text { Head- } \\
\text { count } \\
(\$ 1) \\
\end{array}$ & $\begin{array}{l}\text { Poverty } \\
\text { Head- } \\
\text { count } \\
(\$ 2) \\
\end{array}$ & $\begin{array}{l}\text { Poverty } \\
\text { Gap } \\
(\$ 1)\end{array}$ & $\begin{array}{l}\text { Poverty } \\
\text { Gap } \\
(\$ 2)\end{array}$ \\
\hline & \multicolumn{4}{|c|}{ World } & \multicolumn{4}{|c|}{ OECD Countries } \\
\hline 1970 & 0.212 & 0.425 & 0.073 & 0.202 & 0.000 & 0.001 & 0.000 & 0.000 \\
\hline 1975 & 0.192 & 0.415 & 0.062 & 0.190 & 0.000 & 0.000 & 0.000 & 0.000 \\
\hline 1980 & 0.137 & 0.355 & 0.045 & 0.149 & 0.000 & 0.000 & 0.000 & 0.000 \\
\hline 1985 & 0.083 & 0.272 & 0.029 & 0.102 & 0.000 & 0.000 & 0.000 & 0.000 \\
\hline 1990 & 0.071 & 0.209 & 0.028 & 0.082 & 0.000 & 0.000 & 0.000 & 0.000 \\
\hline 1995 & 0.068 & 0.178 & 0.028 & 0.074 & .000 & 0.000 & 0.000 & 0.000 \\
\hline 2000 & 0.059 & 0.148 & 0.025 & 0.064 & 0.000 & 0.000 & 0.000 & 0.000 \\
\hline 2003 & 58 & 0.142 & 0.025 & 0.062 & 0.000 & 0.000 & 0.000 & 0.000 \\
\hline & \multicolumn{4}{|c|}{ East Asia Pacific } & \multicolumn{4}{|c|}{ Latin America Caribbean } \\
\hline 1970 & 54 & 0.782 & 0.153 & 0.403 & 0.073 & 0.191 & 0.026 & 0.079 \\
\hline 1975 & 0.346 & 0.724 & 0.102 & 0.335 & 0.067 & 0.170 & 0.025 & 0.071 \\
\hline 1980 & 0.235 & 0.612 & 0.067 & 0.255 & 0.026 & 0.092 & 0.008 & 0.033 \\
\hline 1985 & 0.0 & 0.392 & 0.022 & 0.126 & 0.032 & 0.104 & 0.010 & 0.038 \\
\hline 1990 & 0 . & 0.250 & 0.017 & 0.082 & 040 & 0.121 & 0.013 & 0.046 \\
\hline 1995 & 0.030 & 0.129 & 0.011 & 0.042 & 045 & 0.132 & 0.015 & 0.051 \\
\hline 2000 & 0.020 & 0.075 & 0.008 & 0.026 & 0.044 & 0.126 & 0.015 & 0.049 \\
\hline 2003 & 0.024 & 0.082 & 0.009 & 0.029 & 0.043 & 0.123 & 0.015 & 0.049 \\
\hline & \multicolumn{4}{|c|}{ Middle East North Africa } & \multicolumn{4}{|c|}{ Eastern Europe and Central Asia } \\
\hline 1970 & 0.085 & 0.235 & 0.030 & 0.094 & 0.016 & 0.044 & 0.006 & 0.017 \\
\hline 1975 & 0.069 & 0.205 & 0.024 & 0.080 & 0.010 & 0.032 & 0.003 & 0.012 \\
\hline 1980 & & 0.141 & 0.012 & 0.049 & & 0.035 & 0.004 & 0.014 \\
\hline 1985 & 40 & 0.132 & 0.015 & 0.049 & 08 & 0.027 & 0.002 & 0.009 \\
\hline 1990 & 0.035 & 0.116 & 0.013 & 0.043 & 3 & 0.017 & 0.001 & 0.005 \\
\hline 1995 & 0.047 & 0.113 & 0.021 & 0.050 & 0.006 & 0.033 & 0.001 & 0.009 \\
\hline 2000 & & 0.097 & 0.012 & 0.038 & .002 & 0.016 & 0.000 & 0.004 \\
\hline 2003 & 0.051 & 0.113 & 0.024 & 0.052 & .001 & 0.012 & 0.000 & 0.003 \\
\hline & \multicolumn{4}{|c|}{ South Asia } & \multicolumn{4}{|c|}{ Sub-Saharan Africa } \\
\hline 1970 & 0.138 & 0.487 & 0.036 & 0.175 & 0.367 & 0.609 & 0.169 & 0.335 \\
\hline 1975 & 0.199 & 0.518 & 0.063 & 0.214 & 0.352 & 0.590 & 0.161 & 0.321 \\
\hline 1980 & 0.115 & 0.417 & 0.030 & 0.147 & 0.377 & 0.610 & 0.178 & 0.342 \\
\hline 1985 & 0.074 & 0.333 & 0.018 & 0.108 & 0.391 & 0.626 & 0.186 & 0.354 \\
\hline 1990 & 0.042 & 0.236 & 0.009 & 0.070 & 0.396 & 0.620 & 0.196 & 0.359 \\
\hline 1995 & 0.049 & 0.231 & 0.012 & 0.073 & 0.401 & 0.639 & 0.195 & 0.364 \\
\hline 2000 & 0.035 & 0.177 & 0.009 & 0.054 & 0.364 & 0.616 & 0.173 & 0.338 \\
\hline 2003 & 0.026 & 0.141 & 0.006 & 0.041 & 0.347 & 0.598 & 0.162 & 0.323 \\
\hline
\end{tabular}

poor, we take a closer look at semi-decade specific growth incidence curves which allows for a very detailed analysis.

For the first half of the 1970s the top and bottom percentiles of the global income distribution experienced the highest growth rate. If one considers the $\$ 1$ per day poverty line, these years experienced relative pro-poor growth. However, this is not the case, if one applies the $\$ 2$ per day 
Figure 2.1: Global and Regional Distribution of Income
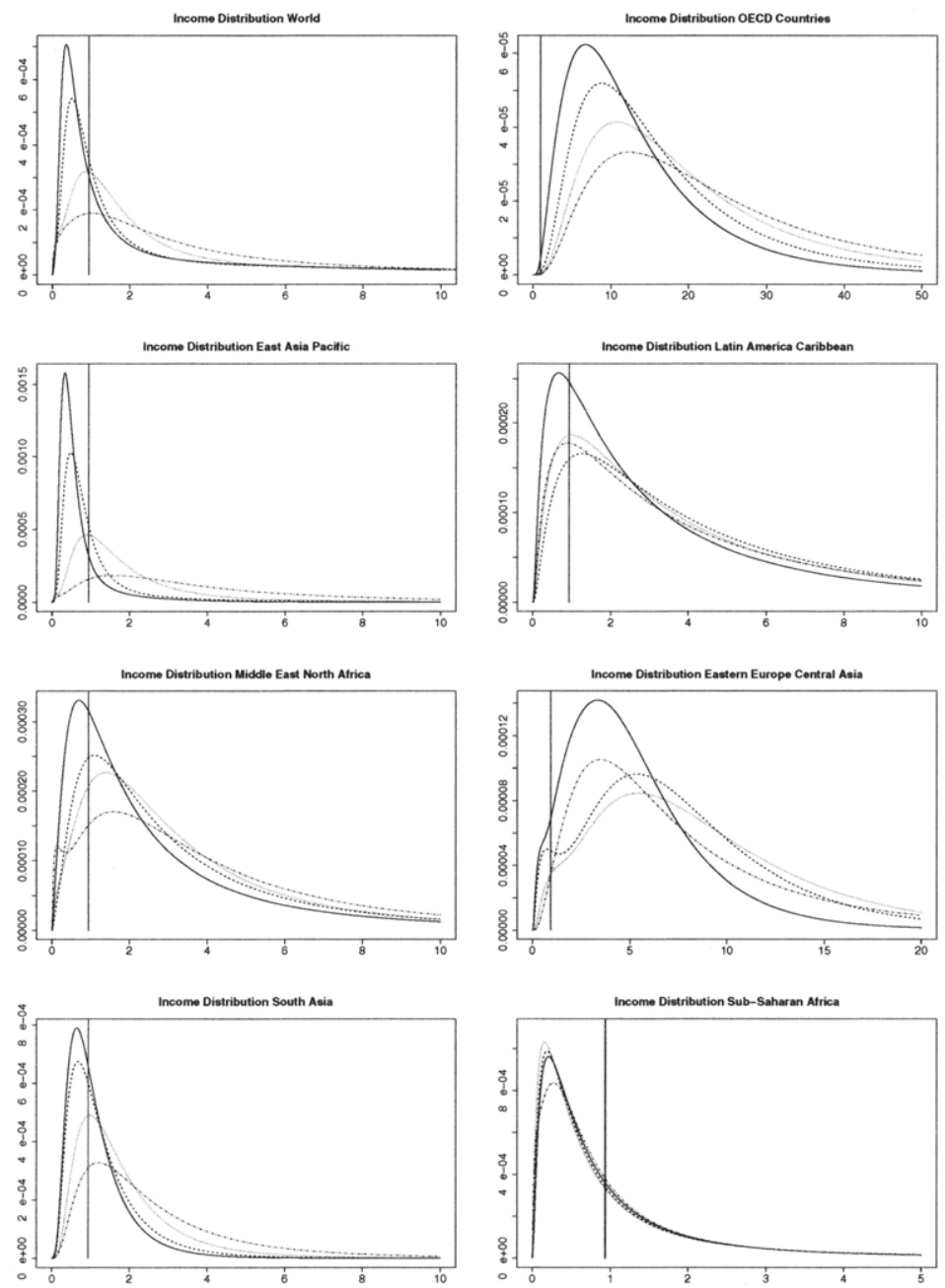

Solid line: 1970, dashed line: 1980, dotted line 1990, dashed-dotted: 2003

line, since the bottom-middle of the income distribution experienced only modest growth rates compared to the mean. The second half of the 1970 s is characterised by the strongest global growth performance of 2.2 percent per annum in mean income and can be considered relatively 
Table 2.3: Global and Regional Population and Absolute Number of $\$ 1$ and $\$ 2$ per day Poor

\begin{tabular}{|c|c|c|c|c|c|c|}
\hline & Population & $\begin{array}{l}\text { Poor } \\
\text { People } \\
(\$ 1)\end{array}$ & $\begin{array}{l}\text { Poor } \\
\text { People } \\
(\$ 2)\end{array}$ & Population & $\begin{array}{l}\text { Poor } \\
\text { People } \\
(\$ 1)\end{array}$ & $\begin{array}{l}\text { Poor } \\
\text { People } \\
(\$ 2)\end{array}$ \\
\hline & \multicolumn{3}{|c|}{ World } & \multicolumn{3}{|c|}{ OECD Countries } \\
\hline 1970 & $3,693,695$ & 784,540 & $1,570,698$ & 701,854 & 33 & 721 \\
\hline 1975 & $4,070,666$ & 779,835 & $1,691,192$ & 730,625 & 8 & 235 \\
\hline 1980 & $4,437,900$ & 609,085 & $1,577,463$ & 755,245 & 2 & 94 \\
\hline 1985 & $4,832,425$ & 399,595 & $1,313,699$ & 777,772 & 2 & 61 \\
\hline 1990 & $5,255,923$ & 370,810 & $1,097,183$ & 802,713 & 1 & 32 \\
\hline 1995 & $5,660,651$ & 385,708 & $1,006,770$ & 829,867 & 3 & 81 \\
\hline 2000 & $6,052,688$ & 359,184 & 894,835 & 854,570 & 1 & 27 \\
\hline \multirow[t]{2}{*}{2003} & $6,275,048$ & 365,006 & 893,394 & 869,918 & 1 & 31 \\
\hline & \multicolumn{3}{|c|}{ East Asia Pacific } & \multicolumn{3}{|c|}{ Latin America Caribbean } \\
\hline 1970 & $1,167,975$ & 530,322 & 913,422 & 282,977 & 20,595 & 53,936 \\
\hline 1975 & $1,307,614$ & 452,382 & 946,337 & 321,049 & 21,521 & 54,661 \\
\hline 1980 & $1,419,429$ & 332,907 & 869,163 & 360,466 & 9,450 & 33,328 \\
\hline 1985 & $1,534,017$ & 125,390 & 601,954 & 400,724 & 12,795 & 41,643 \\
\hline 1990 & $1,662,816$ & 94,202 & 414,950 & 442,008 & 17,500 & 53,657 \\
\hline 1995 & $1,776,351$ & 53,042 & 229,147 & 482,773 & 21,805 & 63,503 \\
\hline 2000 & $1,877,921$ & 38,277 & 140,236 & 522,037 & 23,046 & 65,913 \\
\hline \multirow[t]{2}{*}{2003} & $1,929,034$ & 45,379 & 158,974 & 544,279 & 23,602 & 67,207 \\
\hline & \multicolumn{3}{|c|}{ Middle East North Africa } & \multicolumn{3}{|c|}{ Eastern Europe Central Asia } \\
\hline 1970 & 137,202 & 11,594 & 32,309 & 387,557 & 6,034 & 16,875 \\
\hline 1975 & 157,584 & 10,927 & 32,308 & 408,977 & 4,255 & 13,057 \\
\hline 1980 & 184,880 & 7,180 & 26,057 & 429,959 & 5,276 & 15,128 \\
\hline 1985 & 219,384 & 8,846 & 29,005 & 451,243 & 3,396 & 12,059 \\
\hline 1990 & 253,947 & 8,942 & 29,433 & 469,334 & 1,625 & 7,835 \\
\hline 1995 & 282,784 & 13,259 & 31,838 & 477,391 & 2,744 & 15,936 \\
\hline 2000 & 314,504 & 10,140 & 30,611 & 480,881 & 773 & 7,564 \\
\hline \multirow[t]{2}{*}{2003} & 333,963 & 16,957 & 37,634 & 480,573 & 670 & 5,649 \\
\hline & \multicolumn{3}{|c|}{ South Asia } & \multicolumn{3}{|c|}{ Sub-Sahran Africa } \\
\hline 1970 & 726,192 & 99,960 & 353,579 & 289,938 & 106,307 & 176,593 \\
\hline 1975 & 813,860 & 162,234 & 421,552 & 330,957 & 116,482 & 195,182 \\
\hline 1980 & 906,662 & 103,946 & 377,792 & 381,259 & 143,776 & 232,441 \\
\hline 1985 & $1,009,753$ & 75,083 & 335,824 & 439,532 & 171,901 & 275,029 \\
\hline 1990 & $1,118,609$ & 46,775 & 263,634 & 506,494 & 200,578 & 314,139 \\
\hline 1995 & $1,231,644$ & 60,695 & 285,100 & 579,841 & 232,567 & 370,463 \\
\hline 2000 & $1,346,805$ & 47,109 & 238,323 & 655,972 & 238,775 & 404,047 \\
\hline 2003 & $1,416,242$ & 36,126 & 199,439 & 701,039 & 242,947 & 419,153 \\
\hline
\end{tabular}

pro-poor under the $\$ 1$ and the $\$ 2$ per day poverty definition. It is apparent that the bottom half of the distribution had higher growth rates than the average percentile growth rate and thus the bottom-middle of the global income distribution gained the most.

The first half of the 1980s can be considered the most pro-poor over the given time period as the bottom half of the distribution experienced very high growth rates compared to the top percentiles. The mean income grew by only 0.8 percent per annum, but the rate of pro-poor 
Figure 2.2: Global and Regional Distribution of Log-Income
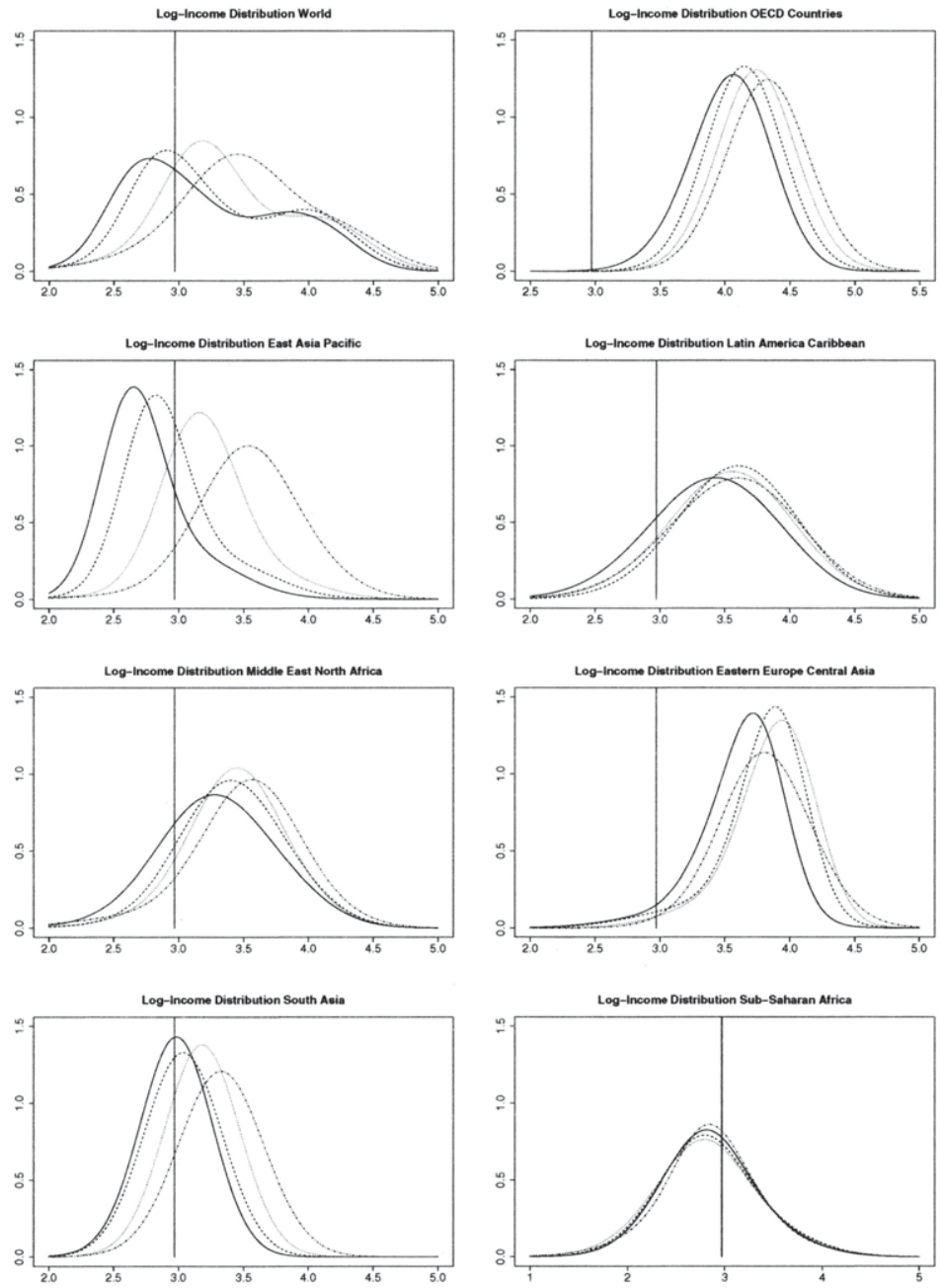

Solid line: 1970, dashed line: 1980, dotted line 1990, dashed-dotted: 2003

growth was 4.6 and 4.7 per annum for the $\$ 1$ and $\$ 2$ per day poverty lines respectively. The second half of the 1980s experienced an increase in the global mean income growth rate to normal 1.9 percent per annum and is characterised by negative pro-poor growth rates for the extreme 
poor, at -0.9 percent per annum, and growth rates for the poor, at 1.0 percent per annum. This is mainly due to the fact that the very bottom percentiles experienced an income decline, whereas the bottom-middle part of the distribution was doing reasonably well, so the bottom-middle half of the income distribution did catch up further to the upper percentiles. However, it is also important to note that the overall poor percentiles in 1985, which are considered to be poor under the $\$ 1$ and $\$ 2$ per day definitions, have been extremely reduced from the previous very pro-poor growth spell. In particular, the bottom-middle percentiles grew consistently, closing the income gap between the developing and developed world, which can also be seen if one looks at the log-income distribution where the two modes start to dissolve over the course of the 1980s. One hypothesis might be that the onset of globalisation and an intensified export-led growth strategy enabled many global poor to participate in the global growth process in particular in China and South East Asia.

The 1990s cannot be considered relatively pro-poor. The highest growth rates over the decade are achieved by the inter-quartile percentiles that experience above mean percentile growth rates. This implies further global income convergence over the 1990s, and at the end of the 1990s no hint of a second peak in the global log-income distribution remains. However, these percentiles are no longer considered poor. The overall growth rate of mean income follows the previous decade pattern with the first half being characterised by relatively slower growth rates, 0.7 percent per annum, followed by stronger growth rates of 2.0 percent per annum in the second half. For the first four years in the new millennium the growth rate of mean income has slowed down again to 1.3 percent per annum. The rate of pro-poor growth is below the average income growth rate with the bottom percentiles growing at only 0.5 percent per annum for the $\$ 1$ per day poverty line and 0.6 percent for the $\$ 2$ per day poverty line.

\subsection{Regional Distributions, Inequality, Poverty and Growth Inci- dence Curves}

\subsubsection{Regional Income and Log-Income Distributions}

In order to get a more detailed picture, we decompose the world into seven regions which are analysed separately: the OECD countries, East Asia and the Pacific, Latin America and the Caribbean, Middle East and North Africa, Eastern Europe and Central Asia, South Asia and Sub-Saharan Africa (cf. Table B.1 for the countries belonging to each region).

The income and log-income distributions for these regions, modeled as described in Section 2.2, are shown in Figures $2.1-2.3$. One observes a significant increase in the income distributions of East Asia and the Pacific and South Asia, whereas Latin America as well as the Middle East and North Africa, which were at the beginning relatively rich regions in comparison to the OECD countries, only saw rather slow progress. Furthermore, Eastern Europe and Central Asia's distribution accounts for the varied experiences of the former Eastern Block countries 
Figure 2.3: Global and Regional Cumulative Distribution of Log-Income
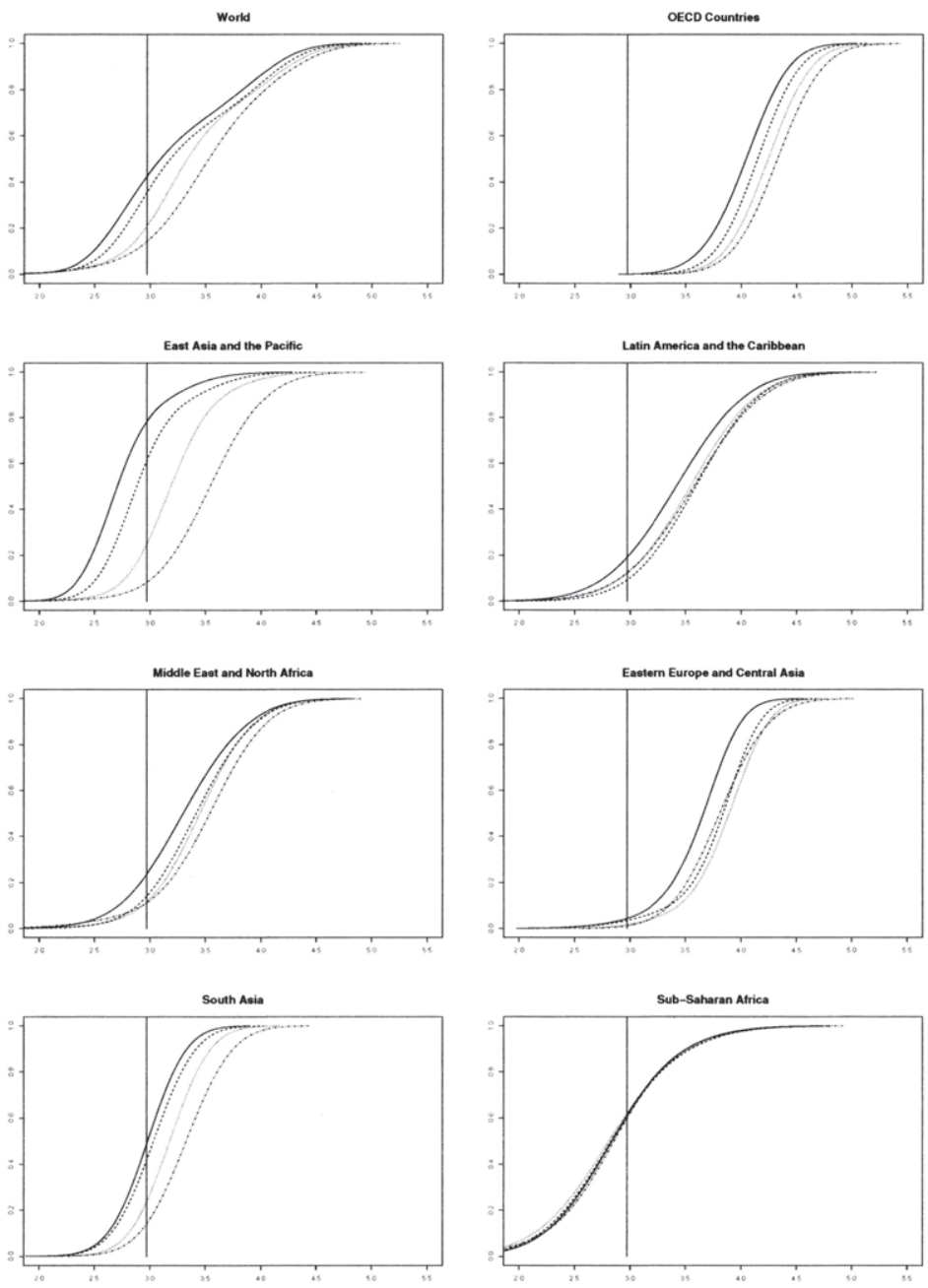

Solid line: 1970, dashed line: 1980, dotted line 1990, dashed-dotted: 2003

with initially increasing and than falling income, finally resulting in a stronger dispersed income distribution. Sub-Saharan Africa's distribution hardly shifts at all implying virtually no gains and a relative deterioration compared to the other regions. 
Table 2.4: Global and Regional Semi-Decade specific Growth Rates 1970-2003.

\begin{tabular}{|c|c|c|c|c|c|c|c|c|}
\hline Year & $\begin{array}{l}\text { Mean } \\
\text { of } \\
\text { Growth } \\
\text { Rates }\end{array}$ & $\begin{array}{l}\text { Growth } \\
\text { Rate of } \\
\text { Mean }\end{array}$ & $\begin{array}{l}\text { Rate of } \\
\text { PPG } \\
(\$ 1)\end{array}$ & $\begin{array}{l}\text { Rate of } \\
\text { PPG } \\
(\$ 2)\end{array}$ & $\begin{array}{l}\text { Mean } \\
\text { of } \\
\text { Growth } \\
\text { Rates }\end{array}$ & $\begin{array}{l}\text { Growth } \\
\text { Rate of } \\
\text { Mean }\end{array}$ & $\begin{array}{l}\text { Rate of } \\
\text { PPG } \\
(\$ 1)\end{array}$ & $\begin{array}{l}\text { Rate of } \\
\text { PPG } \\
(\$ 2)\end{array}$ \\
\hline & \multicolumn{5}{|c|}{ World } & \multicolumn{3}{|c|}{ OECD Countries } \\
\hline $1970-2003$ & 2.332 & 1.830 & 2.192 & 2.679 & 2.000 & 2.079 & 2.210 & 2.210 \\
\hline $1970-1974$ & 1.640 & 2.008 & 2.272 & 1.646 & 2.836 & 2.434 & 4.994 & 4.994 \\
\hline $1975-1979$ & 2.421 & 2.195 & 2.280 & 2.789 & 2.636 & 2.729 & 3.493 & 3.493 \\
\hline $1980-1984$ & 2.347 & 0.838 & 4.560 & 4.684 & 1.230 & 1.273 & 2.061 & 2.061 \\
\hline 1985-1989 & 1.850 & 1.867 & -0.881 & 0.965 & 2.356 & 2.439 & 1.719 & 1.719 \\
\hline $1990-1994$ & 1.169 & 0.739 & -0.005 & 0.817 & 0.750 & 0.936 & -0.894 & -0.894 \\
\hline 1995-1999 & 2.397 & 2.009 & 1.285 & 1.697 & 2.061 & 2.106 & 2.580 & 2.580 \\
\hline \multirow[t]{2}{*}{$2000-2003$} & 1.561 & 1.318 & 0.536 & 0.556 & 0.461 & 0.553 & -0.096 & -0.096 \\
\hline & \multicolumn{4}{|c|}{ East Asia Pacific } & \multicolumn{4}{|c|}{ Latin America Caribbean } \\
\hline $1970-2003$ & 5.475 & 5.646 & 4.919 & 5.376 & 1.048 & 1.123 & 0.876 & 0.946 \\
\hline $1970-1974$ & 3.135 & 3.549 & 3.421 & 3.001 & 2.170 & 3.152 & -0.382 & 0.576 \\
\hline $1975-1979$ & 3.607 & 4.630 & 2.165 & 3.084 & 4.198 & 2.217 & 8.298 & 7.212 \\
\hline $1980-1984$ & 6.562 & 4.578 & 9.257 & 8.151 & -1.538 & -1.557 & -2.026 & -1.764 \\
\hline $1985-1989$ & 4.024 & 5.299 & -0.693 & 1.606 & -0.892 & 0.630 & -3.741 & -3.131 \\
\hline $1990-1994$ & 6.122 & 6.193 & 4.083 & 5.157 & 0.251 & 1.359 & -1.700 & -1.501 \\
\hline 1995-1999 & 4.342 & 4.048 & 2.059 & 3.247 & 0.840 & 1.132 & 0.099 & 0.262 \\
\hline \multirow[t]{2}{*}{ 2000-2003 } & 2.520 & 4.068 & -0.049 & -1.363 & 0.015 & -0.414 & 0.071 & 0.261 \\
\hline & \multicolumn{4}{|c|}{ Middle East North Africa } & \multicolumn{4}{|c|}{ Eastern Europe and Central Asia } \\
\hline $1970-2003$ & 1.384 & 1.222 & 0.375 & 1.175 & 1.274 & 1.536 & 2.905 & 2.230 \\
\hline $1970-1974$ & 2.771 & 3.127 & 2.196 & 2.230 & 4.240 & 4.144 & 4.563 & 3.946 \\
\hline 1975-1979 & 3.177 & 1.591 & 6.417 & 5.490 & 2.618 & 2.737 & -0.440 & -0.321 \\
\hline $1980-1984$ & 0.299 & 0.136 & -1.538 & -0.121 & 1.793 & 2.003 & 3.065 & 2.635 \\
\hline $1985-1989$ & -0.053 & -0.676 & 1.592 & 1.094 & 1.431 & 1.586 & 5.790 & 4.881 \\
\hline $1990-1994$ & 1.397 & 1.669 & -4.718 & -1.196 & -7.764 & -5.340 & -2.685 & -4.197 \\
\hline 1995-1999 & 2.177 & 2.475 & 8.851 & 5.049 & 1.399 & 0.584 & 7.102 & 5.930 \\
\hline \multirow[t]{2}{*}{$2000-2003$} & -0.591 & 0.379 & -13.745 & -8.323 & 4.150 & 4.401 & 0.762 & 1.976 \\
\hline & \multicolumn{4}{|c|}{ South Asia } & \multicolumn{4}{|c|}{ Sub-Saharan Africa } \\
\hline $1970-2003$ & 2.397 & 2.654 & 1.856 & 2.106 & 0.045 & 0.264 & -0.051 & 0.023 \\
\hline $1970-1974$ & -0.316 & -0.277 & -0.221 & -0.329 & 1.374 & 1.292 & 1.127 & 1.202 \\
\hline $1975-1979$ & 2.873 & 1.706 & 5.304 & 4.137 & -0.820 & 0.020 & -1.307 & -1.160 \\
\hline $1980-1984$ & 2.429 & 2.300 & 3.054 & 2.675 & -0.588 & -0.385 & -0.263 & -0.445 \\
\hline 1985-1989 & 3.048 & 2.914 & 3.065 & 3.207 & -0.567 & 0.248 & -1.566 & -1.039 \\
\hline $1990-1994$ & 0.281 & 0.958 & -1.808 & -1.031 & -0.610 & -1.463 & 0.409 & 0.164 \\
\hline 1995-1999 & 3.058 & 3.594 & 1.721 & 2.198 & 1.295 & 1.136 & 1.552 & 1.488 \\
\hline $2000-2003$ & 2.884 & 2.887 & 2.654 & 2.854 & 1.367 & 0.964 & 1.665 & 1.502 \\
\hline
\end{tabular}

\subsubsection{Regional Poverty and Inequality Measures}

Poverty and inequality measures for these seven regions, which reflect the overall picture above, are reported in Tables $2.2-2.1$. Indeed, the region with the highest poverty headcount in 1970, namely East Asia and the Pacific, experienced the most breathtaking poverty decline from 78 percent in 1970 to 8 percent in 2003 combined with a strong decline in inequality 
Figure 2.4: Global Semi-Decade specific Growth Incidence Curves
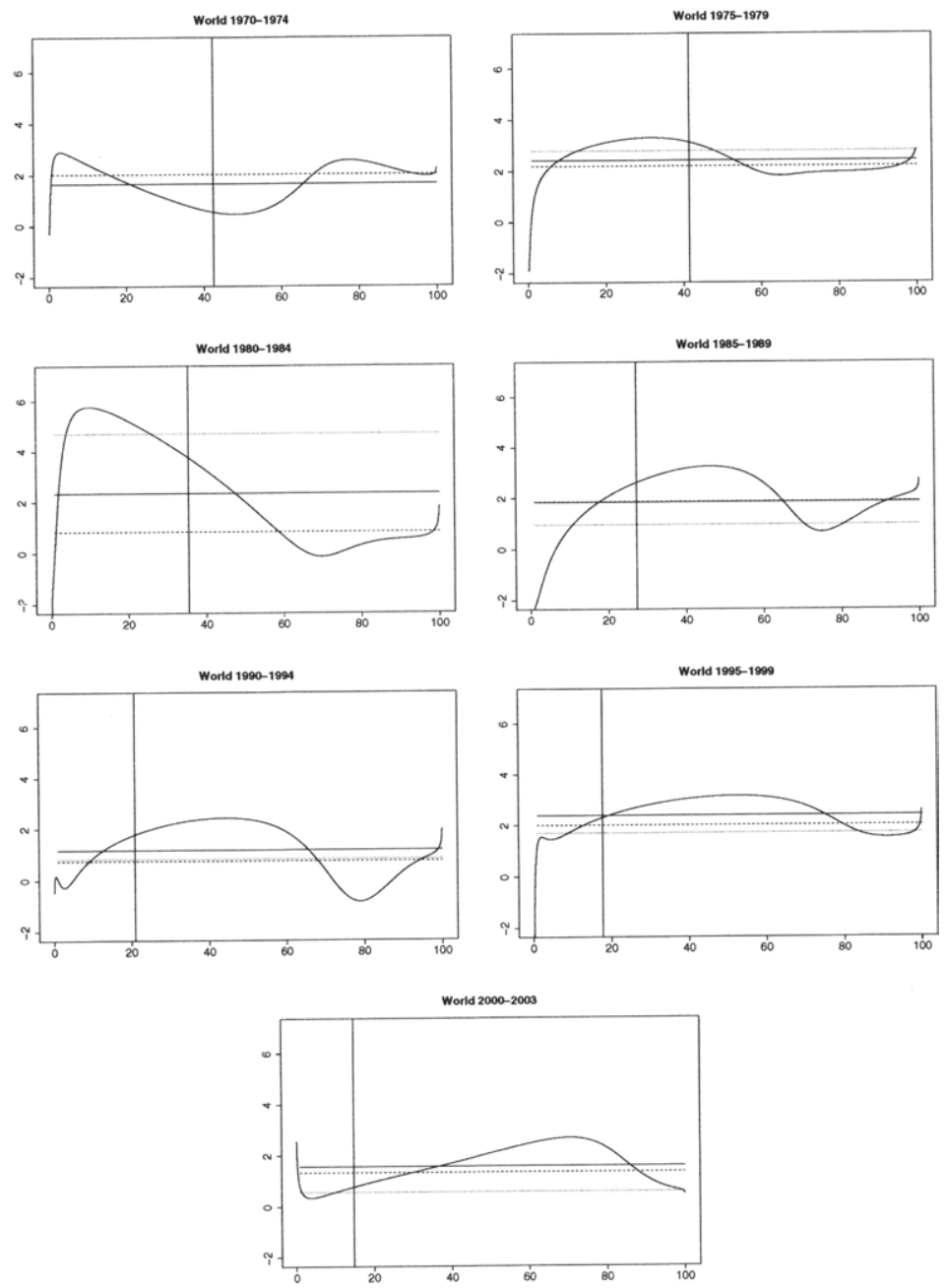

Solid line: Growth Incident Curve, solid vertical line: $\$ 2$ per day Poverty Line, solid horizontal line: Mean of Growth Rates, dashed line: Growth Rate in Mean, dotted line: Pro-poor Growth Rate

between countries in this region. Moreover, the absolute number of poor decreased, despite strong population growth, from about half a billion or one billion to about 45 and 160 million for the $\$ 1$ and $\$ 2$ poverty definition respectively. Furthermore, Latin America and the Caribbean, 
as well as the Middle East and North Africa saw their poverty headcounts decline by almost half. However, their absolute number of poor increased slightly under both definitions due to population growth. Moreover, South Asia also experienced a remarkable poverty decline even though less spectacularly and from a lower initial level than East Asia, causing the absolute number of poor to fall from about 100 or 350 million to about 36 and 200 million for the $\$ 1$ and $\$ 2$ poverty lines respectively. This experience was combined with rising inequality from an initially very low level driven by within country inequality. Furthermore, the often lamented case of Sub-Saharan Africa is confirmed by our numbers, as it is the only region which experiences virtually no improvement in any of the measures. This stagnation of Sub-Saharan Africa and relative decline in comparison to all other regions becomes even more apparent if we take a look at the regional decomposition of the absolute number of poor as part of the global population. While the poverty rates remained more or less constant over the years, the absolute number of people living in poverty more than doubled due to population growth from about 100 and 180 million to about 240 and 420 million for the $\$ 1$ and $\$ 2$ poverty lines respectively. Moreover, inequality measures even saw an increase from initially already very high levels, both for within and between country inequality. This implies that Sub-Saharan Africa is nowadays by far the most unequal and poorest region of the world in relative and absolute terms overall. However, as far as within country inequality is concerned Latin America still has to be considered the most unequal region, as seen by the within Theil inequality measure. Furthermore, Eastern Europe and Central Asia contributes little to the global poor if one considers the $\$ 1$ and $\$ 2$ per day poverty lines and thus is characterised by very low and slightly declining poverty rates and absolute number of poor combined with strongly increasing within country inequality after the breakdown of the Iron Curtain from initially rather low levels. Finally, for the sake of completeness, a quick glance at the OECD countries shows that it basically contributes nothing to the global poverty dynamics under the applied definitions. ${ }^{12}$ However, the region experienced a marked increase in inequality due to an increase in within country inequality.

\subsubsection{Regional Semi-Decade Specific Growth Rates, Rates of Pro-poor Growth and Growth Incidence Curves}

The poverty and inequality dynamics described above become even more apparent if one takes a closer look at the regional growth incidence curves and results over the entire period as shown in Figure 2.5. Moreover, a closer look at the semi-decade specific results conveys an even more detailed picture of the regions' growth experience during shorter time periods. ${ }^{13}$

The OECD Countries. The results for the OECD countries show that even though the average growth rate varied between better semi-decades, such as the late 1990s or late 1970s,

12 Clearly neither the $\$ 1$ nor the $\$ 2$ poverty line is a very suitable poverty measure for rich countries in general.

13 Due to the large amount of semi-decade specific regional incidence curves we only report a few examples for a selected time period here. However, the results in Table 2.4 give a good idea about the semi-decade specific regional growth experience and all graphs are available in Appendix ??. 
Figure 2.5: Global and Regional Growth Incidence Curves 1970-2003
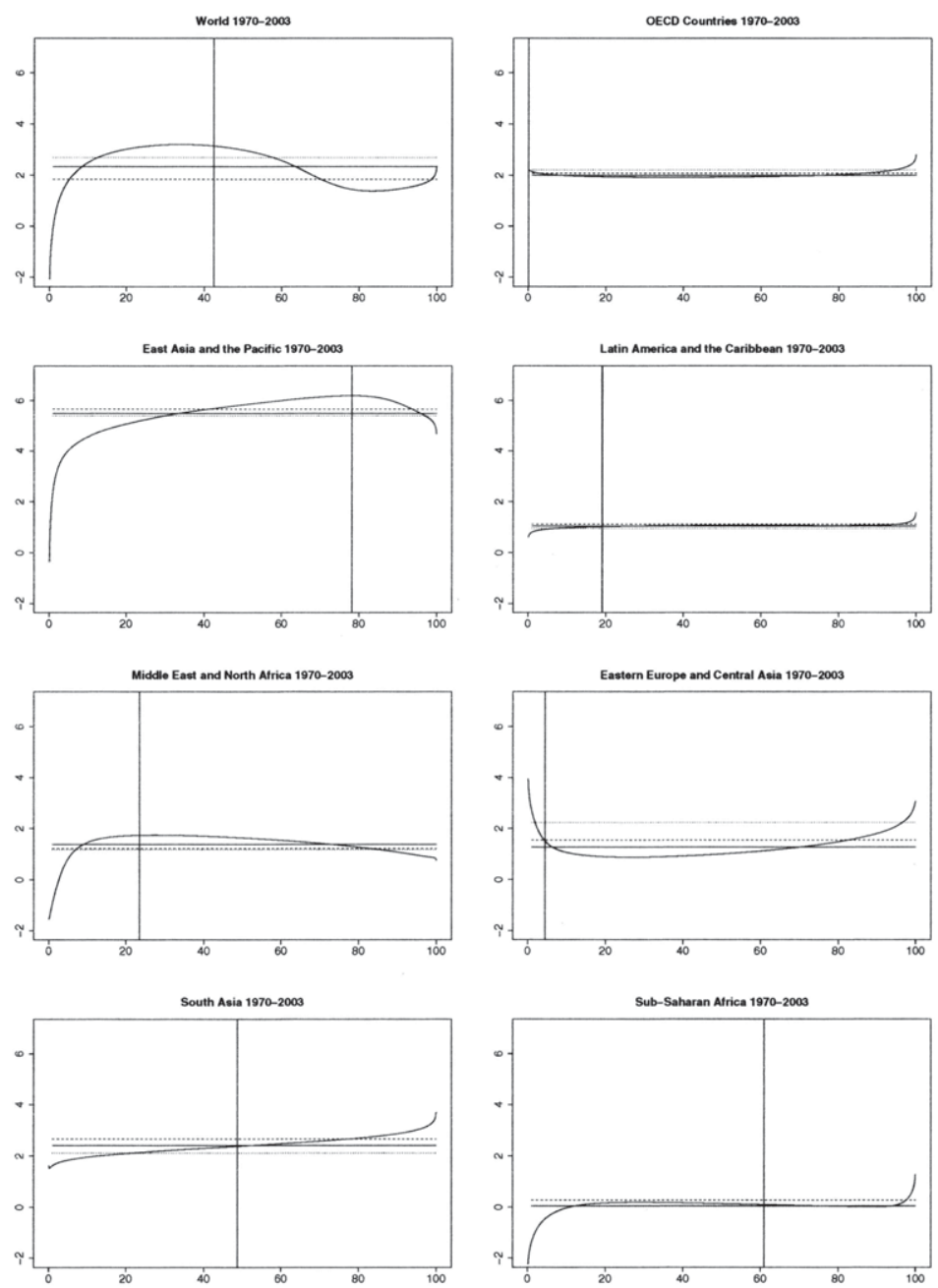

Solid line: Growth Incident Curve, solid vertical line: $\$ 2$ per day Poverty Line, solid horizontal line: Mean of Growth Rates, dashed line: Growth Rate in Mean, dotted line: Pro-poor Growth Rate

and less strong growth periods, such as the early 1990 s and the early 1980 s, the overall intradistributional growth pattern is very stable. During all semi-decades, except for the start of the new millennium, the growth incidence curves show higher growth rates for the richest per- 
Figure 2.6: Growth Incidence Curves of Various Years
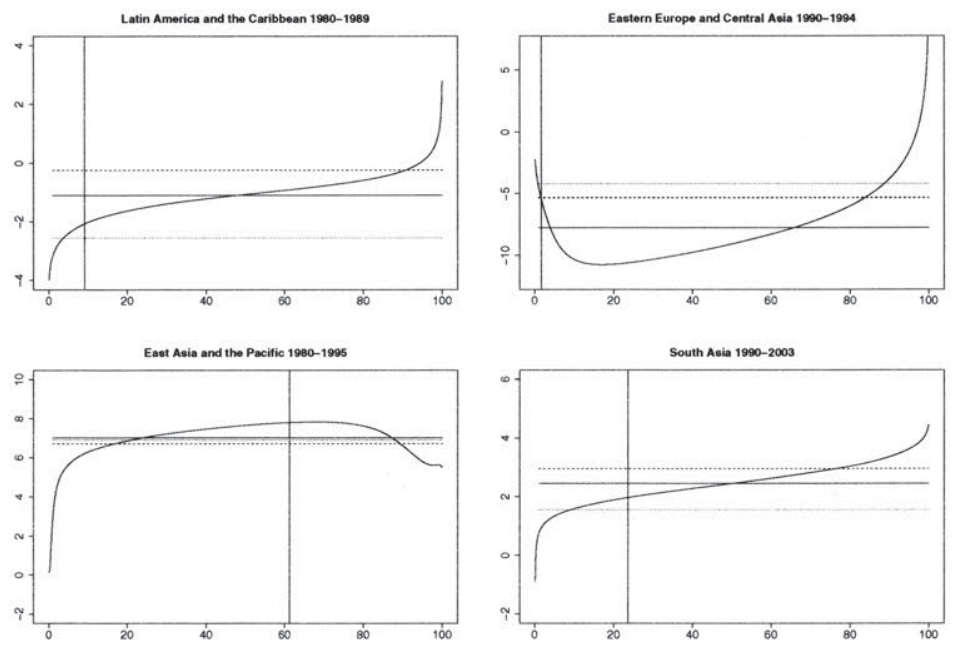

Solid line: Growth Incident Curve, solid vertical line: $\$ 2$ per day Poverty Line, solid horizontal line: Mean of Growth Rates, dashed line: Growth Rate in Mean, dotted line: Pro-poor Growth Rate

centiles. Thus, the higher the population percentile the higher the income growth rate, with the logic consequence of increasing inequality over time.

Eastern Europe and Central Asia. Eastern Europe and Central Asia is telling a more interesting story as it is much less homogeneous. It is clear from the growth incidence curves that during the first half of the 1990s the bottom half of the regional income distribution saw their income decline drastically. These high negative growth rates, directly after the Soviet Regime's collapse, are causing a slight increase in the poverty rate by 1995 . The other semi-decades can be characterised as more pro-poor, except for the very bottom percentiles, accounting for the slightly declining inequality up to 1990 after which inequality increases rather rapidly, before it improves again.

East Asia and the Pacific. The fact that East Asia is by far the most dynamic region and accounts for most of the dramatic global poverty reduction is apparent from a closer look at the regional growth incidence curves. Except for the start of the new millennium, which displays a slow down in the mean of growth rates to about 2.5 percent per annum, and the early $1970 \mathrm{~s}$ which had around 3 percent, all semi-decades are characterised by a high mean of growth rates of about 4 percent per annum. Furthermore, the early 1980s and 1990s saw most remarkable mean percentile growth rates of more than 6 percent per annum, combined with rates of pro-poor growth of 9.2 and 8.1 percent per annum for the early 1980s respectively (see Figure 2.6); no 
other region has such a consistently high growth record. From the 1970s onward, the poverty headcount index is steadily declining mainly due to good growth records in the bottom middle of the regional income distribution. In the early 1980s it is in particular the bottom percentiles which grew most rapidly. Moreover, the growth spurt of China, as the region's most populous country, accounts mostly for these very high growth rates, and thus accounts for a major share of the dramatic poverty headcount reduction from 61 percent to 39 percent over a 5 year period. For the bottom half of the distribution the 1990s were rather successful, lowering poverty rates even further from 25 to 8 percent. Moreover, the region is displaying a clear lead concerning the overall growth rate in mean, and is therefore the main driving force behind the convergence of the global income distribution.

Latin America and the Caribbean. Latin America saw the second lowest growth rate in mean, which was almost distribution neutral, and is characterised by the third and second lowest rates of pro-poor growth (for the $\$ 1$ and $\$ 2$ lines, respectively). Consequently, the poverty headcount dropped only slightly from 19 percent in 1970 to 12 percent in 2003 with inequality remaining high. Hence, Latin America was relatively outperformed in terms of growth and poverty reduction by all other regions except for Sub-Saharan Africa. Despite the overall rather stagnant picture there are some marked semi-decade specific variations. Most pro-poor were the late 1970s, however, the promising high growth rates were not maintained. Thus, the relative deterioration with respect to the other regions is mainly due to the 1980 s, which are characterised by negative growth rates except for the very rich percentiles and are thus known as the lost decade in Latin America (compare Figure 2.6). The 1990s again display low positive growth rates in mean, however, the rate of pro-poor growth remains negative in the first half of the decade. Overall, Latin America's growth record is disappointing as poverty reduction could have been much more rapid and a further divergence from the richer regions is apparent.

Middle East and North Africa. Overall, the Middle East and North Africa display a similarly disappointing growth rate as Latin America with equally bad rates of pro-poor growth. In particular, the very low pro-poor growth rate at $\$ 1$ per day is almost as low as in Sub-Saharan Africa; however, the proportion of the population living below $\$ 1$ per day is clearly much lower. Over the 34 year time-period the region managed to lower its poverty headcount rate from 23 to 11 percent while reducing regional inequality slightly. Taking a closer look at the overall growth incidence curve, one can see that the very poor of the region experienced by far the lowest or even negative income growth. However, from about the 10th percentile the growth incidence curves look relatively pro-poor explaining the slight drop in the Gini coefficient and Theil's inequality measure.

Given this overall 34 year development a closer look at the semi-decade specific pro-poor growth rates for the Middle East and North Africa shows a particularly strong fluctuation of the pro-poor growth rates ranging from -13.7 to 8.8 percent per annum and -8.3 to 5.5 percent per annum for the $\$ 1$ and $\$ 2$ poverty lines respectively. While the 1970 s saw positive and strong growth rates of the poor, the first half of the 1980s, 1990s, and 2000s are characterised by a 
growth collapse of the poor. The results are driven mostly by the growth rates of Iraq, in particular during the Gulf Wars. ${ }^{14}$ In contrast, the second half of these decades saw compensatory pro-poor growth rates, such that overall the region saw a poverty decline and a lower Gini coefficient at the end of the observational period. However, like Latin America the region has been outperformed in terms of growth and poverty reduction by South and East Asia.

South Asia. South Asia is the second most dynamic and populous region of the world over the given time period. Even though growth has not been relatively pro-poor, the overall growth record was sufficiently strong to lower the headcount at $\$ 2$ per day from half the population to 14 percent, while regional inequality saw an increase from initially very low levels due to an increase in within country inequality. In particular, India's growth record accounts for much of the regional dynamics as it is by far the largest country. Even though the early 1970s were characterised by negative growth rates the second half saw very high rates of relative pro-poor growth, initiating a constant poverty decline. The entire 1980s display relative pro-poor growth rates. In particular, during the 1980s the very poorest experienced growth rates of about 3 percent per annum. Average growth rates for the percentiles below the $\$ 2$ per day poverty line increased from 2.7 to 3.2 percent per annum from the first to the second half of the 1980 s respectively. The early 1990s are characterised by a general growth slow down with negative pro-poor growth rates, before growth resurges in the second half of the 1990s and during the first years of the new millennium, however, with only modest gains for the very bottom percentiles (see Figure 2.6). In general, the region's pro-poor and overall growth record is the second major driving force behind global income convergence with India accounting for a large proportion of this income catch-up.

Sub-Saharan Africa. As mentioned above, Sub-Saharan Africa is by far the most troublesome region as it remains virtually stagnant with constantly high rates of poverty and inequality. This is mainly due to the non-existent growth record of the region as a whole and is combined with a worsening of regional inequality at a very high level both within and between countries. This leaves Sub-Saharan Africa in 2003 as the most distinctively poor region in relative and absolute terms, as well as most unequal region in the world. The overall growth rate in mean over the 34 year period is 0.3 percent per annum, with even lower rates of pro-poor growth for both poverty lines with the very bottom of the distribution experiencing even a negative growth record.

Indeed, the semi-decade specific analysis shows a relatively successful early 1970 s followed by a devastating picture for the late 1970s, 1980s and early 1990s, all of which are characterised by a negative average growth rate and negative or only slightly positive growth rates in mean. Results for pro-poor growth are similar, even though the early 1990s saw the first positive propoor growth rates after 15 years. The late 1990s and the start of the new millennium indicate a more encouraging picture. Despite remaining low growth rates at least some slow progress has

\footnotetext{
14 We would expect that the early 1980 s would be characterised by even lower growth records, if we could include data from Iran. However, reliable comparable data is hardly available so that one of the most populous countries of the region cannot be included in our analysis.
} 
been made in particular for the poor, which still account for almost 60 percent of the region's population and experienced positive and for the region unparalleled rates of pro-poor growth. However, over the entire period the region has been virtually stagnant. While it was "only" the second poorest region in the world in 1970 , it is by far the poorest region in the world in the new millennium and experienced high relative income deterioration. In fact, about two thirds of the world's extreme poor and about half of the world's poor live in Sub-Saharan Africa nowadays (compare Table 2.3). Hence, it is clear that any serious attempt to further reduce global poverty will fail, if it fails to reach Sub-Saharan Africa.

\subsection{Conclusion}

In contrast to studies analysing the polarisation of the cross-national average income per capita distribution, this study of the global income distribution as a whole shows strong global income convergence among all the world's citizens. We use a simple parametric mixture approach, with log-normal national income distributions and weights determined by the country's population, which appears to be adequate for the data available in the WIDER database. Our results show that the past 34 years witnessed a strong global income convergence accompanied by a drastic decline of global inequality and poverty no matter what conceivable monetary poverty line is applied. Noticeably, overall inequality declined because of declining inequality between countries, while inequality within countries increased. Furthermore, the analysis of growth incidence curves shows that the bottom-middle part of the income distribution experienced above average percentile growth rates, which explains the occurring global income convergence. In particular, the late 1970s and early 1980s are characterised by high global rates of pro-poor growth, initiating the rapid decline of global poverty rates.

A regional decomposition of our data reveals that in particular the extraordinary growth record of East Asia and South Asia, which includes the two population heavy weights China and India, accounts mostly for the global income convergence and rapidly declining poverty rates. Latin America and the Middle East and North Africa showed slower but steady progress in poverty reduction. However, their more modest growth experience implies a relative income deterioration vis-á-vis the richer regions and also East and South Asia, and thus, can be seen as a remaining diverging factor in the global income distribution. Lastly, Sub-Saharan Africa has remained virtually stagnant and has become the poorest region in relative and absolute terms, implying a steady divergence and disconnection from the global growth process. Nevertheless, from a global perspective, the observational period is characterised by an unparalleled improvement of income per capita and an unprecedented poverty reduction. This in itself can be considered a great success and is in particular due to the fact that the bottom-middle global income percentiles managed to catch up to higher levels of income, thus reducing the dispersion of income from a global perspective. On the other hand, the remaining very lowest percentiles also experienced the lowest percentile growth rates, such that the remaining extreme poor might 
be particularly hard to reach. Given the high share of global extreme poor and high poverty headcounts in Sub-Saharan Africa it is clear from our analysis that any further massive extreme poverty reduction can be only achieved by pro-poor, or at least distributional neutral, growth in Sub-Saharan Africa. The remaining poor seem to be, if Chen and Ravallion's (2007) rural-urban poverty decomposition is any indication, mostly to be found in rural areas. Thus, any attempt to reduce global poverty even further must focus mainly on fostering growth in Sub-Saharan Africa and on remaining, in particular rural, national pockets of poverty. 


\section{Chapter 3}

\section{Ethnic Fractionalisation, Migration and Growth}

\subsection{Introduction}

A wide range of studies have found robust evidence for the negative effect of high ethnic fractionalisation on long-term growth in a cross section of countries. This growth diminishing effect of ethnic fractionalisation has been found to be operating through an adverse policy environment and the suboptimal provision of public goods (Easterly and Levine (1997), Easterly (2001), Alesina et al. (2003)). However, the channels through which ethnic fractionalisation has an impact on growth have only been partially analysed by these studies. Furthermore, the impact of ethnic fractionalisation on economic progress might be far more complex than the existing empirical studies would suggest. For this reason this paper intends to extend the existing analyses.

First of all, it seems reasonable and desirable to update the data set used by Alesina et al.(2003) into the 1990s to analyse the robustness of their results in a wider time range. Interestingly, we find a prevailing negative direct effect of ethnic fractionalisation on growth after the inclusion of the 1990s, despite the inclusion of policy control variables. Hence, we apply decade and region specific regressions, as well as a region specific ethnic fractionalisation interaction term, in order to identify whether this result is driven by decade or regional specific effects. We find that the growth-hampering impact of ethnic fractionalisation remains only in the 1990s and in Sub-Saharan Africa once the policy framework of Alesina et al. (2003) is controlled for. Moreover, we show that this 1990 s effect vanishes if we implement the Kaufman-Kraay-ZoidoLobaton-Indicator of governance in the existing model framework of Alesina et al.. The specific Sub-Saharan effect of fractionalisation instead shows an indirect effect via investment on growth, and not via governance. In line with recent research on violent conflict (Montalvo and ReynalQuerol, 2005), we cannot confirm the hypothesis that the remaining negative impact of ethnic

based on joint work with Dana Schüler 
fractionalisation is due to violent conflicts. Thus, our results indicate that the original model specification of Alesina et al. is incomplete as it fails to fully account for the recent 1990s and Sub-Saharan growth experience.

In addition, it might be the case that the alleged negative effect of ethnic fractionalisation on growth, described above, is possibly mitigated by positive effects prevailing in multi-ethnic societies. In particular, there is a large body of literature which suggests that the existence of co-ethnic networks has a large positive impact on trade and thus on growth. The theoretical argument is, that immigrants have an informational and trust advantage in arranging trade with their home countries over their local counterparts (Epstein and Gang (2004), Casella and Rauch (1997), Rauch (2001)). Co-ethnic networks are also found to promote foreign direct investment (Tong, 2005). Hence, we empirically investigate, whether ethnic fractionalisation might be a positive factor in a nation which is ethnically diverse according to our indicator, partially due to past immigration. We find some indication that countries which are ethnically diverse due to past immigration can mitigate the negative impact of ethnic fractionalisation on growth. We are the first, to our knowledge, to distinguish between these two different kinds of ethnic fractionalisation in order to determine whether the result empirically indicates this multidimensionality of ethnic diversity. We find the positive effect but we cannot confirm the trade and foreign direct investment hypothesis.

This paper is structured as follows: in Sections 3.2 and 3.3 of this chapter we will focus on the existing theoretical consideration and empirical research which has been produced so far. This is followed by a brief discussion of our data and methodology in Section 3.4. Then we shall present and discuss our results in Section 3.5. In Section 3.6 we identify potentially interesting future research questions and conclude.

\subsection{Theoretical Framework}

There are two different strands of literature, one of which suggests that ethnic diversity is harmful to growth and another which suggests the opposite. The first strand is based on economic growth theory and subsequent cross-country growth regressions, while the strand which argues that high ethnic diversity is good for growth is normally a case country study using micro data to evaluate the impact of co-ethnic trading networks on trade and growth.

Zak and Knack (2001), for instance, argue that high ethnic diversity increases the social distance between groups, which in turn reduces the amount of trust in a society. Due to the significant information and enforcement problems in many (particularly risky) economic transactions, lack of trust will reduce the amount of beneficial economic transactions, increase transaction costs on monitoring and enforcement and will make some contracts impossible. A related insight emerges from the literature on 'social capital' which measures the number and intensity of social interactions and linkages between members of a society and has found that social capital is 
potentially conducive to economic development because it favours cooperation and reduces problems due to asymmetric information. The theoretical argument is that social capital is harder to establish between divided ethnic groups in a society. ${ }^{1}$

Furthermore, some authors argue that ethnic diversity increases the likelihood of conflict. Collier and Hoeffler (1998) model the likelihood of a civil war as a cost-benefit calculation of potential rebels. While ethnic diversity is likely to increase the incentive to incite rebellion due to grievances (perceived and actual) experienced by individual ethnic groups, having very large numbers of ethnic groups might make the coordination of a successful rebellion difficult. Thus, Collier and Hoeffler argue that civil wars are particularly likely in ethnically polarised societies, where a few ethnic groups vie for political control.

However, not only violent, but also political conflict has been hypothesised as a channel through which high ethnic diversity negatively influences economic growth. Alesina and Drazen (1991) suggest that groups may attempt to shift the burden of economic stabilisation and reform onto other groups when stabilisation has significant distributional implications. Even though it is agreed that stabilisation requires cuts in public expenditure to eliminate the budget deficit, the distribution of the allocation of the costs is not agreed upon. The process leading to stabilisation can therefore often be described as a war of attrition, which delays stabilisation and only ends when certain groups allow the others to decide on the allocation of the burden of the fiscal adjustment. More politically polarised countries will experience longer periods of instability. In the case that different ethnic groups are also strongly politically polarised then the model also applies in the context of ethnic diversity. Similar arguments are made by Easterly and Levine (1997), who argue that high ethnic diversity leads to poor policy choices. Governments either find it difficult to agree on painful economic reforms, attempt to shift the burden to other groups, or simply try to enrich themselves as they fear that their tenure might be limited due to the strong resistance of other ethnic groups. Svensson (1998) develops a game-theoretic, rent-seeking model in which groups compete for common-pool resources. Even in a repeated interaction game co-operation might not be enforceable and the groups sustain their costly appropriation efforts.

In general, political regimes in ethnically diverse countries are often found to be more engaged in inefficient "identity politics" than in more efficient "performance politics". In the former situation, a political regime or party is supported not for its performance in terms of furthering prosperity, but for being led by people from the same group, while in the latter situation economic and political performance is rewarded. As most ethnically diverse countries are diverse at the national level and relatively homogeneous at the regional level, "identity politics" persist at the national level. With these politics people are reminded of differences and therefore an environment of low trust and cooperation is built and maintained. Collier (1998) argues that loyalty to ethnically-based parties is often maintained irrespective of economic performance and

\footnotetext{
However, the theoretical literature on social capital also suggest that social capital slows down the transition process of development between one stage and the next and is therefore bad for economic growth. See Banerjee and Newman (1998), Arnott and Stiglitz (1991).
} 
the government delivers patronage to the loyalists rather than services to the median voter. A further disadvantage of high ethnic diversity is that it is believed to reduce the provision of public goods. Alesina, Baquir and Easterly (1999) formulate a model which links the heterogeneity of preferences across ethnic groups in a city to the amount and type of public goods the city supplies. A jurisdiction with two or more polarised groups (in the sense that these groups have preferences very far away from the median) would prefer to keep taxes low and deduct resources from the public good to private consumption. This results in a suboptimal provision of the public good which is then to the detriment of all. ${ }^{2}$ These theories may all lead to vicious cycles of high ethnic diversity, poor economic performance, and greater ethnic identification as a result since marginalised groups will build up even stronger identities in the face of poor economic performance and their social exclusion (Akerlof and Kranton, 2000).

On the positive side, ethnic or linguistic diversity which is due to immigration may improve trade opportunities for a country. Immigrants form ethnic networks between their home and host country (Casella and Rauch, 1997). Girma and Yu (2000) provide evidence that the tradeimmigration linkage is driven by the new information brought by immigrants about their home country and not so much by existing business connections and personal contacts with their home country. This would mean that ethnic networks enhance trade between dissimilar countries. Gould (1994) describes the positive effect of co-ethnic networks as immigrants having links to their home country, which is like a human-capital externality that enhances trade opportunities (most likely between developed and developing countries). Trade is enhanced by a decrease in transaction costs to trade. Furthermore, bilateral trade flows are positively affected by the preference of immigrants for home country products. Gould (1994) finds that the trade enhancing effect is the strongest in the export sector and only a relatively small community of immigrants is needed to exhaust this effect. A relatively large community, however, is needed to exhaust the positive trade effect in the import sector.

Similarly, ethnic diversity of a country increases the attractiveness of that country to immigrants who often migrate to countries with existing networks of immigrants of the same origin. This increases the efficiency and adaptability of the labor market to economic change, and to the extent that the skills of the immigrants complement the home country population, is likely to improve the growth performance of that country. Lastly, ethnic diversity might be seen as beneficial because it increases the variety of products on offer in a country. As much of trade between rich countries is driven by such a taste for variety, there would logically be considerable benefit if such variety could be provided within one's own borders.

This paper aims to investigate the respective merits of the two theories on ethnic diversity and co-ethnic networks in an empirical analysis to complete the picture. We will investigate whether ethnic diversity has a growth enhancing effect in "immigration countries" which works against the negative effect of high ethnic diversity due to battles over scarce resources.

$2 \quad$ It should be noted that other forms of social distance, such as high income inequality or a geographical segregation of groups that could be unrelated to ethnic diversity, could also deliver such a result. 


\subsection{Existing Empirical Investigations}

The pioneering paper by Easterly and Levine (1997), as well as a follow-up study by Alesina et al. (2003), argue that ethnic conflicts in the political sphere reduce economic growth by leading governments to adopt inefficient economic policies and low public good provision. Using crosscountry seemingly unrelated regressions the authors show that the negative impact of ethnic fractionalisation operates via certain policy variables on growth. This link between ethnic diversity and the individual policy variable is further analysed by separate regressions which link ethnic fractionalisation significantly to the quality of policy and institutions. These identified channels have hurt Sub-Saharan Africa particularly, which had the highest measured fractionalisation and in turn had the lowest economic growth in the period of 1960-1990. For instance, the negative co-efficient of the ethnic variable of $-0.019^{3}$ implies that Uganda has 1.77 percentage points lower annual growth in per capita income in the base line specification than South Korea which is merely due to different degrees of ethnic fractionalisation - 0.002 in South Korea versus 0.93 in Uganda.

As noted in the last section, other forms of social distance, especially income inequality could also lead to polarisation of interests between groups and therefore have identical implications for the economic performance in a country. Indeed, Easterly (2001) shows that societies with a low class and income divide grow the fastest and the channels through which high ethnic diversity and high inequality have an impact on growth happen to be the same. Moreover, extensions by Easterly (2001) show that the negative impact of high ethnic fractionalisation can be mitigated by strong institutions which they measure using the data from the International Country Risk Guide. These indicators measure the strength of the rule of law, judicial independence, bureaucratic quality, and protection of property rights. In countries with such strong institutions, the negative effect of ethnic fractionalisation on economic growth can be largely avoided (Easterly 2001).

No empirical study has considered the relationship between migration and ethnic fractionalisation so far. Several empirical studies find that immigrant links play an important role in determining bilateral trade flows. Gould (1994) shows that immigrants' ties to their home country play a key role in explaining bilateral trade flows of the U.S.. Girma and $\mathrm{Yu}(2000)$ investigate the link between immigration and trade using U.K. data. They find evidence that immigration from non-Commonwealth countries has a significant trade enhancing effect. Both studies find a pro-import, but most importantly pro-export effect. Frankel and Romer (1999) find that trade has a robust and quantitatively large impact on income when controlling for the direction of causality.

Using a gravity model, Tong (2005) finds that Chinese networks, measured as the number of Chinese people in the country, are important correlate of bilateral foreign direct investment. She further investigates the mechanisms through which this co-ethnic network has an effect on

\footnotetext{
See Table 3.2 .
} 
cross-border investment. She finds that community enforcement of sanctions is important in countries with low bureaucratic quality. Furthermore, Chinese networks provide assistance in overcoming informational barriers.

\subsection{Data and Methodology}

Since our first objective was to update and extend the analysis of Alesina et al. we used the same variables and extended the dataset where possible using the same data sources to include the 1990s. This was possible for all variables except telephones per 1000 workers instead of which we introduced the variable telephones per 1000 people. ${ }^{4}$ We decided to put the focus of our research on the ethnic fractionalisation variable "ethnic" only, which was constructed by Alesina et al. (2003). This is mainly due to the fact that we deemed it to be the most reasonable measure of ethnic fractionalisation available to date.

The variable "ethnic" is measured by a one minus a Herfindahl concentration index

$$
\text { Fract }_{j}=1-\sum_{i=1}^{N} s_{i j}{ }^{2}
$$

where $s$ is the share of group $i(i=1, \ldots, N)$ in country $j$. The index takes values from zero to one for each country. In practical terms, this index measures the probability that two randomly drawn individuals belong to a different ethnic group. The data to construct this index, i.e. the values for the group shares, are mainly taken from the Encyclopaedia Britannica (2001). A separate ethnic group is defined if there exist distinguishing linguistic and/or ethnic characteristics.

Table 3.1 shows the average fractionalisation measures of the different indices for the different regions of the world. Note that Sub-Saharan Africa displays the highest average index for all measures of fractionalisation. The index "ethnic" gives a more realistic picture of fractionalisation in Latin America than the Ethno-Linguistic Measure (ELF) since this region is not primarily fractionalised linguistically but mostly due to ethnic groups. Thus, our dataset is structured as a four wave panel, which includes the time invariant ethnic fractionalisation variable and past immigration dummy. In our empirical analysis we use the common methodology of Seemingly Unrelated Regressions (SUR), for two specific reasons. First of all, it allowed us to be comparable with existing findings such as Easterly and Levine (1997) and Alesina et al. (2003). Secondly, and more importantly, a SUR displays a clear advantage over a OLS regression, including fixed and random effect panels, for this kind of growth regression analysis. In particular, this method allows for country random effects to be correlated across decades and thus yields more efficient estimators than the alternative methods mentioned above. In other words, the effects of the independent variables on growth are allowed to be correlated within a country specific framework

$4 \quad$ Source: WDI 2003, this variable displays a very high correlation with the original variable telephone per 1000 workers. See Appendix C Table C.4. 
Table 3.1: Sample Means of Fractionalisation Indices by Region

\begin{tabular}{|l|cc|cc|}
\hline & ELF & Ethnic & Language & Religion \\
\hline Latin America \& Carribean & 0.265 & 0.405 & 0.179 & 0.442 \\
Sub-Saharan Africa & 0.651 & 0.658 & 0.652 & 0.496 \\
Eastern \& Central Europe & 0.315 & 0.366 & 0.32 & 0.491 \\
Western \& Southern Europe & 0.147 & 0.177 & 0.196 & 0.311 \\
Middle East & 0.244 & 0.453 & 0.33 & 0.346 \\
East \& South East Asia & 0.306 & 0.353 & 0.457 & 0.462 \\
\hline
\end{tabular}

Source: Alesina et al. (2003). Note: ELF is Ethno-Linguistic Fractionalisation, constructed by Easterly and Levine (1997) using the Russian Atlas Narodov Mira

over time, which is a clear advantage over standard OLS estimates, fixed or random panel. Furthermore, SUR seems clearly more favourable since it allows for a more detailed picture than a simple OLS where effects are averaged over a 30 or 40 year horizon. SUR instead assigns a regression to each of the four decades, analysing the impact of a specific variable measured at the start of each decade on growth whereby this impact may be specified to differ between the decades or not. Moreover, like OLS, SUR allows for a time invariant correlation between the independent variable and growth, but the estimates are derived by incorporating decade specific correlations.

The model takes the following form:

$$
\text { growth }_{i t}=\sum_{t=1}^{N} \alpha_{t}+\sum_{j=1}^{N} \beta_{j t} X_{j i t}+\sum_{j=1}^{N} \beta_{j t} Z_{j i}+u_{i t}
$$

Hence, growth is a function of a decade specific intercept alpha, a vector of variables $\mathrm{X}$ which vary across time $t$ and countries $i$, a vector of variables $Z$ which vary only across countries plus an error term.

The second aim of this paper was to combine the two existing strands of literature concerning the possibly counteracting impact of ethnic diversity on economic performance. Thus, we needed to define what constitutes an immigration country in order to single out the alleged positive impact of ethnic diversity due to immigration. There are many possible definitions of the variable "immigration country". However, we are interested in countries which are ethnically heterogeneous according to our measure and this to a large part due to migration. A country like Argentina, for example, has a population consisting up to 97 percent of Spanish and Italian descendants. We are not interested in the typical Western European immigration country as in those countries ethnic fractionalisation is extremely low even though positive trade linkages through migration prevail. Our definition therefore classifies a country as an immigration country if it was characterized by settlement from a non-neighboring country, forced or free, within the past 300 years and the descendants of foreign settlers constitute a significant part (at least 5 percent) of the population today. This variable is unsuspicious in regard to endogeneity. Data is 
taken from the CIA World Factbook, where the group share of ethnic groups and there origins are listed. Table C. 3 in the Appendix C lists the countries included in this definition. ${ }^{5}$

To get a first idea, the methodology we used to test for different effects of ethnic diversity in immigration and non-immigration countries is a simple interaction term between the immigration Dummy and the variable "ethnic". The hypothesis being that, if a country is classified as an immigration country, we would expect a distinct positive or at least compensating impact of ethnic diversity on growth. We analyze the underlying mechanism of the distinct positive effect of the interaction term using SUR also.

\subsection{Results}

\subsubsection{Extending the Data Set}

Before we start to analyse whether ethnic diversity has a distinct effect on growth in immigration countries, we want to confirm and update the baseline analysis by including the 1990s. The results are noteworthy by themselves as they lend support to the original argument, namely, that high ethnic fractionalisation leads to an adverse policy environment, but also show some differences. Table 3.2 shows the results of the updated data analysis. The first two columns in Table 3.2 reproduce the original findings of Alesina et al. with the difference that the variable "log telephones per worker" has been replaced by "log telephones per people" in regression (2). ${ }^{6}$

The adverse impact of ethnic fractionalisation on growth via the policy environment is shown when comparing regressions (1) and (2) of Table 3.2, as the inclusion of variables measuring the quality of the policy environment and public good provision renders the negative impact of "ethnic" to insignificance and strongly reduces the size of the coefficient.

If we now include data up to 1999, the following changes can be observed. First of all, if we concentrate on specification (3), it confirms and strengthens the original findings that ethnic fractionalisation has a negative impact on growth as the results remain almost unchanged in terms of magnitude and significance. However, the coefficient of the Dummy for Sub-Saharan Africa gains in magnitude and significance. This hints at the continuing diverging growth experience of this region and the problem observed first by Easterly and Levine that the model cannot fully explain this diverging growth trend, even though high ethnic diversity is one of the main characteristics of this region.

Secondly, the variable "schooling" becomes insignificant. The significance and magnitude of the other coefficients show not much variation. It is interesting that schooling becomes insignificant once we include the 1990s and telephone per thousand people. One possible explanation is that the variation of schooling has strongly declined in the 1990s and that physical and human capital infrastructure is highly correlated for all decades, but particularly in the 1990s. We find

\footnotetext{
$5 \quad$ However, we cannot prove whether co-ethnic networks exist in each of these countries.

6 To see the changes due to inclusion of this different variable in comparison with the original Alesina et al. results see Appendix C Table C.4.
} 
Table 3.2: Baseline Regression.

\begin{tabular}{|c|c|c|c|c|c|c|}
\hline & \multicolumn{6}{|c|}{ Dependent Variable: Growth rate $1960-1980,1960-1999$} \\
\hline & & & & Inclusion & of $1990 \mathrm{~s}$ & \\
\hline Variable & (1) & (2) & (3) & (4) & (5) & (6) \\
\hline Dummy for the $1960 \mathrm{~s}$ & $\begin{array}{l}-0.099 \\
(-1.19)\end{array}$ & $\begin{array}{l}-0.166^{*} \\
(-1.73)\end{array}$ & $\begin{array}{l}-0.056 \\
(-0.37)\end{array}$ & $\begin{array}{l}-0.06 \\
(-0.90)\end{array}$ & $\begin{array}{l}-0.095 \\
(-1.31)\end{array}$ & $\begin{array}{l}-0,038 \\
(-0,47)\end{array}$ \\
\hline Dummy for the 1970 s & $\begin{array}{l}-0.102 \\
(-1.22)\end{array}$ & $\begin{array}{l}-0.163^{*} \\
(-1.71)\end{array}$ & $\begin{array}{l}-0.059 \\
(-0.89)\end{array}$ & $\begin{array}{l}-0.062 \\
(-0.93)\end{array}$ & $\begin{array}{l}-0.091 \\
(-1.25)\end{array}$ & $\begin{array}{l}-0,034 \\
(-0,43)\end{array}$ \\
\hline Dummy for the 1980 s & $\begin{array}{l}-0.122 \\
(-1.46)\end{array}$ & $\begin{array}{l}-0.179^{*} \\
(-1.88)\end{array}$ & $\begin{array}{l}-0.079 \\
(-1.20)\end{array}$ & $\begin{array}{l}-0.082 \\
(-1.23)\end{array}$ & $\begin{array}{l}-0.109 \\
(-1.49)\end{array}$ & $\begin{array}{l}-0,051 \\
(-0,64)\end{array}$ \\
\hline Dummy for the 1990 s & & & $\begin{array}{l}-0.071 \\
(-1.09)\end{array}$ & $\begin{array}{l}-0.074 \\
(-1.12)\end{array}$ & $\begin{array}{l}-0.107 \\
(-1.47)\end{array}$ & $\begin{array}{l}-0,049 \\
(-0,61)\end{array}$ \\
\hline Dummy for Sub-Saharan Africa & $\begin{array}{l}-0.007 \\
(-1.53)\end{array}$ & $\begin{array}{l}-0.013^{* * *} \\
(-2.75)\end{array}$ & $\begin{array}{l}-0.010^{* * *} \\
(-2.50)\end{array}$ & $\begin{array}{l}-0.011^{* * * *} \\
(-2.76)\end{array}$ & $\begin{array}{l}-0.014^{* *} \\
(-3.22)\end{array}$ & $\begin{array}{l}-0,014^{* * * *} \\
(-3,10)\end{array}$ \\
\hline Dummy for Latin America \& Caribbean & $\begin{array}{l}-0.018^{* * *} \\
(-4.85)\end{array}$ & $\begin{array}{l}-0.017^{* * *} \\
(-4.46)\end{array}$ & $\begin{array}{l}-0.015^{* * * *} \\
(-4.61)\end{array}$ & $\begin{array}{l}-0.013^{* * *} \\
(-3.98)\end{array}$ & $\begin{array}{l}-0.011^{\text {**** }} \\
(-3.29)\end{array}$ & $\begin{array}{l}-0,014^{* * *} \\
(-3,89)\end{array}$ \\
\hline Log of initial income & $\begin{array}{l}0.038^{*} \\
(1.73)\end{array}$ & $\begin{array}{l}0.067^{* * *} \\
(2.76)\end{array}$ & $\begin{array}{l}0.026 \\
(1.60)\end{array}$ & $\begin{array}{l}0.028^{*} \\
(1.69)\end{array}$ & $\begin{array}{l}0.04^{* *} \\
(2.19)\end{array}$ & $\begin{array}{l}0,031 \\
(1,61)\end{array}$ \\
\hline Log of initial income squared & $\begin{array}{l}-0.003^{*} \\
(-1.93)\end{array}$ & $\begin{array}{l}-0.006^{* * *} \\
(-3.66)\end{array}$ & $\begin{array}{l}-0.002^{*} \\
(-1.94)\end{array}$ & $\begin{array}{l}-0.002^{* *} \\
(-2.06)\end{array}$ & $\begin{array}{l}-0.003^{* * *} \\
(-2.77)\end{array}$ & $\begin{array}{l}-0,003^{* * *} \\
(-2,70)\end{array}$ \\
\hline Log of schooling & $\begin{array}{l}0.013^{* * *} \\
(3.11)\end{array}$ & $\begin{array}{l}0.005 \\
(0.96)\end{array}$ & $\begin{array}{l}0.012^{* * *} \\
(3.10)\end{array}$ & $\begin{array}{l}0.011^{* * *} \\
(3.04)\end{array}$ & $\begin{array}{l}0.011^{* * *} \\
(2.80)\end{array}$ & $\begin{array}{l}0,003 \\
(0,63)\end{array}$ \\
\hline Assassinations & & $\begin{array}{l}-17.986^{*} \\
(-1.95)\end{array}$ & & $\begin{array}{l}-31.025^{* * * *} \\
(-3.16)\end{array}$ & $\begin{array}{l}-23.228^{* * * *} \\
(-2.56)\end{array}$ & $\begin{array}{l}-2,196^{* *} \\
(-2,42)\end{array}$ \\
\hline Financial Depth & & $\begin{array}{l}0.011^{* *} \\
(1.99)\end{array}$ & & & $\begin{array}{l}0.016^{* * *} \\
(3.34)\end{array}$ & $\begin{array}{l}0,012^{* *} \\
(2,30)\end{array}$ \\
\hline Black Market Premium & & $\begin{array}{l}-0.015^{* * *} \\
(-3.46)\end{array}$ & & & $\begin{array}{l}-0.018^{* * *} \\
(-4.81)\end{array}$ & $\begin{array}{l}-0,016^{* * *} \\
(-4,04)\end{array}$ \\
\hline Fiscal surplus/GDP & & $0.113^{* * *}$ & & & $0.102^{* * *}$ & $0,111^{* * *}$ \\
\hline Log of telephones per people & & $\begin{array}{l}0.022^{* * * *} \\
(3.64)\end{array}$ & & & & $\begin{array}{l}0,019^{* * *} \\
(3,31)\end{array}$ \\
\hline Ethnic & $\begin{array}{l}-0.019^{* * * *} \\
(-2.96)\end{array}$ & $\begin{array}{l}-0.0040 \\
(-0.55)\end{array}$ & $\begin{array}{l}-0.018 * * * \\
(-3.22)\end{array}$ & $\begin{array}{l}-0.019^{* * * *} \\
(-3.22)\end{array}$ & $\begin{array}{l}-0.013^{* *} \\
(-2.17)\end{array}$ & $\begin{array}{l}-0,009 \\
(-1,50)\end{array}$ \\
\hline No. Obs. & 264 & 179 & 356 & 349 & 267 & 257 \\
\hline Adj R2 & 0.38 & 0.57 & 0.34 & 0.35 & 0.47 & 0.5 \\
\hline
\end{tabular}

estimated constraining the number of observations to 257 as in specification (4). However, the results don't change significantly. 
Table 3.3: 1990s Effect.

\begin{tabular}{|l|l|}
\hline & Growth rate $1960-1999$ \\
\hline Variable & \\
\hline Dummy for the 1960s & $-0,077$ \\
Dummy for the 1970s & $(-0,97)$ \\
& $-0,070$ \\
Dummy for the 1980s & $(-0,89)$ \\
& $-0,088$ \\
Dummy for the 1990s & $(-1,12)$ \\
& $-0,079$ \\
Dummy for Sub-Saharan Africa & $(-1,01)$ \\
& $-0,014^{* * *}$ \\
Dummy for Latin America \& Caribbean & $(-3,20)$ \\
& $-0,014^{* * *}$ \\
Log of initial income & $(-4,24)$ \\
& $0,041^{* *}$ \\
Log of initial income squared & $(2,14)$ \\
Log of schooling & $-0,004^{* * *}$ \\
& $(-3,30)$ \\
Assassinations & 0,004 \\
Financial Depth & $(0,83)$ \\
Black Market Premium & $-2,204^{* * *}$ \\
& $(-2,51)$ \\
Fiscal surplus/GDP & $0,012^{* * *}$ \\
Log of telephones per people & $(2,48)$ \\
& $-0,016^{* * *}$ \\
Ethnic 1960 & $(-4,23)$ \\
Ethnic 1970 & $0,117^{* * *}$ \\
Ethnic 1980 & $(4,21)$ \\
Ethnic 1990 & $0,020^{* * *}$ \\
& $(3,69)$ \\
Adj R2 & 0,001 \\
& $(0,12)$ \\
& $-0,007$ \\
& $(-0,78)$ \\
& $-0,005$ \\
& $(-0,60)$ \\
& $-0,023^{* * * *}$ \\
& $(-2,55)$ \\
\hline & $38 ; 67 ; 74 ; 78$ \\
0,$11 ; 0,36 ; 0,47 ; 0,18$ \\
\hline
\end{tabular}

Source: Own Calculations. Note: t-stats in parentheses ${ }^{*} 0.1,{ }^{* *} 0.05,{ }^{* * *} 0.01$ Significance level.

that the difference between the minimum and maximum value of the "log of $1+$ average years of school attainment" dropped from 2.29 in 1960 to 2.09 in 1990 . In the 1960 s the correlation co-efficient between the level of schooling and telephones per thousand people takes a value of 0.83 , for the 1990s it has increased to $0.89 .{ }^{7}$ However, the most important finding is, once we include data for the 1990s, that we find a remaining effect of ethnic fractionalisation on growth, even after the inclusion of the policy variables. The effect of ethnic fractionalisation remains significant at the 1 percent level, if we do not restrict the co-efficient to be the same across decades. This can be seen in regression (1) in Table 3.3. The effect of ethnic fractionalisation on growth is not mitigated by the inclusion of the policy variables.

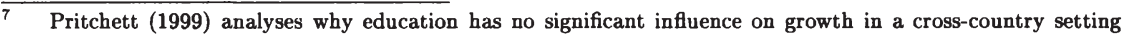
and suggests three different explanations. First of all, it might be the case that indeed schooling creates no human capital. Secondly, the marginal returns to human capital are falling rapidly where demand for educated labour is stagnant. Lastly, the institutional environments in many countries have been sufficiently perverse that the human capital accumulated has been applied to activities that served to reduce economic growth. 
This must be due to the fact that ethnic diversity has gained a bigger impact on growth in the 1990s. To further validate the finding, we ran a separate regression for each decade to assess whether the impact of our variable "ethnic" increased between the 1960s and the 1990s. The results indicate that this is indeed the case as the only decade in which "ethnic" has a negative significant impact, even after the inclusion of the policy variables, is the 1990s. For all other decades the impact of "ethnic" in the extended regression is not statistically different from zero. The findings are shown in Table 3.4.

Moreover, we ran a completely unrestricted version of our SUR model, which means that we loosened the restriction that co-efficients have to be the same across decades for all variables except the decade dummies. The results are shown in Table C.1 in Appendix C. According to the adjusted R-squared, this model can explain growth variations the best. The regression clearly shows that policy variables have very distinct effects in different decades, that conditional $\beta$-convergence can only be found in two decades, and that ethnic fractionalisation has a sizeable impact on growth in the 1990 s besides the policy variables. Therefore, we may well conclude that the model proposed by Alesina et al. (2003) is incomplete.

We tested several other models to explain the negative impact of ethnic fractionalisation on growth in the 1990s. One hypothesis is that the 1990s witnessed an increased importance of good governance on growth. When including the Kaufman-Kraay-Zoido-Lobaton-Indicator in our regression the variable "ethnic" becomes insignificant (see Table C.2 in Appendix C) ${ }^{8}$ Ethnic fractionalisation may lead to inefficient "identity" politics instead of efficient "performance" politics (Collier, 1998). The index measures governance in the dimensions graft, rule of law, voice and accountability, political instability and violence, government effectiveness, and regulatory burden. Governance seems to have gained importance for growth in the 1990s. This may partly be explained by the withdrawal of influence by the two superpowers from many regions of the world with the end of the Cold War. This increased importance of governance on growth is confirmed in Table C.2 in Appendix C which shows that governance, as measured by KKZ, has only a significant influence on growth in the 1990s. Moreover, if we combine this results with Table C.5 in Appendix C we see that high fractionalisation has a significant negative effect on good governance and thus an indirect effect on growth in the 1990s.

Furthermore, if the impact of ethnic fractionalisation is differing in the four decades, it might also differ between regions. The sample is therefore divided into two subgroups. As we do not have sufficient numbers of observations to analyse the model for Sub-Saharan Africa and Latin America separately, we combined both to one group including 85 countries. We compare this with "the rest of the world" including 75 OECD, Asian and some Arabic countries. The results are shown in Table 3.5. Strikingly, the results differ very much between the two sub-groups. Considering Sub-Saharan Africa and Latin America, the impact of the variable measuring ethnic

$8 \quad$ Many observations are lost when including the governance index. We therefore ran the model without the governance variable for the same numbers of observation. Nothing changes. Ethnic fractionalisation remains significant in explaining growth. 
Table 3.4: Decade Specific Growth Regression.

\begin{tabular}{|c|c|c|c|c|c|c|c|c|}
\hline \multirow{3}{*}{ Variable } & \multicolumn{8}{|c|}{ Dependent Variable: Growth rate for noted decades } \\
\hline & \multirow{2}{*}{\multicolumn{2}{|c|}{$\begin{array}{l}1960 \\
(2)\end{array}$}} & \multirow{2}{*}{\multicolumn{2}{|c|}{ 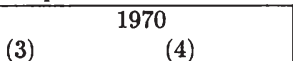 }} & \multirow{2}{*}{\multicolumn{2}{|c|}{1980}} & \multirow{2}{*}{\multicolumn{2}{|c|}{1990}} \\
\hline & & & & & (5) & & & \\
\hline Dummy for the 1960 s & $\begin{array}{l}-0,3644^{*} \\
(-1,72)\end{array}$ & $\begin{array}{l}-0,2611 \\
(-0,93)\end{array}$ & & & & & & \\
\hline Dummy for the 1970 s & & & $\begin{array}{l}-0,4914^{* *} \\
(-2,76)\end{array}$ & $\begin{array}{l}-0,4296^{* *} \\
(-1,98)\end{array}$ & & & & \\
\hline Dummy for the 1980 s & & & & & $\begin{array}{l}-0,2014 \\
(-1,61)\end{array}$ & $\begin{array}{l}-0,1880 \\
(-1,44)\end{array}$ & & \\
\hline Dummy for the 1990 s & & & & & & & $\begin{array}{l}-0,0376 \\
(-0,23)\end{array}$ & $\begin{array}{l}0,0652 \\
(0,37)\end{array}$ \\
\hline Dummy for Sub-Saharan Africa & $\begin{array}{l}-0,0148 \\
(-1,35)\end{array}$ & $\begin{array}{l}-0,0198^{*} \\
(-1,68)\end{array}$ & $\begin{array}{l}-0,0092 \\
(-1,22)\end{array}$ & $\begin{array}{l}-0,0066 \\
(-0,88)\end{array}$ & $\begin{array}{l}-0,0105 \\
(-1,62)\end{array}$ & $\begin{array}{l}-0,0123 \\
(-1,77)\end{array}$ & $\begin{array}{l}-0,0176^{* * *} \\
(-2,36)\end{array}$ & $\begin{array}{l}-0,0165^{* * *} \\
(-2,10)\end{array}$ \\
\hline Dummy for Latin America \& Caribbean & $\begin{array}{l}-0,0206^{* * *} \\
(-3,10)\end{array}$ & $\begin{array}{l}-0,0245^{* * *} \\
(-3,04)\end{array}$ & $\begin{array}{l}-0,0154^{* * *} \\
(-2,49)\end{array}$ & $\begin{array}{l}-0,0155^{* * *} \\
(-2,28)\end{array}$ & $\begin{array}{l}-0,0296^{* * *} \\
(-5,59)\end{array}$ & $\begin{array}{l}-0,0210^{* * *} \\
(-3,63)\end{array}$ & $\begin{array}{l}-0,0099^{*} \\
(-1,79)\end{array}$ & $\begin{array}{l}-0,0073 \\
(-1,06)\end{array}$ \\
\hline Log of initial income & $\begin{array}{l}0,1064^{*} \\
(1,91)\end{array}$ & $\begin{array}{l}0,0899 \\
(1,25)\end{array}$ & $\begin{array}{l}0,1431 * * * \\
(3,10)\end{array}$ & $\begin{array}{l}0,1454^{* * *} \\
(2,70)\end{array}$ & $\begin{array}{l}0,0549^{*} \\
(1,72)\end{array}$ & $\begin{array}{l}0,0643 \\
(1,95)\end{array}$ & $\begin{array}{l}0,0171 \\
(0,43)\end{array}$ & $\begin{array}{l}0,0040 \\
(0,10)\end{array}$ \\
\hline Log of initial income squared & $\begin{array}{l}-0,0074^{*} \\
(-2,01)\end{array}$ & $\begin{array}{l}-0,0070 \\
(-1,50)\end{array}$ & $\begin{array}{l}-0,0098^{* *} \\
(-3,25)\end{array}$ & $\begin{array}{l}-0,0119^{* * *} \\
(-3,40)\end{array}$ & $\begin{array}{l}-0,0036^{*} \\
(-1,74)\end{array}$ & $\begin{array}{l}-0,0053^{* * *} \\
(-2,43)\end{array}$ & $\begin{array}{l}-0,0013 \\
(-0,57)\end{array}$ & $\begin{array}{l}-0,0013 \\
(-0,56)\end{array}$ \\
\hline Log of schooling & $\begin{array}{l}0,0174^{* *} \\
(1,96)\end{array}$ & $\begin{array}{l}0,0127 \\
(1,25)\end{array}$ & $\begin{array}{l}0,0152^{* *} \\
(2,10)\end{array}$ & $\begin{array}{l}0,0058 \\
(0,76)\end{array}$ & $\begin{array}{l}0,0118^{*} \\
(1,74)\end{array}$ & $\begin{array}{l}0,0040 \\
(0,47)\end{array}$ & $\begin{array}{l}0,0086 \\
(1,09)\end{array}$ & $\begin{array}{l}0,0015 \\
(0,14)\end{array}$ \\
\hline Assassinations & & $\begin{array}{l}51,937 \\
(0,87)\end{array}$ & & $\begin{array}{l}-17,867 \\
(-1,06)\end{array}$ & & $\begin{array}{l}-14,798 \\
(-1,33)\end{array}$ & & $\begin{array}{l}-86,466^{* *} \\
(-2,06)\end{array}$ \\
\hline Financial Depth & & $\begin{array}{l}-0,0003 \\
(-0,03)\end{array}$ & & $\begin{array}{l}0,0054 \\
(0,48)\end{array}$ & & $\begin{array}{l}0,0145 \\
(1,63)\end{array}$ & & $\begin{array}{l}0,0097 \\
(1,06)\end{array}$ \\
\hline Black Market Premium & & $\begin{array}{l}-0,0180 \\
(-1,07)\end{array}$ & & $\begin{array}{l}-0,0286^{* * *} \\
(-2,75)\end{array}$ & & $\begin{array}{l}-0,0085 \\
(-1,54)\end{array}$ & & $\begin{array}{l}-0,0211^{* *} \\
(-2,19)\end{array}$ \\
\hline Fiscal surplus/GDP & & $\begin{array}{l}0,0724 \\
(0,56)\end{array}$ & & $\begin{array}{l}0,1988^{* * *} \\
(2,82)\end{array}$ & & $\begin{array}{l}0,1339^{* * *} \\
(3,33)\end{array}$ & & $\begin{array}{l}0,1758^{* * *} \\
(2,49)\end{array}$ \\
\hline Log of telephones per people & & $\begin{array}{l}0,0117 \\
(0,84)\end{array}$ & & $\begin{array}{l}0,0395^{* * *} \\
(3,89)\end{array}$ & & $\begin{array}{l}0,0212^{* *} \\
(2,05)\end{array}$ & & $\begin{array}{l}0,0150 \\
(1,11)\end{array}$ \\
\hline Ethnic & $\begin{array}{l}-0,0069 \\
(-0,54)\end{array}$ & $\begin{array}{l}0,0008 \\
(0,06)\end{array}$ & $\begin{array}{l}-0,0256^{* * *} \\
(-2,35)\end{array}$ & $\begin{array}{l}\mathbf{0 , 0 0 4 8} \\
(0,41)\end{array}$ & $\begin{array}{l}-0,0153^{*} \\
(-1,66)\end{array}$ & $\begin{array}{c}-0,0008 \\
(-0,08)\end{array}$ & $\begin{array}{l}-0,0120^{* * *} \\
(-2,44)\end{array}$ & $\begin{array}{l}-0,0193^{*} \\
(-1,83)\end{array}$ \\
\hline No. Obs. & 38 & 38 & 88 & 67 & 94 & 74 & 92 & 78 \\
\hline Adj R2 & 0,23 & 0,37 & 0,28 & 0,62 & 0,38 & 0,59 & 0,15 & 0,29 \\
\hline
\end{tabular}


Table 3.5: Sub-Saharan African and Latin American Results.

\begin{tabular}{|c|c|c|c|c|}
\hline & \multicolumn{4}{|c|}{ Growth Rate 1960-1999 } \\
\hline \multirow[t]{2}{*}{ Variable } & \multicolumn{2}{|c|}{ Africa and Latinam } & \multicolumn{2}{|c|}{ Rest of the World } \\
\hline & (1) & (2) & (3) & (4) \\
\hline \multirow[t]{2}{*}{ Dummy for the $1960 \mathrm{~s}$} & 0.127 & -0.037 & $-0.249 * * *$ & 0.006 \\
\hline & $(1.2)$ & $(-0.30)$ & $(-2.58)$ & $(0.05)$ \\
\hline \multirow[t]{2}{*}{ Dummy for the 1970 s } & 0.125 & -0.033 & $-0.249 * * *$ & 0.008 \\
\hline & $(1.17)$ & $(-0.27)$ & $(-2.58)$ & $(0.06)$ \\
\hline \multirow[t]{2}{*}{ Dummy for the $1980 \mathrm{~s}$} & 0.099 & -0.053 & $-0.262^{* * *}$ & -0.005 \\
\hline & $(0.93)$ & $(-0.43)$ & $(-2.72)$ & $(-0.04)$ \\
\hline \multirow[t]{2}{*}{ Dummy for the $1990 \mathrm{~s}$} & 0.12 & -0.054 & $-0.256 * * *$ & 0.004 \\
\hline & $(1.03)$ & $(-0.44)$ & $(-2.68)$ & $(0.03)$ \\
\hline \multirow[t]{2}{*}{ Log of initial income } & -0.026 & 0.03 & $0.076^{* * *}$ & 0.026 \\
\hline & $(-0.93)$ & $(0.94)$ & $(3.21)$ & $(0.86)$ \\
\hline \multirow[t]{2}{*}{ Log of initial income squared } & 0.002 & -0.003 & $-0.005^{* * *}$ & $-0.004^{* *}$ \\
\hline & $(0.81)$ & $(-1.50)$ & $(-3.63)$ & $(-2.06)$ \\
\hline \multirow[t]{2}{*}{ Log of schooling } & $0.011^{* *}$ & -0.004 & $0.011^{* *}$ & 0.008 \\
\hline & $(1.98)$ & $(0.54)$ & $(2.25)$ & $(1.54)$ \\
\hline \multirow[t]{2}{*}{ Assassinations } & & $-24.819^{* * *}$ & & -16.353 \\
\hline & & $(-2.57)$ & & $(-0.76)$ \\
\hline \multirow[t]{2}{*}{ Financial Depth } & & $0.036^{* * *}$ & & $0.01^{*}$ \\
\hline & & $(2.33)$ & & $(1.84)$ \\
\hline \multirow[t]{2}{*}{ Black Market Premium } & & $-0.015^{* * *}$ & & $-0.018^{* * *}$ \\
\hline & & $(-2.82)$ & & $(-2.87)$ \\
\hline \multirow[t]{2}{*}{ Fiscal surplus/GDP } & & $0.113^{* * *}$ & & $0.083^{*}$ \\
\hline & & $(2.84)$ & & $(1.95)$ \\
\hline Log of telephones per people & & $0.022^{* * *}$ & & $0.026^{* * *}$ \\
\hline \multirow{2}{*}{ Ethnic } & $-0.014^{*}$ & $-0.016^{*}$ & $-0.019 * * *$ & -0.001 \\
\hline & $(-1.81)$ & $(-1.77)$ & $(-2.52)$ & $(-0.063)$ \\
\hline No. Obs. & 181 & 105 & 175 & 114 \\
\hline Adj R2 & 0.23 & 0.42 & 0.24 & 0.39 \\
\hline
\end{tabular}

Source: Own Calculations. Note: $t$-stats in parentheses ${ }^{*} 0.1,{ }^{* *} 0.05,{ }^{* * *} 0.01$ Significance level.

fractionalisation, however, remains significant only at the 10 percent level after the inclusion of the policy variables. Contrarily, in the "rest of the world" the hypothesis of Alesina et al. and Easterly and Levine seems to explain the growth differences between countries rather well. Inefficient policies and low public good provision explain the diverging growth trends due to ethnic fractionalisation. In these regions it seems to be indeed the case that the transmission channel of high ethnic fractionalisation and its negative impact on growth can be explained by an adverse policy environment alone. Thus, the obtained results show that the negative impact of ethnic fractionalisation on growth above and beyond the policy control variables prevails only in the 1990s and in the regions of Sub-Saharan Africa and Latin America.

The above approach, however, faces the problem that few observations remain when restricting the sample to Sub-Saharan and Latin-American countries. In order to verify the findings 
we included an interaction term for ethnic fractionalisation in Sub-Saharan Africa. The results clearly show that the remaining negative impact of ethnic fractionalisation on economic growth is captured in the last interaction term for ethnic fractionalisation in Sub-Saharan Africa in the regression presented in Table 3.6. ${ }^{9}$ The variable "ethnic" which captures the residual effect of ethnic fractionalisation in general, is no longer statistically significant. The overall effect of the interaction term is on average $-0.032^{10}$, which implies that the inclusion of the policy variables did not change the negative impact of ethnic fractionalisation on growth for Sub-Saharan African countries. These results confirm the hypothesis that the remaining negative impact of ethnic fractionalisation on growth, even after the inclusion of policy variables, is in particular a Sub-Saharan phenomenon.

Given the above results, we wanted to test for the hypothesis that violent civil conflicts could explain this decade and region specific effect of ethnic fractionalisation as existing research found already robust evidence that ethnic polarisation explains civil conflict (Montalvo and ReynalQuerol, 2005). ${ }^{11}$ This hypothesis is conceivable as conflict incidences increased substantially between the 1960s and the 1990s and are concentrated in particular in countries of Sub-Saharan Africa and Latin America, as confirmed by the Prio Database of the International Peace Research Institute Oslo. ${ }^{12}$ However, our empirical results cannot support the hypothesis above because the influence of the violent conflict variables on growth is not significantly different from zero and the variable "ethnic" does not lose significance. ${ }^{13}$ Thus, at least the variable specifications we used for violent civil conflicts cannot explain the remaining sizable negative effect of the ethnic fractionalisation variable on growth after the inclusion of policy variables in the 1990s or for SubSaharan Africa and Latin America. Again the effect of ethnic fractionalisation in Sub-Saharan Africa is mitigated by the inclusion of governance in the restricted SUR model. The results are shown in Table 3.7 below.

$\overline{9}$ We also tested for a Latin American*Ethnic interaction term, however, there was no specific Latin American impact.

10 Which is the coefficient of the interaction term multiplied by the average ethnic fractionalisation in SSA $\left(-0.049^{*} 0.658\right)$. However, this effect should be possibly interpreted jointly with the SSA effect, which is now positive, but is just below the 10 percent significance level $(p$-value $=0.1079)$. Then the overall effect becomes -0.017 of ethnic fragmentation in Sub-Saharan Africa. Also generally interesting to note that the SSA dummy is almost statistically significantly positive which would imply a stronger than average growth in SSA once the effect of ethnic fractionalisation is accounted for.

11 Even though civil conflict is better explained by ethnic polarisation than by ethnic fractionalisation those two concepts are sufficiently correlated to control empirically if the inclusion of a violent conflict variables renders the impact of the ethnic fractionalisation variable above and beyond the inclusion of the policy variables on growth to insignificance.

12 Prio Database of the International Peace Research Institute Oslo, www.prio.no. The database reports the crude measure of numbers of conflicts as follows: 82 incidences of violent conflict beginning in the 1960s (34 of which took place in Sub-Saharan Africa and Latin America), 87 in the1970s (33 of which took place in SSA and LA), 102 in the 1980s (30 of which took place in SSA and LA), jumping to 172 incidences at the beginning of the 1990s in the whole world (77 of which took place in SSA and LA). Even though this measure holds no information concerning the intensity and duration of violent conflict it confirms the sheer fact that the incidences of civil conflict has increased dramatically in the 1990s and that they were mostly concentrated in Sub-Saharan and Latin America.

13 The results are not reported here. Data is from the Prio Database. Multiple definitions of violent civil conflicts were tested: minor-, intermediate civil conflict, civil war (internal and internationalised internal) and frequency in a decade. None of this specifications produced significant results. 
Table 3.6: 1990s and SSA Effect.

\begin{tabular}{|l|l|}
\hline & Growth Rate 1960-1999 \\
\hline Variable & \\
\hline Dummy for the 1960s & 0.029 \\
& $(0.38)$ \\
Dummy for the 1970s & 0.032 \\
Dummy for the 1980s & $(0.41)$ \\
& 0.015 \\
Dummy for the 1990s & $(0.19)$ \\
& 0.017 \\
Dummy for Sub-Saharan Africa & $(0.23)$ \\
& 0.015 \\
Dummy for Latin America \& Caribbean & $(1.61)$ \\
& $-0.014^{* * *}$ \\
Log of initial income & $(-4.39)$ \\
& 0.015 \\
Log of initial income squared & $(0.80)$ \\
Log of schooling & $-0.002^{* *}$ \\
Assassinations & $(-2.04)$ \\
Financial Depth & 0.003 \\
& $(0.64)$ \\
Black Market Premium & $-21.526^{* *}$ \\
Fiscal surplus/GDP & $(-2.48)$ \\
Log of telephones per people & $0.011^{* *}$ \\
Ethnic & $(2.31)$ \\
Ethnic x SSA & $-0.016^{* * *}$ \\
& $(-4.30)$ \\
No. Obs. & $0.105^{* * *}$ \\
Adj R2 & $(3.85)$ \\
& $0,022^{* * *}$ \\
& $(4.08)$ \\
& -0.001 \\
& $(-0.13)$ \\
& $-0.049^{* * *}$ \\
& $(-3.40)$ \\
\hline & 257 \\
& 0.53 \\
\hline
\end{tabular}

Source: Own Calculations. Note: t-stats in parentheses ${ }^{*} 0.1,{ }^{* *} 0.05,{ }^{* * *} 0.01$ Significance level.

To sum up, we find a remaining direct negative effect of fractionalisation on growth in the 1990s and in Sub-Saharan Africa. The specific 1990s and Sub-Saharan Africa effect of fractionalisation can be explained by bad governance and the consequential growth-hampering effect. 
Table 3.7: SSA Effect including Investment and the Kaufmann, Kraay and Zoido-Lobaton- Index.

\begin{tabular}{|l|ll|}
\hline & Growth Rate 1960-1999 \\
\hline Variable & & \\
\hline Dummy for the 1960s & $-0,055$ & $-0,124^{*}$ \\
Dummy for the 1970s & $(-0,83)$ & $(-0,17)$ \\
& $-0,057$ & $-0,124^{*}$ \\
Dummy for the 1980s & $(-0,86)$ & $(-1,67)$ \\
& $-0,077$ & $-0,140^{*}$ \\
Dummy for the 1990s & $(-1,16)$ & $(-1,88)$ \\
& $-0,070$ & $-0,126^{*}$ \\
Dummy for Sub-Saharan Africa & $(-1,05)$ & $(-1,71)$ \\
Dummy for Latin America \& Caribbean & 0,007 & $-0,004$ \\
& $(0,81)$ & $(-0,28)$ \\
Log of initial income & $-0,015^{* * *}$ & $-0,016^{* * *}$ \\
Log of initial income squared & $(-4,72)$ & $(-4,93)$ \\
& 0,026 & $0,048^{* * *}$ \\
Log of schooling & $(1,53)$ & $(2,58)$ \\
&,$-- 002^{* *}$ & $-0,004^{* * *}$ \\
Kaufmann, Kraay and Zoido-Lobaton- Index & $(-1,84)$ & $(-3,15)$ \\
& $0,011^{* * *}$ & 0,004 \\
Ethnic & $(2,96)$ & $(0,85)$ \\
Ethnic $x$ SSA & & $0,012^{* * *}$ \\
& $(4,08)$ \\
No. Obs. & $-\mathbf{0 , 0 1 2 *}$ & $\mathbf{0 , 0 0 4}$ \\
Adj R2 & $\mathbf{( - 1 , 8 3 )}$ & $\mathbf{( 0 , 6 7 )}$ \\
& $-\mathbf{0 , 0 2 9 * *}$ & $\mathbf{- 0 , 0 2 7}$ \\
& $(-2,26)$ & $(-1,31)$ \\
\hline
\end{tabular}

Source: Own Calculations. Note: t-stats in parentheses ${ }^{*} 0.1,{ }^{* *} 0.05,{ }^{* * *} 0.01$ Significance level.

\subsubsection{Migration and Ethnic Fractionalisation}

The second aim of this paper is to reconcile the two theoretical arguments of the different effects of fractionalisation and immigration on growth presented in the first part of this paper. So far we have argued empirically that fractionalisation of groups is problematic as it leads to conflicts of a political nature, hampering growth. Now, we hypothesize that countries in which ethnic fractionalisation partially emerged because of settlers should also experience positive effects due to diversity and not only negative effects. We do not argue that in immigration countries models which explain inefficient policies and low public good provision due to ethnic fractionalisation are no longer valid. We rather investigate whether positive effects of immigration also prevail and which effect dominates in a cross-country setting. Before turning to our empirical analysis of this issue, we would like to highlight some of our constraints in testing the hypothesis. First of all, to draw a clear definition of what constitutes an "immigration country", is less straightforward for our purpose. Secondly, the theory of co-ethnic networks is only tested superficially 
in our setting. Usually, the theory on co-ethnic networks is tested by analysing the relationship between the inflow of migrants and trade, using panel data. Ethnic fractionalisation, however, is time-invariable and the networks we look at have been in existence since a long time. Clearly, it would be interesting to have a measure of ethnic fractionalisation which varies over time, however, to construct such a matter is beyond the scope of this paper.

Utilising the new dataset, we tested whether there is a distinguished effect of ethnic fractionalisation on economic performance in countries which are ethnically diverse partly due to foreign settlement. The argument being that those countries which display high ethnic diversity, partly due to foreign settlement, might be capable to reap the benefits of such an increased diversity via increased trade. Our results indicate that our hypothesis is validated to some extent (see Table 3.8). Countries created by foreign settlement ${ }^{14}$ seem to exhibit positive effects of ethnic fractionalisation on subsequent growth. The coefficient of the interaction-term implies that the negative effect of ethnic diversity on long-run growth is more than mitigated. There is small positive net-effect in countries whose inhabitants are to a majority descendants of foreign settlers. If the policy variables which measure the quality of governmental policy are taken into account, the interaction-term and dummy become insignificant.

However, we caution against over-valuing this result. This is mainly due to the fact that only very few countries can be considered here and therefore the result depends much on the inclusion of particular countries. These results leave the question of the channels through which ethnic fractionalisation in immigration countries has an influence on long-run growth. It might be that immigration countries are especially exposed to conflicts over scarce resources in the political sphere and therefore inefficient policies that subsequently affect long-run growth negatively. We ran simple regressions using all policy variables. Interestingly, the settler country dummy shows a different, in fact positive significant correlation, with the quality of policy as confirmed by other research and probably due to the fact that settlers transferred their institutions. ${ }^{15}$

It is of interest to investigate further whether a growth-enhancing effect of high ethnic fractionalisation via a trade channel prevails in immigration countries. Trade, that is exports and imports as a share of GDP, increased dramatically between the 1960s and 1990s in most countries. Furthermore, the variation of trade between countries changed. ${ }^{16}$ We find no evidence of a positive relationship between ethnic diversity and trade in our settler countries. Ethnic diversity in settler countries is no significant determinant of foreign direct investments or exports. ${ }^{17}$ To conclude this section, we find clear evidence that ethnic fractionalisation in "immigration countries" has a positive growth enhancing effect, which counteracts the measured negative effect.

\footnotetext{
14 Our definition is that a country is classified as an immigration country if it was partly created by settlement from abroad, -forced or free, within the past 300 years and the descendants of foreign settlers constitute the significant part of the population today.

15 This is also in line with the findings of Acemoglu et al.(2001).(The results are not reported here.)

16 Both patterns of change can not be explained by the variable 'ethnic fractionalisation' as we assume it to be constant over the $\mathbf{4 0}$ year horizon. Furthermore the index would also change very slowly in response to migration.

17 Results are not reported here, but are available on request.
} 
Table 3.8: Past Settlement, Ethnic Fractionalisation and Growth.

\begin{tabular}{|c|c|c|c|}
\hline & \multicolumn{3}{|c|}{ Growth rate $1960-1999$} \\
\hline Variable & $(1)$ & $(2)$ & (3) \\
\hline \multirow[t]{2}{*}{ Dummy for the $1960 \mathrm{~s}$} & 0,032 & 0,033 & 0,058 \\
\hline & $(0,48)$ & $(0,49)$ & $(0,71)$ \\
\hline \multirow[t]{2}{*}{ Dummy for the 1970 s } & 0,030 & 0,032 & 0,061 \\
\hline & $(0,45)$ & $(0,48)$ & $(0,76)$ \\
\hline \multirow[t]{2}{*}{ Dummy for the 1980 s } & 0,009 & 0,011 & 0,043 \\
\hline & $(0,13)$ & $(0,17)$ & $(0,53)$ \\
\hline \multirow[t]{2}{*}{ Dummy for the 1990 s } & 0,016 & 0,018 & 0,045 \\
\hline & $(0,24)$ & $(0,27)$ & $(0,55)$ \\
\hline \multirow[t]{2}{*}{ Dummy for Sub-Saharan Africa } & 0,001 & $-0,001$ & $-0,003$ \\
\hline & $(0,17)$ & $(-0,11)$ & $(-0,50)$ \\
\hline \multirow[t]{2}{*}{ Log of initial income } & 0,021 & 0,021 & 0,018 \\
\hline & $(1,28)$ & $(1,25)$ & $(0,92)$ \\
\hline \multirow[t]{2}{*}{ Log of initial income squared } & $-0,002^{*}$ & $-0,002^{*}$ & $-0,002$ \\
\hline & $(-1,88)$ & $(-1,87)$ & $(-2,04)$ \\
\hline \multirow[t]{2}{*}{ Dependency Ratio } & $-0,056^{* * *}$ & $-0,052^{* * *}$ & $-0,042^{* *}$ \\
\hline & $(-5,04)$ & $(-4,63)$ & $(-3,47)$ \\
\hline \multirow{2}{*}{ Log of schooling } & 0,006 & 0,006 & 0,000 \\
\hline & $(1,57)$ & $(1,40)$ & $(0,00)$ \\
\hline \multirow[t]{2}{*}{ Assassinations } & & $-3,421^{* * *}$ & $-2,757^{* * *}$ \\
\hline & & $(-3,47)$ & $(-3,00)$ \\
\hline Financial Depth & & & $\begin{array}{l}0,015^{* * *} \\
(2,86)\end{array}$ \\
\hline Black Market Premium & & & $\begin{array}{l}-0,016^{* * *} \\
(-4,06)\end{array}$ \\
\hline Fiscal surplus/GDP & & & $0,101^{* * *}$ \\
\hline Log of telephones per people & & & $\begin{array}{l}0,014^{* *} \\
(2,38)\end{array}$ \\
\hline Ethnic & $\begin{array}{l}-0,031 \text { *** } \\
(-4,01)\end{array}$ & $\begin{array}{l}-0,033^{* * *} \\
(-4,22)\end{array}$ & $\begin{array}{l}-0,022^{* * *} \\
(-2,60)\end{array}$ \\
\hline Settler Dummy & $\begin{array}{l}-0,016^{* * *} \\
(-2,70)\end{array}$ & $\begin{array}{l}-0,015^{* * *} \\
(-2,44)\end{array}$ & $\begin{array}{l}-0,010 \\
(-1,52)\end{array}$ \\
\hline Settler*Ethnic & $\begin{array}{l}0,039^{* * *} \\
(2,97)\end{array}$ & $\begin{array}{l}0,040^{* * *} \\
(3,02)\end{array}$ & $\begin{array}{l}\mathbf{0 , 0 2 6}^{*} \\
(1,92)\end{array}$ \\
\hline No. Obs. & 356 & 349 & 257 \\
\hline Adj R2 & 0,37 & 0,39 & 0,50 \\
\hline
\end{tabular}

Source: Own Calculations. Note: t-stats in parentheses ${ }^{*} 0.1,{ }^{* *} 0.05,{ }^{* * *} 0.01$ Significance level. Note also that the Latinam Dummy is left out because it is highly correlated with the Settler Dummy.

\subsection{Conclusion and Future Research Questions}

In the end, it seems clear that the negative impact of ethnic fractionalisation on growth remains significant and robust for Sub-Saharan Africa if we include the 1990s in our empirical analysis following the Alesina et al model. Interestingly, the transmission channels which explained how 
ethnic fractionalisation negatively affects growth, namely via the policy variables specified, is less prominent in the extended analysis, as ethnic fractionalisation remains a significant negative explanatory power in the growth regression for Sub-Saharan African countries even after the inclusion of the policy variables. Thus, the negative impact of ethnic fractionalisation on economic growth cannot fully be explained and there might be some other transmission channels which link high ethnic fractionalisation to poor growth performance than the ones investigated and specified so far. In particular, the different results of the different regions in the world suggest that Sub-Saharan Africa does not only face an adverse policy environment, but that high ethnic fractionalisation remains an obstacle to growth, especially in the 1990s. We tried two different channels to explain this increased negative impact of ethnic fractionalisation on growth in the Sub-Saharan African setting of the 1990s, namely, a increased role of good governance as measured by the $\mathrm{KKZ}$ indicator and an increased number of violent conflicts. We managed to show that this increased negative impact of ethnic fractionalisation in the 1990s in Sub-Saharan Africa can be explained by the $\mathrm{KKZ}$ index which is a different measure of governance quality and confirms the hypothesis of growing importance of sound governance to facilitate growth. However, we could not confirm the hypothesis that an increasing number of incidences and severity of violent civil conflicts could explain the remaining negative impact of ethnic fractionalisation above and beyond the policy control variables.

Moreover, as already mentioned above, there might be a further conceivable transmission channel of high ethnic fractionalisation on growth, namely income inequality and especially segregation. Especially, if one considers a longer time span, very high income inequality, which might be a result of high ethnic fractionalisation and segregation in connection with badly designed institutions, might lead to a reduction in growth via the suboptimal provision and accumulation of factors of production, such as physical and human capital. This explanation gains validity especially in countries with imperfect markets. Even more interesting would be a measure for income inequality between ethnic groups. A further inquiry into this matter seems very much worthwhile, but rather difficult to facilitate due to the limitation of useable data sources.

Concerning migration, ethnic fractionalisation and growth, this paper suggests that there is a mitigating positive impact in countries which are characterised as settler countries. This gives some empirical validation to the co-ethnic network theory in a cross-country setting. Promising future research in this field should focus on the network enhancing trade effect of immigration in a country cross-section framework, in order to strengthen the argument above and confirm the case studies' findings on co-ethnic network theory in a wider setting. However, given the data availability it might be difficult to prove the point empirically.

In conclusion, this paper confirms and strengthens the initial assessment that ethnic fractionalisation is one of the key proxys for a negative policy environment and subsequent poor growth performance. However, it also illustrates that our understanding of the impact of ethnic fractionalisation on growth is far from complete, other dimensions and transmission channels of ethnic fractionalisation on growth, in particular in Sub-Saharan Africa, seem to be present, namely, bad 
governance. Moreover, in settler countries ethnic fractionalisation is not necessarily a "problem", but possibly a growth enhancing situation via co-ethnic trade networks. Furthermore, we put emphasis on the findings by Easterly (2001) which show that democratic institutions and low inequality can resolve ethnic conflict in the political sphere. Thus, countries with high ethnic fractionalisation and a strong income-divide between groups face the danger, but not necessarily the consequences of growth retardation. Hence, the challenge ahead, in particular in Sub-Saharan Africa, is the full participation of all ethnic groups in the economic development process and the blurring of ethnic ties, which might be a way to overcome this serious obstacle in many developing countries. 


\section{Chapter 4}

\section{Pathways out of Poverty in Indonesia}

\subsection{Introduction}

With the development community dedicated to meeting the Millennium Development Goals (MDGs), policy research has begun to focus on rigorous testing of models that explain MDG outcomes. Most basic, of course, is the goal to reduce poverty and hunger by half. Many "narrative" pathways out of poverty exist, but there are few quantitative models that have been tested over significant historical periods. One reason for this shortage of empirical results is a simple lack of data.

However, the number of panel data sets is growing and empirical pathways out of poverty are now being described. We contribute to this effort by empirically analysing the pathways out of poverty in Indonesia during a period of economic and political turmoil. Since most poor people live in rural areas, special attention is devoted to rural pathways out of poverty. The generally positive results, even during this difficult period, hold broader promise for achievement of the MDGs.

Most of the world's poor live in rural areas and are primarily engaged in low productivity, mainly agricultural, activities. Thus, the main pathway out of poverty will be connected to increases in the productivity of the rural poor, whether these increases are realised in farming, rural non-farm enterprises, by rural-urban migration or a combination of all of the afore. One strand of recent and past literature argues that from an empirical perspective growth originating in the agricultural sector has tended to be more "pro-poor" than growth originating in the industrial or service sectors (Mellor, 1976; Ravallion and Datt, 1996; Ravallion and Chen, 2004; Timmer, 2002). Indeed, agricultural growth has often been an important ingredient in the formula that connects economic growth to the poor (Ravallion and Huppi, 1991; Ravallion and Datt, 1996; Ravallion and Chen, 2004; Sumarto and Suryahadi, 2003; Fan, Zhang and Zhang, 2004; Fan, Thorat and Rao, 2004; Timmer, 1997, 2004) and separate reviews by Thirtle, et al. (2003)

based on joint work with Neil McCulloch and C. Peter Timmer. Conceptualised as academic background paper for the Indonesian Poverty Assessment during a three month stay at the World Bank Office, Jakarta, Indonesia, Summer 2005. 
and by Majid (2004) confirm the strong empirical link between higher agricultural productivity and poverty reduction. Moreover, the current interest in this topic is well documented by the forthcoming World Development Report "Agriculture for Development" (2008).

However, an equally important and connected debate is concerned with the role of rural non-farm activities in rural income growth and rapid poverty alleviation. This is particularly true, as in most developing countries rural non-farm output is now accounting for roughly half of rural income. Non-farm activities can be most conducive towards poverty reduction, especially in the absence of physical infrastructure and human capital constraints (Datt and Ravallion, 1996, 1998a\&b, 2002a). Moreover, rural non-farm enterprises are likely to be pro-poor, as they tend to use factors of production at their real opportunity costs to the economy, so that they are often labour-intensive in nature, reduce underemployment, help to smooth income seasonally and bid up local wages (Lanjouw and Lanjouw, 2001).

These papers on rural poverty reduction are part of a broader literature which attempts to understand the nature of pro-poor growth, which inevitably must encompass the rural poor and their potential pathways out of poverty (Ravallion 2004, World Bank, 2004a, 2006b). Thus, they try to identify whether agriculture productivity is the main driver behind rural poverty alleviation. Moreover, do non-farm enterprises encompass predominantly low productivity, supplementary and insurance activities or are they a potential source of dynamic growth and poverty alleviation in rural areas? Most of the above papers suggests that productivity gains in both, agriculture and non-farm activities, matter. Furthermore, the rural non-farm activities seem to fulfil both important functions, namely, supplementary insurance activity and source of rural productivity growth.

However, whether the farm or the non-farm sector has been the most important pathway out of poverty is ultimately an empirical question, as is the relative importance of inter-sectoral transitions and rural-urban migration. The answer for any given country depends both on its factor endowments as well as on its policy and institutional history. We therefore explore the empirical evidence concerning the pathways out of poverty for Indonesia over the last decade.

Indonesia provides an interesting case study for several reasons. First, between the late 1960s and the mid-1990s it experienced high and sustained economic growth, pulling millions of people out of poverty, followed by a severely felt, but rather short, financial crisis in the late 1990s which hit Jakarta the most and was a period of economic hardship for many. Second, Indonesia is large enough to display spatial and sectoral diversity, as reflected in the large-scale household panel dataset - the Indonesia Family Life Survey (IFLS), which allows a detailed investigation of the characteristics of households that move in and out of poverty. This paper draws on this Indonesian experience by using the panel household survey data from IFLS to assess the importance of changes in sector and location in driving changes in individual incomes and household poverty over time. We find that urbanisation has been rapid, but only a small part is due to actual physical migration of workers and households while most of it is due to local economic agglomeration and subsequent re-classification of former rural areas. In rural areas, a gradual di- 
versification of economic activities is taking place, characterised by greater reliance on non-farm sources of income. This process of rural diversification reflects greater opportunities for growth in a dynamic non-farm economy than in agriculture per se, although increases in agricultural productivity have remained a very important path out of poverty for the poorest. Moreover, rural non-farm activities can be a stepping stone out of poverty in rural areas and towards urban non-farm employment, which in turn, is the least vulnerable sector regarding poverty transition.

Concerning the determinants of income and poverty change our analysis yields broad support for the idea that movement to the non-farm sector increases income growth and makes an exit from poverty more likely. Understandably, less support is gathered for the importance of migration, although local level migration does appear to boost income growth, particularly for the poorest, while longer range district and provincial movements are associated with an increased chance of exiting poverty. Furthermore, age, sex and education all have a strong positive influence on income growth, whereas certain elements of the demographic composition of the household, most notably the household size and the number of young children have a negative effect. Poor schooling and large household size are also key barriers to exiting poverty, additionally a broader range of individual and demographic characteristics contribute towards income vulnerability. Moreover, geographic aspects matter. The crisis hit people in urban areas harder than those in rural areas. As a result, our analysis shows that being in an urban area substantially reduces the probability of exiting poverty once controlling for other factors.

The paper is structured as follows: Section 4.2 describes the conceptual framework, the data and the poverty line, in addition, it reports the descriptive IFLS statistics. Moreover, Section 4.3 provides a decomposition of income growth and poverty transition according to sector and location utilising transition matrices. Furthermore, Section 4.4 analyses the micro-determinants of income and poverty changes using the IFLS panel data and estimates our "naive" pathways out of poverty model, before we conclude with implications for policy in the final section.

\subsection{Conceptualisation and Methodological Issues}

\subsubsection{Conceptualisation and the "Naive" Model}

Since the early works of Lewis (1954) one of the main questions in development economics has been the nature of the "structural transformation", that takes place as countries develop, and how it influences growth and poverty reduction in the long-term. More recently, a theoretical model by Foster and Rosenzweig (2004) models the rural economy as a three-sector economy encompassing agriculture, non-farm non-tradable goods and services and non-farm tradable goods. Income growth is realised in two main ways: either by the increase in agricultural productivity due to technological change or by increasing urban or world demand for manufactured goods produced in rural areas. So both sources of productivity growth, agriculture and increased non-farm 
Figure 4.1: Pathways out of Poverty

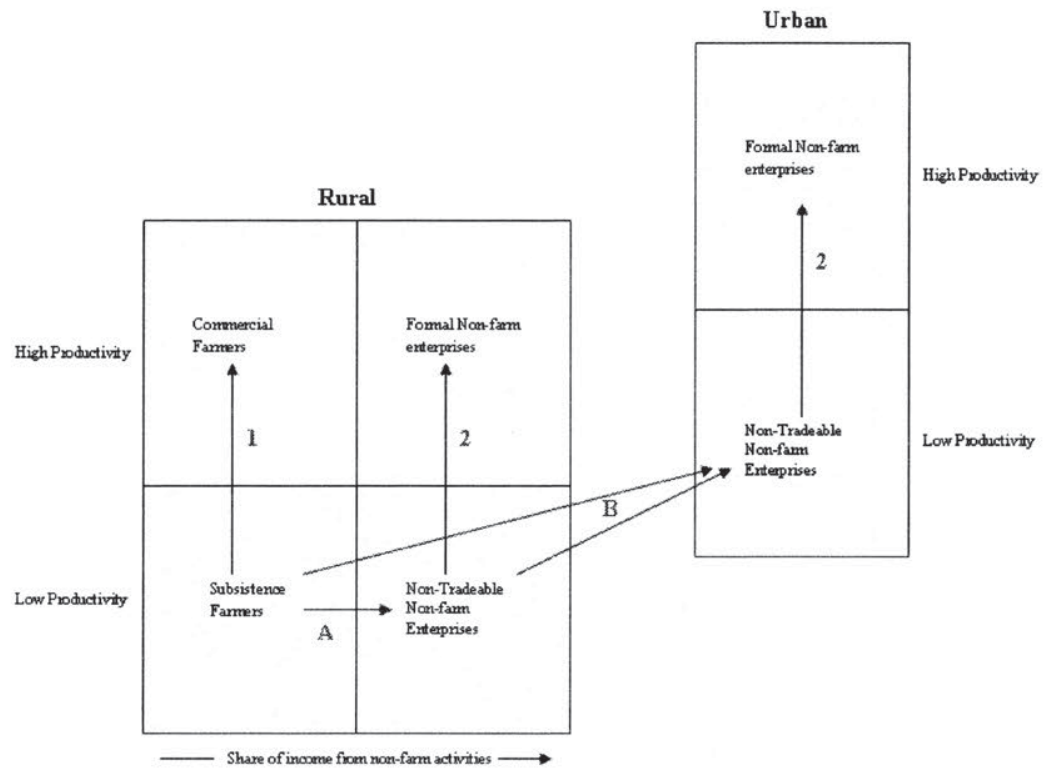

activities, can raise income and alleviate poverty. Correspondingly, Figure 4.1 presents our simple conceptual framework for how structural transformation translates into poverty reduction. ${ }^{1}$ We use this framework for our later empirical work. There are arguably two simplified pathways out of poverty. Firstly, there is the move from low to high productivity farming (Pathway 1). This includes both intensification through raising productivity of traditional crops, as well as diversification into higher value crops, whether food or non-food. This pathway also includes those individuals who exit poverty by obtaining better paid employment on higher productivity commercial farms. Thus, staying in agriculture does not necessarily mean staying as a self-employed farmer. Secondly, some people exit poverty because of increases in the productivity and profitability of their non-farm enterprises, or by finding better-paid employment in such enterprises (often more formal) owned by others (Pathway 2). This pathway applies to both rural and urban non-farm activities.

Complementing these two pathways, there are two "transition phases" which individuals may go through to reach the second route out of poverty. The first is a shift out of subsistence

1 However, it is a "naive" model in the sense that it does not specify any functional interactive relationship between different sectors and is not corresponding to the algebraic theoretical framework of the Foster and Rosenzweig model. Moreover, we consider the non-farm sector to encompass all non-farm activities, not only the manufacturing sector. 
agriculture towards petty trading and manufacturing, as well as local non-tradable service provision (Transition Path A). This corresponds to the long-term sectoral shift from agriculture to non-agricultural activities as countries develop. Similarly, rural-urban migration, which can come both from households currently engaged in low-productivity agriculture and those currently engaged in petty trade, manufacturing and services, corresponds to the shift in location of economic activity seen during the structural transformation (Transition Path B). Before we analysis the determinants of income and poverty change and estimate our simplified "naive" model, as shown in Figure 4.1 in Section 4.4, a detailed analysis of the descriptive statistics is highly informative.

\subsubsection{Data}

To explore the microeconomic determinants of exiting poverty requires a panel data set over a reasonable length of time. There are two large national household surveys in Indonesia SUSENAS and IFLS. The SUSENAS data set is the official national representative Indonesian socioeconomic household dataset, which has a slightly better coverage, but lacks panel data structure. ${ }^{2}$ Hence, we decided to use the Indonesia Family Life Survey (IFLS), which has a panel data structure and was first conducted in 1993 (IFLS1) and then again in 1997 (IFLS2), 1998 (IFLS2+) and finally in 2000 (IFLS3). For IFLS1, 7,224 households were interviewed with data collected on 22,000 individuals in those households. This sample is representative of about 83 percent of the Indonesian population in 13 provinces. In 1993, IFLS did a face-to-face interview with the household head, the spouse, a sample of their children and a sample of other household members. In 1997, 94 percent of IFLS1 households were re-interviewed consisting of all 1993 "main" respondents and all 1993 household members born before $1967 .{ }^{3}$ In 2000, IFLS managed to re-contact 95.3 percent of IFLS1 households interviewed: all 1993 "main" respondents, all 1993 household members born before 1967 and a sample of other 1993 household members. The sample size in 2000 was 10,400 households and 39,000 individuals.

Our main aim is to understand to what extent sectoral and locational shifts determine productivity/income change and thus movements out of poverty. For this reason, we restrict the panel used for our analysis to the individuals who were between the ages of 15 and 55 in 1993 and were working in both years. For these individuals we have an estimate of their income and household expenditure, ${ }^{4}$ individual, household and community characteristics, as well as whether they shifted the sector of employment and if they moved location. Hence, we have a highly de-

Panel structure was implemented after 2004. Nevertheless, the SUSENAS data is useful as a general crossreference to benchmark our findings from the IFLS and will be cited as such.

3 Unfortunately, the 1997 data on sectoral employment and migration were not published - thus for our analysis we will use only data from 1993 and 2000 .

4 The IFLS collected data on individual income. This is calculated as the sum of gross profit, net profit, and wages. Combining these sources attributes too much income to individuals since, for some households, multiple members will contribute toward the profits from a household enterprise. We therefore tested for the possible biases which this might generate, by estimating our regressions only for individual income sources (wages, net profits, gross profits) to test the robustness of the results. However, the main findings were not altered substantially. The results are available on request. 
tailed panel dataset with the required information for a representative sample of the working population in 1993.

There are two main caveats associated with our choice of sample. First, the sample used for the analysis does not account for the unemployed or for newcomers to the labour market after 1993. Thus, if a key pathway out of poverty is the entrance into the labour force of people who were out of the labour force in 1993, we will not capture this effect. Similarly, if individuals fall into poverty as a result of leaving the labour force (for example through death, illness or old age) this will not be observed. If the aim of our study had been to capture all poverty dynamics, these would have be serious omissions. However, our aim is to understand the extent to which changes in sector and location of existing workers drives poverty entrances and exits. Moreover, evidence from other developing countries suggests that, although entrances and exits from the labour force can be important, it is usually the changes in income status of existing working household members that drives most poverty entrance or exit (McCulloch and $\mathrm{Cao}, 2007$ ).

Second, we focus on the individual earnings of main household members. However, poverty is clearly a phenomenon that is experienced at the household level since, in most households, there is some pooling of resources. Thus, individuals were classified as poor or non-poor based on the per capita household expenditure of their households in the respective years. Hence, it is possible that the poverty transitions we observe may be due to changes in the incomes of household members that are not in our (or the IFLS) sample or simply change in household composition. However, although the IFLS sample did not interview every member of the household, the method used means that it is likely to have captured almost all the significant sources of income in the household. Moreover, the vast majority of individuals in our sample are the sole or main income earner of their household, so changes in their earnings are likely to have a much larger impact on poverty transitions than changes in the earnings of other household members. ${ }^{5}$ In fact, the individual earnings used for the analysis account on average for 70 and 67 percent of their actual specific total household income in 1993 and 2000 respectively. The corresponding median is even higher at 74 and 77 percent. Thus, the individual earnings in our sample account on average for 70 percent of household income. With these caveats in mind, our sample seems adequate for exploring the questions asked.

\subsubsection{Poverty Line}

The poverty line used for all the analysis below is derived from the 2000 BPS poverty line. ${ }^{6}$ For 1993 BPS also calculated a poverty line, but implemented a methodology which is rather different than that used for the calculation of the 2000 poverty line. ${ }^{7}$ To ensure that the poverty

\footnotetext{
$5 \quad$ Clearly, household composition and size matters if poverty is determined on a household level. However, we control for this effect in our regressions.

6 This uses a variant of the Bidani and Ravallion (1993) methodology for calculating poverty lines.

7 The BPS estimation methodology concerning the poverty line changed in 1996.
} 
line in 1993 represents the same purchasing power as that in 2000, the easiest approach would be to take the 2000 poverty line and deflate it using the provincial consumer price index (CPI) published by BPS. However, the published CPI uses a set of weights for its sub-indices which are heavily weighted in favour of wealthy consumers in urban areas. ${ }^{8}$ This bias in the CPI is particularly inappropriate for our analysis. In particular, since food prices rose more quickly than other prices over the period and the poor have a much higher share of their expenditure on food than the better off, the published CPI understates the inflation experienced by the poor over this period. When this downward-biased CPI is used as a deflator, it produces a poverty line that is too high in 1993 and implausibly high measured levels of poverty. For this reason we re-weighted the individual commodity group indices from the CPI published for each province using the expenditure shares for each commodity group of the bottom quintile in 1996. All subsequently reported real figures are deflated utilising the method described above. This poverty line is applied to real per capita household expenditure in order to classify a household or the individual income earner as poor or non poor for both years respectively.

\subsection{Descriptive Analysis, Income \& Poverty Transition Matrices}

\subsubsection{Descriptive Statistics}

Table 4.1 shows some of the key variables from the panel for 1993 and 2000 . For the individual variables, the average age of the panel obviously rose as did the years of schooling, indicating that some panel participants completed further schooling in the intervening years. Interestingly, 62 percent of individuals worked in the non-farm sector, and this share did not change over the period. ${ }^{9}$ The mean real individual income in the sample rose between 1993 and 2000 by 15.2 percent. However, as is often the case with income data, the mean is distorted by high outliersthe median income is a little more than half mean income in both years-but it also grew by a similar amount, 16.4 percent, over the 7 year period. Working hours remained roughly constant, while there was a small decline in the share of individuals who were employees. It is important to remember that this 7 year period experienced considerable economic and political turmoil, and the economy had not recovered fully from the 1998 crisis when the 2000 interviews were held.

Concerning the household variables, a substantial increase of 8 percent occurred in the share of households classified as living in urban areas between the two years. In 1993, 32 percent of respondents lived in urban areas. In 2000, 40 percent lived in urban areas. However, this large change in only 7 years is partly misleading and can hardly be reconciled with the also occurring "reverse migration" of several million urban workers to rural areas during the economic crisis

\footnotetext{
$8 \quad$ For example, the CPI share on food is 38 percent but the food share of the bottom quintile from SUSENAS is 66 percent. A detailed discussion of this general problem is to be found in Grimm and Günther (2006).

9 However, there were significant changes in sub-sectors. The share of respondents in manufacturing declined from 14.3 percent to 10.8 percent, whereas those working in social services rose from 13.6 percent to 19.6 percent. These changes reflect the impact of the crisis and the growing informal service economy.
} 
Table 4.1: Descriptive Statistics for IFLS 1993 and 2000

\begin{tabular}{|c|c|c|c|c|}
\hline $\begin{array}{c}\text { Variable } \\
\mathrm{N}=4797\end{array}$ & Mean in 1993 & Median in 1993 & Mean in 2000 & Median in 2000 \\
\hline Individual Variables & & & & \\
\hline Age & 37.3 & 37 & 45.2 & 45 \\
\hline Years of Schooling & 5.7 & 6 & 6.2 & 6 \\
\hline Non-farm & 0.62 & 1 & 0.62 & 1 \\
\hline Real individual income & 179,746 & 93,145 & 207,021 & 108,453 \\
\hline Working hours per month & 213.5 & 207.8 & 211.7 & 207.8 \\
\hline Employee dummy & 0.47 & 0 & 0.44 & 0 \\
\hline Household Variables & & & & \\
\hline Urban & 0.32 & 0 & 0.4 & 0 \\
\hline Household Size & 4.83 & 5 & 5.81 & 6 \\
\hline Number of children below 5 & 0.7 & 1 & 0.47 & 0 \\
\hline Number of children below 15 & 1.16 & 1 & 1.06 & 1 \\
\hline Sex of household head & 0.91 & 1 & 0.92 & 1 \\
\hline Real household expenditure pc & 78,956 & 50,276 & 80,944 & 55,673 \\
\hline Expenditure Poverty & 0.28 & 0 & 0.24 & 0 \\
\hline
\end{tabular}

individual probability weights for 1993 and 2000 respectively. Real income and expenditure variables in 1996 Rupiah per month. 
in 1998 and thus overestimates "true" rural-urban migration. One explanation for this large increase in the percentage of people in urban areas is the reclassification of rural villages as urban over the observation period, as at least 3.26 percent of individuals had been reclassified as urban by 2000 without moving location. ${ }^{10}$ Thus, we used the rural/urban classification in 1993 to determine rural/urban status throughout our analysis in order to avoid the confusion between re-classification (possibly even due to successful non-farm development) and true rural-urban migration.

Demographic changes are also clearly illustrated: the average household size increases by one over the period of the panel with a shift towards more adults in the typical household as the children grow up. Households remain overwhelmingly male-headed in both periods. The growth in individual incomes of the panel members is not reflected in similarly high growth in the per capita expenditures of the households from which they come, which is most likely due to increased household size. Mean real expenditure barely rose over the period, but what growth there was took place at the bottom end of the distribution, with the median per capita expenditure rising by 10.7 percent. This most likely implies that wealthier households were more willing and/or capable to incorporate another household member during times of crisis. However, as a result of the steepness of the distribution near the poverty line this relatively modest increase in the per capita expenditure of the bottom percentiles resulted in a significant fall in poverty from 27.7 percent to 23.6 percent. $^{11}$

\subsubsection{Income Growth}

Before we take a closer look at the determinants of income change and poverty transition it is highly informative to take a closer look at income and poverty transition matrices. With the IFLS panel it is possible to calculate directly the income growth for individuals who were working in particular sectors or locations. Table 4.2 is a transition matrix which shows the median income growth for individuals according to whether they lived in rural or urban areas and whether they

10 We compared this results with the SUSENAS data which shows a even stronger trend in urbanisation. However, the re-classifications of rural areas as urban is even higher with the SUSENAS data (at least 10 percent of rural villages). This is due to the fact that the definition of "urban" used by the Central Statistic Bureau relates to the number of amenities available in an administrative village, the population density and the share of income coming from agriculture. To get a sense of the role played by "true" rural-urban migration rather than urbanisation, Table D.1 in Appendix D shows estimates obtained from the inter-censal survey (Supas) in 1995. Only 2.8 percent of those individuals in rural villages in 1990 were living in urban villages in 1995. Moreover, the 3.6 million people who moved to urban villages between these two years were compensated in part by 1.8 million people who moved from urban to rural villages over the same period. Overall, around 5 percent of those in urban areas in 1995 had been living in rural areas five years previously. Hence, role of "true" rural-urban migration is certainly not trivial, but overall, "urbanisation" rather than rural-urban migration has been the dominant factor in changing the percentage of people considered to live in urban areas.

11 Note that the 2000 figure is similar to the official poverty figure from BPS for 2000, but the 1993 figure is much higher. This is because we are comparing "like with like" by expressing both the 2000 poverty line and the expenditure/income figures in $\mathbf{1 9 9 6}$ prices. The official figure uses a poverty line with a completely different methodology, as noted earlier. 
worked in agriculture or outside of agriculture in 1993 and 2000. For example, the first row, first column reports 48,470 real rupiahs median income of all 1,590 individuals which were classified as rural agriculture workers in 1993. The following columns show how these individuals' incomes developed according to the sectoral and locational transition and reports the percentage change of median income restricted to the individuals who ended up in that sector and location in $2000 .{ }^{12}$ Table 4.2 tells an intriguing story of how income and income growth is associated with sectoral transition and rural-urban migration. First, the dramatic impact of both urban location and work outside of agriculture is evident if we look at the first column reporting median income in 1993: the median agricultural worker earns about half the income of the median worker working outside agriculture in both rural and urban areas; similarly the rural median worker (whether farm or non-farm) earns little more than half the income of the corresponding median worker in the same sector in urban areas.

Moreover, Table 4.2 shows that the vast majority of rural farm workers in 1993 continued to be rural farm workers in 2000 and saw their real median incomes decline by 11 percent. Almost all of those who moved out of farming in rural areas did so by moving to non-farm activities in rural areas; these individuals saw their real median incomes rise by almost a third. Very few rural agricultural workers moved to urban areas, so we do not place any confidence in the income growth figures for these transitions. However, we note that real median income fell by 7 percent between 1993 and 2000 for this poorest category of workers, with only those that shifted out of agriculture managing to increase their median incomes significantly. Workers who were already working outside agriculture in rural areas in 1993 were already much better off than their agricultural counterparts. Around 70 percent of these workers stayed in the same sector, seeing their median incomes rise by 11 percent over the period. However, more than a fifth of these workers moved into the agricultural sector and experienced a sharp reduction of their median real incomes as a result. By contrast, a small number managed to obtain non-farm work in urban areas. In fact, these workers did not fare particularly well as their median incomes fell by 9.5 percent, but it is worth noting that those that managed to migrate to non-farm jobs in urban areas started out with a median income almost 60 percent higher than the median income of rural non-farm workers in 1993. The handful of individuals who found work in the agricultural sector in urban areas saw their median incomes collapse, but again we treat this result with caution given the very small number of individuals involved.

Furthermore, the majority of the richest group, urban non-farm workers, stayed in this category and experienced a 7 percent fall in their real median income, probably associated with the economic crisis of the late 1990s. Moreover, 5 percent of this group shifted to urban agricultural activities and saw their median income fall by 32 percent. A further 5 percent shifted back into rural areas while staying in non-agricultural activities. This group saw its median income rise

12 In this example individuals which were both rural farm workers in 1993 and 2000 saw their median real income decline by $\mathbf{1 1 . 2}$ percent, where as individuals which were originally rural farm workers but moved into rural non-farm work saw their median real income increase by 31.1 percent. 
by 28 percent. ${ }^{13}$ To sum up, three major themes emerge. First, for the poorest, who are mostly employed in rural agriculture, getting out of agriculture was the key to increasing their incomes. Only a handful of these individuals were able to migrate to urban areas, but almost a fifth left agriculture and in doing so substantially increased their incomes. Conversely, for those that had already left agriculture, moving back into agriculture was a sign of distress; all shifts back into agriculture from non-agricultural employment were associated with major income collapses, an outcome consistent with the drastic impact of the economic crisis. Second, most of those who migrated to non-farm jobs in urban areas were already doing non-agricultural jobs in rural areas and tended to be among the better off non-farm rural workers. But only 6 percent of rural nonfarm workers managed to move to urban areas - while almost a quarter fell back into agriculture. Third, movements from urban non-farm employment to rural non-farm employment appear not to be associated with distress. This suggests that these better off workers may move back to rural areas voluntarily for the purpose of investment in their home areas.

\subsubsection{Poverty Transitions}

The income growth table shows what happened to median incomes. But median income growth does not necessarily translate into movements out of poverty. To evaluate these movements, Table 4.3 shows a detailed poverty transition matrix between 1993 and 2000, disaggregated by rural and urban as well as agricultural and non-agriculture. The poverty of individuals is, of course, determined by the level of welfare of their whole households. We therefore determine the poverty status of individuals who were aged between 15 and 55 in 1993 and were earning income by whether the per capita expenditure of their households fell above or below the poverty line.

Although the IFLS data are not entirely representative of the Indonesian population ${ }^{14}$, the 5308 individuals tracked in Table 4.3 do represent basic Indonesian poverty patterns reasonably faithfully. Rural poverty made up 74.9 percent of total poverty in 1993 in the unweighted IFLS data, compared with 74.0 percent in the 1993 SUSENAS data. Analysis of how these 5308 individuals with income fared between 1993 and 2000 should provide very useful insights into the dynamics of poverty in Indonesia.

The central cells of Figure 4.2 show the net flows in employment of all the individuals in the sample between the eight categories or sub-samples according to three characteristics (rural/urban, non-farm/farm, poor/non-poor). Most of the employment dynamics in the IFLS data comes from employment gains in agriculture, with the rural, non-farm economy actually losing workers. There is a modest shift towards urban employment although in net more of that gain is in urban agriculture than in non-agriculture, which might reflect the impact of the economic crisis, which was still a major factor in 2000 .

\footnotetext{
13 A handful of others shifted back into rural agriculture - by coincidence all of these individuals report zero income in 2000 , but once again we interpret this result with caution given the small numbers involved.

14

Representative of about 83 percent of the Indonesian population in the 13 main provinces.
} 
Table 4.2: Income Growth Transitions by Rural, Urban and Sector 1993-2000

\begin{tabular}{|c|c|c|c|c|c|c|c|c|c|c|c|c|}
\hline & & & & & & & & 2000 & & & & \\
\hline & & & & Rural & & & & Urban & & & & Total \\
\hline 1993 & & Income & NrObs & Farm & NrObs & Nonfarm & NrObs & Farm & NrObs & Nonfarm & NrObs & 2000 \\
\hline Rural & Farm & 48,470 & 1,590 & $\begin{array}{l}40,660 \\
-11.20 \%\end{array}$ & 1,268 & $\begin{array}{l}78,519 \\
31.10 \%\end{array}$ & 274 & $\begin{array}{l}22,305 \\
-56.40 \%\end{array}$ & 31 & $\begin{array}{l}107,177 \\
116.00 \%\end{array}$ & 17 & $\begin{array}{l}44,868 \\
-7.40 \%\end{array}$ \\
\hline & Nonfarm & 103,792 & 1,415 & $\begin{array}{l}50,006 \\
-37.40 \%\end{array}$ & 329 & $\begin{array}{l}121,182 \\
11.00 \%\end{array}$ & 984 & $\begin{array}{l}49,788 \\
-40.00 \%\end{array}$ & 18 & $\begin{array}{l}150,425 \\
-9.50 \%\end{array}$ & 84 & $\begin{array}{l}109,966 \\
5.90 \%\end{array}$ \\
\hline Urban & Farm & 90,049 & 293 & $\begin{array}{l}101,827 \\
-15.40 \%\end{array}$ & 52 & $\begin{array}{r}118,379 \\
-22.20 \%\end{array}$ & 15 & $\begin{array}{l}79,019 \\
4.00 \%\end{array}$ & 143 & $\begin{array}{l}93,485 \\
8.80 \%\end{array}$ & 83 & $\begin{array}{l}92,595 \\
2.80 \%\end{array}$ \\
\hline & Nonfarm & 192,893 & 2,220 & $\begin{array}{l}0 \\
-100.00 \%\end{array}$ & 24 & $\begin{array}{l}269,483 \\
28.30 \%\end{array}$ & 109 & $\begin{array}{l}90,356 \\
-32.00 \%\end{array}$ & 111 & $\begin{array}{l}176,623 \\
-6.70 \%\end{array}$ & 1,976 & $\begin{array}{l}176,623 \\
-8.40 \%\end{array}$ \\
\hline All & & 95,904 & 5,518 & & 1,673 & & 1,382 & & 303 & & 2,160 & 107,875 \\
\hline
\end{tabular}

Note: Data are for individuals who were aged 15-55 in 1993 and were working in both years. Income figures are median monthly income in Rupiah in 1996 prices. Starting income figures are for 1993; all other income figures are for 2000. Income values and percentage changes in each cell represent the median incomes and percentage change in income of those individuals who made that transition. For example, the real income of the median rural agricultural worker that moved into non-agricultural activities in rural areas increased by $31 \%$, ending at $R p 78,519 /$ month in 2000 . 
Moreover, due to the panel structure of the IFLS data we can decompose these net flows and track the origin and destination (in terms rural/urban, non-farm/farm, poor/non-poor) of each individual in each category as reported in Table 4.3. The IFLS data reveals astonishing mobility of individuals across cells. Figure 4.2 displays two illustrative examples of two specific categories or sub-samples. The smaller top cells show the 2000 destination of the 1993 rural/agricultural/poor and corresponds directly to the numbers in the top row of Table 4.3. The mobility out of rural, agricultural poverty between 1993 and 2000 is striking. Of the 713 workers (13.4 percent of the total sample) who started in this category, 307 (5.78 percent of the total sample) exited poverty by improving their agricultural productivity and 68 exited poverty by moving to the rural non-agricultural sector (41 remained poor after this move). Only 21 poor rural farmers moved to urban areas.

Correspondingly, the small bottom cells show the original category of those 577 individuals (or 10.9 percent of the entire sample) which ended up in the rural/agricultural/poor category in 2000 and corresponds to the numbers in the second $2000 \mathrm{rural} /$ poor/agri column in Table 4.3 . They show that more than half (unsurprisingly the same 307 workers or 5.2 percent of the total as above) started out in this sub-sample, less than a third or 162 (3.05 percent of the total sample) fell into poverty remaining in the rural/agricultural category, almost a quarter came from the rural non-farm category non-poor and poor, 69 and 61 individuals (1.15 and 1.3 percent of the total sample) respectively, while few came originally from the urban area. There are even 4 individuals who were urban, non-poor and non-agricultural in 1993 who ended up as poor, rural and agricultural in 2000. This particular number is small, but clearly the economic crisis fostered great mobility in the workforce.

Three key lessons emerge from this descriptive analysis of the IFLS data:

Improved productivity in agriculture is still an important route out of poverty, as most of the rural agricultural poor in this sample who exit poverty do so while staying in rural agriculture. Over 80 percent of the poor rural farmers in the sample were still working in rural agriculture in 2000 , but more than half of the households from which they come still managed to exit from poverty. Most of the rest moved into non-agricultural activities in rural areas and, more often than not, out of poverty too. Few moved to urban areas, thus, raising agricultural productivity seems to be an effective way of reaching these households. ${ }^{15}$

Rural non-agricultural activities can be a stepping stone out of poverty in rural areas, as individuals from poor rural households who worked off-farm in 1993 were more mo-

15 We compared this results to the aggregate SUSENAS data as a benchmark exercise. However, it important to keep in mind that the IFLS sample is restricted and does not necessarily correspond exactly to the SUSENAS data as it does not include new labour force entries, is based on a slightly different sampling base and, most importantly, displays partly diverging methodology and variable definitions. Thus, if we compare these numbers reporting net employment flows between sectors, location and poverty status to similar, but not strictly comparable, aggregate numbers based on the SUSENAS data (reported in Appendix D Table D.2 and Figure D.1) we find that the IFLS dataset reports a lower percentage in the rural non-farm sector and displays a slight increase in the agricultural workforce compared to a decrease in the SUSENAS data. Unfortunately, the full reason for the diverging numbers is not entirely clear and must remain partly speculative and subject to future research. 
Table 4.3: Poverty Transition Matrix, 1993 to 2000

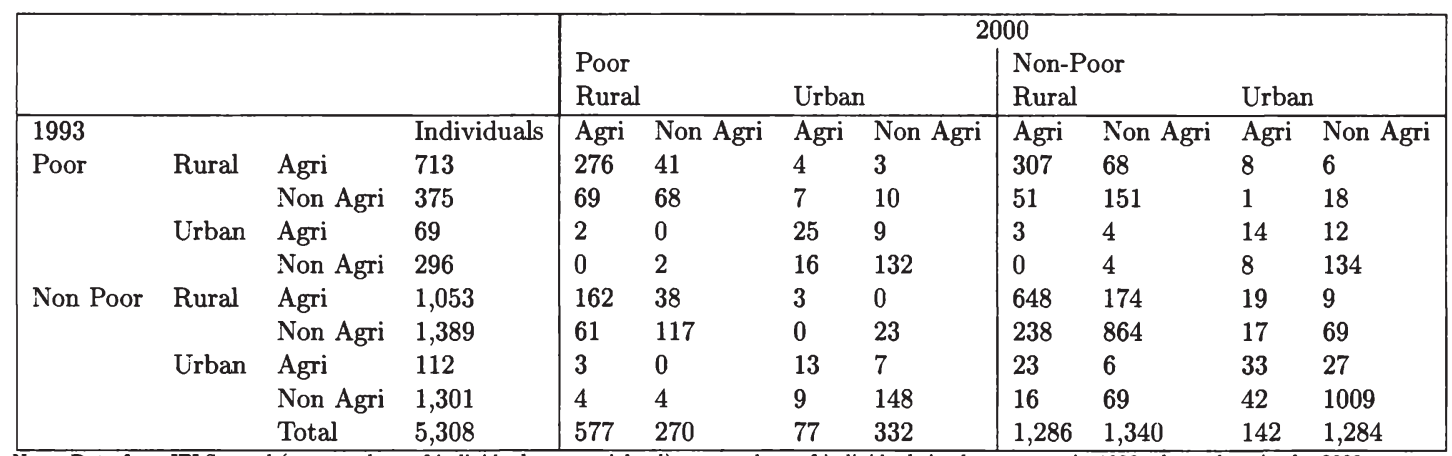

Note: Data from IFLS panel (raw numbers of individuals, not weighted) are numbers of individuals in the category in 1993 who end up in the 2000 category.

The individuals are those who were aged $15-55$ in 1993 and were working. 
Figure 4.2: Poverty Transition Matrix, 1993 to 2000, IFLS Panel Data, Unweighted.

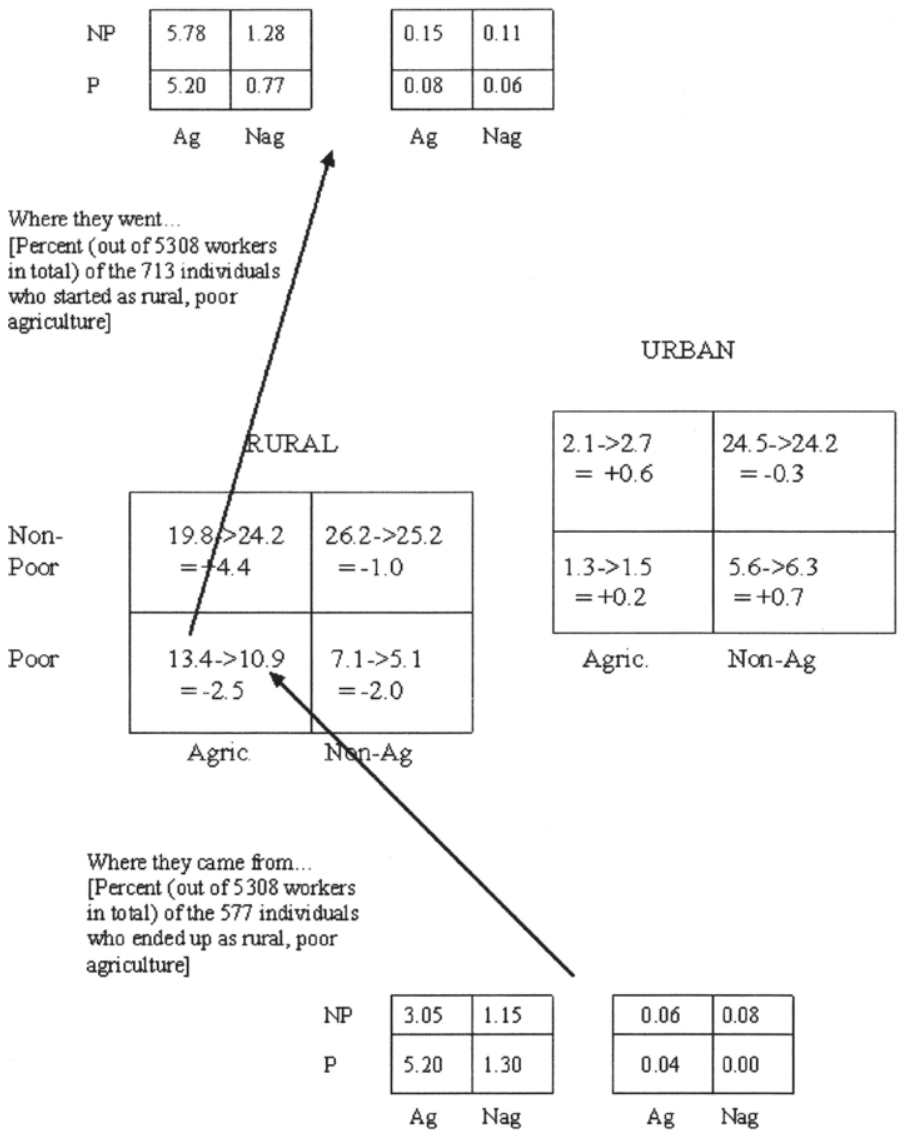

The central tables show the percent of the total IFLS workers who were tracked between 1993 and 2000 ( 5308 in number). In each cell, the first number is the percent in that cell in 1993, with the arrow pointing to the number in that cell in 2000. The bottom number is then the net difference between 1993 and 2000 . Additionally to these net flows the numbers of the poverty transition matrix in Table 4.3 permits the identification of which workers made up different net flow and thus their original or destination category. This is shown in the smaller top and bottom cells for the destination and original categories of rural, agricultural, poor in 1993 and 2000 respectively.

bile than those working in agriculture. Less than a fifth stayed poor in rural non-agricultural activities-but overall they were equally likely to stay poor, as a similar number shifted back to agriculture while remaining poor. More than half of them escaped poverty while staying in rural areas-a similar rate to those who started poor in agriculture. Urban migration played a more important role for this group, but still a minor one - less than 10 percent of this group moved 
to urban areas, and only half of those that did so exited poverty. ${ }^{16}$ Still, this migration rate -almost 10 percent of poor, rural non-farm workers migrated to urban areas in just 7 years- is more than three times the rural-to-urban migration rate of poor farm workers (only 2.9 percent of poor farm workers moved to urban areas, and one third of those remained in poverty). During the same period, 15.4 percent of poor, rural farmers moved to rural non-agricultural jobs and almost two thirds of these exited poverty in the process. The potential for the non-farm rural economy to be a stepping stone out of poverty is clear.

Non-agricultural activities in urban areas appear to be somewhat more stable, as Table 4.3 shows, 77.6 percent of the non-poor in this category remained non-poor, nonagricultural and in urban areas. At the same time, 44.6 percent of the urban, non-agricultural poor remained in that category. Both rates of "stability" are the highest of the four categories. This stability may arise because earnings are much higher in urban areas, so the poor prefer to stay in the hope of a good job; or it may be difficult for poor urban workers to move or return to rural areas. The distinction should not be overdrawn, however, as 61.5 percent of the rural, agricultural non-poor remained in this category and 62.2 percent of the rural, non-agricultural non-poor experienced similar stability. Indeed, when agricultural and non-agricultural activities are combined, a common occurrence for households in rural areas, 78.0 percent of rural agricultural households and 79.3 percent of rural non-agricultural households (in 1993) remained stable out of poverty. Importantly, only the panel results can bring a clear picture of how much "churning" there is near the poverty line. Clearly, there is a small but significant probability of falling below that line for rural workers, whether farm or non-farm.

In summary, urbanisation has been rapid, but only a small part is due to actual physical migration of workers and households. In rural areas, there is a gradual diversification of economic activities taking place, characterised by greater reliance on non-farm sources of income. This process of rural diversification reflects greater opportunities for growth in a dynamic non-farm economy than in agriculture per se, although increases in agricultural productivity have remained a very important path out of poverty. These highly detailed descriptive transition matrices give us great details regarding the pathways out of poverty as conceptualised in Section 4.2.1. However, many of the transition paths described above are strongly influenced by the individual characteristics of workers, which have not been considered so far. The following section explores the importance of these determinants (including family characteristics) on income growth and movements out of poverty.

\footnotetext{
16 As mentioned above in section 4.3.1, all the rural-urban movements displayed involve actual physical movement of the person. This adds weight to the evidence that urbanisation rather than rural-urban migration is the principle form of rural-urban transition, This is confirmed if one looks at the results from a sample which does not take reclassification into account, as it will display higher percentages who "migrated" into urban areas, even though their home location was simply reclassified.
} 


\subsection{Micro Determinants of Income and Poverty Transitions}

\subsubsection{The Determinants of Income and Poverty Levels}

Before we analyse the dynamics of the IFLS panel, a brief glimpse at the level regressions is informative. We follow the common methodology of a mincer type OLS regression for 1993 and 2000. Furthermore, we also run a Logit regression of the probability of being poor using the same explanatory variables as the OLS regression. The results are displayed in Appendix D (Table D.3 for the OLS results and Table D.4 for the logit results both for 1993 and 2000) which show much of the expected correlations between certain determinants and income level and poverty status. The main results are briefly summarised below.

Several variables are strongly associated with log real income. Real income increases with age but at a declining rate. A person who was one year older in 1993 received on average 9 percent more income and 10 percent in 2000 (due to the aging of the panel). Male income is 44 percent higher than female income in 1993, even when age and education are taken into account. This gap widens as the panel ages-younger women marry and have children, reducing their individual income and are consequently on average characterised by a more marginal attachment to the labour force. Years of schooling, as expected, have a strong effect with each additional year of schooling raising the level of real income by 8.7 percent in 1993 .

Moreover, workers who were part of a household gain on average 7.3 percent more income in 1993 for each additional family member. ${ }^{17}$ However, this coefficient has to be interpreted jointly with the coefficients of number of children, as having a larger number of children below the age of 5 seems to lower real income. The "number of children" effect cancels out the positive effect of household size, suggesting that any advantage of having a larger household is lost once one takes small children into account. Interestingly, the number of men in a household affects average real income negatively. Having more male adults living in the same household may be an indication of poverty (reflected in low individual income) even if their presence boosts household income.

Geographical variables have an extremely strong impact on income. Individuals in urban areas in 1993 earned on average 25 percent more than similar workers in rural areas, ${ }^{18}$ but this differential had fallen to 5.5 percent by 2000 . This is consistent with rural income growth being much faster than urban income growth over this period because of the economic crisis. There are also wide variations between incomes in different provinces. Relative to Jakarta, incomes are lower in all provinces, all other things being equal, with the most pronounced income gaps in 1993 occurring in Yogyakarta, South Sulawesi, Lampung, Central Java, and East Java. This changed dramatically in 2000 as Jakarta was badly hit by the crisis, reducing the income disparity between it and the other provinces. Furthermore, deriving income predominantly from wages does appear to raise income slightly, but the effect turns negative and is not statistically

\footnotetext{
17 This result is anomalous since usually larger households are associated with lower per capita incomes. It may result from the attribution of all profit income earned by family labour to the main earner in the household.

18 This difference is likely to be overstated since nominal income is deflated by provincial CPI, which is based on prices in the province's main city.
} 
significant in 2000. Working more hours also increases income, but the effect is rather small. By contrast there are large sectoral differences in income. Working primarily in the non-farm sector boosts real income in 1993 by 56.2 percent relative to agricultural activities, although this advantage declined to 26.4 percent in 2000 . For specific sectors of employment there are large disparities relative to agriculture: Finance (81 percent), Mining and Quarrying (83 percent), and Social Services (70 percent) display particularly large differentials. These differences were substantially reduced between 1993 and 2000 due to the poor performance (and partial decline) of many of these sectors relative to agriculture over this period.

The results of the Logit poverty regressions confirm and strengthen the OLS regression results. Even though we determine the poverty status of the individual by the per capita expenditure of the household rather than by their individual incomes, these two concepts are sufficiently linked, particularly when the sample is restricted to income earners. Hence, as expected, being older and more educated reduces the chance of being poor. Larger households increase the probability of being poor as does the number of children below the age of five. The number of men in the household increases the probability of being poor in our sample. This may be because the females in our sample are income earners and households in which the woman is also earning an income are likely to be better off than those in which only the male is earning. Interestingly, this positive probability disappeared in 2000, suggesting either that males managed to increase their earning situation considerably or that women lost out relatively more during the crisis.

Surprisingly, living in an urban area increases the probability of being poor, and this effect increases over time. Similarly, the probability of being poor is generally higher outside Jakarta, although this effect is reduced in 2000 due to the improving relative position of the provinces with respect to Jakarta. Employment outside of agriculture reduces the probability of being poor, particularly in the 1993 sample.

The level regressions above confirm many of the links expected from the literature between personal, household, sectoral and regional characteristics and level of income and poverty. However, they do not tell us much about the dynamics of income and poverty. For this we need to utilise the panel nature of the dataset to identify the determinants of income and poverty changes.

\subsubsection{The Determinants of Income Change}

To identify the determinants of income change we estimate a difference regression on both initial characteristics and changes in those characteristics. In other words we estimate:

$$
d l n y=\beta_{0}+\beta_{1} I N D+\beta_{2} H H+\beta_{3} G E O+\beta_{4} S E C+\beta_{1}^{d} d I N D+\beta_{2}^{d} d H H+\beta_{3}^{d} d G E O+\beta_{4}^{d} d S E C+\varepsilon
$$

where IND is a vector of individual characteristics, $\mathrm{HH}$ is a set of household characteristics, GEO is a set of geographical variables, and SEC is a set of sectoral variables; $\varepsilon$ is an error term and the prefix $\mathrm{d}$ indicates changes. In particular, we are interested in observing the size and sign of 
the dummies for changing sector to see to what extent a change from the farm to the non-farm sector has an important impact upon income growth. The results are shown in Table D.5.

As is commonly found in the micro growth regression literature, the log of real initial income has a negative coefficient, implying conditional income convergence. In fact, the data also show strong absolute convergence (Table D.6) of income implying declining income inequality. ${ }^{19}$ Individuals who were older in 1993 tended to have higher growth rates, although the size of this effect declines with age. Male workers also experienced much higher income growth than female workers, but those whose income came from wages experienced slower growth consistent with the impact of the crisis on formal wages. People with higher working hours in 1993 also experienced slightly lower income growth and the expansion of working hours is also associated with slower growth implying that it indicates stress rather than success.

Furthermore, individuals who were better educated in 1993 tended to have higher subsequent income growth (around 6 percent higher growth per extra year of schooling). Households which were initially larger had faster income growth and growing households are also associated with higher income growth (although, of course, the causality here may run in the opposite direction). Having a large number of younger children is not only associated with lower income, but also with slower growth, although, as would be expected, increases in the number of young children are positively (but not statistically significantly) associated with growth. Having a larger number of men in the households is also associated with slower growth, although the effect is not statistically significant.

Moreover, the geographical variables are not as important in explaining changes as they were in explaining levels. Individuals in regions outside Jakarta show slower income growth, but the effect is only statistically significant in a few locations. Furthermore, the coefficients on the regional dummies only display regional-specific effects after controlling for all other variables, in particular initial income. Hence, they are in some sense a measure of our ignorance, as they display the regional variation unexplained by other elements in the model specification. This can clearly be seen in Table D.6, which shows income growth regressed against only initial income and the regional dummies. When growth is regressed against the regional dummies alone, it is clear that individuals living outside Jakarta generally experienced higher income growth than their counterparts in Jakarta. However, once we control for the initial level of income, all the coefficients on the regional dummies turn negative and many lose their significance as the income convergence is now captured in the negative and statistically significant initial income coefficient which implies that the initially poorer regions grew subsequently faster. TableD.5 also explores the implications of moving location (province, district, or sub-district) on income

\footnotetext{
19 This is also consistent with the results obtained by Fields et al (2003) showing declining inequality for Indonesia between 1993 and 1997, as well as results reported in the World Bank's Poverty Assessment for Indonesia (2006b). Theoretically, the negative initial income term could also be due to measurement error and or endogeneity issues. For an excellent general discussion of this topic see Klasen and Woolard (2005), however, they could find no evidence that the initial income term was biased in such a way in their South African household panel dataset.
} 
growth through the inclusion of movement variables. The variables Moved Province, Moved Kabupaten, and Moved Kecamatan take the value one if the individual migrated to a different province, kabupaten or kecamatan over the given time period. ${ }^{20}$ The coefficients on these dummies are statistically insignificant in specifications (1) and (3). However, when we interact initial income with the migration dummies in specifications (2) and (4) we find that people who move relatively small distances (sub-district) tend to have stronger income growth, but only if they were initially less well off. This supports the view that local level migration can support income mobility particularly for the poor.

In order to analyse the impact of sectoral occupation on subsequent income change, a set of dummy variables was constructed to indicate whether an individual stayed in non-farm employment, moved to agriculture for those originally earning income in the non-farm sector in 1993, or moved into the non-farm sector, for those who where engaged in agriculture in 1993. The omitted variable was those individuals remaining in agriculture. Those who where engaged in non-farm activities in 1993 and stayed in the non-farm sector experienced higher than average income growth compared to individuals who remained in agriculture; their income growth was also significantly higher than that of individuals who moved to the farming sector, which is clearly associated with income decline. Interestingly, individuals who moved from agriculture to the non-farm sector seem to have experienced higher income growth than those remaining in agriculture, although the effect is not statistically significant. However, it is important to keep in mind that individuals who moved into the non-farm sector had a median of 5 years of schooling as compared to 3 years for those remaining in agriculture. Hence, much of the associated beneficial effect of moving into the non-farm sector might be captured in the education variable.

\subsubsection{Poverty Dynamics}

The regression above tells us something about the determinants of income growth, but it tells us nothing specific about the dynamics of poverty. In order to determine what factors increase the likelihood of exiting or falling into poverty we run two Logit regressions: first we restrict the sample to people from poor households in 1993 (1186 Individuals) and estimate the determinants of leaving poverty; second we restrict the sample to people from households whose per capita expenditure was above the poverty line in 1993 (3690 Individuals) and look at the determinants of falling into poverty. ${ }^{21}$ Before turning to a more detailed model, Table 4.4 shows a simple Logit model which focuses on the transition paths described above in our "naive" model in Figure 4.1 Section 4.2 .1 , i.e. we examine the effect of movement between rural and urban areas and movement in and out of agriculture on poverty entry and exit. Both regressions control for initial income. Unsurprisingly, higher initial income increases the chances of exit and reduces the

\footnotetext{
20 Note: these migration dummies are not mutually exclusive. Thus, a person who moved province also moved Kabupaten and Kecamatan so that total effect of provincial migration is the joint effect of all associated migration variables.

21 Of course this analysis can also be done simultaneously using a multinomial logit model, but the results would be almost identical. We therefore prefer the more intuitive presentation of the two Logit models.
} 
chances of falling into poverty. However, staying in an urban area reduces the chances of exit and increases the chances of entering poverty, another indication of the predominantly urban impact of the crisis. Neither transition to rural nor urban areas is statistically significant.

On the other hand, moving into the non-farm sector, or simply staying there, is significantly associated with exiting poverty and reduces the chances of entering poverty too, relative to those who stayed in agriculture. Thus, the simple model gives support to the importance of sectoral transitions in movements out of poverty.

Moreover, Table D.7 shows how this assessment changes when the impact of individual, household and geographical characteristics on poverty exit and entry are taken into account. Some of the determinants of income growth are not strongly associated with exiting poverty. For example, neither age, nor sex, nor working hours are significantly associated with exit from poverty. The strongest effects come from education, which strongly increases the chances of exit and reduces those of entry, and from household size-large households are less likely to exit poverty and more likely to enter. The demographic composition of the household also matters for poverty entry, with higher numbers of small children and men making falling into poverty more likely. It is not clear why having more males in the household should be associated with a higher chance of entering poverty. In most of the literature having more males is associated with higher rather than lower incomes, but several male adults in the household in this sample may reflect the impact of the crisis, as many urban construction workers returned to their village households, at least temporarily. Furthermore, the economic characteristics of the individual also play a role. Wage earners have a higher probability of entering poverty, probably as a consequence of formerly non-poor employees falling into poverty as a result of the crisis. By contrast the initial level of working hours in 1993 has no significant influence on exit or entry.

As always, geography is important, with people living outside of Jakarta often more likely to enter poverty or less likely to exit it (although the latter effect is always statistically insignificant). Individuals from certain provinces (all of Java except central Java, South and West Sumatra, West Nusa Tenggara and South Kalimantan) appear to have been particularly vulnerable to poverty relative to those in Jakarta. The same was true of workers in urban households who, ceteris paribus, were less likely to exit poverty than their rural counterparts and more likely to enter. Moreover, moving either province or kabupaten appears to be positively associated with exiting poverty. Such movements are not associated with entering poverty, suggesting that geographical movements are associated with things getting better for the initially poor rather than with distress movement as a result of a shock.

Finally, looking at the sectoral characteristics, it is interesting to note that moving to or staying in non-farm employment, which was strongly and significantly associated with poverty exit in Table 4.4, is no longer statistically significant. Clearly, moving to and staying in the nonfarm sector is correlated with other characteristics, as for example education, which themselves support exit from poverty. By contrast, moving back into agriculture clearly and significantly reduces the chances of exiting poverty relative to those who stay in agriculture. 
Table 4.4: Simple Logit Regression of Poverty Exit and Entry (1993-2000)

\begin{tabular}{|l|ll|}
\hline & exit & entry \\
& $(1)$ & $(2)$ \\
\hline Log real income 1993 & 0.119 & -0.352 \\
& $(1.61)$ & $(7.01)^{* *}$ \\
Stay Urban & -0.768 & 0.317 \\
& $(4.11)^{* *}$ & $(2.28)^{*}$ \\
Move to Rural & 0.760 & -0.333 \\
Move to Urban & $(1.44)$ & $(0.80)$ \\
& -0.280 & 0.395 \\
Stay Non-farm & $(0.57)$ & $(1.00)$ \\
& 0.537 & -0.385 \\
Move to Non-farm & $(2.86)^{* *}$ & $(2.46)^{*}$ \\
& 0.601 & -0.336 \\
Move to farm & $(2.46)^{*}$ & $(1.47)$ \\
& -0.513 & 0.079 \\
Constant & $(1.90)$ & $(0.37)$ \\
& -0.536 & 0.619 \\
& $(1.34)$ & $(2.11)^{*}$ \\
\hline Observations & 1186 & 3690 \\
& Initially poor & Initially non-poor \\
\hline
\end{tabular}

\subsection{Conclusion}

This paper started with a simple question: What were the pathways out of poverty in Indonesia between 1993 and 2000? Two stylised pathways were put forward: improved productivity in agriculture and the growth of non-farm productivity; and two transitions to reach these paths were hypothesised: a sectoral transition from farm to non-farm, and a geographical transition from rural to urban.

The results presented above suggest that there is no single or simple answer to this question. There are many factors which affect movements out of poverty. The IFLS panel data set allows us to explore precisely these transitions between 1993 and 2000. Among the poorest individuals who were aged $15+$ and working in 1993, getting out of agriculture appears to be an important factor in increasing incomes. Almost a fifth of these individuals left agriculture and in doing so substantially increased their incomes. This said, getting out of agriculture is not the only route out of poverty. Indeed over 80 percent of the individuals from poor households working in rural agriculture in 1993 were still working in rural agriculture seven years later, but more than half of the households from which they came managed to exit from poverty. Thus boosting agricultural productivity is also an important pathway out of poverty. 
Rural-urban migration, by contrast, would appear to play a relatively small role, although this period in Indonesia's modern economic history, from 1993 to 2000, was a particularly difficult one for successful rural to urban migration. Only a handful of those idividuals working in rural agriculture in 1993 were able to migrate to urban areas. Most of those who migrated to non-farm jobs in urban areas were already doing non-agricultural jobs in rural areas and tended to be among the better off non-farm rural workers. Thus, it may be that the rural non-farm sector acts as a stepping stone between rural agricultural work and more productive non-farm employment in urban areas. Even if the individual, household and geographical determinants of income and poverty are taken into account, our analysis yields broad support for the idea that movement to the non-farm sector increases income growth and makes exit from poverty more likely. Understandably, somewhat less support is gathered for the importance of migration, although local level migration does appear to boost income growth, particularly for the poorest, while longer range district and provincial movements are associated with an increased chance of exiting poverty.

However, it is clear that some key characteristics have a very significant influence on movements out of poverty. Age, sex and education all have a strong influence on income growth, as, negatively, do certain elements of the demographic composition of the household, most notably the household size and the number of young children. Poor schooling and large household size are also key barriers to exiting poverty, whereas a broader range of individual and demographic characteristics contribute to vulnerability. Moreover, geography matters. The crisis hit people in urban areas harder than those in rural areas. As a result, our analysis shows that being in an urban area substantially reduces the probability of exiting poverty once controlling for other factors. Similarly, once income convergence is taken into account, individuals outside Jakarta experienced slower income growth and a lower chance of exiting poverty than those in the capital. However, our analysis suffers from one important drawback. Because we are specifically interested in whether changes in the sector of employment are an important pathway out of poverty, we have had to restrict our panel to individuals who were aged 15 or over and working in 1993. This, by definition, excludes the young and the unemployed. It also excludes from our analysis new entrants into the panel in 2000 . Nonetheless, although this restriction will certainly impart a bias on the calculated levels of income and poverty relative to the full sample, our sample still provides a representative picture of the impact of sectoral and geographical changes on income growth and poverty transitions.

What are the policy implications of these findings and are there any wider lessons to be learned which might also hold true for other countries? We suggest four. First, notwithstanding the growing importance of the non-farm sector, it is still clear that the majority of the poor will remain in rural agricultural activities for some time to come. Our results suggest that boosting agricultural productivity is their principle pathway out of poverty. It would therefore seem appropriate for the government to shift resources towards actions which boost agricultural productivity. These might include increased spending on agricultural research, improving the 
extension service, reducing costs by improving rural roads, and facilitating access to and use of more modern technology.

Second, our results also highlight the key role played by the rural non-farm sector. This is an area which has been relatively neglected by policy. Improving the investment climate for the rural non-farm sector will be key to broadening access to this stepping stone out of poverty (World Bank, 2006a). Our results show that, all other things being equal, the provinces still display a growth disadvantage relative to Jakarta, suggesting the need for better market integration and infrastructure investment outside the capital. Similarly, broadening access to commercial credit for small businesses and improving access to marketing and technology will support the growth of this sector. Also, more controversially, the government may wish to reconsider the current strong policy bias against the conversion of agricultural land for non-agricultural purposes, as well as the price supports that discourage exit from agriculture. These policies may be slowing down movement along a key pathway out of poverty.

Third, our results point to a rather modest role of migration in poverty reduction, although this was not a typical period for testing this hypothesis. There can be no doubt that urbanisation is proceeding rapidly, particularly on Java, with the result that many formerly rural areas are now considered to be parts of urban economic space. This process goes hand in hand with the shift towards a greater emphasis on non-farm activities. Again, the role of policy here should be to support and facilitate this change by ensuring that newly urbanised areas have access to the economic and social services needed to reduce urban poverty.

Finally, our analysis reiterates the importance of education for exiting poverty. While sectoral change and migration have a role to play, improved education is still one of the most effective routes out of poverty, for two reasons. First, better education enables people to participate in higher productivity activities. Second, better education raises the probability of being able to make the sectoral and locational changes that give access to the other pathways out of poverty. Ensuring that the poor have access to education, including post-primary education, should therefore be a cornerstone of the government's anti-poverty strategy. 


\section{Appendix A}


Julian Weisbrod - 978-3-631-75361-3

Downloaded from PubFactory at 01/11/2019 05:55:15AM

via free access 
Table A.1: Results Posterior Estimation

\begin{tabular}{|c|c|c|c|c|c|c|}
\hline & \multicolumn{6}{|c|}{ Definitions for Columns Below } \\
\hline Country & 1 & 2 & 3 & 4 & 5 & 6 \\
\hline China & 1 & 115 & 2 & 60 & 1 & 1 to 2 \\
\hline Korea Republic of & 1.999 & 60 & 2.984 & 27 & 0.985 & 2 to 3 \\
\hline Taiwan & 2.041 & 47 & 2.994 & 25 & 0.953 & 2 to 3 \\
\hline Sri Lanka & 1.087 & 87 & 1.996 & 66 & 0.909 & 1 to 2 \\
\hline India & 1.014 & 97 & 1.891 & 76 & 0.877 & 1 to 2 \\
\hline Equatorial Guinea & 1.787 & 72 & 2.639 & 36 & 0.852 & 2 to 3 \\
\hline Cyprus & 2.195 & 42 & 2.997 & 22 & 0.802 & 2 to 3 \\
\hline Malaysia & 2.018 & 55 & 2.723 & 34 & 0.705 & 2 to 3 \\
\hline Indonesia & 1.291 & 81 & 1.994 & 69 & 0.703 & 1 to 2 \\
\hline Pakistan & 1.035 & 90 & 1.673 & 79 & 0.638 & 1 to 2 \\
\hline Mauritius & 2.339 & 39 & 2.972 & 29 & 0.633 & 2 to 3 \\
\hline Chile & 2.117 & 43 & 2.724 & 33 & 0.607 & 2 to 3 \\
\hline Egypt & 1.462 & 79 & 2 & 60 & 0.538 & 1 to 2 \\
\hline Botswana & 1.603 & 74 & 2.077 & 44 & 0.474 & 2 \\
\hline Thailand & 1.598 & 75 & 2.034 & 47 & 0.436 & 2 \\
\hline Cameroon & 1.428 & 80 & 1.761 & 78 & 0.333 & 1 to 2 \\
\hline Bangladesh & 1.024 & 93 & 1.255 & 82 & 0.231 & 1 \\
\hline Hungary & 2.645 & 32 & 2.825 & 32 & 0.18 & 3 \\
\hline Portugal & 2.832 & 30 & 2.981 & 28 & 0.149 & 3 \\
\hline Lesotho & 1.001 & 112 & 1.148 & 85 & 0.147 & 1 \\
\hline Ireland & 2.87 & 28 & 3 & 1 & 0.13 & 3 \\
\hline Swaziland & 2.051 & 46 & 2.167 & 39 & 0.116 & 2 \\
\hline Hong Kong & 2.906 & 26 & 3 & 1 & 0.094 & 3 \\
\hline Morocco & 1.903 & 70 & 1.992 & 70 & 0.089 & 2 \\
\hline Singapore & 2.918 & 24 & 3 & 1 & 0.082 & 3 \\
\hline Puerto Rico & 2.917 & 25 & 2.998 & 19 & 0.081 & 3 \\
\hline Panama & 2.036 & 48 & 2.091 & 43 & 0.055 & 2 \\
\hline Tunisia & 2.003 & 59 & 2.048 & 46 & 0.045 & 2 \\
\hline Cuba & 1.974 & 65 & 2.01 & 52 & 0.036 & 2 \\
\hline Dominican Republic & 1.988 & 64 & 2.022 & 49 & 0.034 & 2 \\
\hline Trinidad + Tobago & 2.961 & 21 & 2.989 & 26 & 0.028 & 3 \\
\hline Guinea & 1.825 & 71 & 1.853 & 77 & 0.028 & 2 \\
\hline Philippines & 1.951 & 68 & 1.977 & 73 & 0.026 & 2 \\
\hline Spain & 2.977 & 19 & 2.996 & 23 & 0.019 & 3 \\
\hline Japan & 2.991 & 18 & 2.999 & 11 & 0.008 & 3 \\
\hline Paraguay & 1.993 & 62 & 2.001 & 59 & 0.008 & 2 \\
\hline Finland & 2.992 & 15 & 2.999 & 11 & 0.007 & 3 \\
\hline Italy & 2.992 & 15 & 2.998 & 19 & 0.006 & 3 \\
\hline Nepal & 1.001 & 112 & 1.007 & 89 & 0.006 & 1 \\
\hline Korea Dem. Rep. & 1 & 115 & 1.006 & 92 & 0.006 & 1 \\
\hline United Kingdom & 2.995 & 14 & 2.999 & 11 & 0.004 & 3 \\
\hline Israel & 2.992 & 15 & 2.996 & 23 & 0.004 & 3 \\
\hline Laos & 1.002 & 111 & 1.006 & 92 & 0.004 & 1 \\
\hline Austria & 2.997 & 8 & 3 & 1 & 0.003 & 3 \\
\hline Australia & 2.997 & 8 & 3 & 1 & 0.003 & 3 \\
\hline Belgium & 2.996 & 13 & 2.999 & 11 & 0.003 & 3 \\
\hline
\end{tabular}




\begin{tabular}{|c|c|c|c|c|c|c|}
\hline Mongolia & 1.016 & 95 & 1.019 & 87 & 0.003 & 1 \\
\hline Norway & 2.998 & 5 & 3 & 1 & 0.002 & 3 \\
\hline Canada & 2.998 & 5 & 3 & 1 & 0.002 & 3 \\
\hline Germany & 2.997 & 8 & 2.999 & 11 & 0.002 & 3 \\
\hline France & 2.997 & 8 & 2.999 & 11 & 0.002 & 3 \\
\hline United States & 2.999 & 2 & 3 & 1 & 0.001 & 3 \\
\hline Denmark & 2.999 & 2 & 3 & 1 & 0.001 & 3 \\
\hline Netherlands & 2.998 & 5 & 2.999 & 11 & 0.001 & 3 \\
\hline New Zealand & 2.997 & 8 & 2.998 & 19 & 0.001 & 3 \\
\hline Ghana & 1.006 & 105 & 1.007 & 89 & 0.001 & 1 \\
\hline Mali & 1 & 115 & 1.001 & 100 & 0.001 & 1 \\
\hline Switzerland & 3 & 1 & 3 & 1 & 0 & 3 \\
\hline Sweden & 2.999 & 2 & 2.999 & 11 & 0 & 3 \\
\hline Tanzania & 1 & 115 & 1 & 105 & 0 & 1 \\
\hline Malawi & 1 & 115 & 1 & 105 & 0 & 1 \\
\hline Cambodia & 1 & 115 & 1 & 105 & 0 & 1 \\
\hline Guinea-Bissau & 1 & 115 & 1 & 105 & 0 & 1 \\
\hline Ethiopia & 1 & 115 & 1 & 105 & 0 & 1 \\
\hline Bhutan & 1 & 115 & 1 & 105 & 0 & 1 \\
\hline Burkina Faso & 1 & 115 & 1 & 105 & 0 & 1 \\
\hline Oman & 2.97 & 20 & 2.969 & 30 & -0.001 & 3 \\
\hline Greece & 2.961 & 21 & 2.96 & 31 & -0.001 & 3 \\
\hline Burundi & 1.001 & 112 & 1 & 105 & -0.001 & 1 \\
\hline Rwanda & 1.006 & 105 & 1.003 & 97 & -0.003 & 1 \\
\hline Uganda & 1.004 & 107 & 1.001 & 100 & -0.003 & 1 \\
\hline Chad & 1.003 & 109 & 1 & 105 & -0.003 & 1 \\
\hline Gambia & 1.003 & 109 & 1 & 105 & -0.003 & 1 \\
\hline Turkey & 2.008 & 58 & 2.004 & 57 & -0.004 & 2 \\
\hline Mozambique & 1.012 & 101 & 1.008 & 88 & -0.004 & 1 \\
\hline Central African Rep. & 1.004 & 107 & 1 & 105 & -0.004 & 1 \\
\hline Guatemala & 1.993 & 62 & 1.988 & 71 & -0.005 & 2 \\
\hline Jordan & 1.994 & 61 & 1.986 & 72 & -0.008 & 2 \\
\hline Benin & 1.013 & 98 & 1.004 & 96 & -0.009 & 1 \\
\hline Kenya & 1.01 & 103 & 1.001 & 100 & -0.009 & 1 \\
\hline Niger & 1.009 & 104 & 1 & 105 & -0.009 & 1 \\
\hline Madagascar & 1.011 & 102 & 1 & 105 & -0.011 & 1 \\
\hline Sudan & 1.013 & 98 & 1.001 & 100 & -0.012 & 1 \\
\hline Somalia & 1.013 & 98 & 1 & 105 & -0.013 & 1 \\
\hline Congo Dem Rep. & 1.015 & 96 & 1 & 105 & -0.015 & 1 \\
\hline Papua New Guinea & 2.015 & 57 & 1.999 & 64 & -0.016 & 2 \\
\hline Fiji & 2.017 & 56 & 2 & 60 & -0.017 & 2 \\
\hline Nigeria & 1.018 & 94 & 1.001 & 100 & -0.017 & 1 \\
\hline Colombia & 2.027 & 54 & 2.008 & 54 & -0.019 & 2 \\
\hline Sierra Leone & 1.027 & 92 & 1 & 105 & -0.027 & 1 \\
\hline Algeria & 2.035 & 50 & 2.007 & 55 & -0.028 & 2 \\
\hline Romania & 2.033 & 52 & 2.005 & 56 & -0.028 & 2 \\
\hline Togo & 1.03 & 91 & 1 & 105 & -0.03 & 1 \\
\hline El Salvador & 2.031 & 53 & 2 & 60 & -0.031 & 2 \\
\hline Jamaica & 2.036 & 48 & 1.999 & 64 & -0.037 & 2 \\
\hline Ecuador & 2.035 & 50 & 1.995 & 67 & -0.04 & 2 \\
\hline
\end{tabular}




\begin{tabular}{|l|cccccc|} 
Syria & 1.193 & 83 & 1.153 & 84 & -0.04 & 1 \\
Bolivia & 1.959 & 67 & 1.895 & 75 & -0.064 & 2 \\
Zambia & 1.064 & 89 & 1 & 105 & -0.064 & 1 \\
Mauritania & 1.077 & 88 & 1.007 & 89 & -0.07 & 1 \\
Namibia & 2.089 & 45 & 2.004 & 57 & -0.085 & 2 \\
Senegal & 1.1 & 86 & 1.006 & 92 & -0.094 & 1 \\
Congo Republic of & 1.113 & 85 & 1.006 & 92 & -0.107 & 1 \\
Peru & 2.114 & 44 & 1.995 & 67 & -0.119 & 2 \\
Honduras & 1.503 & 78 & 1.384 & 81 & -0.119 & 2 to 1 \\
Poland & 2.387 & 37 & 2.205 & 38 & -0.182 & 2 \\
Liberia & 1.184 & 84 & 1 & 105 & -0.184 & 1 \\
Russia & 2.861 & 29 & 2.672 & 35 & -0.189 & 3 \\
Mexico & 2.298 & 40 & 2.068 & 45 & -0.23 & 2 \\
Brazil & 2.274 & 41 & 2.031 & 48 & -0.243 & 2 \\
Costa Rica & 2.376 & 38 & 2.124 & 42 & -0.252 & 2 \\
Comoros & 1.283 & 82 & 1.002 & 98 & -0.281 & 1 \\
South Africa & 2.525 & 35 & 2.153 & 41 & -0.372 & 3 to 2 \\
Uruguay & 2.534 & 34 & 2.155 & 40 & -0.379 & 3 to 2 \\
Zimbabwe & 1.968 & 66 & 1.532 & 80 & -0.436 & 2 \\
Cote d'Ivoire & 1.598 & 75 & 1.155 & 83 & -0.443 & 2 to1 \\
Solomon Islands & 1.549 & 77 & 1.036 & 86 & -0.513 & 2 to 1 \\
Nicaragua & 2.523 & 36 & 1.965 & 74 & -0.558 & 3 to 2 \\
Argentina & 2.937 & 23 & 2.371 & 37 & -0.566 & 3 to 2 \\
Ukraine & 2.645 & 32 & 2.012 & 50 & -0.633 & 3 to 2 \\
Afghanistan & 1.651 & 73 & 1 & 105 & -0.651 & 2 to 1 \\
Iran & 2.8 & 31 & 2.012 & 50 & -0.788 & 3 to 2 \\
Venezuela & 2.891 & 27 & 2.01 & 52 & -0.881 & 3 to 2 \\
Iraq & 1.912 & 69 & 1.002 & 98 & -0.91 & 2 to 1 \\
\hline
\end{tabular}

Note: Column 1: Posterior Mean 1976; Column 2: Rank 1976; Column 3: Posterior Mean 2003; Column 4: Rank 2003 Column 5: Change Posterior Mean; Column 6:Group 1976 and 2003 
Julian Weisbrod - 978-3-631-75361-3

Downloaded from PubFactory at 01/11/2019 05:55:15AM

via free access 


\section{Appendix B}


Julian Weisbrod - 978-3-631-75361-3

Downloaded from PubFactory at 01/11/2019 05:55:15AM

via free access 
Table B.1: Regions and Associated Countries

\section{OECD Countries}

Australia, Austria, Belgium, Canada, Denmark, Finland, France, Germany, Greece, Ireland, Italy, Japan, Luxembourg, Netherlands, New Zealand, Norway, Portugal, Spain, Sweden, Switzerland, United Kingdom, United States

East Asia and the Pacific

Cambodia, China, Fiji, Hong Kong, Indonesia, Republic of Korea, Laos, Malaysia, Mongolia, Papua New Guinea, Philippines, Singapore, Taiwan, Thailand

\section{Latin America and the Caribbean}

Argentina, Bahamas, Barbados, Bolivia, Brazil, Chile, Colombia, Costa Rica, Cuba, Dominican Republic, Ecuador, El Salvador, Guatemala, Honduras, Jamaica, Mexico, Nicaragua, Panama, Paraguay, Peru, Puerto Rico, Suriname, Trinidad and Tobago, Uruguay, Venezuela

Middle East and North Africa

Algeria, Egypt, Iran, Iraq, Israel, Jordan, Morocco, Tunisia

Eastern Europe and Central Asia

Hungary, Poland, Romania, Russia, Turkey, Ukraine

South Asia

Bangladesh, India, Nepal, Pakistan, Sri Lanka

Sub-Saharan Africa

Botswana, Burkina Faso, Burundi, Cameroon, Central African Republic, Chad, Democratic Republic of Congo, Republic of Congo, Cote d'Ivoire, Ethiopia, The Gambia, Ghana, Guinea, Guinea-Bissau, Kenya, Lesotho, Madagascar, Malawi, Mali, Mauritania, Mauritius, Mozambique, Namibia, Niger, Nigeria, Senegal, Sierra Leone, South Africa, Sudan, Swaziland, Tanzani, Uganda, Zambia, Zimbabwe 
Figure B.1: Semi-Decade specific Growth Incidence Curves, OECD Countries
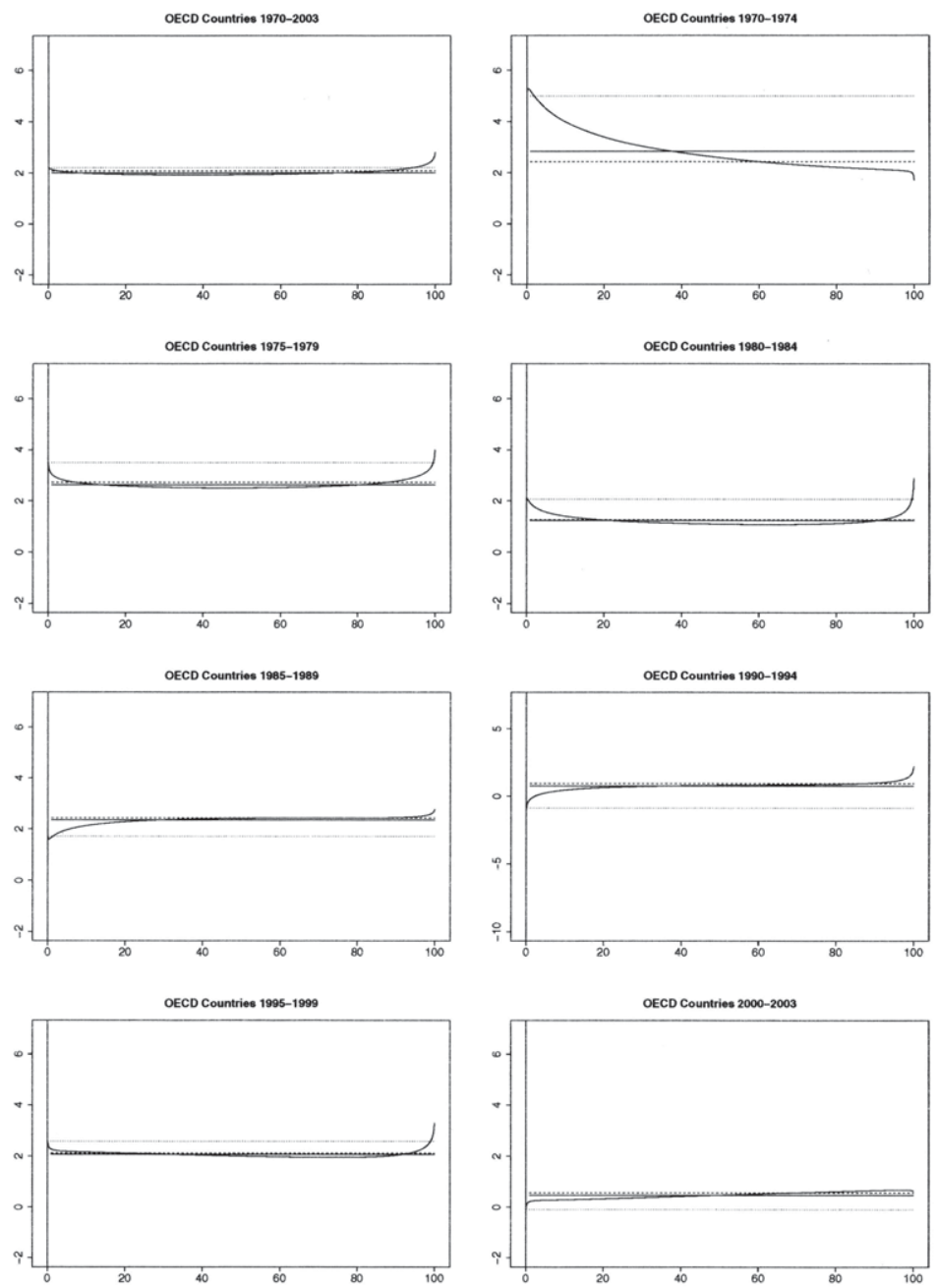

Solid line: Growth Incident Curve, solid vertical line: $\$ 2$ per day Poverty Line, solid horizontal line: Mean of Growth Rates, dashed line: Growth Rate in Mean, dotted line: Pro-poor Growth Rate 
Figure B.2: Semi-Decade specific Growth Incidence Curves, East Asia and the Pacific
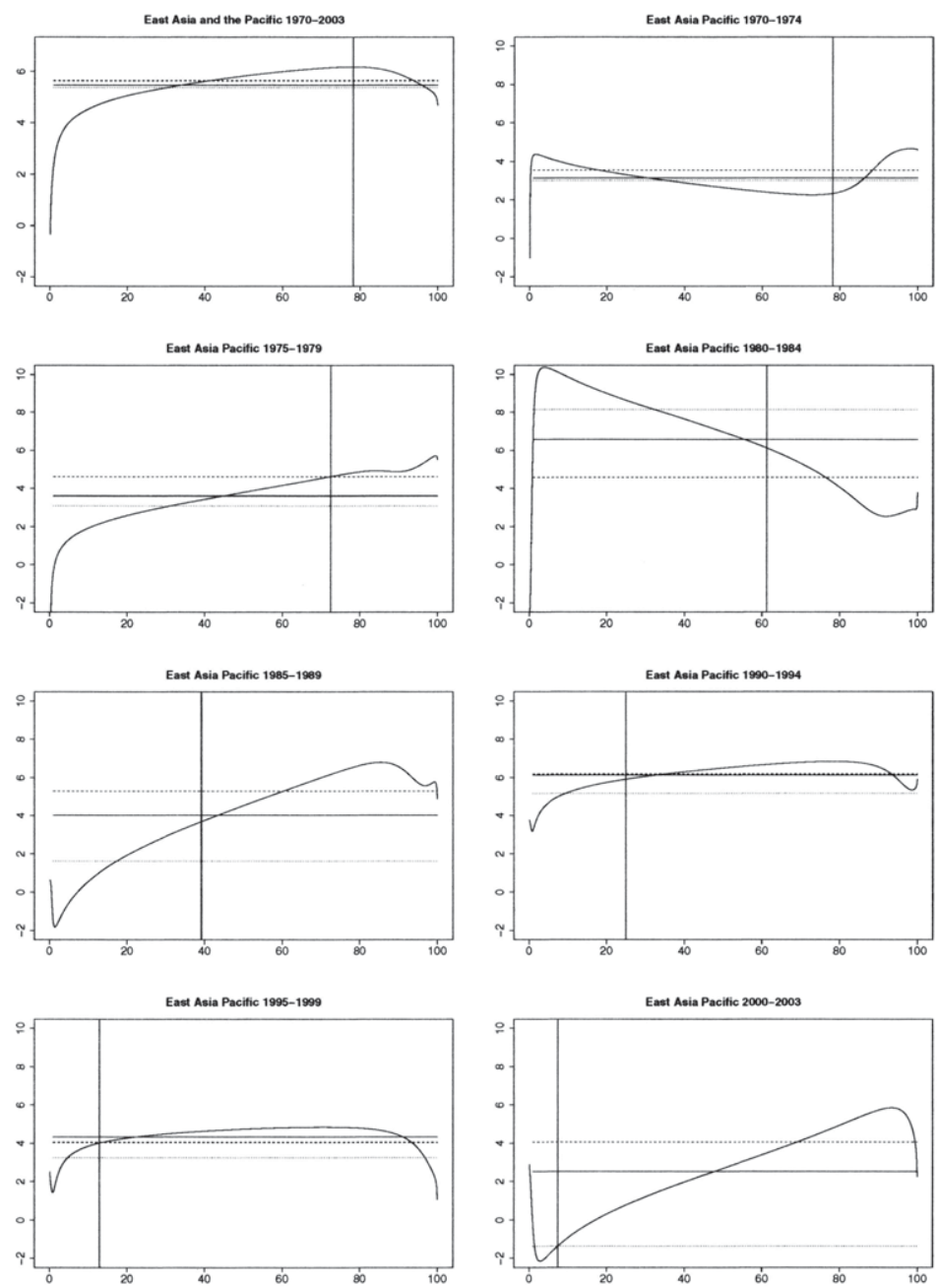

Solid line: Growth Incident Curve, solid vertical line: $\$ 2$ per day Poverty Line, solid horizontal line: Mean of Growth Rates, dashed line: Growth Rate in Mean, dotted line: Pro-poor Growth Rate 
Figure B.3: Semi-Decade specific Growth Incidence Curves, Latin America and the Caribbean
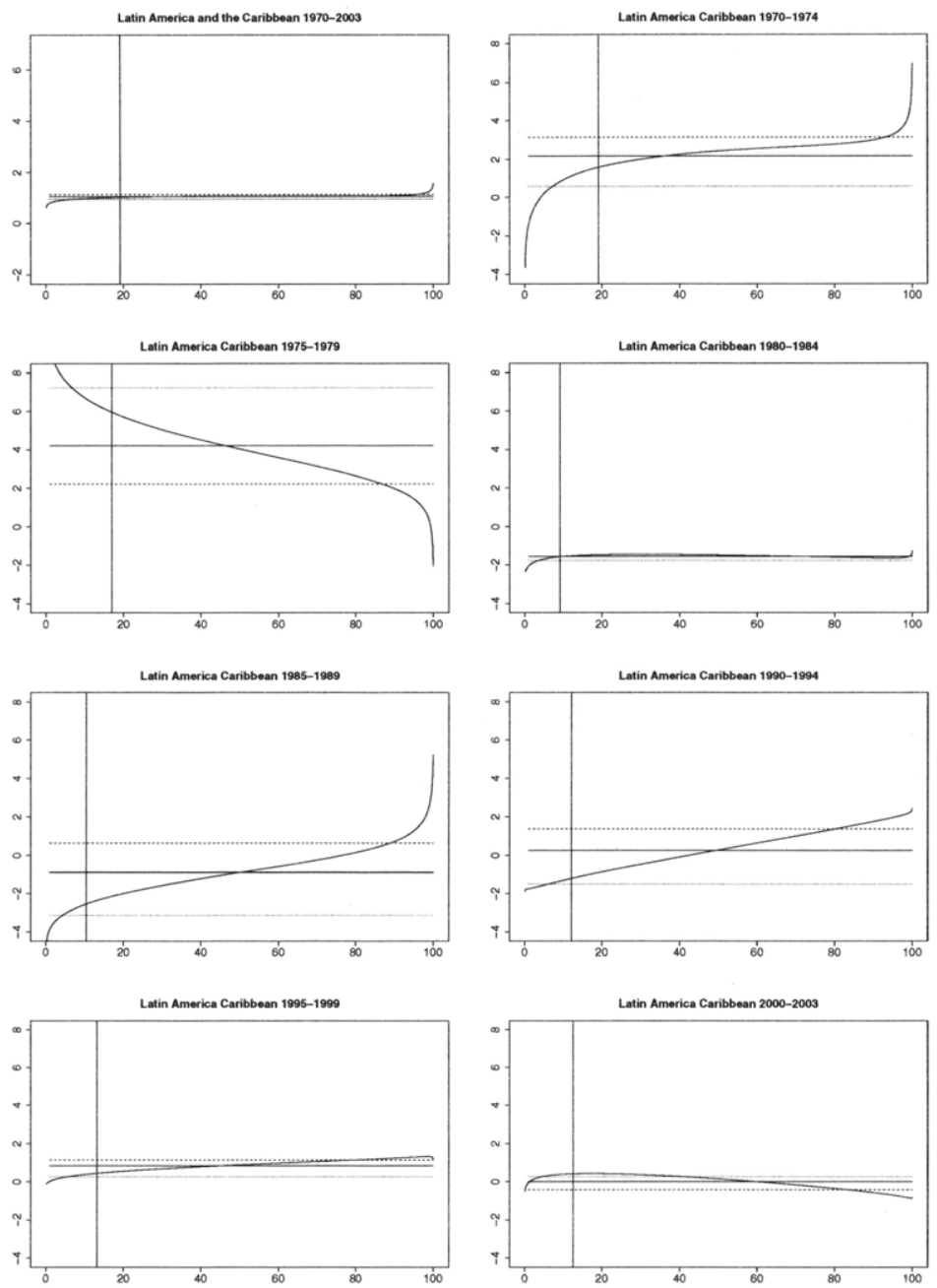

Solid line: Growth Incident Curve, solid vertical line: \$2 per day Poverty Line, solid horizontal line: Mean of Growth Rates, dashed line: Growth Rate in Mean, dotted line: Pro-poor Growth Rate 
Figure B.4: Semi-Decade specific Growth Incidence Curves, Middle East and North Africa
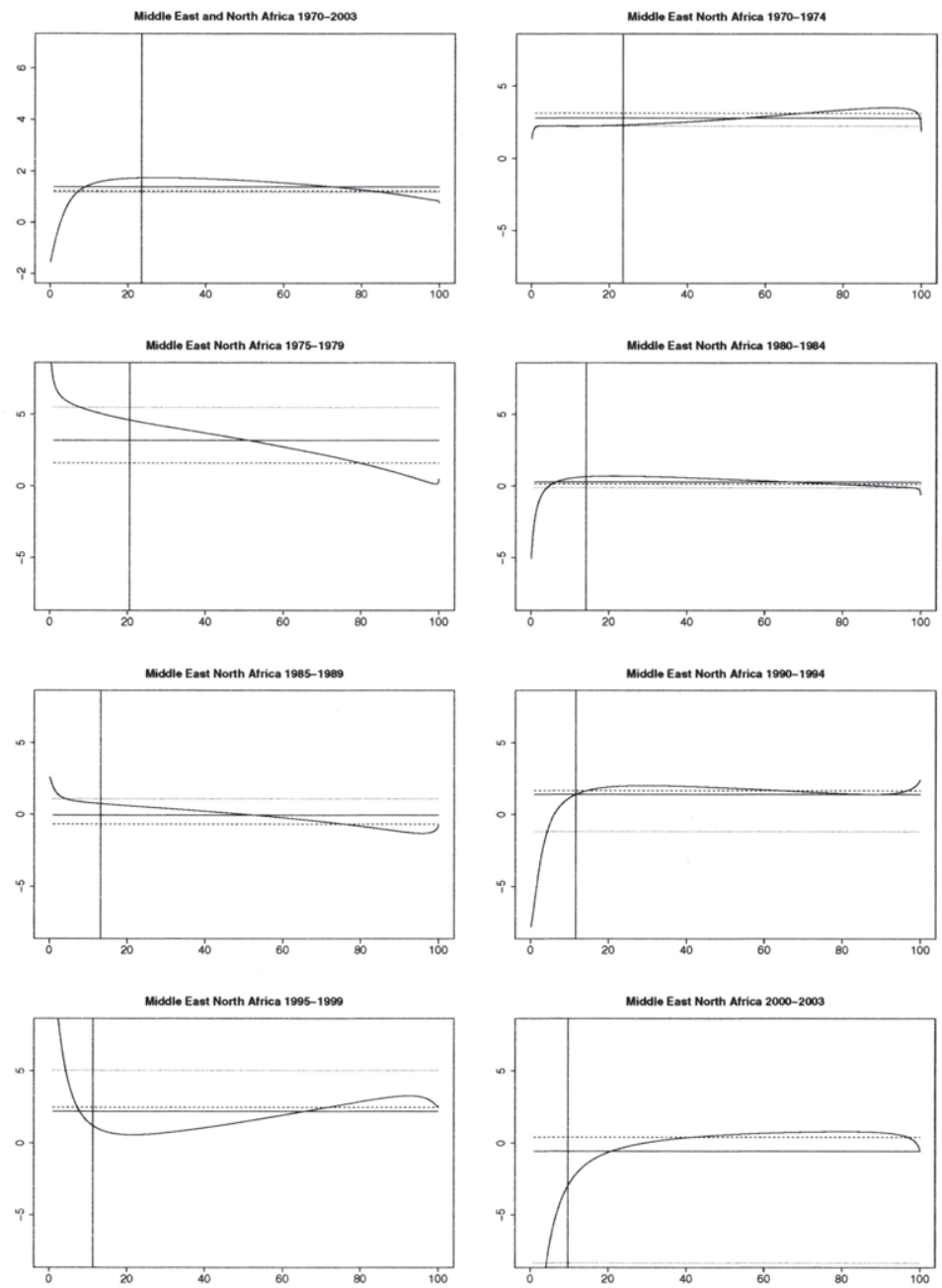

Solid line: Growth Incident Curve, solid vertical line: \$2 per day Poverty Line, solid horizontal line: Mean of Growth Rates, dashed line: Growth Rate in Mean, dotted line: Pro-poor Growth Rate 
Figure B.5: Semi-Decade specific Growth Incidence Curves, Eastern Europe and Central Asia
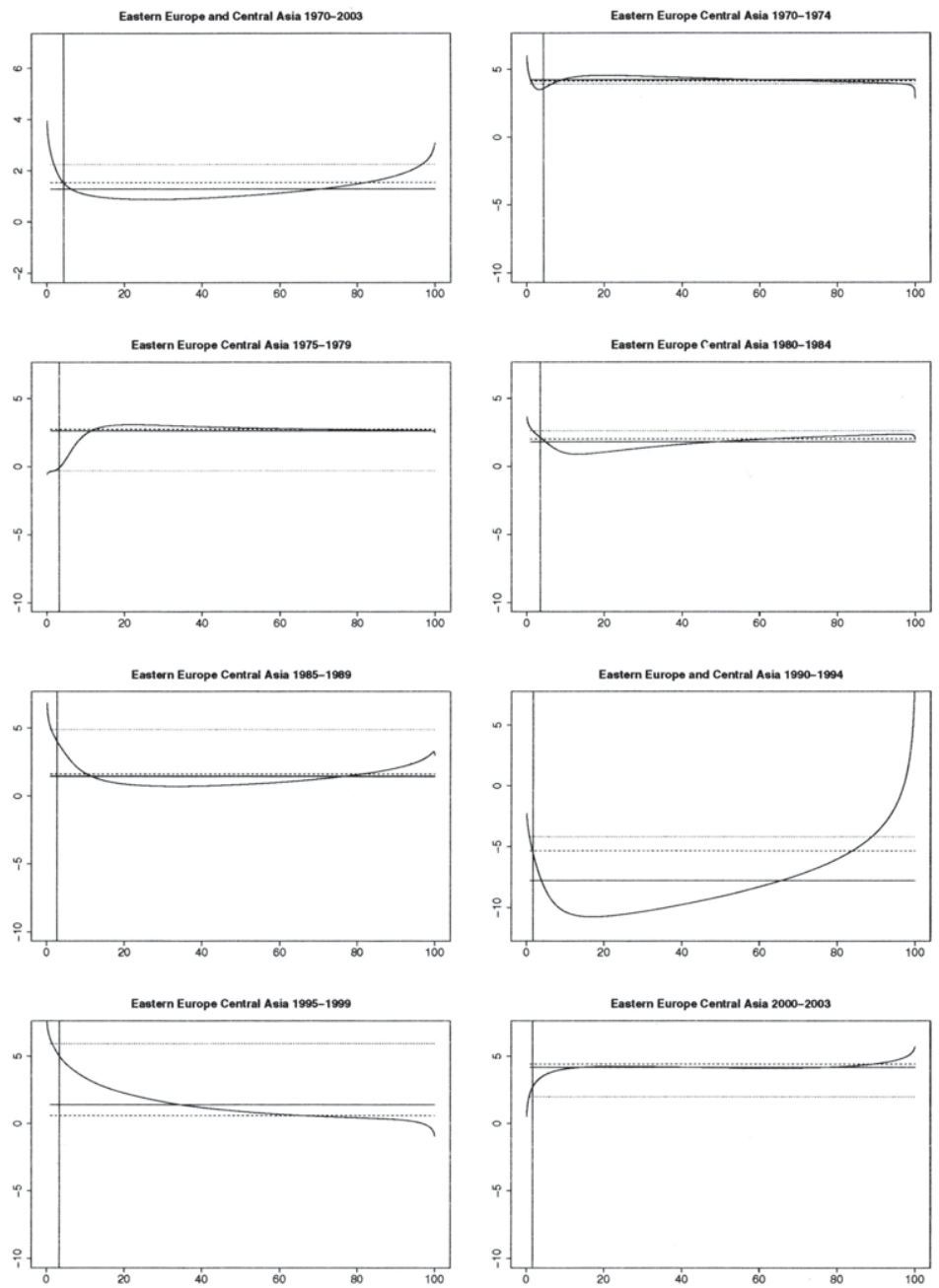

Solid line: Growth Incident Curve, solid vertical line: \$2 per day Poverty Line, solid horizontal line: Mean of Growth Rates, dashed line: Growth Rate in Mean, dotted line: Pro-poor Growth Rate 
Figure B.6: Semi-Decade specific Growth Incidence Curves, South Asia
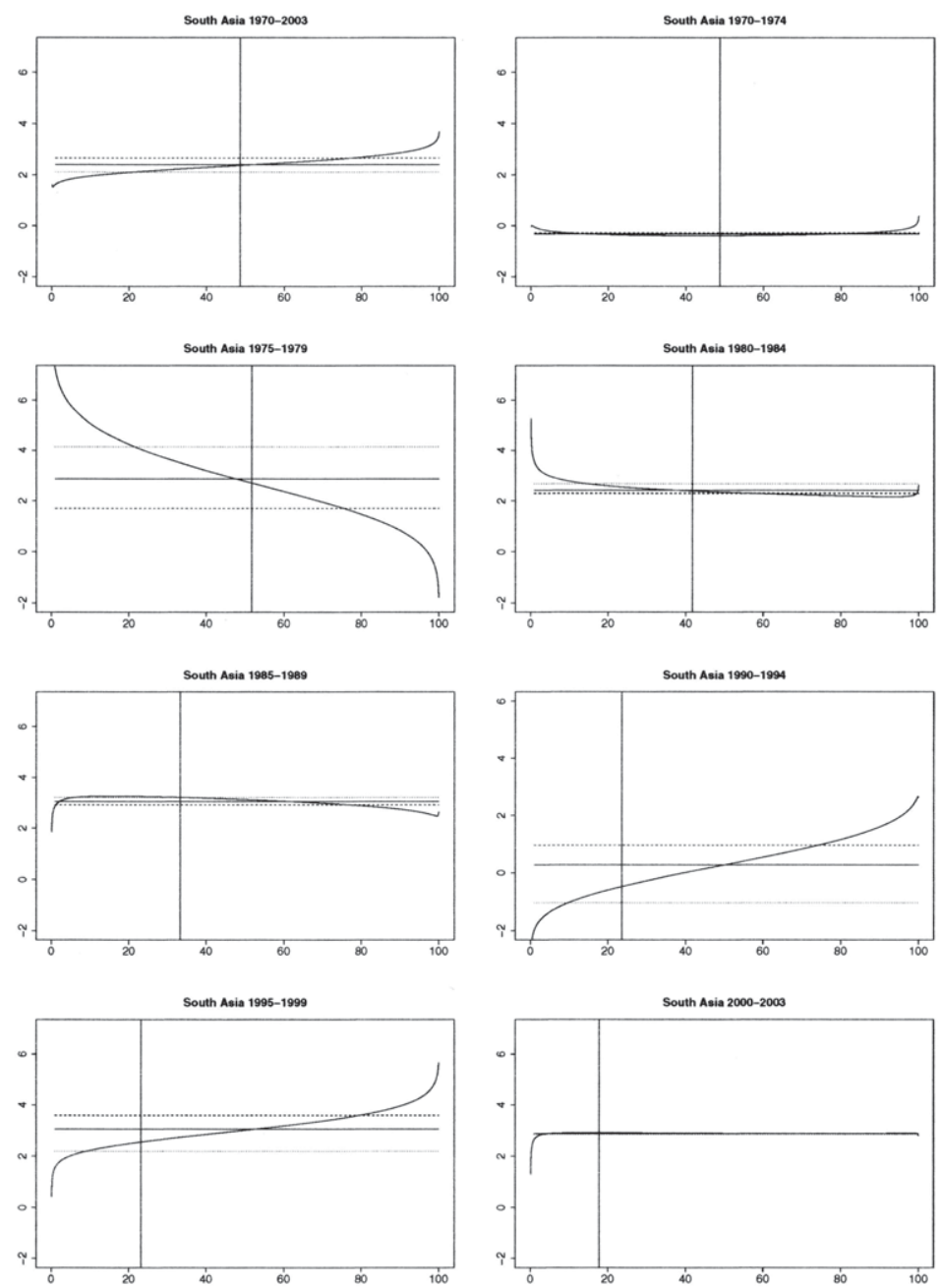

Solid line: Growth Incident Curve, solid vertical line: $\$ 2$ per day Poverty Line, solid horizontal line: Mean of Growth Rates, dashed line: Growth Rate in Mean, dotted line: Pro-poor Growth Rate 
Figure B.7: Semi-Decade specific Growth Incidence Curves, Sub-Saharan Africa
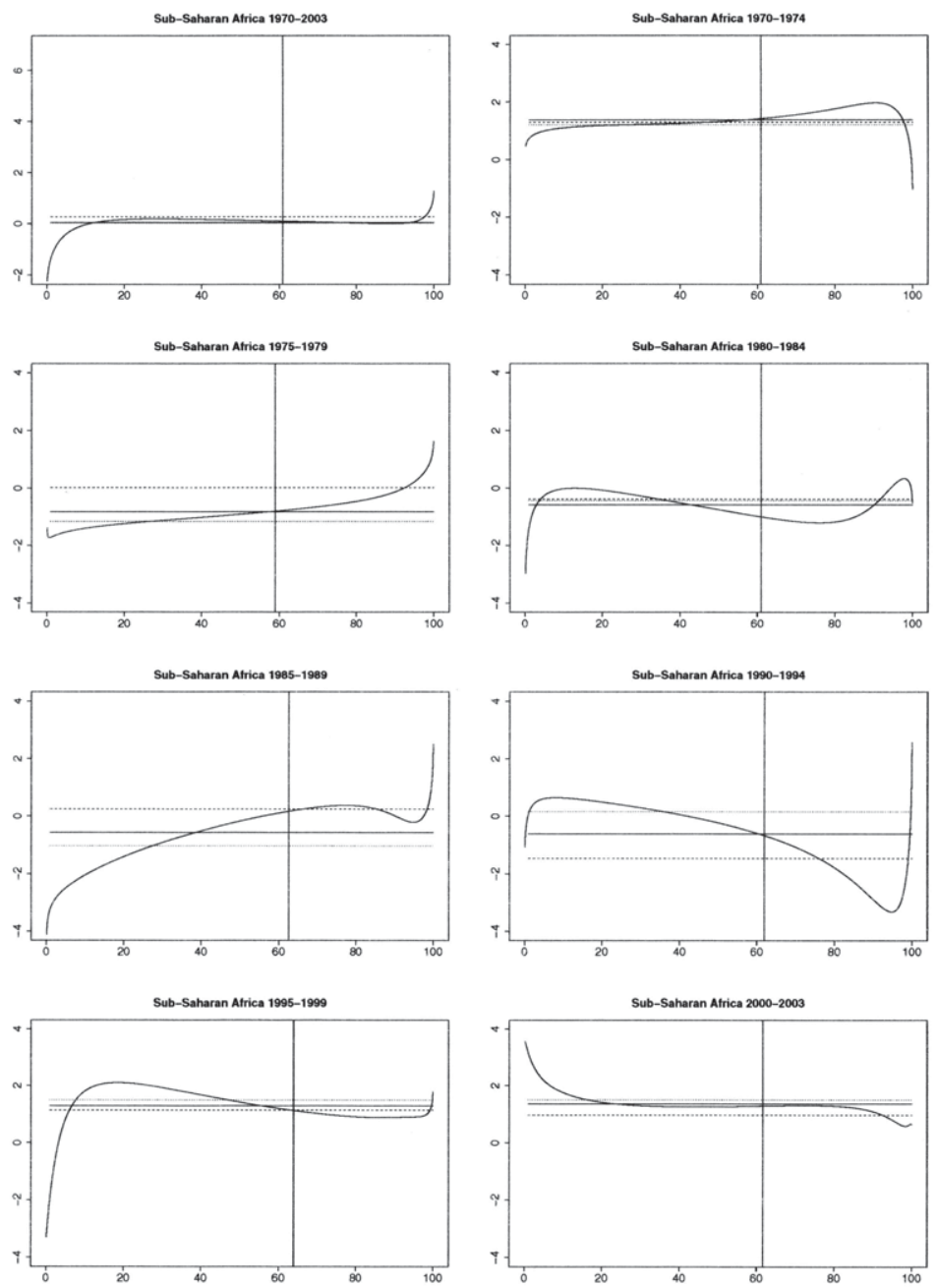

Solid line: Growth Incident Curve, solid vertical line: \$2 per day Poverty Line, solid horizontal line: Mean of Growth Rates, dashed line: Growth Rate in Mean, dotted line: Pro-poor Growth Rate 


\section{Appendix C}


Julian Weisbrod - 978-3-631-75361-3

Downloaded from PubFactory at 01/11/2019 05:55:15AM

via free access 
Table C.1: Unrestricted SUR Model.

\begin{tabular}{|c|c|c|}
\hline & \multicolumn{2}{|c|}{ Growth Rate 1960-1999 } \\
\hline Variable & Coefficient & t-Statistic \\
\hline Dummy for the $1960 \mathrm{~s}$ & -0.267 & -1.15 \\
\hline Dummy for the 1970 s & $-0.396^{* *}$ & $-2.14^{* *}$ \\
\hline Dummy for the 1980 s & -0.167 & -1.45 \\
\hline Dummy for the $1990 \mathrm{~s}$ & 0.103 & -0.65 \\
\hline \multicolumn{3}{|c|}{$1960 \mathrm{~s}$} \\
\hline Africa & $-0.019^{* *}$ & $-1.94^{* *}$ \\
\hline Latin America & $-0.024^{*}$ & $-3.68^{*}$ \\
\hline Log of initial income & 0.091 & 1.54 \\
\hline Log of initial income squared & -0.007 & -1.83 \\
\hline Log of schooling & 0.013 & 1.50 \\
\hline Assassinations & 46.595 & 0.94 \\
\hline Financial Depth & 0.0001 & 0.01 \\
\hline Black Market Premium & -0.0187 & -1.34 \\
\hline Fiscal surplus/GDP & 0.084 & 0.78 \\
\hline Log of telephones per people & 0.011 & 0.99 \\
\hline Ethnic & 0.000 & 0.05 \\
\hline Adj R2 & 0.29 & \\
\hline Observations & 38 & \\
\hline \multicolumn{3}{|c|}{1970 s } \\
\hline Africa & -0.005 & -0.80 \\
\hline Latin America & $-0.014^{* *}$ & $-2.23^{* *}$ \\
\hline Log of initial income & $0.138^{*}$ & $2.92^{*}$ \\
\hline Log of initial income squared & $-0.011^{*}$ & $-3.65^{*}$ \\
\hline Log of schooling & 0.002 & 0.34 \\
\hline Assassinations & -22.564 & -1.52 \\
\hline Financial Depth & 0.009 & 0.92 \\
\hline Black Market Premium & $-0.028^{*}$ & $-3.06^{*}$ \\
\hline Fiscal surplus/GDP & $0.197^{*}$ & $3.19^{*}$ \\
\hline Log of telephones per people & $0.038^{*}$ & $4.25^{*}$ \\
\hline Ethnic & 0.002 & 0.21 \\
\hline Adj R2 & 0.51 & \\
\hline Observations & 67 & \\
\hline \multicolumn{3}{|c|}{$1980 \mathrm{~s}$} \\
\hline Africa & $-0.012^{* *}$ & $-1.98^{* *}$ \\
\hline Latin America & $-0.019^{*}$ & $-3.76^{*}$ \\
\hline Log of initial income & $0.061^{* *}$ & $2.09^{* *}$ \\
\hline Log of initial income squared & $-0.005^{*}$ & $-2.75^{*}$ \\
\hline Log of schooling & 0.004 & 0.61 \\
\hline Assassinations & $-21.280^{* *}$ & $-2.19^{* *}$ \\
\hline Financial Depth & $0.016^{* *}$ & $2.02^{* *}$ \\
\hline Black Market Premium & $-0.009^{* * *}$ & $-1.82^{* * *}$ \\
\hline Fiscal surplus/GDP & $0.121^{*}$ & $3.46^{*}$ \\
\hline Log of telephones per people & $0.024^{*}$ & $2.63^{*}$ \\
\hline Ethnic & -0.002 & -0.22 \\
\hline Adj R2 & 0.48 & \\
\hline Observations & 74 & \\
\hline
\end{tabular}




\begin{tabular}{|l|ll|}
\hline \multicolumn{3}{|c|}{$1990 \mathrm{~s}$} \\
Africa & $-0.01^{*}$ & $-2.63^{*}$ \\
Latin America & -0.008 & -1.34 \\
Log of initial income & -0.005 & -0.13 \\
Log of initial income squared & -0.001 & -0.42 \\
Log of schooling & 0.005 & 0.58 \\
Assassinations & $-72.156^{* *}$ & $-1.99^{* *}$ \\
Financial Depth & 0.008 & 0.94 \\
Black Market Premium & $-0.020^{* *}$ & $-2.28^{* *}$ \\
Fiscal surplus/GDP & $0.165^{*}$ & $2.58^{*}$ \\
Log of telephones per people & 0.015 & 1.25 \\
Ethnic & $-\mathbf{0 . 0 1 8 * *}$ & $-\mathbf{1 . 9 3 * *}$ \\
\hline Adj R2 & 0.24 & \\
Observations & 78 \\
\hline \hline No. Obs. & 257 \\
\hline \hline
\end{tabular}

Source: Own Calculations. ${ }^{*} 0.1,{ }^{* *} 0.05,{ }^{* * *} 0.01$ Significance level 
Table C.2: Unrestricted SUR Model including Kaufmann, Kraay and Zoido-Lobaton Index.

\begin{tabular}{|c|c|c|}
\hline & \multicolumn{2}{|c|}{ Growth Rate $1960-1999$} \\
\hline Variable & Coefficient & t-Statistic \\
\hline Dummy for the $1960 \mathrm{~s}$ & -0.325 & -1.44 \\
\hline Dummy for the 1970 s & $-0.437^{* *}$ & $-2.45^{* *}$ \\
\hline Dummy for the 1980 s & $-0.277^{* *}$ & $-2.37^{* *}$ \\
\hline Dummy for the $1990 \mathrm{~s}$ & 0.135 & -0.71 \\
\hline \multicolumn{3}{|l|}{$1960 s$} \\
\hline Africa & $-0.018^{* * *}$ & $-1.88^{* * *}$ \\
\hline Latin America & $-0.015^{* *}$ & $-2.17^{* *}$ \\
\hline Log of initial income & $0.116^{* *}$ & $2.01^{* *}$ \\
\hline Log of initial income squared & $-0.010^{*}$ & $-2.59^{*}$ \\
\hline Log of schooling & 0.011 & 1.40 \\
\hline Assassinations & 56.408 & 1.27 \\
\hline Financial Depth & $0.026^{* *}$ & $2.13^{* *}$ \\
\hline Black Market Premium & -0.016 & -0.92 \\
\hline Fiscal surplus/GDP & 0.009 & 0.08 \\
\hline Log of telephones per people & $0.021^{* * *}$ & $1.81^{* * *}$ \\
\hline Ethnic & 0.006 & 0.58 \\
\hline Kaufmann, Kraay and Zoido-Lobaton- Index & 0.007 & 1.34 \\
\hline Adj R2 & 0.38 & \\
\hline Observations & 36 & \\
\hline \multicolumn{3}{|l|}{$1970 \mathrm{~s}$} \\
\hline Africa & -0.011 & -1.44 \\
\hline Latin America & $-0.016^{*}$ & $-2.81^{*}$ \\
\hline Log of initial income & $0.143^{*}$ & $3.14^{*}$ \\
\hline Log of initial income squared & $-0.011^{*}$ & $-3.73^{*}$ \\
\hline Log of schooling & 0.004 & 0.61 \\
\hline Assassinations & -18.421 & -1.46 \\
\hline Financial Depth & 0.003 & 0.31 \\
\hline Black Market Premium & $-0.035^{*}$ & $-3.95^{*}$ \\
\hline Fiscal surplus/GDP & $0.174^{*}$ & $3.04^{*}$ \\
\hline Log of telephones per people & $0.031^{*}$ & $3.67^{*}$ \\
\hline Ethnic & 0.009 & 0.84 \\
\hline Kaufmann, Kraay and Zoido-Lobaton- Index & -0.002 & -0.30 \\
\hline Adj R2 & 0.52 & \\
\hline Observations & 57 & \\
\hline \multicolumn{3}{|l|}{$1980 \mathrm{~s}$} \\
\hline Africa & $-0.019 *$ & $-2.92^{*}$ \\
\hline Latin America & $-0.028^{*}$ & $-5.30^{*}$ \\
\hline Log of initial income & $0.088^{*}$ & $2.94^{*}$ \\
\hline Log of initial income squared & $-0.006^{*}$ & $-3.32^{*}$ \\
\hline Log of schooling & -0.004 & -0.51 \\
\hline Assassinations & $-19.084^{* *}$ & $-2.32^{* *}$ \\
\hline Financial Depth & 0.007 & 1.013 \\
\hline Black Market Premium & $-0.008 * * *$ & $-1.68^{* * *}$ \\
\hline Fiscal surplus/GDP & $0.099^{*}$ & $2.90^{*}$ \\
\hline Log of telephones per people & $0.017^{* *}$ & $2.02^{* *}$ \\
\hline Ethnic & -0.008 & -0.84 \\
\hline
\end{tabular}




\begin{tabular}{|l|ll|} 
Kaufmann, Kraay and Zoido-Lobaton- Index & 0.004 & 0.77 \\
\hline Adj R2 & 0.56 \\
Observations & 63 & \\
\hline & & \\
Africa & $-0.017^{* *}$ & $-1.99^{* *}$ \\
Latin America & -0.010 & -1.34 \\
Log of initial income & 0.054 & 1.18 \\
Log of initial income squared & $-0.004^{* * *}$ & $-1.68^{* * *}$ \\
Log of schooling & 0.013 & 1.24 \\
Assassinations & -52.058 & -1.42 \\
Financial Depth & 0.002 & 0.28 \\
Black Market Premium & -0.018 & -1.34 \\
Fiscal surplus/GDP & $0.120^{* * *}$ & $1.68^{* * *}$ \\
Log of telephones per people & 0.004 & 0.30 \\
Ethnic & -0.016 & -1.40 \\
Kaufmann, Kraay and Zoido-Lobaton- Index & $0.011^{* * *}$ & $1.73^{* * *}$ \\
\hline Adj R2 & 0.22 \\
Observations & 65 \\
\hline \hline No. Obs. & 257 \\
\hline \hline
\end{tabular}

Source: Own Calculations. ${ }^{*} 0.1,{ }^{* *} 0.05,{ }^{* * *} 0.01$ Significance level 
Table C.3: Immigration Country Definition

\begin{tabular}{|l|}
\hline Countries Included \\
\hline ARGENTINA \\
AUSTRALIA \\
BAHAMAS \\
BOLIVIA \\
BRAZIL \\
BARBADOS \\
BRUNEI \\
CANADA \\
CHILE \\
COLOMBIA \\
COSTA RICA \\
DOMINICA \\
DOMINICAN REPUBLIC \\
ECUADOR \\
FIJI \\
GRENADA \\
GUATEMALA \\
GUYANA \\
HAITI \\
HONDURAS \\
ISRAEL \\
MEXICO \\
MALAYSIA \\
NAMIBIA \\
NICARAGUA \\
PANAMA \\
PERU \\
PUERTO RICO \\
PARAGUAY \\
SINGAPORE \\
EL SALVADOR \\
SAO TOME AND PRINCIPE \\
SURINAME \\
THAILAND \\
TRINIDAD AND TOBAGO \\
URUGUAY \\
UNITED STATES \\
VENEZUELA \\
SOUTH AFRICA \\
\end{tabular}


Table C.4: Comparison Alesina et al. with our Results

\begin{tabular}{|c|c|c|}
\hline & \multicolumn{2}{|c|}{ Growth Rate $1960-1989$} \\
\hline Variable & 1 & 2 \\
\hline Dummy for the $1960 \mathrm{~s}$ & $\begin{array}{l}-0.233^{* * *} \\
(-2.34)\end{array}$ & $\begin{array}{l}-0.166^{*} \\
(-1.73)\end{array}$ \\
\hline Dummy for the 1970 s & $\begin{array}{l}-0.227^{* * *} \\
(-2.28)\end{array}$ & $\begin{array}{l}-0.163^{*} \\
(-1.70)\end{array}$ \\
\hline Dummy for the 1980 s & $\begin{array}{l}-0.243^{* * *} \\
(-2.45)\end{array}$ & $\begin{array}{l}-0.179^{*} \\
(-1.88)\end{array}$ \\
\hline Dummy for Sub-Saharan Africa & $\begin{array}{l}-0.017^{* * *} \\
(-3.11)\end{array}$ & $\begin{array}{l}-0.013^{* * *} \\
(-2.75)\end{array}$ \\
\hline Dummy for Latin America \& Caribbean & $\begin{array}{l}-0.015^{* * *} \\
(-4.14)\end{array}$ & $\begin{array}{l}-0.017^{* * *} \\
(-4.46)\end{array}$ \\
\hline Log of initial income & $\begin{array}{l}0.081^{* * *} \\
(3.23)\end{array}$ & $\begin{array}{l}0.067^{* * *} \\
(2.76)\end{array}$ \\
\hline Log of initial income squared & $\begin{array}{l}-0.007^{* * *} \\
(-3.98)\end{array}$ & $\begin{array}{l}-0.006^{* * *} \\
(-3.66)\end{array}$ \\
\hline Log of schooling & $\begin{array}{l}\text { 0.009* } \\
(1.85)\end{array}$ & $\begin{array}{l}0.005 \\
(0.96)\end{array}$ \\
\hline Assassinations & $\begin{array}{l}-23.705^{* * *} \\
(-2.58)\end{array}$ & $\begin{array}{l}-17.985^{*} \\
(-1.95)\end{array}$ \\
\hline Financial Depth & $\begin{array}{l}0.013^{* *} \\
(2.12)\end{array}$ & $\begin{array}{l}0.011^{* *} \\
(1.99)\end{array}$ \\
\hline Black Market Premium & $\begin{array}{l}-0.018^{* * *} \\
(-4.10)\end{array}$ & $\begin{array}{l}-0.015^{* * *} \\
(-3.45)\end{array}$ \\
\hline Fiscal surplus/GDP & $\begin{array}{l}0.165^{* * *} \\
(4.45)\end{array}$ & $\begin{array}{l}0.11^{* * *} \\
(3.64)\end{array}$ \\
\hline Log of telephones per worker & $\begin{array}{l}0.006^{* * *} \\
(2.41)\end{array}$ & \\
\hline Log of telephones per people & & $\begin{array}{l}0.022^{* * *} \\
(3.64)\end{array}$ \\
\hline Ethnic & $\begin{array}{c}-0.005 \\
(-0.75) \\
\end{array}$ & $\begin{array}{l}-0.004 \\
(-0.54)\end{array}$ \\
\hline $\begin{array}{l}\text { No. Obs. } \\
\text { Adj R2 }\end{array}$ & $\begin{array}{l}175 \\
0,56 \\
\end{array}$ & $\begin{array}{l}179 \\
0,57 \\
\end{array}$ \\
\hline
\end{tabular}

Source: Own Calculations. Note: t-stats in parentheses ${ }^{*} 0.1,{ }^{* *} 0.05,{ }^{* * *} 0.01$ Significance level. 
Table C.5: Indirect Effect of Fractionalisation on Good Governance.

\begin{tabular}{|c|c|c|}
\hline & \multicolumn{2}{|c|}{ Dependent Variable: KKZ- Index } \\
\hline Variable & Coefficient & t-Statistic \\
\hline Dummy for the $1960 \mathrm{~s}$ & $-1,153^{* * *}$ & $-3,60$ \\
\hline Dummy for the $1970 \mathrm{~s}$ & $-1,292^{* * *}$ & $-3,95$ \\
\hline Dummy for the $1980 \mathrm{~s}$ & $-1,467^{* * *}$ & $-4,44$ \\
\hline Dummy for the $1990 \mathrm{~s}$ & $-1,673^{* * *}$ & $-4,89$ \\
\hline Africa & 0,147 & 1,18 \\
\hline Latin America & $-0,323^{* * *}$ & $-3,34$ \\
\hline Log of initial income & $0,242^{* * *}$ & 6,70 \\
\hline Log of schooling & $0,279^{* * *}$ & 4,19 \\
\hline Dependency Ratio & $-0,309^{*}$ & $-1,92$ \\
\hline \multicolumn{3}{|c|}{$1960 \mathrm{~s}$} \\
\hline Ethnic & $-1,071^{* * *}$ & $-5,58$ \\
\hline Adj R2 & \multirow{2}{*}{\multicolumn{2}{|c|}{$\begin{array}{l}0,63 \\
69\end{array}$}} \\
\hline Observations & & \\
\hline \multicolumn{3}{|c|}{$1970 \mathrm{~s}$} \\
\hline Ethnic & $-1,028 * * *$ & $-5,65$ \\
\hline Adj R2 & \multicolumn{2}{|l|}{0,67} \\
\hline Observations & \multicolumn{2}{|l|}{71} \\
\hline \multicolumn{3}{|c|}{$1980 \mathrm{~s}$} \\
\hline Ethnic & $-0,929 * * *$ & $-5,07$ \\
\hline Adj R2 & \multicolumn{2}{|l|}{0,66} \\
\hline Observations & \multicolumn{2}{|l|}{72} \\
\hline \multicolumn{3}{|c|}{$1990 \mathrm{~s}$} \\
\hline Ethnic & $-0,802^{* * *}$ & $-4,06$ \\
\hline Adj R2 & \multicolumn{2}{|l|}{0,63} \\
\hline Observations & \multicolumn{2}{|l|}{74} \\
\hline No. Obs. & \multicolumn{2}{|l|}{286} \\
\hline
\end{tabular}

Source: Own Calculations. ${ }^{*} 0.1,{ }^{* *} 0.05,{ }^{* * *} 0.01$ Significance level 
Julian Weisbrod - 978-3-631-75361-3

Downloaded from PubFactory at 01/11/2019 05:55:15AM

via free access 
Appendix D

Julian Weisbrod - 978-3-631-75361-3

Downloaded from PubFactory at 01/11/2019 05:55:15AM

via free access 
Julian Weisbrod - 978-3-631-75361-3

Downloaded from PubFactory at 01/11/2019 05:55:15AM

via free access 
Table D.1: True Rural-Urban Migration, 1990-1995

\begin{tabular}{|ll|lll|}
\hline & & \multicolumn{3}{|c|}{1995} \\
& & Rural & Urban & Total \\
\hline 1990 & Rural & $122,037,729$ & $3,570,511$ & $125,608,240$ \\
& & 97.16 & 2.84 & 100 \\
& & 98.53 & 5.13 & 64.91 \\
& & & \\
& Urban & $1,823,701$ & $66,089,601$ & $67,913,302$ \\
& 2.69 & 97.31 & 100 \\
& 1.47 & 94.87 & 35.09 \\
& & & \\
& Total & $123,861,430$ & $69,660,112$ & $193,521,542$ \\
& 64 & 36 & 100 \\
& 100 & 100 & 100 \\
\hline
\end{tabular}

Source: Supas (1995)

Table D.2: Employment in Agriculture and Non Agriculture.

\begin{tabular}{|l|cc|cc|cc|}
\hline & \multicolumn{2}{|c|}{1982} & \multicolumn{2}{c|}{1993} & \multicolumn{2}{c|}{2002} \\
\hline \multirow{3}{*}{ Agriculture } & N $(000)$ & Percent & N (000) & Percent & N (000) & Percent \\
Non Agriculture & 30.487 & 54.24 & 39.137 & 49.88 & 39.035 & 44.92 \\
Rural & 25.724 & 45.76 & 39.329 & 50.12 & 47.874 & 55.08 \\
Urban & 15.939 & 28.36 & 18.992 & 24.2 & 16.785 & 19.31 \\
\hline All sector & 9.785 & 17.41 & 20.337 & 25.92 & 31.088 & 35.77 \\
\hline
\end{tabular}

Source: Susenas, 1982, 1993, 2002 Note: Excludes Aceh, Maluku, North Maluku and Papua. Employment is defined as self employed without help, self employed with help of householders/temporary workers, self employed with help of regular workers, employees and family workers with age 10 years and over (definition until 1997). Definition of employment since 1998 is the same as above, but persons 15 years and above, rural classification status of 1993 used throughout. 
Figure D.1: Changes in Employment Share, 1993 to 2002

Urban

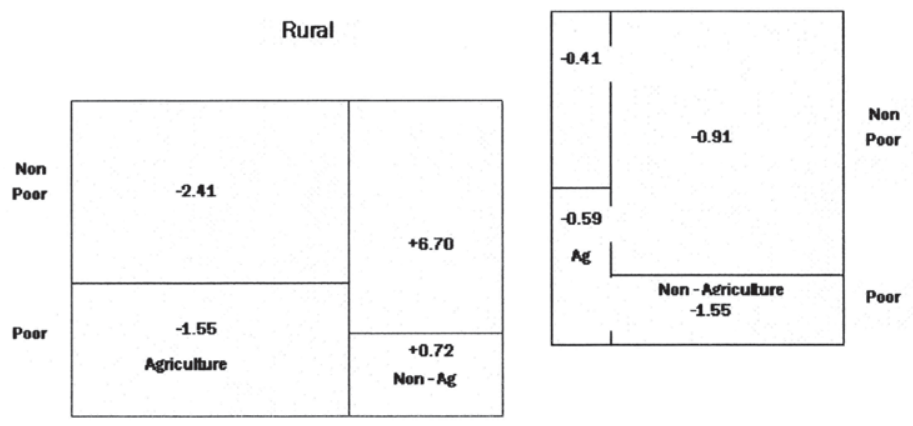

Note: The size of each rectangle is about proportionate to the numbers of workers employed in each category in 1993 . There were 78.5 million workers employed in 1993 and 86.9 million in 2002. Source: Susenas 1993 and 2002. 
Table D.3: The Determinants of Log Real Income in 1993 and 2000

\begin{tabular}{|c|c|c|c|c|}
\hline & \multicolumn{2}{|c|}{1993} & \multicolumn{2}{|c|}{2000} \\
\hline Age & $\begin{array}{l}0.096 \\
(5.78)^{* *}\end{array}$ & $\begin{array}{l}0.092 \\
(5.44)^{* *}\end{array}$ & $\begin{array}{l}0.103 \\
(5.58)^{* *}\end{array}$ & $\begin{array}{l}0.098 \\
(5.28)^{* *}\end{array}$ \\
\hline Age squared & $\begin{array}{l}-0.001 \\
(5.47)^{* *}\end{array}$ & $\begin{array}{l}-0.001 \\
(5.22)^{* *}\end{array}$ & $\begin{array}{l}-0.001 \\
(5.85)^{* *}\end{array}$ & $\begin{array}{l}-0.001 \\
(5.61)^{* *}\end{array}$ \\
\hline Sex & $\begin{array}{l}0.433 \\
(11.14)^{* *}\end{array}$ & $\begin{array}{l}0.44 \\
(10.83)^{* *}\end{array}$ & $\begin{array}{l}0.596 \\
(15.58)^{* *}\end{array}$ & $\begin{array}{l}0.607 \\
(15.22)^{* *}\end{array}$ \\
\hline Working hours per month & $\begin{array}{l}0.002 \\
(12.21)^{* *}\end{array}$ & $\begin{array}{l}0.002 \\
(12.16)^{* *}\end{array}$ & $\begin{array}{l}0.001 \\
(6.70)^{* *}\end{array}$ & $\begin{array}{l}0.001 \\
(6.87)^{* *}\end{array}$ \\
\hline Wage income dummy & $\begin{array}{l}0.145 \\
(4.13)^{* *}\end{array}$ & $\begin{array}{l}0.137 \\
(3.50)^{* *}\end{array}$ & $\begin{array}{l}-0.024 \\
(0.67)\end{array}$ & $\begin{array}{l}-0.05 \\
(1.29)\end{array}$ \\
\hline Years of schooling & $\begin{array}{l}0.087 \\
(20.27)^{* *}\end{array}$ & $\begin{array}{l}0.082 \\
(17.64)^{* *}\end{array}$ & $\begin{array}{l}0.103 \\
(25.71)^{* *}\end{array}$ & $\begin{array}{l}0.097 \\
(22.13)^{* *}\end{array}$ \\
\hline Household size & $\begin{array}{l}0.073 \\
(4.86)^{* *}\end{array}$ & $\begin{array}{l}0.074 \\
(4.94)^{* *}\end{array}$ & $\begin{array}{l}0.058 \\
(4.52)^{* *}\end{array}$ & $\begin{array}{l}0.057 \\
(4.50)^{* *}\end{array}$ \\
\hline Number of Children below 5 & $\begin{array}{l}-0.094 \\
(3.70)^{* *}\end{array}$ & $\begin{array}{l}-0.094 \\
(3.71)^{* *}\end{array}$ & $\begin{array}{l}-0.064 \\
(2.25)^{*}\end{array}$ & $\begin{array}{l}-0.063 \\
(2.20)^{*}\end{array}$ \\
\hline Number of Children below 15 & $\begin{array}{l}-0.049 \\
(2.66)^{* *}\end{array}$ & $\begin{array}{l}-0.048 \\
(2.59)^{* *}\end{array}$ & $\begin{array}{l}-0.037 \\
(2.09)^{*}\end{array}$ & $\begin{array}{l}-0.036 \\
(2.01)^{*}\end{array}$ \\
\hline Number of Men in hh & $\begin{array}{l}-0.043 \\
(2.29)^{*}\end{array}$ & $\begin{array}{l}-0.045 \\
(2.39)^{*}\end{array}$ & $\begin{array}{l}-0.038 \\
(2.09)^{*}\end{array}$ & $\begin{array}{l}-0.036 \\
(1.99)^{*}\end{array}$ \\
\hline Urban Dummy & $\begin{array}{l}0.248 \\
(7.02)^{* *}\end{array}$ & $\begin{array}{l}0.251 \\
(7.14)^{* *}\end{array}$ & $\begin{array}{l}0.055 \\
(1.49)\end{array}$ & $\begin{array}{l}0.068 \\
(1.82)\end{array}$ \\
\hline North Sumatra & $\begin{array}{l}-0.204 \\
(2.79)^{* *}\end{array}$ & $\begin{array}{l}-0.198 \\
(2.69)^{* *}\end{array}$ & $\begin{array}{l}-0.124 \\
(1.67)\end{array}$ & $\begin{array}{l}-0.102 \\
(1.36)\end{array}$ \\
\hline West Sumatra & $\begin{array}{l}-0.236 \\
(3.05)^{* *}\end{array}$ & $\begin{array}{l}-0.24 \\
(3.05)^{* *}\end{array}$ & $\begin{array}{l}-0.26 \\
(2.69)^{* *}\end{array}$ & $\begin{array}{l}-0.259 \\
(2.67)^{* *}\end{array}$ \\
\hline South Sumatra & $\begin{array}{l}-0.401 \\
(5.00)^{* *}\end{array}$ & $\begin{array}{l}-0.414 \\
(5.11)^{* *}\end{array}$ & $\begin{array}{l}-0.189 \\
(2.18)^{*}\end{array}$ & $\begin{array}{l}-0.184 \\
(2.09)^{*}\end{array}$ \\
\hline Lampung & $\begin{array}{l}-0.542 \\
(6.20)^{* *}\end{array}$ & $\begin{array}{l}-0.538 \\
(6.12)^{* *}\end{array}$ & $\begin{array}{l}-0.305 \\
(3.33)^{* *}\end{array}$ & $\begin{array}{l}-0.297 \\
(3.24)^{* *}\end{array}$ \\
\hline West Java & $\begin{array}{l}-0.307 \\
(5.17)^{* *}\end{array}$ & $\begin{array}{l}-0.288 \\
(4.78)^{* *}\end{array}$ & $\begin{array}{l}-0.06 \\
(0.96)\end{array}$ & $\begin{array}{l}-0.054 \\
(0.85)\end{array}$ \\
\hline Central Java & $\begin{array}{l}-0.593 \\
(9.58)^{* *}\end{array}$ & $\begin{array}{l}-0.578 \\
(9.19)^{* *}\end{array}$ & $\begin{array}{l}-0.304 \\
(4.79)^{* *}\end{array}$ & $\begin{array}{l}-0.276 \\
(4.31)^{* *}\end{array}$ \\
\hline Di Yogyakarta & $\begin{array}{l}-0.7 \\
(9.83)^{* *}\end{array}$ & $\begin{array}{l}-0.69 \\
(9.78)^{* *}\end{array}$ & $\begin{array}{l}-0.472 \\
(6.21)^{* *}\end{array}$ & $\begin{array}{l}-0.456 \\
(6.01)^{* *}\end{array}$ \\
\hline East Java & $\begin{array}{l}-0.565 \\
(9.37)^{* *}\end{array}$ & $\begin{array}{l}-0.554 \\
(9.12)^{* *}\end{array}$ & $\begin{array}{l}-0.26 \\
(4.12)^{* *}\end{array}$ & $\begin{array}{l}-0.244 \\
(3.83)^{* *}\end{array}$ \\
\hline Bali & $\begin{array}{l}-0.196 \\
(2.83)^{* *}\end{array}$ & $\begin{array}{l}-0.208 \\
(2.98)^{* *}\end{array}$ & $\begin{array}{l}-0.149 \\
(1.91)\end{array}$ & $\begin{array}{l}-0.162 \\
(2.05)^{*}\end{array}$ \\
\hline West NusaTenggara & $\begin{array}{l}-0.462 \\
(5.36)^{* *}\end{array}$ & $\begin{array}{l}-0.462 \\
(5.32)^{* *}\end{array}$ & $\begin{array}{l}-0.228 \\
(3.02)^{* *}\end{array}$ & $\begin{array}{l}-0.22 \\
(2.91)^{* *}\end{array}$ \\
\hline South Kalimantan & $\begin{array}{l}0.012 \\
(0.16)\end{array}$ & $\begin{array}{l}-0.006 \\
(0.08)\end{array}$ & $\begin{array}{c}-0.115 \\
(1.32)\end{array}$ & $\begin{array}{l}-0.126 \\
(1.44)\end{array}$ \\
\hline South Sulawesi & $\begin{array}{l}-0.563 \\
(6.61)^{* *}\end{array}$ & $\begin{array}{l}-0.56 \\
(6.55)^{* *}\end{array}$ & $\begin{array}{l}-0.368 \\
(3.59)^{* *}\end{array}$ & $\begin{array}{l}-0.371 \\
(3.62)^{* *}\end{array}$ \\
\hline Non-farm dummy & $\begin{array}{l}0.562 \\
(12.84)^{* *}\end{array}$ & & $\begin{array}{l}0.264 \\
(5.78)^{* *}\end{array}$ & \\
\hline Mining Quarry & & $\begin{array}{l}0.83 \\
(7.49)^{* *}\end{array}$ & & $\begin{array}{l}0.535 \\
(3.64)^{* *}\end{array}$ \\
\hline Manufacturing & & $\begin{array}{l}0.416 \\
(7.03)^{* *}\end{array}$ & & $\begin{array}{l}0.104 \\
(1.59)\end{array}$ \\
\hline Electricity & & $\begin{array}{l}0.592 \\
(4.80)^{* *}\end{array}$ & & $\begin{array}{l}0.345 \\
(1.26)\end{array}$ \\
\hline Construction & & $\begin{array}{l}0.524 \\
(7.77)^{* *}\end{array}$ & & $\begin{array}{l}0.247 \\
(3.98)^{* *}\end{array}$ \\
\hline Wholesale & & $\begin{array}{l}0.6 \\
(11.06)^{* *}\end{array}$ & & $\begin{array}{l}0.269 \\
(4.93)^{* *}\end{array}$ \\
\hline Transport & & $\begin{array}{l}0.545 \\
(8.57)^{* *}\end{array}$ & & $\begin{array}{l}0.109 \\
(1.54)\end{array}$ \\
\hline Finance & & $\begin{array}{l}0.813 \\
(5.63)^{* *}\end{array}$ & & $\begin{array}{l}0.607 \\
(4.58)^{* *}\end{array}$ \\
\hline Social services & & $\begin{array}{l}0.704 \\
(11.80)^{* *}\end{array}$ & & $\begin{array}{l}0.417 \\
(7.23)^{* *}\end{array}$ \\
\hline Constant & $\begin{array}{l}8.071 \\
(25.51)^{* *}\end{array}$ & $\begin{array}{l}8.178 \\
(25.46)^{* *}\end{array}$ & $\begin{array}{l}8.096 \\
(20.20)^{* *}\end{array}$ & $\begin{array}{l}8.235 \\
(20.43)^{* * *}\end{array}$ \\
\hline Observation & 5059 & 5059 & 4521 & 4521 \\
\hline R-squared & 0.39 & 0.4 & 0.32 & 0.32 \\
\hline
\end{tabular}


Table D.4: Cross Sectional Poverty Logit Regression in 1993 and 2000

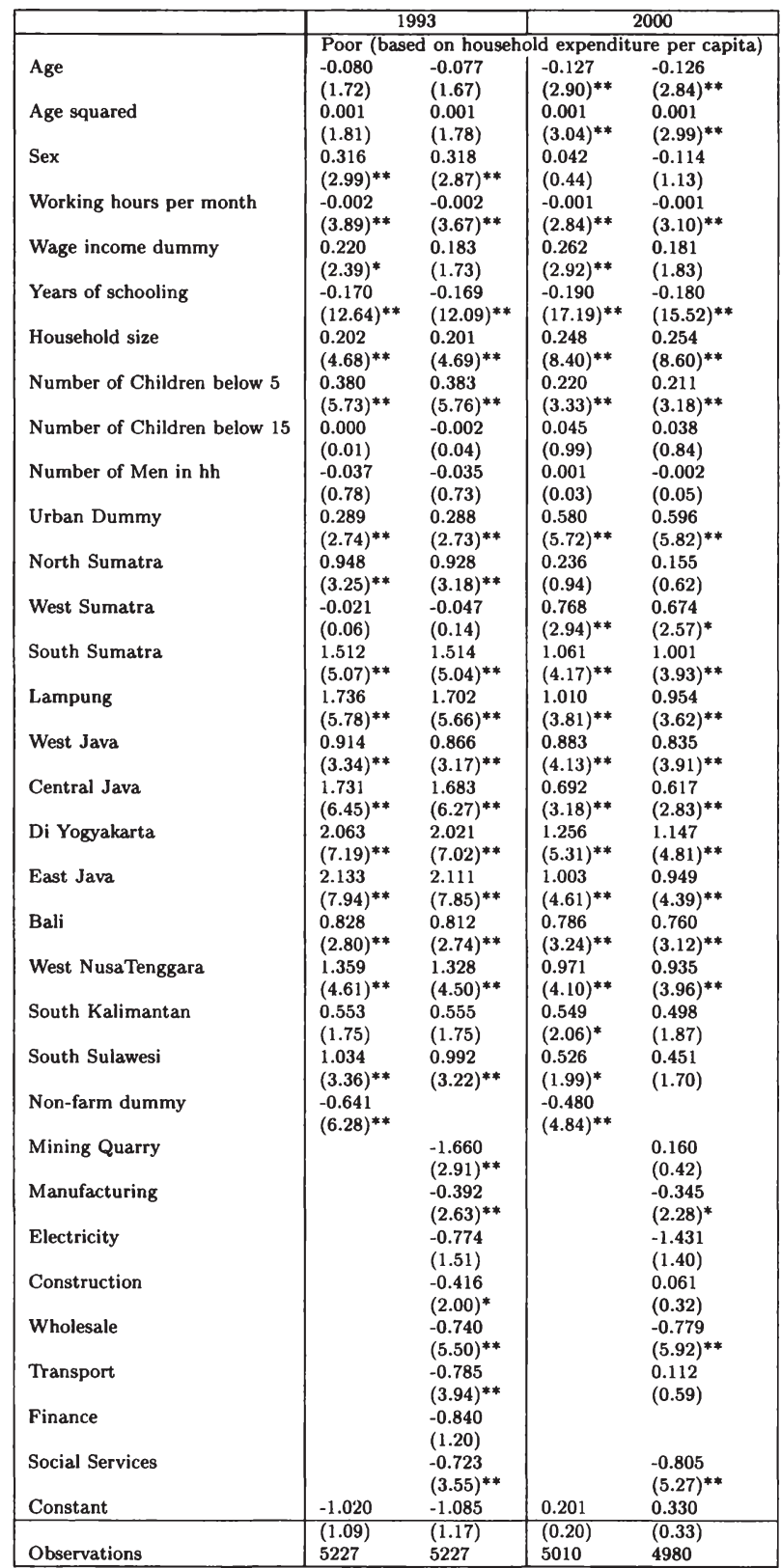


Table D.5: Income Difference Regression 1993-2000

\begin{tabular}{|c|c|c|c|c|}
\hline & \multicolumn{4}{|c|}{ Dependent variable: Change in log real income } \\
\hline & (1) & (2) & (3) & (4) \\
\hline Log Real Income 1993 & $\begin{array}{l}-0.623 \\
(23.32)^{* *}\end{array}$ & -0.570 & $\begin{array}{l}-0.632 \\
(23.64)^{* *}\end{array}$ & $\begin{array}{l}-0.581 \\
(18.19)^{* *}\end{array}$ \\
\hline Age & $\begin{array}{l}0.043 \\
(2.50)^{*}\end{array}$ & $\begin{array}{l}0.043 \\
(2.48)^{*}\end{array}$ & $\begin{array}{l}0.040 \\
(2.38)^{*}\end{array}$ & $\begin{array}{l}0.040 \\
(2.37)^{*}\end{array}$ \\
\hline Age Squared & $\begin{array}{l}-0.001 \\
(2.96)^{* *}\end{array}$ & $\begin{array}{l}-0.001 \\
(2.94)^{* *}\end{array}$ & $\begin{array}{l}-0.001 \\
(2.91)^{* *}\end{array}$ & $\begin{array}{l}-0.001 \\
(2.90)^{* *}\end{array}$ \\
\hline Sex & $\begin{array}{l}0.446 \\
(9.85)^{* *}\end{array}$ & $\begin{array}{l}0.443 \\
(9.82)^{* *}\end{array}$ & $\begin{array}{l}0.481 \\
(10.19)^{* *}\end{array}$ & $\begin{array}{l}0.478 \\
(10.17)^{* *}\end{array}$ \\
\hline Working hours per month & $\begin{array}{l}-0.002 \\
(7.44)^{* *}\end{array}$ & $\begin{array}{l}-0.002 \\
(7.37)^{* *}\end{array}$ & $\begin{array}{l}-0.002 \\
(7.31)^{* *}\end{array}$ & $\begin{array}{l}-0.002 \\
(7.24)^{* *}\end{array}$ \\
\hline Change in Working hours per month & $\begin{array}{l}-0.001 \\
(5.98)^{* *}\end{array}$ & $\begin{array}{l}-0.001 \\
(6.11)^{* *}\end{array}$ & $\begin{array}{l}-0.001 \\
(6.08)^{* *}\end{array}$ & $\begin{array}{l}-0.001 \\
(6.21)^{* *}\end{array}$ \\
\hline Wage Income Dummy & $\begin{array}{l}-0.032 \\
(0.78)\end{array}$ & $\begin{array}{l}-0.028 \\
(0.71)\end{array}$ & $\begin{array}{l}-0.036 \\
(0.76)\end{array}$ & $\begin{array}{l}-0.032 \\
(0.69)\end{array}$ \\
\hline Years of schooling & $\begin{array}{l}0.064 \\
(11.90)^{* *}\end{array}$ & $\begin{array}{l}0.064 \\
(11.87)^{* *}\end{array}$ & $\begin{array}{l}0.057 \\
(10.00)^{* *}\end{array}$ & $\begin{array}{l}0.057 \\
(9.99)^{* *}\end{array}$ \\
\hline Household size & $\begin{array}{l}0.048 \\
(3.22)^{* *}\end{array}$ & $\begin{array}{l}0.046 \\
(3.12)^{* *}\end{array}$ & $\begin{array}{l}0.046 \\
(3.13)^{* *}\end{array}$ & $\begin{array}{l}0.045 \\
(3.04)^{* *}\end{array}$ \\
\hline Change in household size & $\begin{array}{l}0.036 \\
(1.46)\end{array}$ & $\begin{array}{l}0.039 \\
(1.59)\end{array}$ & $\begin{array}{l}0.033 \\
(1.34)\end{array}$ & $\begin{array}{l}0.036 \\
(1.47)\end{array}$ \\
\hline Number of Children below 5 & $\begin{array}{l}-0.090 \\
(2.20)^{*}\end{array}$ & $\begin{array}{l}-0.088 \\
(2.16)^{*}\end{array}$ & $\begin{array}{l}-0.081 \\
(2.00)^{*}\end{array}$ & $\begin{array}{l}-0.079 \\
(1.96)\end{array}$ \\
\hline Change in the number of children below 5 & $\begin{array}{l}0.051 \\
(1.49)\end{array}$ & $\begin{array}{l}0.049 \\
(1.45)\end{array}$ & $\begin{array}{l}0.042 \\
(1.25)\end{array}$ & $\begin{array}{l}0.040 \\
(1.20)\end{array}$ \\
\hline Number of Men in hh & $\begin{array}{l}-0.036 \\
(1.64)\end{array}$ & $\begin{array}{c}-0.035 \\
(1.60)\end{array}$ & $\begin{array}{l}-0.036 \\
(1.69)\end{array}$ & $\begin{array}{l}-0.036 \\
(1.65)\end{array}$ \\
\hline Change in Number of Men in hh & $\begin{array}{l}-0.030 \\
(0.91)\end{array}$ & $\begin{array}{l}-0.033 \\
(1.02)\end{array}$ & $\begin{array}{l}-0.028 \\
(0.86)\end{array}$ & $\begin{array}{l}-0.031 \\
(0.98)\end{array}$ \\
\hline Urban Dummy & $\begin{array}{c}-0.052 \\
(1.30)\end{array}$ & $\begin{array}{c}-0.049 \\
(1.20)\end{array}$ & $\begin{array}{l}-0.043 \\
(1.06)\end{array}$ & $\begin{array}{l}-0.039 \\
(0.97)\end{array}$ \\
\hline North Sumatra & $\begin{array}{l}-0.167 \\
(1.87)\end{array}$ & $\begin{array}{l}-0.237 \\
(2.58)^{* *}\end{array}$ & $\begin{array}{l}-0.157 \\
(1.76)\end{array}$ & $\begin{array}{l}-0.224 \\
(2.44)^{*}\end{array}$ \\
\hline West Sumatra & $\begin{array}{l}-0.185 \\
(1.59)\end{array}$ & $\begin{array}{l}-0.245 \\
(2.09)^{*}\end{array}$ & $\begin{array}{l}-0.195 \\
(1.68)\end{array}$ & $\begin{array}{l}-0.253 \\
(2.16)^{*}\end{array}$ \\
\hline South Sumatra & $\begin{array}{l}-0.062 \\
(0.65)\end{array}$ & $\begin{array}{l}-0.088 \\
(0.91)\end{array}$ & $\begin{array}{l}-0.042 \\
(0.42)\end{array}$ & $\begin{array}{l}-0.067 \\
(0.68)\end{array}$ \\
\hline Lampung & $\begin{array}{l}-0.189 \\
(1.83)\end{array}$ & $\begin{array}{c}-0.285 \\
(2.57)^{*}\end{array}$ & $\begin{array}{l}-0.185 \\
(1.80)\end{array}$ & $\begin{array}{l}-0.275 \\
(2.49)^{*}\end{array}$ \\
\hline West Java & $\begin{array}{l}-0.001 \\
(0.01)\end{array}$ & $\begin{array}{l}-0.043 \\
(0.63)\end{array}$ & $\begin{array}{l}0.022 \\
(0.34)\end{array}$ & $\begin{array}{l}-0.019 \\
(0.29)\end{array}$ \\
\hline Central Java & $\begin{array}{l}-0.053 \\
(0.74)\end{array}$ & $\begin{array}{l}-0.090 \\
(1.21)\end{array}$ & $\begin{array}{l}-0.045 \\
(0.62)\end{array}$ & $\begin{array}{l}-0.081 \\
(1.09)\end{array}$ \\
\hline Di Yogyakarta & $\begin{array}{l}-0.239 \\
(2.69)^{* *}\end{array}$ & $\begin{array}{l}-0.285 \\
(3.14)^{* *}\end{array}$ & $\begin{array}{l}-0.225 \\
(2.52)^{*}\end{array}$ & $\begin{array}{l}-0.269 \\
(2.96)^{* *}\end{array}$ \\
\hline East Java & $\begin{array}{l}-0.092 \\
(1.27)\end{array}$ & $\begin{array}{l}-0.136 \\
(1.83)\end{array}$ & $\begin{array}{l}-0.078 \\
(1.08)\end{array}$ & $\begin{array}{l}-0.120 \\
(1.63)\end{array}$ \\
\hline Bali & $\begin{array}{l}-0.004 \\
(0.05)\end{array}$ & $\begin{array}{l}-0.060 \\
(0.69)\end{array}$ & $\begin{array}{l}-0.015 \\
(0.18)\end{array}$ & $\begin{array}{l}-0.069 \\
(0.79)\end{array}$ \\
\hline West NusaTenggara & $\begin{array}{l}-0.062 \\
(0.68)\end{array}$ & $\begin{array}{l}-0.097 \\
(1.04)\end{array}$ & $\begin{array}{l}-0.077 \\
(0.84)\end{array}$ & $\begin{array}{l}-0.110 \\
(1.20)\end{array}$ \\
\hline South Kalimantan & $\begin{array}{l}-0.111 \\
(1.34)\end{array}$ & $\begin{array}{l}-0.146 \\
(1.74)\end{array}$ & $\begin{array}{l}-0.120 \\
(1.43)\end{array}$ & $\begin{array}{l}-0.153 \\
(1.80)\end{array}$ \\
\hline South Sulawesi & $\begin{array}{l}0.036 \\
(0.33)\end{array}$ & $\begin{array}{l}-0.010 \\
(0.09)\end{array}$ & $\begin{array}{l}0.022 \\
(0.20)\end{array}$ & $\begin{array}{l}-0.023 \\
(0.20)\end{array}$ \\
\hline Moved Province & $\begin{array}{l}-0.243 \\
(1.84)\end{array}$ & $\begin{array}{l}0.929 \\
(1.29)\end{array}$ & $\begin{array}{l}-0.263 \\
(2.05)^{*}\end{array}$ & $\begin{array}{l}0.869 \\
(1.22)\end{array}$ \\
\hline Moved Kabupaten/Kota & $\begin{array}{l}0.136 \\
(1.82)\end{array}$ & $\begin{array}{l}0.100 \\
(0.24)\end{array}$ & $\begin{array}{l}0.133 \\
(1.80)\end{array}$ & $\begin{array}{l}0.062 \\
(0.15)\end{array}$ \\
\hline Moved Kecamatan & $\begin{array}{l}0.033 \\
(0.75)\end{array}$ & $\begin{array}{l}0.637 \\
(2.36)^{*}\end{array}$ & $\begin{array}{l}0.037 \\
(0.83)\end{array}$ & $\begin{array}{l}0.620 \\
(2.31)^{*}\end{array}$ \\
\hline Moved Prov x Initial Income & & $\begin{array}{l}-0.181 \\
(1.69)\end{array}$ & & $\begin{array}{l}-0.175 \\
(1.64)\end{array}$ \\
\hline Moved Kab x Initial Income & & $\begin{array}{l}0.010 \\
(0.16)\end{array}$ & & $\begin{array}{l}0.015 \\
(0.25)\end{array}$ \\
\hline Moved Kec $x$ Initial Income & & $\begin{array}{l}-0.097 \\
(2.31)^{*}\end{array}$ & & $\begin{array}{l}-0.094 \\
(2.25)^{*}\end{array}$ \\
\hline Non-farm in 1993 & 0.362 & 0.373 & & \\
\hline
\end{tabular}




\begin{tabular}{|c|c|c|c|c|}
\hline & $(1.99)^{*}$ & $(2.18)^{*}$ & & \\
\hline Stayed Non-farm & $\begin{array}{l}-0.269 \\
(1.56)\end{array}$ & $\begin{array}{l}-0.282 \\
(1.75)\end{array}$ & $\begin{array}{l}-0.143 \\
(0.72)\end{array}$ & $\begin{array}{l}-0.155 \\
(0.80)\end{array}$ \\
\hline Moved to non-farm & $\begin{array}{l}0.082 \\
(0.92)\end{array}$ & $\begin{array}{l}0.077 \\
(0.87)\end{array}$ & $\begin{array}{l}0.082 \\
(0.93)\end{array}$ & $\begin{array}{l}0.077 \\
(0.88)\end{array}$ \\
\hline Moved to farm & $\begin{array}{l}-0.474 \\
(2.49)^{*}\end{array}$ & $\begin{array}{l}-0.499 \\
(2.76)^{* *}\end{array}$ & $\begin{array}{l}-0.329 \\
(1.55)\end{array}$ & $\begin{array}{l}-0.352 \\
(1.69)\end{array}$ \\
\hline Mining Quarry & & & $\begin{array}{l}-0.082 \\
(0.22)\end{array}$ & $\begin{array}{l}-0.067 \\
(0.18)\end{array}$ \\
\hline Manufacturing & & & $\begin{array}{l}0.132 \\
(0.65)\end{array}$ & $\begin{array}{l}0.143 \\
(0.72)\end{array}$ \\
\hline Electricity & & & $\begin{array}{l}0.126 \\
(0.52)\end{array}$ & $\begin{array}{l}0.144 \\
(0.59)\end{array}$ \\
\hline Construction & & & $\begin{array}{l}0.052 \\
(0.25)\end{array}$ & $\begin{array}{l}0.059 \\
(0.29)\end{array}$ \\
\hline Wholesale & & & $\begin{array}{l}0.292 \\
(1.42)\end{array}$ & $\begin{array}{l}0.302 \\
(1.50)\end{array}$ \\
\hline Transport & & & $\begin{array}{l}0.218 \\
(1.04)\end{array}$ & $\begin{array}{l}0.225 \\
(1.10)\end{array}$ \\
\hline Finance & & & $\begin{array}{l}0.535 \\
(2.21)^{*}\end{array}$ & $\begin{array}{l}0.527 \\
(2.20)^{*}\end{array}$ \\
\hline Social Services & & & $\begin{array}{l}0.450 \\
(2.16)^{*}\end{array}$ & $\begin{array}{l}0.455 \\
(2.21)^{*}\end{array}$ \\
\hline Constant & $\begin{array}{l}3.104 \\
(8.71)^{* *}\end{array}$ & $\begin{array}{l}2.826 \\
(7.63)^{* *}\end{array}$ & $\begin{array}{l}3.218 \\
(9.07)^{* *}\end{array}$ & $\begin{array}{l}2.950 \\
(7.94)^{* *}\end{array}$ \\
\hline Observations & 4225 & 4225 & 4225 & 4225 \\
\hline R-squared & 0.32 & 0.33 & 0.33 & 0.34 \\
\hline
\end{tabular}

Robust $t$ statistics in parentheses * significant at $5 \%$; ** significant at $1 \%$ Note: All variables which are not difference variables are from the IFLS 1993. 
Table D.6: Geographic and Absolute Convergence

\begin{tabular}{|c|c|c|c|}
\hline \multirow[b]{2}{*}{ North Sumatra } & $\begin{array}{l}\text { (1) } \\
\text { Depender }\end{array}$ & \multicolumn{2}{|c|}{ Dependent variable Change in log real income } \\
\hline & $\begin{array}{l}0.276 \\
(3.01)^{* *}\end{array}$ & $\begin{array}{l}-0.037 \\
(0.46)\end{array}$ & \\
\hline West Sumatra & $\begin{array}{l}0.147 \\
(1.22)\end{array}$ & $\begin{array}{l}-0.102 \\
(0.92)\end{array}$ & \\
\hline South Sumatra & $\begin{array}{l}0.467 \\
(4.05)^{* *}\end{array}$ & $\begin{array}{l}0.019 \\
(0.19)\end{array}$ & \\
\hline Lampung & $\begin{array}{l}0.585 \\
(5.08)^{* *}\end{array}$ & $\begin{array}{l}-0.046 \\
(0.45)\end{array}$ & \\
\hline West Java & $\begin{array}{l}0.308 \\
(4.09)^{* *}\end{array}$ & $\begin{array}{l}-0.031 \\
(0.47)\end{array}$ & \\
\hline Central Java & $\begin{array}{l}0.467 \\
(6.40)^{* *}\end{array}$ & $\begin{array}{l}-0.044 \\
(0.63)\end{array}$ & \\
\hline Di Yogyakarta & $\begin{array}{l}0.274 \\
(3.13)^{* *}\end{array}$ & $\begin{array}{l}-0.178 \\
(2.05)^{*}\end{array}$ & \\
\hline East Java & $\begin{array}{l}0.408 \\
(5.36)^{* *}\end{array}$ & $\begin{array}{l}-0.053 \\
(0.71)\end{array}$ & \\
\hline Bali & $\begin{array}{l}0.360 \\
(4.38)^{* *}\end{array}$ & $\begin{array}{l}0.027 \\
(0.35)\end{array}$ & \\
\hline West NusaTenggara & $\begin{array}{l}0.436 \\
(4.29)^{* *}\end{array}$ & $\begin{array}{l}-0.066 \\
(0.74)\end{array}$ & \\
\hline South Kalimantan & $\begin{array}{l}0.108 \\
(1.17)\end{array}$ & $\begin{array}{l}-0.149 \\
(1.78)\end{array}$ & \\
\hline South Sulawesi & $\begin{array}{l}0.649 \\
(5.92)^{* *}\end{array}$ & $\begin{array}{l}0.111 \\
(1.08)\end{array}$ & \\
\hline Log Real Income 1993 & & $\begin{array}{l}-0.423 \\
(18.63)^{* *}\end{array}$ & $\begin{array}{l}-0.422 \\
(19.87)^{* *}\end{array}$ \\
\hline Constant & $\begin{array}{l}-0.225 \\
(4.26)^{* *}\end{array}$ & $\begin{array}{l}2.824 \\
(16.70)^{* *}\end{array}$ & $\begin{array}{l}2.782 \\
(20.34)^{* *}\end{array}$ \\
\hline Observations & 4229 & 4229 & 4229 \\
\hline $\mathrm{R}$-squared & 0.01 & 0.18 & 0.18 \\
\hline
\end{tabular}

Robust $t$ statistics in parentheses * significant at $5 \% ;{ }^{* *}$ significant at $1 \%$ 
Table D.7: Full Logit Regression of Poverty Exit and Entry (1993-2000)

\begin{tabular}{|c|c|c|}
\hline & (1) & (2) \\
\hline & exit & entry \\
\hline Log real income 1993 & 0.155 & -0.295 \\
\hline & $(1.88)$ & $(4.75)^{* *}$ \\
\hline Age & $\begin{array}{l}0.098 \\
(1.38)\end{array}$ & $\begin{array}{l}-0.128 \\
(2.45)^{*}\end{array}$ \\
\hline Age squared & -0.001 & 0.002 \\
\hline & $(1.61)$ & $(2.68)^{* *}$ \\
\hline Sex & $\begin{array}{l}-0.056 \\
(0.31)\end{array}$ & $\begin{array}{l}0.088 \\
(0.64)\end{array}$ \\
\hline Working hours per month & $\begin{array}{l}0.001 \\
(0.81)\end{array}$ & $\begin{array}{l}-0.001 \\
(0.79)\end{array}$ \\
\hline Wage income dummy & $\begin{array}{l}-0.153 \\
(0.95)\end{array}$ & $\begin{array}{l}0.299 \\
(2.30)^{*}\end{array}$ \\
\hline Years of schooling & $\begin{array}{l}0.132 \\
(5.03)^{* *}\end{array}$ & $\begin{array}{l}-0.136 \\
(7.84)^{* *}\end{array}$ \\
\hline Household size & $\begin{array}{l}-0.180 \\
(3.03)^{* *}\end{array}$ & $\begin{array}{l}0.118 \\
(2.30)^{*}\end{array}$ \\
\hline Number of Children $<5$ & $\begin{array}{l}-0.004 \\
(0.04)\end{array}$ & $\begin{array}{l}0.196 \\
(2.23)^{*}\end{array}$ \\
\hline Number of Men & $\begin{array}{l}0.044 \\
(0.57)\end{array}$ & $\begin{array}{l}0.191 \\
(2.67)^{* *}\end{array}$ \\
\hline Urban Dummy & $\begin{array}{l}-0.777 \\
(4.13)^{* *}\end{array}$ & $\begin{array}{l}0.535 \\
(3.53)^{* *}\end{array}$ \\
\hline North Sumatra & $\begin{array}{l}-0.938 \\
(1.29)\end{array}$ & $\begin{array}{l}-0.128 \\
(0.34)\end{array}$ \\
\hline West Sumatra & $\begin{array}{l}0.019 \\
(0.02)\end{array}$ & $\begin{array}{l}1.315 \\
(3.68)^{* *}\end{array}$ \\
\hline South Sumatra & $\begin{array}{l}-0.418 \\
(0.58)\end{array}$ & $\begin{array}{l}0.913 \\
(2.63)^{* *}\end{array}$ \\
\hline Lampung & $\begin{array}{l}-0.954 \\
(1.27)\end{array}$ & $\begin{array}{l}0.471 \\
(1.18)\end{array}$ \\
\hline West Java & $\begin{array}{l}-0.322 \\
(0.50)\end{array}$ & $\begin{array}{l}0.818 \\
(2.78)^{* *}\end{array}$ \\
\hline Central Java & $\begin{array}{l}0.128 \\
(0.20)\end{array}$ & $\begin{array}{l}0.227 \\
(0.70)\end{array}$ \\
\hline Di Yogyakarta & $\begin{array}{l}-0.166 \\
(0.24)\end{array}$ & $\begin{array}{l}0.686 \\
(1.94)\end{array}$ \\
\hline East Java & $\begin{array}{l}0.428 \\
(0.67)\end{array}$ & $\begin{array}{l}0.850 \\
(2.67)^{* *}\end{array}$ \\
\hline Bali & $\begin{array}{l}0.158 \\
(0.23)\end{array}$ & $\begin{array}{l}0.672 \\
(1.94)\end{array}$ \\
\hline West NusaTenggara & $\begin{array}{l}0.277 \\
(0.41)\end{array}$ & $\begin{array}{l}1.311 \\
(3.74)^{* *}\end{array}$ \\
\hline South Kalimantan & $\begin{array}{l}-0.071 \\
(0.10)\end{array}$ & $\begin{array}{l}0.679 \\
(1.98)^{*}\end{array}$ \\
\hline South Sulawesi & $\begin{array}{l}0.721 \\
(1.03)\end{array}$ & $\begin{array}{l}-0.028 \\
(0.07)\end{array}$ \\
\hline Moved Province & $\begin{array}{l}3.830 \\
(3.40)^{* *}\end{array}$ & $\begin{array}{l}0.018 \\
(0.03)\end{array}$ \\
\hline Moved Kabupaten & $\begin{array}{l}0.938 \\
(2.62)^{* *}\end{array}$ & $\begin{array}{l}-0.203 \\
(0.94)\end{array}$ \\
\hline Moved Kecamatan & $\begin{array}{l}-0.105 \\
(0.58)\end{array}$ & $\begin{array}{l}-0.024 \\
(0.16)\end{array}$ \\
\hline Stayed Non-farm & $\begin{array}{l}0.262 \\
(1.29)\end{array}$ & $\begin{array}{l}-0.203 \\
(1.19)\end{array}$ \\
\hline Moved to non-farm & $\begin{array}{l}0.510 \\
(1.87)\end{array}$ & $\begin{array}{l}-0.331 \\
(1.36)\end{array}$ \\
\hline Moved to farm & $\begin{array}{l}-0.620 \\
(2.20)^{*} \\
(1.21)\end{array}$ & $\begin{array}{l}-0.054 \\
(0.24) \\
(1.07)\end{array}$ \\
\hline Observations & $\begin{array}{l}1185 \\
\text { Initially poor }\end{array}$ & $\begin{array}{l}3687 \\
\text { Initially non-poor }\end{array}$ \\
\hline
\end{tabular}

Robust $\mathrm{z}$ statistics in parentheses * significant at $5 \%$; ${ }^{* *}$ significant at $1 \%$ 


\section{Bibliography}

[1] Acemoglu D. B., et al. (2001) The Colonial Origins of Comparative Development. The American Economic Review, Vol. 91, 1369-1401.

[2] Aghion, P. et al. (2004) Endogenous Political Institutions. The Quarterly Journal of Economics, Vol. 119, Issue 2, 565-612.

[3] Akaike, H. (1973) Information theory and an extension of the maximum likelihood principle. In: B. N. Petrov 6 F. Csaki (eds.), Second international symposium on information theory, pp. 267-281.

[4] Akerlof, G. A. and Kranton, R. E. (2000) Economics and Identity. The Quarterly Journal of Economics., Vol. CXV, Issue 3.

[5] Alesina, A. and Baquir, R. and Easterly, W. (1999) Public Goods and Ethnic Divisions. The Quarterly Journal of Economics, 1243-1284.

[6] Alesina, A. and Drazen, A. (1991) Why are Stabilizations delayed? The Quarterly Journal of Economics, Vol. 81, No. 5, 1170-1188.

[7] Alesina, A. et al.(2003) Fractionalization. Journal of Economic Growth, No. 8, 155-194.

[8] Alesina, A. and Ferrara, E. L. (2005) Ethnic Diversity and Economic Performance. Journal of Economic Literature, Vol. 43, 721-761

[9] Anderson, G. (2004) Making Inferences about the Polarization, Welfare amd Poverty of Nations: A Study of 101 Countries from 1970-1995. Journal of Applied Econometrics, Volume 19, pp. 537-550.

[10] Annett, A. (1991) Social Fractionalisation, political instabilits and the size of government. The American Economic Review, Volume 81, Issue 1, 179-190.

[11] Arnott, R. and Stiglitz, J. E. (1991) Moral Hazard and Nonmarket Institutions: Dysfunctional Crowding Out of Peer Monitoring? The American Economic Review, Vol. 81, No. 1, 179-190.

[12] Banerjee, A. and Newman, A. F.(1998) Information, the Dual Economy and Development. Review of Economic Studies, Vol 65, No. 4, 631-653. 
[13] Barret, D. B. (1982) Endogenous Political Institutions, Christian Encyclopedia. New York: Oxford University Press.

[14] Barro, R. (1991) Economic Growth in a Cross Section of Countries, The Quarterly Journal of Economics 3120, Vol. 106, No. 2, 407-443

[15] Barro, R. and X. Sala-i-Martin (1992) Convergence. Journal of Political Economy, Vol. 100(2), 223-251.

[16] Bates, R. H. (2005) Ethnicity. Havard University www.cid.havard.edu/cidpeople/ bates/Ethnicity_Paper.pdf/.

[17] Beaudry, P., Collard, F. and Green, D. A. (2005) Changes in the world distribution of output per worker, 1960-1998: How a standard decomposition tells us an unorthodox story. Review of Economics and Statistics, Vol. 87, 741-753.

[18] Bernhard, A. and C. Jones (1996) Technology and Convergence. The Economic Journal, Vol. 106, 1037-1044.

[19] Berry, A., F. Bourguignon and C. Morrisson (1983) Changes in the World Distribution of Income between 1950 and 1977. The Economic Journal, Vol. 113, 331-350.

[20] Besley, Timothy, Robin Burgess and Berta Esteve-Volart (2006) The Policy Origins of Poverty and Growth in India. In: Besley and Cord (eds) Delivering on the Promise of Pro-Poor Growth, Palgrave Macmillan and the World Bank, New York, pp. 59-78.

[21] Besley, Timothy, and Louise Cord, eds (2006) Delivering on the Promise of Pro-Poor Growth, Palgrave Macmillan and the World Bank, New York.

[22] Bhalla, Surjit (2002) Imagine There's No Country: Poverty, Inequality, and Growth in the Era of Globalization. Washington DC, Institute for International Economics.

[23] Bianchi, M. (1997) Testing for Convergence: Evidence from Non-Parametric Multimodality Tests. Journal of Applied Econometrics, Vol. 12, pp. 393-409.

[24] Bourguignon, F. and C. Morrisson (2002) Inequality Among World Citizens: 1820-1992. American Economic Review, Vol. 92, pp. 727-744.

[25] Bourguignon, F. (2003) The growth elasticitys of poverty reduction: explaining heterogeneity across countries and time periods. In: T.Eicher and S. Turnovski, (eds), Inequality and Growth : Theory and Policy Implications, MIT Press, Cambridge, Massasuchets.

[26] Bourguignon, F. (2005) Comment on "Measuring Poverty in a Growing World (or Measuring Growth in a Poor World)" by Angus Deaton. The Review of Economics and Statistics, 'Vol. 87 , Issue 1 , pages $20-22$. 
[27] Casella A. and Rauch J. E.(1997) Anonymous Market and Group Ties in International Trade. NBER Working Paper Series, Working Paper 6186.

[28] Chen, H., Chen, J. and Kalbfleisch, J. D. (2001) A modified likelihood ratio test for homogeneity in finite mixture models. J. R. Stat. Soc. Ser. B Stat. Methodol., Vol. 63, 19-29.

[29] Chen, H., Chen, J. and Kalbfleisch, J. D. (2004) Testing for a finite mixture model with two components. J. R. Stat. Soc. Ser. B Stat. Methodol., Vol. 66, 95-115.

[30] Chen, J. and Kalbfleisch,J. D. (2005) Modified likelihood ratio test in finite mixture models with a structural parameter. J. Statist. Plann. Inference, Vol. 129, 93-107.

[31] Chen, S. and M. Ravallion (2004) How Have the World's Poorest Fared since the Early 1980s? World Bank Research Observer, Vol. 19, No. 2, pp. 141-169.

[32] Chotikapanich D., R. Valenzuela and P. Rao (1997) Global and regional inequality in the distribution of income: Estimation with limited and incomplete data. Empirical Economics, Vol. 22, No.4, pp. 533-546.

[33] (2004) Center for Research on Inequality, Human Security and Ethnicity (CRISE). About CRISE. http://www.crise.ox.ac.uk/.

[34] Collier, P. (1998) The Political Economy of Ethnicity. www.worldbank.org/html/rad/abcde/collier.pdf

[35] Collier, P. and Hoeffler, A. (1998) On economic causes of civil war. Oxford Economic Papers, 50:563-573.

[36] Dacunha-Castelle, D. and Gassiat, E. (1999) Testing the order of a model using locally conic parametrization: population mixtures and stationary ARMA processes. Ann. Statist., Vol. 27, 1178-1209.

[37] Datt, G. and M. Ravallion (1992) Growth and Redistribution Components of Changes in Poverty Measure: A Decomposition with Applications to Brazil and India in the 1980s. Jounral of Development Economics, Vol. 38, 275-295.

[38] Datt, Guarav and Martin Ravallion (1998) Farm Productivity and Rural Poverty in India. Journal of Development Studies, Vol. 34, pp. 62-85.

[39] Deaton, A. (2005) Measuring Poverty in a Growing World (or Measuring Growth in a Poor World. The Review of Economics and Statistics, Vol. 87, pp. 1-19.

[40] Deininger, K., Jin, S. and M. Sur, Sri Lanka's rural non-farm economy: Removing constraints to pro-poor growth. forthcoming. 
[41] Delgado, L. Chris, J. Hopkins, and V. A. Kelly (1998) Agricultural Growth Linkages in Sub-Saharan Africa. IFPRI Research Report 107, Washington, DC: IFPRI.

[42] Dickson, E. and Scheve, K. (2004) Social Identity, Political Speech, and Electoral Competition. Working Paper www-personal.umich.edu/ scheve/edks0204.pdf

[43] Dollar, David, and Aart Kraay (2002) "Growth is Good for the Poor. Journal of Economic Growth, Vol. 7, pp.195-225.

[44] Dowrick, S. and M. Akmal (2003) Contradicting Trends in Global Income Inequality: A Tale of Two Biases. Review of Income and Wealth, Vol. 51, pp. 201-229.

[45] Durlauf, S. (1996) On the Convergence and Divergence of Growth Rates. The Economic Journal, Vol. 106, pp. 1016-1018.

[46] Durlauf, S. and Quah, D.T. (1999) The new Empirics of Economic Growth. In: Taylor, J.B: and Woodford, M. (ds), Handbook of Macroeconometrics, I. Elsevier, Amsterdam, pp. 235-308.

[47] Easterly, W. and Levine, R.(1997) Africa's Growth Tragedy: Policies and Ethnic Divisions The Quarterly Journal of Economics, Vol. 112, No. 4, 1203-1250.

[48] Easterly, W.(2001a) Can Institutions Resolve Ethnic Conflict. Economic Development and Cultural Change, Vol. 49, 687-706.

[49] Easterly, W.(2001b) The Middle Class Consensus and Economic Development. Journal of Economic Growth, No. 6, page 317-335.

[50] Easterly, W.(2004) Empirics of Strategic Interdependence: The Case of the Racial Tipping Point. DRI Working Paper, No. 5.

[51] Efron, B. (1979) Bootstrap Methods: Another Look at the Jackknife Ann. Statist., Vol. $7(1), 1-26$.

[52] Englebert, P. (2004) Solving the Mystery of the Africa Dummy. CEPR Discussion Paper Series, No. 4616.

[53] Epstein, G.S. and Gang I.(2000) Ethnic Networks and International Trade. World Development, Vol. 28, No. 10, 1821-1835.

[54] Fan, Shenggen, Peter Hazell and S. K. Thorat (2000) Government Spending, Agricultural Growth and Poverty in Rural India. American Journal of Agricultural Economics, Vol. 82, No. 4, pp. 1038-1051.

[55] Fan, Shenggen, L. Zhang and X. Zhang (2002) Growth, Inequality and Poverty in Rural China: The Role of Public Investments. IFPRI Research Report 125, International Food Research Institute, Washington, DC. 
[56] Fan, Shenggen., S. K. Thorat, and Neetha Rao (2004) Investment, Subsidies, and ProPoor Growth in Rural India. In: Andrew Dorward, et al. (eds.), Institutions and Policies for Pro-Poor Agricultural Growth: Report on Project 7989, Department for International Development Social Science Research Unit.

[57] Fan, Y. (2004) Testing the Goodness of Fit of a Parametric Density Function by Kernel Method. Econometric Theory, Vol. 10, pp. 316-356.

[58] Fearon, J. D.(2003) Ethnic Structure and Cultural Diversity by Country. Journal of Economic Growth, Vol. 8, 195-222.

[59] Feyrer, J. (2007) Demographics and Productivity The Review of Economics and Statistics, Vol. 89, pp. 100-109.

[60] Fields, G et al. (2003) For richer or for poorer? Evidence from Indonesia, South Africa. Spain, and Venezuela. Journal of Economic Inequality, Vol. 1, pp. 67-99.

[61] Firebaugh, G. (1999) Empirics of World Income Inequality. American Journal of Sociology, Vol. 104, pp. 1597-1630.

[62] Fisher, N. I., Mammen, E. and Marron, J. S. (1994) Testing for multimodality. Comput. Statist. Data Anal., Vol. 18, pp. 499-512.

[63] Foster, Andrew D., and Mark R. Rosenzweig (2004) Agricultural Productivity Growth, Rural Economic Diversity, and Economic Reforms: India, 1970-2000. Economic Development and Cultural Change, 52.3 (April): pp. 509-542.

[64] Fraley, C. and Raftery, A. E. (2002) Model-based clustering, discriminant analysis, and density estimation. J. Amer. Statist. Assoc., Vol. 97, 611-631.

[65] Frankel, J. A. and Romer, D.(1999) Does Trade Cause Growth? The American Economic Review, Vol. 89, No.3:379-399.

[66] Galor, O. (1996) Convergence? Inference from Theoretical Models. The Economic Journal, Vol. 106, 1056-1069.

[67] Girma, S. and Yu, Z.: The Link between Immigration and Trade: Evidence from the UK. GLM Research Paper University of Nottingham, No. 23, 2000.

[68] Gould, D. M.(1994) Immigrant Links to the Home Country: Empirical Implications for U.S. Bilateral Trade Flows. The Review of Economics and Statistics, 302-316.

[69] Greif, A. (1993) Contract Enforcement and Economic Institutions in Early Trade: The Mehgrebi Traders' Coalition. The American Economic Review, Vol. 83, 525-548. 
[70] Gruen, C. and S. Klasen (2007) Growth, Inequality, and Well-Being: Comparisons across Space and Time. forthcoming.

[71] Grimm, M: and Günther, I: (2006) Measuring Pro-Poor Growth when Relative Prices shift. Journal of Development Economics, forthcoming.

[72] Haggblade, Steven, Peter Hazell and James Brown (1989) Farm-Nonfarm Linkages in Rural Sub-Saharan Africa. World Development, Vol. 17 No 8, 1173-1201.

[73] Haggblade, Steven, Jeffrey Hammer, and Peter Hazell (1991) Modelling Agricultural Growth Multipliers. American Journal of Agricultural Economics, Vol. 73, No. 2, pp. 36174.

[74] Haggblade, Steven, Peter Hazell and Thomas Reardon (2002) Strategies for Stimulating Poverty-alleviating Growth in the Rural Non-farm Economy in Developing Countries. Environment and Production Technology Division Discussion Paper, 92. IFPRI, Washington, D.C.

[75] Hall, P. and York, M. (2001) On the calibration of Silverman's test for multimodality. Statist. Sinica, Vol. 11, 515-536.

[76] Hathaway, R. J. (1985) A constrained formulation of maximum-likelihood estimation for normal mixture distributions. Ann. Statist., Vol. 13, 795-800.

[77] Hayami, Y., and V. Ruttan (1985) Agricultural Development: An International Perspective, Revised and expanded edition. Baltimore: Johns Hopkins University Press.

[78] Hazell, Peter, and Steven Haggblade (1993) Farm-Nonfarm Growth Linkages and the Welfare of the Poor. In: Michael Lipton and Jacques van der Gaag (eds.) Including the Poor: Proceedings of a Symposium Organized by the World Bank and the International Food Policy Research Institute. The World Bank: Washington, DC.

[79] Hazell, Peter, and Ailsa Roell (1983) Rural Growth Linkages: Household Expenditure Patterns in Malaysia and Nigeria. IFPRI Research Report 41, Washington, DC.

[80] Heston, A.; Summers, R. and Aten, B. (2006) Penn World Tables Version 6.2 Center for International Comparisons of Production, Income and Prices at the University of Pennsylvania.

[81] Johnston, B.F., and J.W. Mellor (1961) The Role of Agriculture in Economic Development. American Economic Review, Vol. 51, no. 4, pp. 566-93.

[82] Jones, C. (1997) On the Evolution of the World Income Distribution. The Journal of Economic Perspectives, Vol. 11,19-36. 
[83] Keribin, C. (2000) Consistent estimation of the order of mixture models. Sankhyā Ser. A, Vol. 62, 49-66.

[84] King, Robert. P. and Derek Byerlee (1978) Factor Intensity and Locational Impacts of Rural Consumption Patterns in Sierra Leone. American Journal of Agricultural Economics, Vol. 60, No. 2, pp. 197-206.

[85] Klasen, S. and Woolard, I. (2005) Income Mobility and Household Poverty Dynamics in South Africa. Journal of Development Studies Vol. 41, pp. 865-897 .

[86] Klump, Ranier. 2006. Pro-Poor Growth in Vietnam: Miracle or Model? In: Besley and Cord (eds.) Delivering on the Promise of Pro-Poor Growth, Palgrave Macmillan and the World Bank, New York, pp. 119-146.

[87] Kremer, M., A. Onatski and J. Stock (2001) Searching for Prosperity. Carnegie-Rochester Conference Series on Public Policy, No. 55, pp. 275-303.

[88] Lanjouw, Jean and Peter Lanjouw (2001) The Rural Non-Farm Sector: Issues and Evidence from Developing Countries. Agricultural Economics, Vol. 26, No. 1, pp. 1-23.

[89] Larson, Donald and Yair Mundlak (1997) On the Intersectoral Migration of Agricultural Labor. Economic Development and Cultural Change, Vol. 45, No. 2 (Jan., 1997), pp. 295319.

[90] Levine, R. and D. Renelt (1992) A Sensetivity Analysis of Cross-Country growth Regressions. American Economic Review, Vol. 82, pp. 942-963.

[91] Lewis, W. Arthur (1954) Economic Development with Unlimited Supplies of Labor. The Manchester School, Vol. 22, pp. 3-42.

[92] Maasoumi, E., Racine, J. and Stengos, T. (2007) Growth and Convergence: A Profile of Distribution Dynamics and Mobility. Journal of Econometrics, Vol. 136, 483-508.

[93] Majid, Nooman (2004) Reaching Millennium Goals: How Well Does Agricultural Productivity Growth Reduce Poverty? Employment Strategy Paper, International Labor Organization (ILO), Geneva.

[94] Mankiw, G., D. Romer and D. Weil (1992) A Contribution to the Empirics of Economic Growth. Quarterly Journal of Economics, Vol. 107, 407-437.

[95] McCulloch, Neil and Cao Yiying (2006) What Caused Changes In Household Income and Poverty in Rural Sichuan in the early 1990s?. Institute of Development Studies, University of Sussex, mimeo.

[96] McLachlan, G. J. (1987) On bootstrapping the likelihood ratio test statistic for the number of components in a normal mixture, Applied Statistics, Vol. 36, 318-324. 
[97] Melchior, A., K. Telle and H. Wiig (2000) Globalization and Inequality - World Income Distribution and Living Standards, 1960-1998. Studies on Foreign Policy Issues, Report 6B, Oslo, Norway: Royal Norwegian Ministry of Foreign Affairs.

[98] Mellor, John W. (1976) The New Economics of Growth: A Strategy for India and the Developing World. Ithaca, NY: Cornell University Press.

[99] Mellor, John W. (2000) Agricultural Growth, Rural Employment, and Poverty Reduction: Non-Tradables, Public Expenditure, and Balanced Growth. Prepared for the World Bank Rural Week 2000, March.

[100] Mellor, John W., and Uma Lele (1973) Growth Linkages of the New Food Grain Technologies. Indian Journal of Agricultural Economics, Vol. 18, No. 1, pp. 35-55.

[101] Milanovic, B. (2002). True world income distribution, 1988 and 1993: First calculation based on household surveys alone. Economic Journal, Vol. 112, Issue 476, pp. 51-92.

[102] Milanovic, B. (2006) Global Income Inequality: What it is and Why it Matters. World Bank Policy Research Working Paper No. 3865.

[103] Mkandawire, T. (1998) Shifting Commitments and National Cohesion in African Countries. In: Wohlgemuth, L, S. Gibson, S. Klasen, and E. Rothschild (eds.) Common Security and Civil Society in Africa. Uppsala: NAI.

[104] Montalvo, J.G. and Reynal-Querol, M.: Ethnic Polarization, Potential Conflict, and Civil Wars. In:American Economic Review, American Economic Association, Vol. 95(3), 796816, 2005.

[105] Pittau, M. G. (2005) Fitting regional income distributions in the European Union. Oxford Bulletin of Economics and Statistics, Vol. 67, 135-161.

[106] Pittau, M. G. and Zelli, R. (2006) Empirical evidence of income dynamics across EU regions. J. Applied Econometrics, Vol. 21, 605-628.

[107] Posner, D. N. Measuring Ethnic Fractionalization in Africa. American Journal of Political Science, forthcoming.

[108] Pritchett, L. (1999) Where Has the Education Gone? World Bank Policy Research Working Paper Series, No. 1581.

[109] Quah, D. T. (1996a) Convergence Empirics across Economies with (some) capital mobility Journal of Economic Growth, Vol. 1, pp. 95-124.

[110] Quah, D. T. (1996b) Twin Peaks: Growth and Convergence in Models of Distribution Dynamics. The Economic Journal, Vol. 106, 1045-1055. 
[111] Quah, D. T. (1997) Empirics for growth and distribution: Stratification, polarisation and convergence clubs Journal of Economic Growth, Vol. 2(1), 27-59.

[112] Quah, D. (2002) One Third of the World's Growth and Inequality. CEPR DP3316.

[113] Rauch, J. E. (2001) Business and Social Networks in International Trade. Journal of Economic Literature, Vol. 39, 4: 1177-1203.

[114] Ravallion, M. (2003) The debate on globalization, poverty and inequality: why measurement matters. Policy Research Working Paper 3038.

[115] Ravallion, Martin (2004a) Pro-Poor Growth: A Primer. The World Bank, Policy Research Working Paper No. 3242.

[116] Ravallion, M.(2004b) Competing concepts of inequality in the globalization debate. World Bank Policy Research Working Paper 3243.

[117] Ravallion, M. and S. Chen (2003) Measuring pro-poor Growth. Economic Letters, Vol. 78, pp. 93-99.

[118] Ravallion, Martin, and Shaohua. Chen (2004) China's (Uneven) Progress Against Poverty. Development Research Group, World Bank, Washington, DC., August, Processed.

[119] Ravallion, Martin., and G. Datt (1996) How Important to India's Poor Is the Sectoral Composition of Economic Growth? The World Bank Economic Review, Vol. 10, no. 1, pp. $1-25$.

[120] Ravallion, Martin., and G. Datt (1998) Why Have Some Indian States Done Better than Others at Reducing Rural Poverty? Economica, Vol. 65 Issue 257, February, pp. 17- .

[121] Ravallion, Martin., and G. Datt (2002a) Why Has Economic Growth Been More Pro-Poor in Some States of India than Others? Journal of Development Economics, Vol. 68 pp 381-400.

[122] Ravallion, Martin, and Monika Huppi (1991) Measuring Changes in Poverty: A Methodological Case Study of Indonesia during an Adjustment Period. World Bank Economic Review, Vol. 5, no. 1, pp. 57-82.

[123] Rodrik, D. (1999) Where did all the Growth go? External Shocks, Social Conflict, and Growth Collapses. Journal of Economic Growth, Vol. 4: 385-412.

[124] Reddy, S. and T. Pogge (2005) How Not to Count the Poor. Available at SSRN: http://ssm.com/abstract $=893159$.

[125] Romer, P. (1990) Endogenous Technological Change. The Journal of Political Economy, Vol. 98, No. 5, 71-102. 
[126] Sala-i-Martin, X. (1996) The Classic Approach to Convergence Analysis. The Economic Journal, Vol. 106, pp. 1019-1036.

[127] Sala-i-Martin, X. (2002) The Disturbing "Rise" of Global Income Inequality. NBER Working Paper 8904.

[128] Sala-i-Martin, X. (2006) The World Distribution of Income: Falling Poverty and ... Convergence, Period. Quarterly Journal of Economics, Vol. 121, 351-397.

[129] Schultz, P.(1998) Inequality and the Distribution of Personal Income in the World: How is it Changing and Why? Journal of Population Economics, Vol. 11, pp. 307-344.

[130] Schwarz, G. (1978) Estimating the dimension of a model, Annals of Statistics, Vol. 6, 461-464.

[131] Sen, Binayak, Mustafa K. Mujeri and Quazi Shahabuddin (2006) Explaining Pro-Poor Growth in Bangladesh. In: Besley and Cord (eds.) Delivering on the Promise of Pro-Poor Growth, Palgrave Macmillan and the World Bank, New York, pp. 79-118.

[132] Silverman, B. W. (1981) Using kernel density estimates to investigate multimodality. J. Roy. Statist. Soc. Ser. B, Vol. 43, 97-99.

[133] Smith, L. E. D., and I. Urey (2002) Agricultural Growth and Poverty Reduction: A Review of Lessons from the Post-Independence and Green Revolution Experience in India. Research project on Institutions and Economic Policies for Pro-Poor Agricultural Growth, funded by the Department for International Development (DfID) of the United Kingdom. Department of Agricultural Sciences, Imperial College at Wye, (October), processed.

[134] Sumarto, Sudarno, and Asep Suryhadi (2003) The Indonesian Experience on Trade Reform, Economic Growth and Poverty Reduction. Presented at the Trade, Growth and Poverty Conference, December 8-9, London. The SMERU Research Institute, Jakarta, processed.

[135] Sutcliffe, B. (2004) World Inequality and Globalization. Oxford Review of Economic Policy, Vol. 20, No. 1 .

[136] Svensson, J.(1998) Foreign Aid and Rentseeking. Policy Research Working Paper, World Bank, No. 1880.

[137] Theil, H. (1979) World Income Inequality and its Components. Economic Letters, Vol. 2, pp. 99-102.

[138] Theil, H. and J. Seale (1994) The Geographic Distribution of World Income, 1950-1990. De Economist, Vol. 142, No. IV, pp. 387-419. 
[139] Thirtle, Colin, Lin Lin, and Jenifer Piesse (2003) The Impact of Research-Led Agricultural Productivity Growth on Poverty Reduction in Africa, Asia and Latin America. World Development, Vol. 31, No. 12, pp. 1959-1975.

[140] Tiffin, Richard, and Irz, Xavier (2006) Is Agriculture the Engine of Growth? Agricultural Economics, Vol. 35, pp. 79-89.

[141] Timmer, C. P (1988) The Agricultural Transformation. In: H. Chenery and T.N. Srinivasan (eds.) Handbook of Development Economics, Vol. 1. Amsterdam: North-Holland, pp. 275331.

[142] Timmer, C. P. (1995) Getting Agriculture Moving: Do Markets Provide the Right Signals? Food Policy, Vol. 20, no. 5, pp. 455-72.

[143] Timmer, C. P. (1997) How Well do the Poor Connect to the Growth Process? Harvard Institute for International Development for the USAID/CAER project, December, processed.

[144] Timmer, C. P. ( 2002) Agriculture and Economic Growth. In: Bruce Gardner and Gordon Rausser (eds.) Handbook of Agricultural Economics, Vol. IIA. Amsterdam: North-Holland. . 1487-1546.

[145] Timmer, C. P. (2004) The Road to Pro-Poor Growth: Indonesia's Experience in Regional Perspective. Bulletin of Indonesian Economic Studies, Vol. 40, no. 2 (August), pp. 177-207.

[146] Timmer, C. P. (2006) How Indonesia Connected the Poor to Rapid Economic Growth. In: Besley and Cord (eds.) Delivering on the Promise of Pro-Poor Growth, Palgrave Macmillan and the World Bank, New York, pp. 29-58.

[147] Tong, S. Y.: Ethnic Networks in FDI and the Impact of Institutional Development. In:Review of Development Economics,9(4), 563-580, 2005

[148] UNDP: Human Development Report 2004 (2004) Cultural Liberty in Today's Diverse World, New York: Oxford University Press.

[149] Wade, R. (2004) Is Globalization Reducing Poverty and Inequality? World Development, Vol. 32, No. 4, pp. 567-589.

[150] Wand, M. P. and Jones, M. C. (1995) Kernel smoothing. Chapman and Hall, Ltd., London.

[151] World Bank (1992) World Development Report 1992, New York: Oxford University Press.

[152] World Bank (2002) World Development Report 2002/03, New York: Oxford University Press. 
[153] World Bank (2004a) Operationalizing Pro-Poor Growth. A Research Project Sponsored by AFD, DFID, GTZ, KfW and PREM. Washington, DC.

[154] World Bank (2004b) Promoting the Rural Non-Farm Sector in Bangladesh. Rural Development Unit, South Asia Region, Team led by Forhad Shilpi, (August), processed in two volumes.

[155] World Bank (2004c) Directions in Development: Agriculture and Poverty Reduction. Agriculture and Rural Development Department. September.

[156] World Bank (2006a) Revitalising the Rural Economy: An assessment of the investment climate faced by non-farm enterprises at the District level. Jakarta, Indonesia, July.

[157] World Bank (2006b) Making the New Indonesia Work for the Poor. Jakarta, Indonesia, December.

[158] World Bank (2006c) The Rural Investment Climate: It Differs and it Matters. Washington, DC.

[159] World Bank (2008) World Development Report 2008, New York: Oxford University Press.(forthcoming)

[160] Zak P. J. and Knack S.(2001) Trust and Growth. The Economic Journal, No. 111, pages 295-321. 


\section{Göttinger Studien zur Entwicklungsōkonomik Göttingen Studies in Development Economics}

Herausgegeben von/Edited by Hermann Sautter und/and Stephan Klasen

Die Bănde 1-8 sind über die Vervuert Verlagsgesellschaft (Frankfurt/M.) zu beziehen.

Bd.Nol. 9 Hermann Sautter / Rolf Schinke (eds.): Social Justice in a Market Economy. 2001.

Bd.Nol.10 Philipp Albert Theodor Kircher: Poverty Reduction Strategies. A comparative study applied to empirical research. 2002.

Bd.Nol.11 Matthias Blum: Weltmarktintegration, Wachstum und Innovationsverhalten in Schwellen lândern. Eine theoretische Diskussion mit einer Fallstudie über .Argentinien 1990-1999". 2003.

Bd.Nol.12 Jan Müller-Scheeßel: Die Privatisierung und Regulierung des Wassersektors. Das Beispiel Buenos Aires/Argentinien. 2003.

Bd.Nol.13 Ludger J. Lorning: Economic Growth, Biodiversity Conservation, and the Formation of Human Capital in a Developing Country. 2004.

Bd.Nol.14 Silke Woltermann: Transitions in Segmented Labor Markets. The Case of Brazil. 2004.

Bd.Nol.15 Jorg Stosberg: Political Risk and the Institutional Environment for Foreign Direct Investment in Latin America. An Empirical Analysis with a Case Study on Mexico. 2005.

Bd.Nol.16 Derk Bienen: Die politische Ókonomie von Arbeitsmarktreformen in Argentinien. 2005.

Bd.Nol.17 Dierk Herzer: Exportdiversifizierung und Wirtschaftswachstum. Das Fallbeispiel Chile. 2006.

Bd.Nol.18 Jann Lay: Poverty and Distributional Impact of Economic Policies and External Shocks. Three Case Studies from Latin America Combining Macro and Micro Approaches. 2007.

Bd.Nol.19 Kenneth Harttgen: Empirical Analysis of Determinants, Distribution and Dynamics of Poverty. 2007.

Bd.Nol.20 Stephan Klasen / Felicitas Nowak-Lehmann: Poverty, Inequality and Migration in Latin America. 2008.

Bd.Nol.21 Isabel Günther: Empirical Analysis of Poverty Dynamics. With Case Studies from Sub-Saharan Africa. 2007.

Bd.Nol. 22 Peter Dung: Malaysia und Indonesien: Wirtschaftliche Entwicklungsstrategien in zwei Vielvölkerstaaten. 2008.

Bd.Nol. 23 Thomas Otter: Poverty, Income Growth and Inequality in Paraguay During the 1990s. Spatial Aspects, Growth Determinants and Inequality Decomposition. 2008.

Bd.Nol. 24 Mark Misselhorn: Measurement of Poverty, Undernutrition and Child Mortality. 2008.

Bd.Nol. 25 Julian Weisbrod: Growth, Poverty and Inequality Dynamics. Four Empirical Essays at the Macro and Micro Level. 2008.

unw.peterlang.de 
Julian Weisbrod - 978-3-631-75361-3

Downloaded from PubFactory at 01/11/2019 05:55:15AM

via free access 


\section{Poverty, Income Growth and Inequality in Paraguay During the 1990s}

\section{Spatial Aspects, Growth Determinants and Inequality Decomposition}

Frankfurt am Main, Berlin, Bern, Bruxelles, New York, Oxford, Wien, 2008. 139 pp., num. fig. and tab.

Göttingen Studies in Development Economics.

Edited by Hermann Sautter and Stephan Klasen. Vol. 23

ISBN 978-3-631-57201-6 • pb. € 27.50*

The Paraguayan economy did not suffer debt crises in the eighties and had significant growth rates in the second half on the seventies, but poverty remained a problem. Understanding the performance and spatial distribution of poverty and inequality over a period of more than ten years can shed new light on structural causes behind what seems to be a low growth - high poverty high inequality trap in Paraguay. How did poverty and inequality change during the 1990s. Did inequality reduce income growth? What were the growth determinants and what are the main forces driving inequality changes? These are the questions being answered in this book.

Contents: Spatial distribution of poverty and inequality and their changes over a decade - Case study from Latin America - Growth determinants - Inequality decomposition - Downstream regressions - Poverty maps

Frankfurt am Main - Berlin - Bern - Bruxelles - New York - Oxford - Wien

Distribution: Verlag Peter Lang AG

Moosstr. 1, CH-2542 Pieterlen

Telefax 0041 (0) 32/3761727

"The $€$-price indudes German tax rate Prices are subject to change without notice

Homepage http://www.peterlang.de 
Julian Weisbrod - 978-3-631-75361-3

Downloaded from PubFactory at 01/11/2019 05:55:15AM

via free access 